\title{
Fatigue of Composite Material Beam Elements Representative of Wind Turbine Blade Substructure
}

John F. Mandell, Daniel D. Samborsky, David W. Combs, M. Ethan Scott, Douglas S. Cairns Department of Chemical Engineering Montana State University Bozeman, Montana

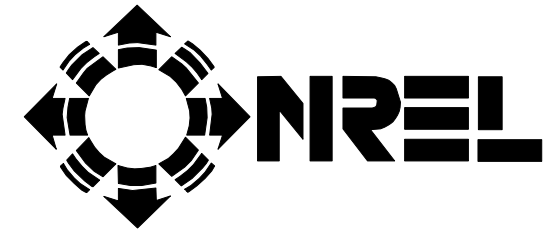

National Renewable Energy Laboratory 1617 Cole Boulevard Golden, Colorado 80401-3393 A national laboratory of the U.S. Department of Energy Managed by Midwest Research Institute for the U.S. Department of Energy under Contract No. DE-AC36-83CH10093 


\section{Fatigue of Composite Material Beam Elements Representative of Wind Turbine Blade Substructure}

NREL Technical Monitors:

Richard Osgood and Walt Musial

John F. Mandell, Daniel D. Samborsky, David W. Combs, M. Ethan Scott, Douglas S. Cairns

Department of Chemical Engineering Montana State Univerisity

Bozeman, Montana

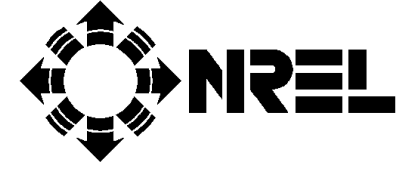

National Renewable Energy Laboratory 1617 Cole Boulevard Golden, Colorado 80401-3393

A national laboratory of the U.S. Department of Energy Managed by Midwest Research Institute for the U.S. Department of Energy under contract No. DE-AC36-83CH10093

Work performed under Subcontract No. XF-1-11009-5 and XAF-5-14076-04

November 1998 


\section{NOTICE}

This report was prepared as an account of work sponsored by an agency of the United States government. Neither the United States government nor any agency thereof, nor any of their employees, makes any warranty, express or implied, or assumes any legal liability or responsibility for the accuracy, completeness, or usefulness of any information, apparatus, product, or process disclosed, or represents that its use would not infringe privately owned rights. Reference herein to any specific commercial product, process, or service by trade name, trademark, manufacturer, or otherwise does not necessarily constitute or imply its endorsement, recommendation, or favoring by the United States government or any agency thereof. The views and opinions of authors expressed herein do not necessarily state or reflect those of the United States government or any agency thereof.

Available to DOE and DOE contractors from:

Office of Scientific and Technical Information (OSTI)

P.O. Box 62

Oak Ridge, TN 37831

Prices available by calling (423) $576-8401$

Available to the public from:

National Technical Information Service (NTIS)

U.S. Department of Commerce

5285 Port Royal Road

Springfield, VA 22161

(703) 487-4650 


\section{FOREWORD}

This final report is the culmination of five years of effort by researchers at Montana State University (MSU) to study the fatigue behavior of sub-structural elements that are representative of the critical building blocks in a composite wind turbine blade. This is the primary deliverable for two NREL subcontracts, XF-1-11009-5 and XAF-5-1407604. It is the first comprehensive study that addresses the gap in complexity between the composite material coupon database and the full-scale structure of the blade. Our experience in the testing of full-scale blade structures at NREL has shown time and again that the failure strength of wind turbine blades cannot usually be predicted with certainty by simply applying the strength data of the parent material. Not surprising, it is usually the details of the design that determine the actual strength of the full-structure. Bonded joints, ply drops, or geometric transitions are typical failure locations for a full-scale blade structure, but these areas are also the most difficult to characterize by material tests or analysis. The work performed under the contracts at MSU gives the designer a basic foundation from which to proceed from by illustrating the generic effects of some of the more probable failure modes that a wind turbine blade might encounter. Although this guidance cannot substitute for a rigorous sub-component design/test program for a specific blade, hopefully it will serve the industry by elevating our gut-level intuition about critical aspects of the design and fabrication of wind turbine blades.

Walter D. Musial

Subcontract Technical Monitor

National Wind Technology Center

National Renewable Energy Laboratory 


\section{Preface}

This final report covers work done at Montana State University (MSU) under National Renewable Energy Laboratory (NREL) sponsorship from August 1991 through September 1996. The first portion of the work, covering the Beam Test Specimen Development, was carried out under NREL Subcontract XF-1-110095 (August 22, 1991-July 30, 1994), with Richard Osgood as the technical monitor. The remainder of the work was carried out under NREL Subcontract XAF-5-14076-04 (October 10, 1994-September 30, 1996) with Walt Musial as the technical monitor. The final year of the latter subcontract was consolidated with other fatigue studies monitored by Herbert Sutherland at Sandia National Laboratories, to be reported separately. The final year includes further studies of structural details.

The work was carried out primarily by the authors at MSU. However, the interactions with the technical monitors at NREL, as well as Herb Sutherland and others at Sandia National Laboratories, were critical to the selection of materials, structural details, and tests to be performed. Interactions with many participants from the wind industry were important in directing the study towards problems of real concern in the industry that could be addressed in a university setting. 


\section{Summary}

Designers of wind turbine blades must consider prediction of stiffness, static strength under overload conditions, dynamic response, and fatigue lifetime under the anticipated load spectrum. Blade design is based on a materials database combined with appropriate structural and structural dynamics analysis and lifetime prediction methodology. The step from materials data to blade structural response and lifetime is significant. Experience is limited with composite materials, particularly those based on less costly glass fibers. Full-scale tests on wind turbine blades at the National Renewable Energy Laboratory (NREL) frequently showed static and fatigue failures at stresses and strains well below the values to be anticipated from materials tests. This implies that either the materials perform less well in structures than they do in small laboratory coupon tests, or that structural problems such as buckling and details responsible for load transfer (including root connections, adhesive joints, ply drops, and stiffeners) are leading to premature failure.

A summary of the overall wind turbine blade structural program at MSU, and the anticipated impacts of the program on blade structural technology are shown in Figure 1 and Table 1. We report on that part of the program relating to validation of the database and design methodologies through the design, fabrication, and testing of substructural elements.

The objective of this program was to develop an intermediate-scale, composite-beam structural element representative of wind turbine blades to validate the database and analysis methods used to predict blade structural performance. This intermediate-size structure would also serve as a test bed for exploring improved manufacturing methods and structural design details. We could also test the accuracy of buckling predictions with a representative structural geometry.

The substructure was chosen to represent the spar area of a typical wind turbine blade, as shown in Figure 2. We designed an I-beam with flanges and web to represent blade structure, using materials typical of many U.S.-manufactured blades. In the course of developing the beam structure, we intended to use materials that were optimized for fatigue resistance as well as static properties. The materials selection process led to a detailed parametric study of the fatigue response of several types of materials with several fiber contents, representing different potential manufacturing processes. These coupon results were included in the Department of Energy (DOE)/MSU Fatigue Database [1]* and are described in detail along with results from other fatigue studies in a Sandia National Laboratories contractors report [2]. Details of the materials studies will not be repeated here except as they relate to the beam study. Optimization of materials in the web for tensile resistance in the area adjacent to the flanges also became an unexpected topic of the beam study.

Our initial task was to develop the I-beam test specimen and the testing apparatus. The structural details responsible for load introduction proved to be a major design problem and led to extensive finite-element runs in an iterative design-test-analyze-redesign process. We used the final beam specimen, shown in Figure 3 as the basis of the validation studies. Stiffness and strain measurements for the beam were in good agreement with predictions from simple beam theory and finite-element analysis. In most cases the load transfer details allowed us to introduce loads sufficient to produce 
flange and web gage section failures under static and fatigue loading.

We fabricated and static- or fatigue-tested 52 beams and many coupons of the materials included in the beams. All beams were strain-gaged. We also analyzed damage and failure modes in detail, as reported in the Appendix for each beam. After initial beam-test specimen development, we tested a series of beams with triax material flanges. These beams generally failed in the predicted mode, and the fatigue lifetimes were consistent with predictions based on the coupon database. Beams with improved flange materials tended to fail in the web flange area rather than in the main flange. However, once again, the lifetimes were consistent with predictions from the web and flange material coupon database. In most cases attempts to improve the web material stiffened the beams and resulted in delamination failures in the load transfer area. Overall, the beam results are a validation of the coupon database and the methodologies for predicting substructure strength, stiffness, failure mode, and lifetime. No major contradictions are evident in the results.

The final section of the report deals with initial findings on the effects of severe flaws (13-mmdiameter holes) and ply drops. We ran tests on coupons and selected cases were explored with beams. The results again show consistent behavior between coupons and beams. We present initial conclusions regarding the preferred way of using ply drops in thickness tapering to minimize delamination problems.

* Numbers in [ ] brackets refer to cited references listed at the end of the text. 


\section{TABLE OF CONTENTS}

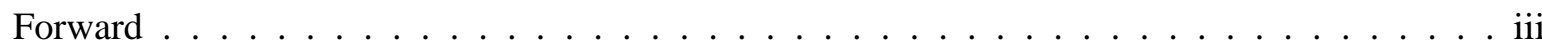

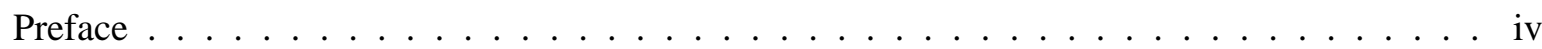

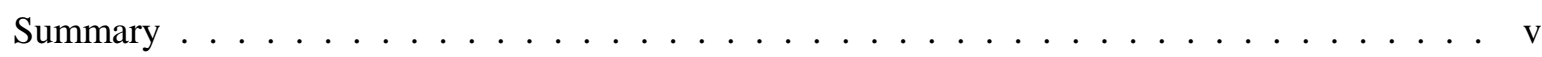

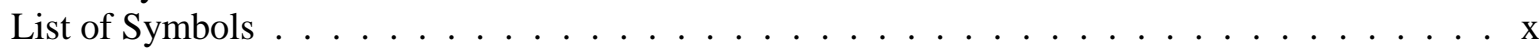

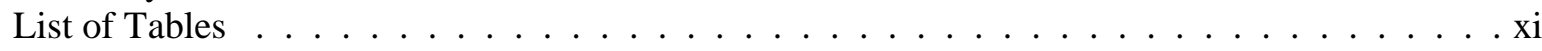

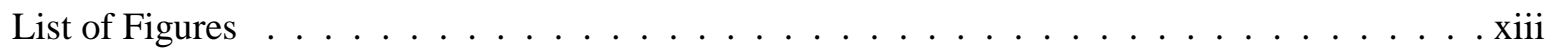

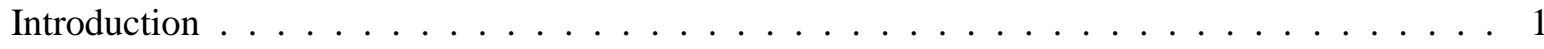

Development of Beam Test Specimen . . . . . . . . . . . . . . . . . 2

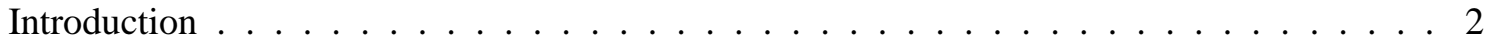

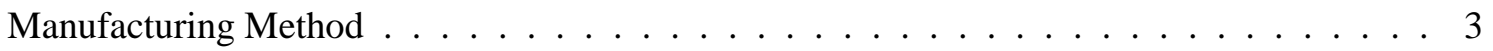

Beam Test Fixture . . . . . . . . . . . . . . . . . . . . . . . 4

Beam Design and Analysis . . . . . . . . . . . . . . . . . 4

Initial Sizing Using Beam Theory . . . . . . . . . . . . . . . . . . 4

Finite-Element Analysis Overview . . . . . . . . . . . . . . . . 7

Iterative Development of Beam Details . . . . . . . . . . . . . . . . 7

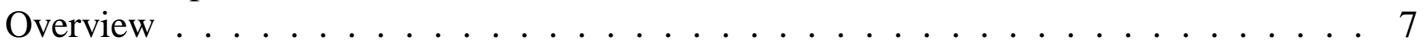

Beam Configuration $1 \ldots \ldots \ldots \ldots \ldots$

Beam Configuration $2 \ldots \ldots \ldots \ldots \ldots$

Beam Configuration $3 \ldots \ldots \ldots \ldots \ldots$

Validation of Stiffness and Strain Predictions . . . . . . . . . . . . . . . 11

Conclusions from Beam Test Specimen Development . . . . . . . . . . . . . . 13

Final Test Specimen Definition . . . . . . . . . . . . . . . . . . . . 14

Experimental Investigation of Beam Static and Fatigue Behavior . . . . . . . . . . . 15

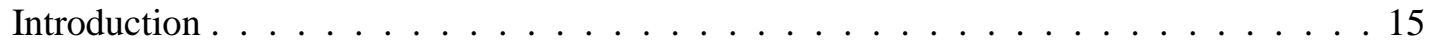

Material and Beam Description . . . . . . . . . . . . . . . . . . 15

Studies of Beams with Triax Material Flanges . . . . . . . . . . . . . . . 16

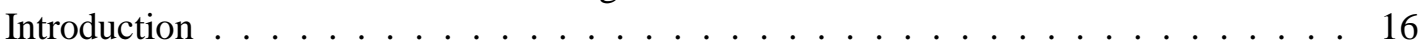

Behavior of Beams . . . . . . . . . . . . . . . . . . 16

Studies of Beams with Improved Flange and Web Materials . . . . . . . . . . . . 17

Introduction . . . . . . . . . . . . . . . . . . . . . 17

Material Development and Coupon Results . . . . . . . . . . . . . . . . 18

Beam Test Results . . . . . . . . . . . . . . . . . . . . . . . . . 18

Conclusions for Beams With Improved Flange and Web Materials . . . . . . . . . . 19

Stiffness Changes . . . . . . . . . . . . . . . . . . . . . 19

Studies of Structural Details . . . . . . . . . . . . . . . . . . . . 20

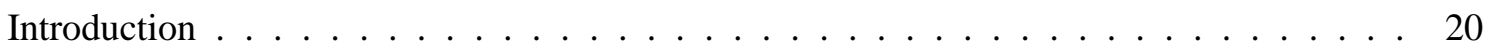

Effects of Through-Thickness Holes . . . . . . . . . . . . . . . . . 20

Coupon Results with Holes . . . . . . . . . . . . . . . . . . . 20

Beam Results with Holes . . . . . . . . . . . . . . . . . . . 21

Studies of Ply Drops . . . . . . . . . . . . . . . . . . . 21

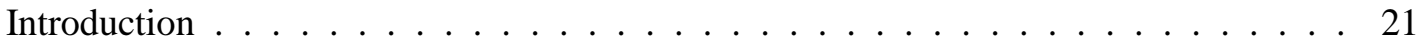

Coupon Tests . . . . . . . . . . . . . . . . . . . . . 21

Beams with Ply Drops In Flanges . . . . . . . . . . . . . . . . . 22

Conclusions and Design Recommendations for Ply Drop Study . . . . . . . . . . . . 23

Conclusions for Overall Study . . . . . . . . . . . . . . . . . . . . . . 24 


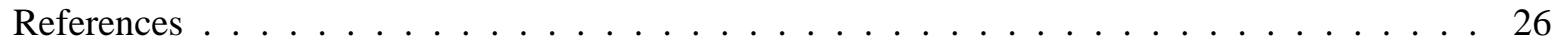

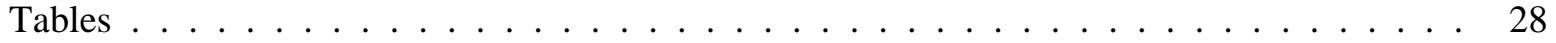

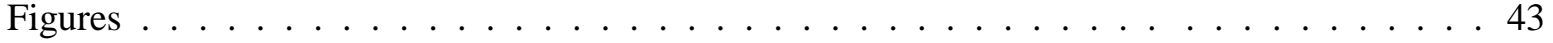

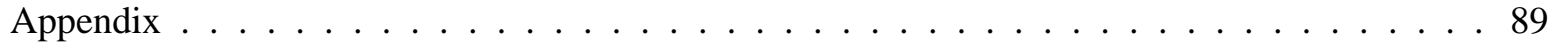




\section{List of Symbols}

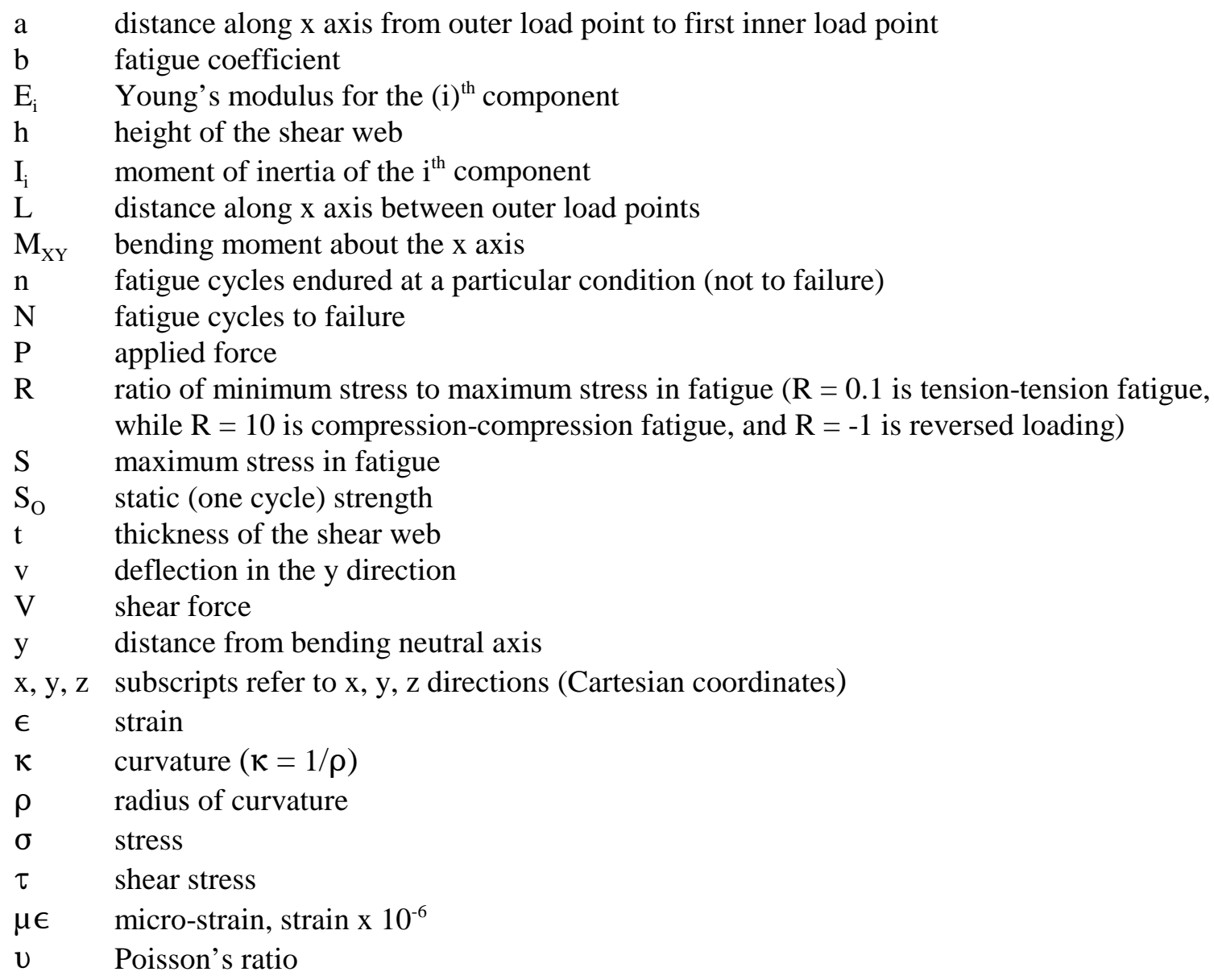




\section{List of Tables}

1. Anticipated MSU Program Impacts: Areas of Improved Technology in Wind

Turbine Blade Structures . . . . . . . . . . . . . . . . . . . . . . . . 28

2. Characteristics and Properties of Sections of Beams 1-5 . . . . . . . . . . . . . . 29

3. A Summary of Beam Configurations and Testing Regime . . . . . . . . . . . . . . 30

4. Test History for Beam 1 . . . . . . . . . . . . . . . . . . . . . . 31

5. Summary of Cycles and Loads for Beam $1 \ldots \ldots \ldots$. . . . . . . . . . . . . 31

6. Test history for Beam $2 \ldots \ldots \ldots \ldots \ldots \ldots \ldots \ldots$

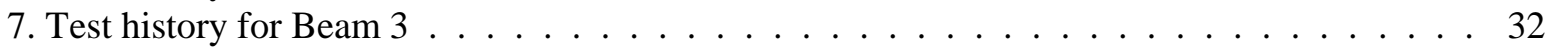

8. Test History (Top) and Load, Micro-strain and Cycles Summary, Beam 4. Micro-strain

Values are the Average Magnitudes of Tension and Compression Strain Measured at

the Initiation of Each Sequence. . . . . . . . . . . . . . . . . . . . 33

9. Comparison of FEA, Beam Theory and Experimental Strain vs. Load Slopes, Beam 2 . . . . 34

10. Comparison for FEA, Beam Theory, and Average 1st Cycle Experimental

Displacement and Micro-strain vs. Load Slopes, Beams 4 and 5 . . . . . . . . . . . . . . . 34

11. Ratios of Predicted Displacement and Micro-strain Slopes Over Average

Experimental Slopes for Beams 4 and 5. The Experimental Slopes Listed are

Those Derived from the First Cycle of Testing. . . . . . . . . . . . . . . . . . . . . 34

12. Comparison of FEA and Experimental Strain vs. Load Slopes, Beam 1 . . . . . . . . . 35

13. Comparison of FEA and Experimental Strain vs. Load Slopes, Beam 2 . . . . . . . . . . 35

14. Comparison of FEA, Theoretical, and Experimental Displacement vs. Load

Slopes, Beams 4 and $5 \ldots \ldots \ldots \ldots$. . . . . . . . . . . . . . . . . . . .

15 Comparison of FEA, Theoretical, and Experimental Micro-strain vs. Load

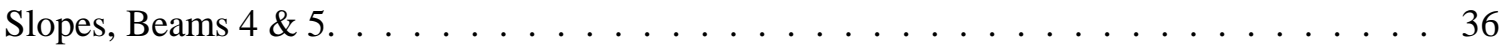

16. Summary of Data for Beams with Triax Flanges and Material CH10 Webs . . . . . . . . . 37

17. Summary of Data for Beams with Material DD5P Flanges and Material CH10 Webs . . . . 38

18. Summary of Data for Beams with Material DD5P Flanges and Web Materials With

Increasing $0^{\circ}$ Content. . . . . . . . . . . . . . . . . . . . . . 39

19. Summary of Data for Beams with Triax Flanges Containing $13 \mathrm{~mm}$

Diameter Through-Thickness Holes and Material CH10 Webs . . . . . . . . . . . . . . 40

20. Summary of Data For Beams with Ply Drops in Flanges With Material CH12 Webs . . . . . 41

21. Laminate Configurations with Ply Drops . . . . . . . . . . . . . . . . . 42

22. Ply Reference Notation for Beams 6 through 9, 12 through 17, 22 and $23 \ldots \ldots$. . . . . . 92

23. Ply Reference Notation for Beams 10 and $11 \ldots \ldots$. . . . . . . . . . . . . . . . 93

24. Ply Reference Notation for Beams $18-21$ and $24-29$. . . . . . . . . . . . . . . . . . 113

25. Beam 18 Stiffness vs. Cycles . . . . . . . . . . . . . . . . . . . . . . . 114

26. Beam 20 Stiffness vs. Cycles . . . . . . . . . . . . . . . . . . . . . . 117

27. Beam 21 Stiffness vs. Cycles . . . . . . . . . . . . . . . . . . . . . . . . . . . . 119

28. Beam 26 Stiffness vs. Cycles . . . . . . . . . . . . . . . . . . . . . . . . 122

29. Ply Reference Notation for Beams 30, 31, 32 and 33 . . . . . . . . . . . . . . . 126

30. Beam 32 Stiffness vs. Cycles . . . . . . . . . . . . . . . . . . . . . . . . . . . . 129

31. Beam 33 Stiffness vs. Cycles . . . . . . . . . . . . . . . . . . . . . . . . 130

32. Ply Reference Notation for Beams 51 through $55 \ldots \ldots \ldots$. . . . . . . . . . 136

33. Lay up of Fiberglass Materials with Ply Drops . . . . . . . . . . . . . . . . . . . 145 
34.

34. Reference Notation for Beams 39, 44 and 48 with ESA Laminate . . . . . . . . . . . . 146

35. Average Tension Flange Delamination vs. Cycles for Beam 39 . . . . . . . . . . . . . . 146

36. Average Flange Delamination vs. Cycles for Beam $44 \ldots \ldots$. . . . . . . . . . . . . . . 148

37.Average 38. Reference Notation for Beam 40 with ESB Laminate . . . . . . . . . . . . . . 149

38. Flange Delamination vs. Cycles for Beam $48 \ldots \ldots$. . . . . . . . . . . . 150

39. Reference Notation for Beams 41 and 42 with ESG Laminate . . . . . . . . . . . . . . . 153

40. Average Flange Delamination vs. Cycles for Beam $41 \ldots \ldots$. . . . . . . . . . . 154

41. Average Tension Flange Delamination vs. Cycles for Beam $42 \ldots \ldots$

42. Reference Notation for Beams 49 and 50 with ESH Laminate . . . . . . . . . . . . . . 157

43. Average Flange Delamination vs. Cycles for Beam 49 . . . . . . . . . . . . . . . . 157

44. Average Tension Flange Delamination for Beam $50 \ldots \ldots$. . . . . . . . . . . 159 


\section{List of Figures}

Page

1. Overall iterative program for wind turbine blade structural optimization at MSU . . . . . . 43

2. Cross section of NREL 9.6 meter airfoil . . . . . . . . . . . . . . . . . . 44

3. Sketch and photograph of composite I-beam (configuration 3) . . . . . . . . . . . 45

4. I-beam assembly. . . . . . . . . . . . . . . . . . . . . . . 46

5. Three-dimensional view of $\mathrm{C}$-channel mold. . . . . . . . . . . . . . . . 46

6. Thickness variations in C-channels . . . . . . . . . . . . . . . . . 47

7. Four-point loading fixture in a (a) MTS and (b) Instron testing machines . . . . . . . . . . 48

8a. Laminate and beam coordinate systems . . . . . . . . . . . . . . . . . . . . . 49

8b. Alignment of FEA coordinate system . . . . . . . . . . . . . . . . . . . 49

9. Geometric and elastic entities for composite I-beam. . . . . . . . . . . . . . . . . . 50

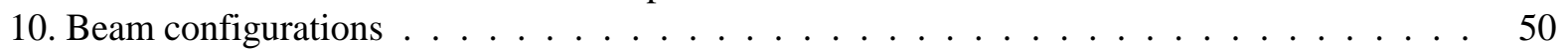

11. Convergence of FEA solution for configuration 1 (Beams 1 and 2) . . . . . . . . . 51

12. (a) Load pad damage and compression damage zone, tension side of Beam 1

(b) Adhesive failure of Beam $2 \ldots \ldots \ldots \ldots \ldots$

13. Ply drops, configuration 3 , xy plane . . . . . . . . . . . . . . . 53

14. Delamination of ply drops, beam $3 \ldots \ldots \ldots \ldots$

15. Shear stress $X Y$ at the adhesive interface of flanges, configuration $2 \ldots \ldots \ldots 4$

16. Shear stress $X Y$ at the adhesive interface of flanges, configuration $3 \ldots \ldots 5$

17. Shear stress $X Z$ at the adhesive interface of flanges, configuration $2 \ldots \ldots$. . . . . . 56

18. Shear stress $X Z$ at the adhesive interface of flanges, configuration $3 \ldots \ldots$. . . . . . . 57

19. Shear stress $Y Z$ at the adhesive interface of flanges, configuration $3 \ldots \ldots$. . . . . . . 58

20. FEA Shear stress $X Y$ at flange interface, configuration 2, with isotropic material properties. 59

21. FEA and experimental strain versus load data, beams 1 and $2 \ldots \ldots$. . . . . . . . . . 60

22. FEA and experimental strain versus load data, beam $3 \ldots \ldots \ldots 1$

23. Center point and actuator displacement versus load, beam $4 \ldots \ldots \ldots 2$

24. FEA and experimental strain versus load data, beam $4 \ldots \ldots$. . . . . . . . . . . 63

25. FEA and experimental displacement versus load results, beam $5 \ldots$. . . . . . . . . . 64

26. FEA and experimental strain versus load results, beam $5 \ldots \ldots$. . . . . . . . . . . 65

27. Accumulated damage on inner surface of tension flange, $\pm 45^{\circ}$ plies, 2.26 million cycles, beam $4 \ldots \ldots \ldots$. . . . . . . . . . . . . . 66

28. Outer surface of compression flange, 2.26 million cycles, beam $4 \ldots \ldots 6$

29a. Fatigue data for materials AA and DD5P, $\mathrm{R}=0.1 \ldots \ldots \ldots$. . . . . . . 67

29b. Fatigue data for materials AA and DD5P, $\mathrm{R}=10 \ldots \ldots \ldots$. . . . . . . . 67

30a. Fatigue data for materials $\mathrm{CH} 3, \mathrm{CH} 10, \mathrm{CH} 12$ and DD5P, $\mathrm{R}=0.1 \ldots \ldots$

30b. Fatigue data for material AA, $\mathrm{R}=0.1$ and $10 \ldots \ldots \ldots$

31a. Beams 6 - 14, 22 and 23 with material AA flanges and material CH10 web compared with material AA coupon fatigue data . . . . . . . . . . . . . 69

31b. Beams 6 - 14, 22 and 23 with material AA flanges and material CH10 web Compensated for flange thickness compared with material $\mathrm{CH} 10$ coupon fatigue data . . . . 69

32. Tensile and compressive flanges of failed beams with material AA flanges and material $\mathrm{CH} 10$ webs . . . . . . . . . . . . . . . . . . . 70

33a. Beam 13 static compression flange failure . . . . . . . . . . . . . 70

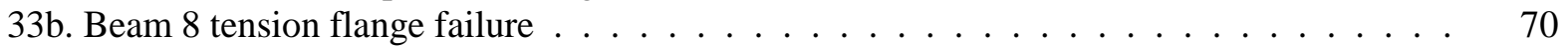


34. Beams 18 - 21 and 24 - 29 with material DD5P flanges and material $\mathrm{CH} 10$ web compared with material DD5P coupon fatigue data . . . . . . . . . . . . . 73

35. Beams 18 - 21 and 24 - 29 with material DD5P flanges and material CH10 web compensated for flange thickness compared with material $\mathrm{CH} 10$ coupon fatigue data $\ldots . .73$

36. Tension flanges of failed beams with material DD5P flanges and material CH3 webs . . . . 74

37. Beams 30 - 33 with material DD5P flanges and material $\mathrm{CH} 3$ web compared with DD5P coupon fatigue data . . . . . . . . . . . . . 75

38. Beams 30 - 33 with material DD5P flanges and material $\mathrm{CH} 3$ web compensated for flange thickness compared with $\mathrm{CH} 3$ coupon fatigue data . . . . . . . . 75

39. Beams 34 and 35 with material DD5P flanges and material CH12 web compared with material DD5P coupon fatigue data . . . . . . . . . . . . . 75

40. Beams 34 and 35 with material DD5P flanges and material $\mathrm{CH} 12$ web compensated for flange thickness compared with material $\mathrm{CH} 12$ coupon fatigue data $\ldots .75$

41a. Beams 51 - 54 with material DD5P flanges and web compared with material DD5P coupon fatigue data . . . . . . . . . . . . . . . 76

41b. Tension and compression flanges of failed beams with material DD5P flanges and webs. . 77

42. Beam stiffness versus lifetime . . . . . . . . . . . . . . . . . . . 78

43a. Tensile fatigue data for material AA coupons with and without a $13 \mathrm{~mm}$ diameter hole, $\mathrm{R}=0.1 \ldots \ldots \ldots \ldots \ldots \ldots$

43b. Tensile fatigue data for material AA coupons with and without a $13 \mathrm{~mm}$ diameter hole, $\mathrm{R}=0.1 \ldots \ldots \ldots \ldots \ldots \ldots$. . . . . . . . . . . . . . . . . . .

43c. Normalized tensile fatigue data for material AA coupons with and without a $13 \mathrm{~mm}$ diameter hole, $\mathrm{R}=0.1 \ldots \ldots \ldots \ldots \ldots$. . . . . . . . . . . .

43d. Compressive fatigue data for material AA coupons with and without a $13 \mathrm{~mm}$ diameter hole, $\mathrm{R}=10 \ldots \ldots \ldots \ldots$. . . . . . . . . 80

43e. Fatigue data for material AA coupons with and without a $13 \mathrm{~mm}$ diameter hole, $\mathrm{R}=-1 . \quad . \quad 80$

44. Damage around the $13 \mathrm{~mm}$ diameter hole vs. fatigue lifetime . . . . . . . . . . . 81

45. Photograph of damage around the $13 \mathrm{~mm}$ diameter hole at different stress levels, $\mathrm{R}=0.1 . \quad 82$

46. Delamination on a compression fatigue coupon . . . . . . . . . . . . . . 82

47a. Comparison of AA material flange beams without holes to AA beams with $13 \mathrm{~mm}$ diameter holes in the flanges . . . . . . . . . . . . . . . . . 83

47b. Comparison of AA material flange beams with holes to AA material coupons with $13 \mathrm{~mm}$ diameter holes $\ldots \ldots \ldots \ldots \ldots$. . . . . . . . . . 83

48. Beam 15 with holes, static compression flange failure . . . . . . . . . . . . . . . . . . 84

49. ESB Laminate . . . . . . . . . . . . . . . . . . . . . . . . . . . 84

50. Delamination length vs. cycles for ESA (single exterior $0^{\circ}$ ply drop) laminate, $\mathrm{R}=0.1 \ldots 85$

51. Delamination length vs. cycles for ESB (single interior $0^{\circ}$ ply drop) laminate, $\mathrm{R}=0.1 \quad \ldots \quad 85$

52. Delamination length vs. cycles for ESC (single center interior $0^{\circ}$ ply drop) laminate, $R=0.1 \quad 86$

53. Delamination length vs. cycles for ESB, ESH, ESF (all interior $0^{\circ}$ ply drop) laminates at a maximum running stress of $275 \mathrm{MPa}, \mathrm{R}=0.1 \ldots \ldots \ldots$

54. Delamination length vs. cycles for ESA, ESG, ESE (all exterior $0^{\circ}$ ply drop) laminates at a maximum running stress of $275 \mathrm{MPa}, \mathrm{R}=0.1 \ldots \ldots \ldots$. . . . . . 87

55. Tapered beam flange with ply drops, $\mathrm{R}=0.1 \ldots \ldots \ldots$. . . . . . . . 87

56. Beam (tension flange) vs. coupon data $(\mathrm{R}=0.1)$ for ESA (single exterior $0^{\circ}$ ply drop) $\ldots 88$ 
57. Delamination length vs. cycles for tension flange ESG laminate with two exterior ply drops compared with coupon data . . . . . . . . . . . . . . . . 88

58. Beam $6 \ldots \ldots \ldots \ldots \ldots \ldots$

59. Beam $6 \ldots \ldots \ldots \ldots \ldots \ldots$

60. Load vs. maximum flange strain, beam 6 , static test $\ldots \ldots \ldots$. . . . . . . . . . 95

61. Load vs. maximum flange strain, beam 7 , initial loading . . . . . . . . . . . . . . . 96

62. Maximum flange strain, beam 7, initial loading . . . . . . . . . . . . . . . . . 97

63. Actuator amplitude vs. cycles, beam $7 \ldots \ldots$. . . . . . . . . . . . . 97

64. Load vs. strain for beam 7, delta strain gage rosette on web . . . . . . . . . . . . . . . 98

65. Load vs. web shear stress for beam 7,9 mm ahead of shear stiffener . . . . . . . . . . . 98

66. Beam $7 \ldots \ldots \ldots \ldots \ldots$

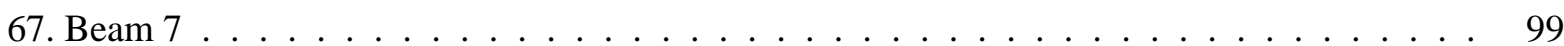

68. Beam $8 \ldots \ldots \ldots \ldots \ldots \ldots \ldots \ldots \ldots$

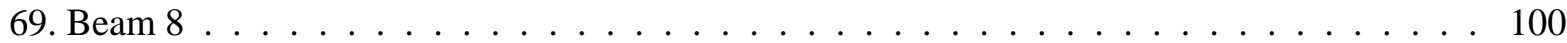

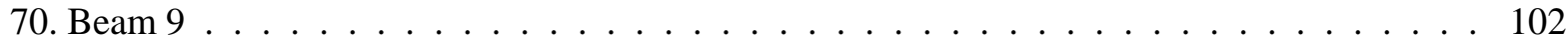

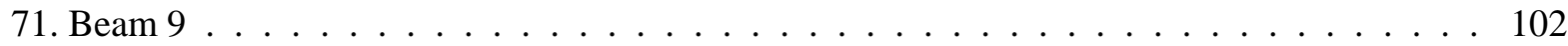

72. Load vs. maximum flange strain, beam 9 , static test $\ldots \ldots \ldots$. . . . . . . . . . 103

73. Initial hysteresis of beam $10 \ldots \ldots \ldots$

74. Beam $10 \ldots \ldots \ldots \ldots \ldots$

75. Load vs. flange midspan deflection, beam $11 \ldots \ldots \ldots$. . . . . . . . . . 105

76. Absolute maximum flange fatigue strain vs. cycles, beam $11 \ldots \ldots$. . . . . . . . 105

77. Beam $11 \ldots \ldots \ldots \ldots \ldots \ldots$

78. Beam $11 \ldots \ldots \ldots \ldots \ldots \ldots$

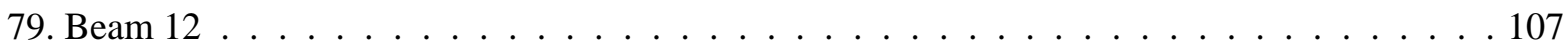

80. Load vs. maximum flange strain, beam 13, static test . . . . . . . . . . . . . . 108

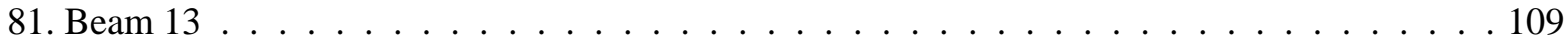

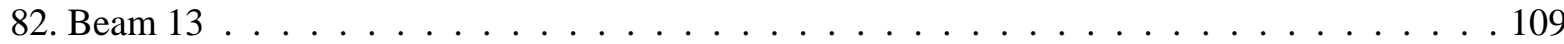

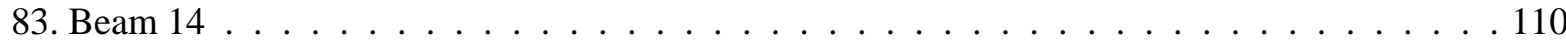

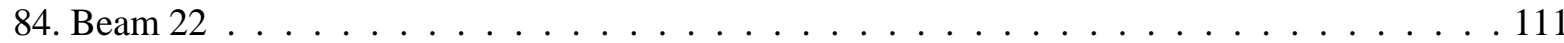

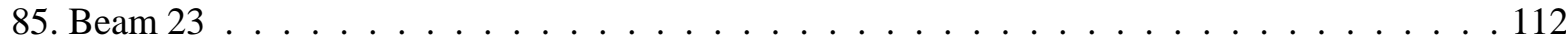

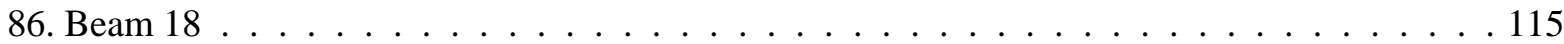

87. Load vs. maximum flange strain, beam 19, static test . . . . . . . . . . . . . . . 116

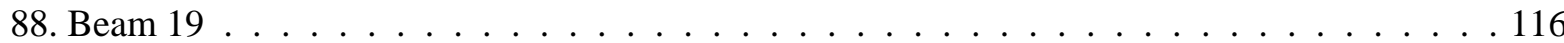

89. Beam $20 \ldots \ldots \ldots \ldots \ldots \ldots \ldots$

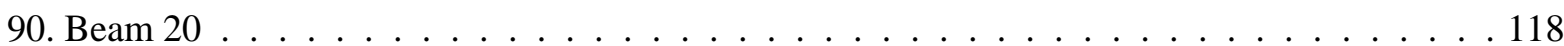

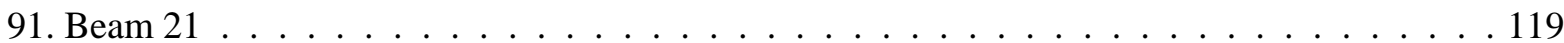

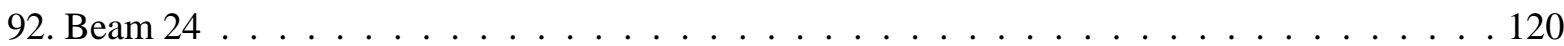

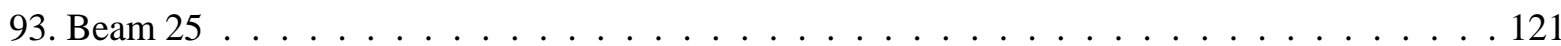

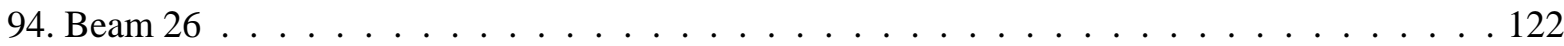

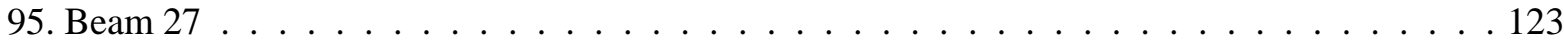

96. Beam $28 \ldots \ldots \ldots \ldots$

97. Beam $29 \ldots \ldots \ldots \ldots \ldots \ldots$

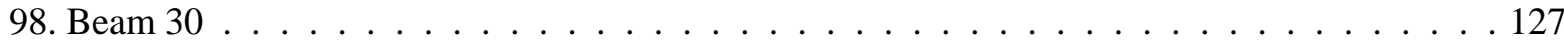

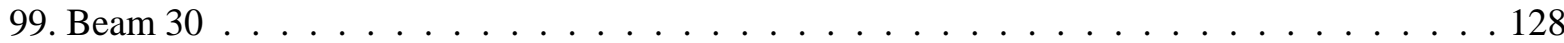

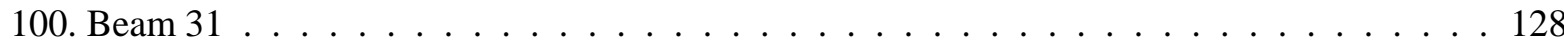

101. Beam $32 \ldots \ldots \ldots \ldots$ 
102.

102. Beam $33 \ldots \ldots \ldots \ldots \ldots$

103. Absolute flange strain vs. load, initial four point loading, beam $34 \ldots \ldots$. . . . . . . 131

104. Load vs. compressive flange strain, beam $34 \ldots \ldots$. . . . . . . . . . . . . 131

105. Beam $34 \ldots \ldots \ldots \ldots$

106. Beam $34 \ldots \ldots \ldots \ldots \ldots$

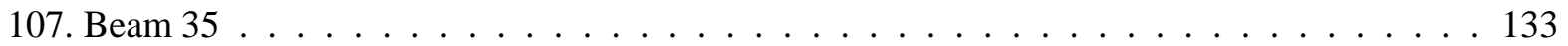

108. Beam $35 \ldots \ldots \ldots \ldots \ldots$

109. Beam $51 \ldots \ldots \ldots \ldots \ldots \ldots \ldots$

110. Additional shear stiffener material . . . . . . . . . . . . . . . . . . . 137

111. Beam $52 \ldots \ldots \ldots \ldots \ldots$

112. Beam $53 \ldots \ldots \ldots \ldots \ldots \ldots \ldots$

113. Beam $54 \ldots \ldots \ldots \ldots$

114. Beams 15, 16 and 17 flange geometry . . . . . . . . . . . . . . . . 140

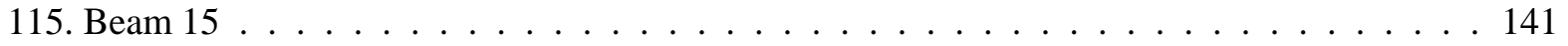

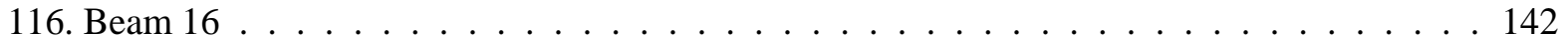

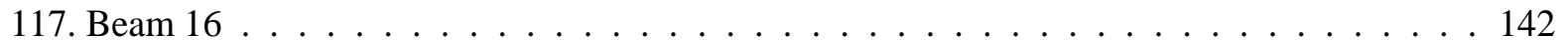

118. Load vs. maximum flange strain, beam 17, static test . . . . . . . . . . . . . . . . . . 144

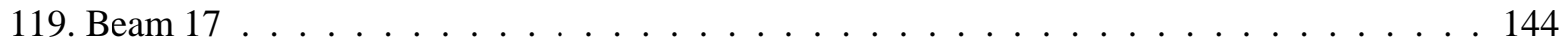

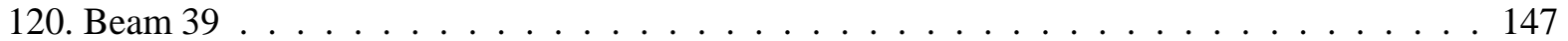

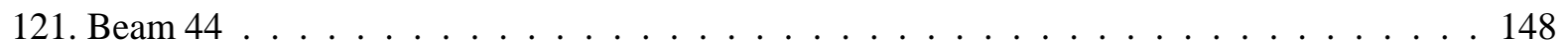

122. Beam $48 \ldots \ldots \ldots \ldots \ldots \ldots$

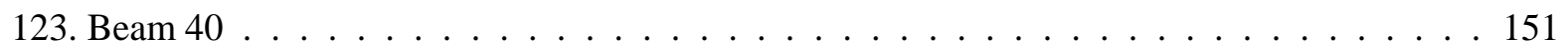

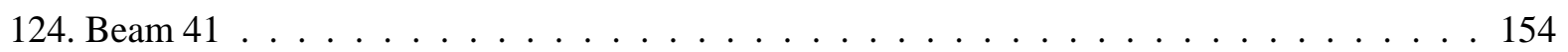

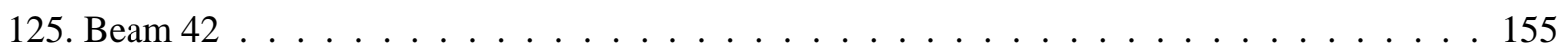

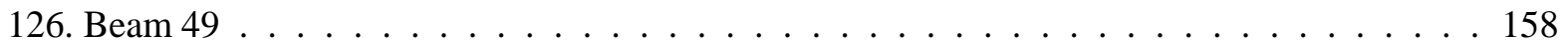

127. Beam $50 \ldots \ldots \ldots \ldots \ldots$ 


\section{Introduction}

This report describes the development of a beam structural element representative of wind turbine blade substructure, and its application in the following areas: (1) validation of the use of coupon static and fatigue data in the DOE/MSU database, combined with finite-element analysis, to predict the strength, fatigue life, and failure mode of composite structures; (2) development of procedures to optimize the performance of composite structures such as blades; (3) validation of improved structural performance from materials with better fatigue behavior in coupon tests; (4) study of severe flaw effects (13-mm-diameter hole) relating to coupons and beams; and (5) study of ply drop effects in coupons, with validation in beams.

The first section of the report describes the development of the beam substructure test specimen, including comparisons between predicted and measured stiffness and strains. We used an iterative process of design, manufacturing, testing, and redesign to develop beam details with adequate loadtransfer characteristics in fatigue.

In the second part of the report, we describe beam tests that correlate beam performance with the coupon fatigue database. The first series of tests were run using a triax material typical of many commercial blades in the flanges. Additional test series used improved flange and web materials, again correlating coupon and beam. In the final section we explore, the effects of severe flaws in the form of through-holes and thickness tapering using ply drops. Also in the final section, we present our design recommendations for ply drop geometries. 


\section{Development of Beam Test Specimen}

\section{Introduction}

The purpose of the work described in this section was to develop a test specimen representative of the main substructural details of wind turbine blades and to analyze the specimen in detail. The test specimen was intended to fulfill the following requirements:

- Be representative in geometry and materials of the primary substructure of wind turbine blades.

- Allow convenient laboratory testing at maximum forces below $100 \mathrm{kN}$ at frequencies of at least $5 \mathrm{~Hz}$ (cycles/second), so that tests could be conducted out to about $10^{6}$ cycles in a few days.

- Allow the inclusion of significant structural details such as ply drops for thickness tapering and adhesive bonding, and flaws such as holes, matrix-rich areas, and fiber misorientation.

- Provide a gage section where the stress conditions are representative of blade stresses (primarily bending stresses).

- Allow study of buckling representative of blade-buckling conditions.

- Be designed to produce failure in the gage section to allow meaningful comparison with the behavior of the materials in coupon tests.

- Be convenient to analyze by finite-element analysis (FEA), and to instrument in tests.

- Allow the incorporation of either MSU manufactured parts or industry-supplied materials, particularly in the flanges.

Figure 2 shows the type of blade structure the beam element is intended to represent: the main structural spar area, which carries most of the flapwise bending loads. The beam configuration was selected as four-point loading to provide a central section of constant moment; this section is where most of our study was concentrated. Four-point loading also reduces both the load to be applied and resulting load-transfer problems as compared to three-point loading. The load introduction problem in the four-point configuration is still much more severe than that for the in-service wind turbine blade, with the exception of the root area. However, the tapered character and special devices such as ailerons or tip devices cause other load-transfer problems in typical turbine blades.

The I-beam configuration we selected for development is shown in its final configuration (configuration 3) in Figure 3. In this configuration, it is convenient to fabricate beams by producing various parts, then use secondary bonding to assemble the final beam, as shown in Figure 4 . The modular nature of the beam allowed for the possibility of using materials supplied by industry for the flanges, which was a concern early in the program.

Because the main area of interest was the middle section of the beam between the inner load points, the outer parts of the beam were stiffened with the shear stiffeners shown, which reduced deflections and prevented shear failures in this area. Despite the shear stiffening and relatively low span-to-depth ratio of the beam, it still behaved approximately according to simple beam theory. 


\section{Manufacturing Method}

Manufacturing of the beam structural parts, shown in Figure 4, was by resin transfer molding (RTM) and was carried out in parallel with an associated study of the RTM process parameters [3, 4]. As compared with hand layup, RTM allows more precise control of dimensions, two molded surfaces, and a broad range of carefully controlled fiber content and ply-stacking arrangements. This process is also being adopted because of its low volatile emissions compared with processes where the resin is open to the air. For this study, it was also important that the reinforcing fabrics and resins be the same as those commonly used by industry with hand layup and bag processes, so that the results would relate to typical industry blade structures and structural details.

Although the entire beam could have been molded in one piece by RTM, the modular arrangement shown in Figure 4 was used to better simulate industry manufacturing, which typically includes secondary bonding of molded parts. This procedure would also allow for including industry-supplied materials in the flanges, as noted earlier. Structurally, the modular assembly of the beam allows for direct study of the adhesive bond detail between the web and flange, which is a topic of current study. Variations of the flange width and the addition of flange curvature in buckling studies are also conveniently accomplished without major mold modification.

RTM involves assembling a reinforcement preform in a closed mold, then pumping liquid resin into the mold, followed by curing in the mold. This requires at least one resin injection port and one outlet port for air and excess resin $[3,4]$. The flow of resin to fill the space not occupied by fibers, with a minimum of porosity, requires sufficient reinforcement permeability, low resin viscosity, and flow distances that are not excessively long. Figure 5 depicts the mold for the $\mathrm{C}$-channels which, when bonded back-to-back, form the web of the I-beam. Other mold details are given in Reference 5 .

The properties of the laminates used in beams 1-5 in this study (all with E-glass fiber strands) are listed in Table 2. This class of materials was studied in detail in related programs; more information can be found in References 1 and 2. The resin was an unsaturated, orthophthalic polyester (CoRezyn 63-AX-051) catalyzed with 2\% methyl ethyl ketone peroxide, and cured at room temperature. A twohour post cure at $60^{\circ} \mathrm{C}$ was used for all parts in the central gage section. The beam parts were then secondary-bonded in jigs with an epoxy adhesive, Hysol EA 9309.2 NA. In some cases the shear stiffeners and load pads were built up to final thickness by bonding thinner plates with the same adhesive. The final assembled beams were then cured for two hours at $60^{\circ} \mathrm{C}$.

The flat parts showed well-controlled thickness and fiber content. The C-channels showed some variations resulting from deflection in the mold. Figure 6 shows the thickness variation in the Cchannels for several molded parts: channels 1 and 2 included excess mold pressure, which deflected the mold significantly [3], whereas channels 3 and 4 gave more consistent results when excess resin bleed-off was allowed at the end of the mold filling cycle. Molded surfaces were contaminated with mold release; surface preparation prior to secondary bonding consisted of sanding and methanol cleaning. 
An extensive coupon database for the various materials used in the beams is given in References 1 and 2. Materials for coupon tests were fabricated in the same mold used for the beam flanges and both coupons and flanges were machined from a flat-molded plate with planar dimensions of 225 $\mathrm{mm}$ by $850 \mathrm{~mm}$, with the thickness controlled by various gaskets and spacers for particular cases.

\section{Beam Test Fixture}

We ran beam static and fatigue tests using specially fabricated fixtures in standard servohydraulic testing machines (MTS 880 and Instron 8501). Figure 7(a) shows the test setup with Fixture 1 in the MTS machine and Figure 7(b) shows Fixture 2 in the Instron. Fixture 2 is a redesigned, lighterweight version of the first fixture, with less potential for lateral force introduction to the load cell. Details of the first fixture may be found in Reference 5. The initial version of the first fixture included freely rotating roller-bearing supports at the inner load points only, with nonrotating circular supports on the outside. As noted later, early beam tests (beams 1-3) showed damage resulting from the nonrotating outer supports. All later tests include freely rotating supports at all load points. Beams 1-5 used Fixture 1, whereas beams 6 and greater used Fixture 2 because of a change from the MTS to the Instron testing machines.

\section{Beam Design and Analysis}

\section{Initial Sizing Using Beam Theory}

As noted earlier, the beam design was intended to provide a flexural member simulating the geometry in Figure 2, with primarily flexural loading as in a typical blade. The mid-span section of a four-point-loaded beam provides pure flexural loading with no shear if it is sufficiently long relative to the beam depth. However, a long beam section also produces large displacements relative to the flange maximum strain, requiring greater hydraulic flow capacity to achieve a particular fatigue test frequency. The initial sizing of the beams using elastic-beam theory was intended to provide a relatively stiff, short beam, but one that still behaved like a classical beam in the center section.

A beam in bending, regardless of its elastic properties, experiences strain that is proportional to the curvature and a linear function of the distance from the neutral axis $[5,6]$. Using the coordinate systems in Figure 8(a), this relationship is expressed as:

$$
\varepsilon=-(k * y)
$$

Symbols are defined in the list of symbols.

Hooke's Law for an orthotropic material in a state of plane stress (with a $\sigma_{Y}=0$ ) reduces to [7]

$$
\begin{gathered}
\varepsilon_{X}=\frac{\sigma_{X}}{E} \\
\varepsilon_{Y}=-v_{X Y} \frac{\sigma_{X}}{E}
\end{gathered}
$$


For a laminate or a composite beam, Equation 2 is expressed as

$$
\varepsilon_{x i}=\frac{\sigma_{x i}}{E_{i}}
$$

Substitution of Equation 4 into Equation 1 yields the expression

$$
\sigma_{x i}=-\left(E_{i} k y\right)
$$

The resultant bending moment acting on the beam is expressed as

$$
M_{x x}=\int E_{i} k_{x x} y^{2} d A
$$

Replacing the integral in Equation 5 with its primitive, a summation, and rearrangement yields [6],

$$
k=\frac{M}{\sum_{i=1}^{n} E_{i} I_{i}}
$$

By viewing the shear webs and flanges of the C-channels and the outer flanges as separate and distinct geometric and elastic entities (See Figure 9 and the elastic constants in Table 2), a composite flexural rigidity (EI) may be calculated for any given cross section. Using Equation 6, we can then calculate $\mathrm{k}_{\mathrm{XX}}$, and consequently the strain at any given point in the cross section of the I-beam. For a $76 \mathrm{~mm}$ by $71 \mathrm{~mm}$ cross section, a flange thickness of $4.3 \mathrm{~mm}$, and a 610-mm outer span, Equation 6 and the deflection equation for four-point bending of a beam at the inner points of load introduction yield [6]

$$
v(a)=\frac{P a^{2}}{6 E I}(3 L-4 a)
$$

Equation 7 predicts that a force of $66.7 \mathrm{kN}$ will result in a deflection at the load points of $4.3 \mathrm{~mm}$ and 5800 micro-strain (strain $\times 10^{6}$ ) at the center of the beam on the flange surface. The deflection levels would limit the test to approximately $5 \mathrm{~Hz}$ in the MTS machine used in this study. Based on coupon fatigue data for the flange materials we selected 6000 micro-strain as an initial testing range. 
The predictions considered thus far do not include shear deformation. The length/height ratio for the selected geometry is eight, indicating significant shear influence. The average shear stress in the web of a beam is given by [7]

$$
\tau_{\text {avg }}=\frac{V}{t h}
$$

where $\mathrm{V}$ is the shear force, $t$ is the thickness of shear web and $h$ is the height of shear web. The average shear stress resulting from the above load (between the outer and inner load points) is approximately $186 \mathrm{MPa}$, a stress level that would fail the web without shear web reinforcement. As in steel construction [8], web stiffeners were introduced to carry the excessive shear loads. The use of structural adhesives in joining composite materials influenced the design solution for excessive shear stress resulting from the large surface area available for bonding (See Figure 10, configuration 1). The compound angle of the stiffener, similar to the beveling of tabs on standard material test coupons, was chosen to reduce stress concentrations.

In order to evaluate deflections predicted by classic beam theory in comparison with FEA and experimental results, the differential equations of the deflection curve for a beam, expressed in terms of shear force and bending moment [9], were integrated. The flexural rigidity term, EI, was derived following Equation 6. Additionally, the differential equation describing the displacement effects of shear deformation [10], modified for a composite beam, is expressed as

$$
\frac{d v}{d x}=\frac{\alpha_{S} V}{\sum_{i=1}^{n} G_{i} A_{i}}
$$

Equation 9 was integrated and included in the deflection solution. The derivation of the composite shear rigidity $\left(\mathrm{G}_{\mathrm{i}} \mathrm{A}_{\mathrm{i}}\right)$ in Equation 9 was premised on the same principals as those of the composite flexural rigidity. On the interval $0 \leq \mathrm{x} \leq a$, the total displacement solution is given by $v_{1}$

$$
v_{1}(x)=\frac{P x}{6}\left[\frac{3 a(L-2 a)}{(E I)_{2}}+\frac{3 a^{2}-x^{2}}{(E I)_{1}}\right]+\frac{\alpha P x}{(G A)_{1}}
$$

and for the interval $a \leq \mathrm{x} \leq \mathrm{L} / 2$ the displacement is given by $\mathrm{v}_{2}$

$$
v_{2}(x)=\frac{P a}{2(E I)_{2}}\left(L x-x^{2}\right)+\frac{P a^{3}}{6}\left[\frac{2}{(E I)_{1}}-\frac{3}{(E I)_{X}}\right]+\frac{\alpha P a}{(G A)_{1}}
$$




\section{Finite Element Analysis Overview}

We used the commercial finite-element program ANSYS was used for all FEA analysis. Solutions were executed on an IBM RS 6000 resident at MSU and on a CRAY Y-MP resident at the National Center for Supercomputing Applications, University of Illinois at Urbana-Champaign.

The ANSYS element selected for analysis was Solid45, a three-dimensional, curved-sided brick or isoparametric hexahedra. Solid45 was chosen for its three-dimensional and orthotropic modeling capabilities and reduced model size relative to other three-dimensional ANSYS elements. Models were run with element planar dimensions set for 0.5. The convergence of FEA results was verified with runs on the Cray Y-MP with a planar dimension of 0.25 (See Figure 11).

\section{Iterative Development of Beam Details}

\section{Overview}

The early objective of this work was to develop a beam substructure that would fail at either the tensile or compressive flange, in the mid-section of the beam. Although the initial sizing of the beam sections was reasonably accurate, the details of the load-transfer areas around the load points required several iterations before adequate force could be transferred onto the flanges to produce failure. This was particularly true for fatigue loading.

The problems of load introduction and distribution are common to most composite structures. The low polymer matrix elastic and strength properties produce corresponding low composite shear strengths in many directions. It is the shear properties of materials that are generally responsible for distributing loads. Low shear strengths in the matrix and adhesive layers generate a requirement for large bonding areas over which to transfer forces. The design and analysis of efficient load-transfer details typically require finite-element or similar analysis.

The stages followed in this program to develop adequate load-transfer details may be of interest to blade designers. In this section, this ad hoc, iterative, design-materials-testing-manufacturingredesign procedure is reported for each stage of development. Although many modifications such as the tapering of details are intuitive in nature, detailed finite-element analysis and repeated testing were necessary to obtain improved geometries.

We dedicated the initial phase of our work to the development and testing of five separate beam specimens (numbers 1-5). These five beams included three different configurations (1, 2, and 3). Figure 10 and Table 3 summarize the geometries of these beams. Later beam tests (beam numbers >5) used Configuration 3, with slight changes indicated later. Table 3 also indicates the test regime for each of the first five beams. Two types of shear stiffeners were used: shear stiffener 1, previously described, was used on configurations 1 and 2 and beams 1-3; shear stiffener 2 (see Figure 10(c)), which was symmetric with respect to the XZ plane of the beam, was used on beams 4-5. (The rationale for stiffener 2 follows.) Using conventional beam terminology, the outside load points are 
referred to as supports and the inside load points are referred to as load points/pads. Figure 8(b) identifies the beam coordinate system.

Note that the FEA incorporated two planes of beam symmetry; therefore, one quarter of the beam was modeled. The YZ plane of symmetry divides the beam in half axially and the XY plane of symmetry divides the beam in half laterally.

\section{Beam Configuration 1}

Beam 1 (see Figure 10(a)), the first beam tested in fatigue, was a shakedown for both beam design and the test fixture. Beam 1, using Configuration 1, encountered load pad failure that was largely attributable to a design compromise of the test fixture. Initial fixture design called for roller supports for inner load points and fixed semicircular outer supports. The dynamics at the interface of a roller and pad are those of slip and roll, whereas those at the interface of a fixed support and pad are pure slip. The effects of pure slip were catastrophic to the support pads, resulting in shear failure (Figure 12(a)). By changing the fixture design to include outside rollers, support pad failure was eliminated until $10^{6}$ cycles for Beam 1. Load pad failure also caused a compression damage zone directly under one of the support pads (see Figure 12(a)), in the region of the C-channel fillet. Insufficient control of the MTS hydraulics probably resulted in an overload condition, resulting in this damage. Test histories for beams 1 and 2 are found in Tables 4-6.

Beam 1 failed with massive damage in the shear web, separation of the outer flange from the flanges of the C-channels, and growth of the compression damage zone under the load pad. We hypothesized that the initial compression damage was a nucleation site for crack growth in the adhesive joint between the outer flange and the flanges of the $\mathrm{C}$-channel. Under cycling, cracks extended, releasing the tension flange from the $\mathrm{C}$-channel flanges and the next stroke of the piston crushed the shear web.

Beam 2 was manufactured and tested to judge the validity of this hypothesis. We terminated the testing of beam 2 before failure because of the growth of damage zones on the tension side flange at the center of both support pads. After dissecting beam 2 we determined that the aforementioned damage was failure of the tension flange-to-web adhesive joint. Visual inspection revealed a smooth fracture surface, which is indicative of an adhesive-line failure as opposed to a rough fracture surface. The latter would have indicated matrix damage (see Figure 12(b)). Therefore, the original hypothesis was incorrect: beam 1 failed because of adhesive failure at the interface of the flanges.

\section{Beam Configuration 2}

The adhesive failure of beams 1 and 2 called for a redesign of the beam. The deflection equation for four-point bending (Equation 7) revealed that reducing the value $\mathrm{I}_{\mathrm{ZZ}}$ of the beam by a factor of $n$ allows for a reduction of the load by the same factor to achieve the same deflection. Also recall that $\epsilon=\mathrm{f}(\mathrm{k}, \mathrm{y})$, i.e., for a given curvature/deflection, the strain is a linear function of $\mathrm{y} . \mathrm{I}_{\mathrm{zZ}}$ was reduced by narrowing the flange width from $76 \mathrm{~mm}$ to $51 \mathrm{~mm}$ (now equal to the flange width of the 
C-channels) and incorporating two $0^{\circ}$ ply drops in the gage section of the flange (see Figure 13). The ply drops reduced flange thickness to $3.3 \mathrm{~mm}$ from $4.3 \mathrm{~mm}$. The resulting cross-sectional area of the flanges in the gage section of the beam was reduced by approximately $50 \%$.

The addition of ply drops to the list of experimental parameters seemed desirable, as they are used extensively in the fabrication of wind turbine blades. Ply drops are commonly used in any composite structure where a decrease in laminate thickness is required. We also hoped that the ply drops would facilitate flange failure in the gage section, away from the load pads. Further details of the effects of ply drops and their optimal design are given in the last section.

During the testing of beam 3 (see Table 7 for test history), delaminations (see Figure 14) were severe at the ply drops on the tension side of the beam. There is an opening (peeling) mode component to the delamination crack on the tension side of the beam, which favors delamination. (Delaminations did also occur on the compression flange of beam 4, at approximately $10^{6}$ cycles.) We repaired the delaminations when the size reached a subjective threshold, as continued growth could have resulted in an undesirable failure mode. We used Hysol EA9412, a low-viscosity epoxy to repair the delaminations. Visual inspection of the repaired delaminations showed good wetting; however reinitiation and further delamination growth could not be suppressed. We then applied a single layer of chopped mat on top of all ply drops in a vain attempt to inhibit delamination. As reported in previous beams, cracks in the adhesive joint of the tension-to-web flange appeared at approximately 400,000 cycles. Continued growth of this damage dictated a design change. Testing was stopped at 757,239 cycles, prior to failure.

Although beam 3 was tested at close to $10^{6}$ cycles, it was apparent that conducting tests at higher strains and/or cycles would require further reduction of shear stress at the flange interface. A shear force diagram for four-point bending describes constant shear between the supports and the points of load introduction. The design of shear stiffener 1, used in beam configurations 1 and 2 , created a complex geometry immediately above the tension flange and center of the outside support, with greatly reduced web thickness (Figure 10(b)). Constant thickness of the shear web/stiffener between the outside support and load pad would provide a constant cross section for distribution of the shear force.

Closed-form approximate analysis [6] of shear stresses for open-section members describes the single, in-plane stress distribution that is assumed constant through the thickness. The shear distribution for an I section predicts maximum flange shear stress at the intersection of the web and flange [6]. FEA of the interface between the outer flange and the C-channel flanges corroborates the closed form solution regarding the lateral location of maximum shear stress. Complete resolution of the FEA shear stresses depicted a complicated shear-stress distribution that provides insight into to the cause of the shear failure and reinforced the selection of the proposed design solution, i.e., shear stiffener 2 (see Figure 10(c)).

The shear stress concentrations with shear stiffener 1 that appear in Figures 15-20 under the tension flanges, are most severe for configuration 2. Shear stresses are more than twice as high for 
configuration 2 as they are for configuration 3 . The results we obtained foe configuration 2 were similar to those we obtained for configuration 1, which also used stiffener 1 . Figure 16 shows the shear stress concentration on the tension flange to be immediately in front of the support pad, $76<$ $\mathrm{x}<127$, corresponding to the position where the stiffener loses contact with the inner surface of the C-channel flange. The shear stress distribution for configuration 3 shows two peaks, the larger occurring at the initiation of taper in the shear stiffener, at $\mathrm{x}=178 \mathrm{~mm}$, where contact is once again lost between the inner surface of the C-channel flange and the surface of the stiffener. The smaller stress spike on this surface is located at the point of outside support, $x=76 \mathrm{~mm}$. Stress spikes occur on all graphs at sites of thickness change of the shear web/stiffener and tension and compression flanges. The redesign from configuration 2 to configuration 3 reduced the maximum XY shear stress from about 9.7 MPa to about 4.1 $\mathrm{MPa}$ at $17.8 \mathrm{kN}$ load. This effectively solved the adhesive failure problem.

Figures 17 and 18 depict the $\mathrm{XZ}$ component of the shear stress at the flange interface for configurations 2 and 3 . The magnitude of shear stress $\mathrm{XZ}$ is not appreciably affected by the different shear stiffeners, although the distribution is affected. Furthermore, the magnitude of this component of shear stress is significant.

For completeness, Figure 19 shows that the YZ component of the shear stress, configuration 3, is negligible. This is consistent with the XY symmetry boundary conditions imposed on the FEA. Minimal YZ shear was found for all configurations.

The FEA predicted a significant shear stress concentration at the same site, the adhesive layer under the outside support on the tension flange, where crack initiation was observed in configurations 1-2, using shear stiffener 1 . The outer flanges in the FEA mesh were a single element thick, with orthotropic material properties. Outer-flange elements shared common nodes with the orthotropic elements defining the flanges of the $\mathrm{C}$-channel, with distinct orthotropic material properties. The adhesive was not modeled. Investigation of the possible influences of material discontinuity at the shared nodes was warranted. Additionally, curiosity is piqued when noting the change in sign of shear stress XY acting on the compression flange at $\mathrm{x}=127 \mathrm{~mm}$ in the $\mathrm{Z}$ direction (see Figures 15 and 16). The shift in sign of the XY shear stress is similar to that predicted by closed-form solution [6] for a Z-section. To determine the role of material discontinuity, FEA was completed for configuration 2 with the isotropic material properties of aluminum substituted throughout. Shear stress XY results (see Figure 20) demonstrate that material discontinuity does not affect the FEA shear stress solution on this plane. (All FEA concerning the shear failure of the flange adhesive joint were run with an equivalent total load of $17.8 \mathrm{kN}$.)

\section{Beam Configuration 3}

Beam 4, using configuration 3, included shear stiffener 2 and ply drops; it was the final design of this phase of the project. The change in shear stiffener shape completely eliminated any signs of shear failure in the flange adhesive joint, thus supporting the FEA prediction. Delamination of the ply drops was a chronic problem with this beam, one which was never adequately resolved. Load pad 
failure at 1.3 million cycles was unexpected and catastrophic for all pads. Steel layers 3.2-mm thick were connected to a new set of composite pads using epoxy adhesive and machine screws. The steel pads spalled, but no further problems occurred with the load pads for the duration of testing. Beam 4 was tested to failure in fatigue (see Table 8).

We tested beam 5, configuration 3, to failure in a static ramp-loading test, although three attempts were required to achieve failure. Piston displacement approached $13 \mathrm{~mm}$ at failure. This large deflection presented unexpected difficulties. At $89 \mathrm{kN}$, the first attempt was terminated by failure of a fixture-end constraint on the apparatus. Damage to the test specimen was limited to a $100-\mathrm{mm}$ delamination, at the top surface of the compression flange, extending from the end of the beam that contacted the failed constraint. We repaired the delamination as previously described and removed the end constraints from the test fixture. The second attempt had the beam slip off the load rollers, which initiated an axially directed translation. We believe that this type of translation caused the endconstraint failure at $100 \mathrm{kN}$. The explanation for this occurrence of slip is found in the asymmetric design of the load pads (see Figure 10), coupled with large deflections and corresponding shortening of the compression flange. All pads were removed and replaced with rectangular-shaped pads measuring $51 \mathrm{~mm}$ by $76 \mathrm{~mm}$ by $13 \mathrm{~mm}$. The third loading did result in compression flange failure of the beam, which is described later.

\section{Validation of Stiffness and Strain Predictions}

We explored the correlation between experimental and predicted beam stiffness and strain in detail for the first five beams. The beam stiffness and strain versus load were predicted for beams 1-5, based on the classical beam theory equations and finite-element procedure given previously. Tables 9-11 and Figures 21-26 provide comparisons of predicted and measured data. Table 9, taken from Figure 21, compares the slope of the strain versus load curve on the tensile and compressive flanges to the classical beam theory and FEA predictions for beam 2 .

The close correlation of beam theory with both FEA and experimental results (3\% maximum variation) is surprising in light of the low length-to-depth (1/d) ratio of the beam. Shear deformation effects are not incorporated in these initial beam theory predictions, but are considered later. These results indicate that the shear stiffener 1 design, used in configurations 1 and 2, was effective in eliminating shear deflections.

Results for beams 4 and 5 are given in Figures 23-25 and Tables 10 and 11. Shear stiffener geometry 2 , used in beam configuration 3, effectively suppressed shear deformation in beams 4 and 5 as shown by the contribution of the last term in Equation 8, the shear deflection component. The shear component of deflection at $35.6 \mathrm{kN}$ total load is approximately $5 \%$ of the total deflection at the load pads. Also, beam theory and experimental micro-strain results for beams 4 and 5 differ by only $8 \%$. Correlation of theoretical micro-strain and FEA results for beams 4 and 5 is not as close as for beam 2 , yet the agreement is still generally good. Both beam theory and FEA predict a similar load versus deflection curve that varies from the experimental curve (see Table 10). Both FEA and beam theory predictions underestimate the displacements at the load pads and overestimate the deflection at the 
center of the beam. Equation 9 predicts a center-point displacement that is $23 \%$ greater than the average value recorded in the laboratory.

In contrast to the close correlation of experimental and predicted results for beams 2, 4 and 5 are the results for beams 1 and 3 (see Tables 12 and 13 which were taken from Figures 21 and 22). Firstcycle comparison of beam 3 micro-strain results with FEA results (see Table 13) shows a 15\% discrepancy in slope values. Beam 1 at 100,000 cycles (initial micro-strain data was not gathered for beam 1) shows a $13 \%$ difference between experimental and FEA tensile micro-strain results (see Table 15). The compressive micro-strain slope value for beam 1 at 100,000 cycles is at an acceptable $8 \%$ difference from experimental values. The most plausible explanation for these discrepancies is variation in the manufacturing process. The change in experimental boundary conditions at 200,000 cycles for beam 1 (when the outside rollers were installed in the test fixture) would account for a less stiff beam, more closely matching the boundary conditions of the FEA and possibly accounting for part of the $9 \%$ shift in the tensile micro-strain curve for this beam. However, this reasoning is inconsistent with the compressive micro-strain data for beam 1, which did not appreciably change after introduction of the outside roller supports, and the $15 \%$ variation in first-cycle results for beam 3 , which was tested with all roller supports throughout its testing regime. The consistency of firstcycle experimental results for beams 4 and 5 (see Tables 14 and 15 which were taken from Figures 23-26) does demonstrate repeatability in the manufacturing process, which is vital for both experimental and composite production purposes. Thus, the observed variation between experimental and FEA micro-strain results may be explained by initial inconsistencies in the beam fabrication process and test supports for the first few beams produced, relative to the assumed elastic constants and geometric parameters.

Beam 4 was tested at sufficient strain/stress and cycle levels to produce definite shifts in all data curves with cycling (see Figures 23 and 24 and Tables 14 and 15). Comparison of micro-strain versus load data for all beams shows a significant shift in the slopes for beams 1-3 at much lower cycles relative to beam 4 . This variation is directly attributable to the change in shear stiffener geometry and the suppression of shear failure at the adhesive joint between $\mathrm{C}$-channel flanges and the outer flanges. The advancing crack in the adhesive joints of beams 1-3 was softening the beam, increasing the displacement and strain under load. Figures 27 and 28 show the accumulated damage on beam 4 .

Flange materials were largely comprised of unidirectional layers (see Table 2); previous research [11] indicated that decay in modulus of $0^{\circ}$-dominated laminates is noticeable and precipitous only at the end of the lifetime of the laminate. This finding is corroborated by the results of beam 4 . However, an interesting departure from the expected trend is also seen in the stiffness change of beam 4. Although the beam is less stiff on the average, the stiffness is increasing as the load increases at 2.2 million cycles (see Figures 23 and 24). This phenomenon is especially noticeable in the displacement plots (see Figure 23). We do not completely understand this effect. 


\section{Conclusions from Beam Test Specimen Development}

The development of the composite beam required several iterations of design, testing, analysis, and redesign to produce gage-section flange failures prior to the breakdown of the load-transfer details. The final beam, configuration 3, shows strain and stiffness values in good agreement with simple beam theory and finite-element analysis. Fatigue testing did produce moderate stiffness changes, and the initial testing fixture required modification in the supports to properly function under fatigue loading. The final beam specimen is representative of blade substructure in the flapwise direction, and meets all of the original requirements stated in the introduction. 


\section{Final Test Specimen Definition}

We described the evolution and validation of the composite beam test specimen (given as configuration 3), which is shown in Figure 3. (Note that the term configuration refers to geometry; various materials are used for the web and flanges.) We increased the thickness of the web area to $5 \mathrm{~mm}$ in subsequent tests (beam numbers greater than 5) to reduce the possibility of web failures prior to flange failure. For beams numbered 30 and greater, the web was molded by RTM as a single piece, rather than back-to-back bonding of C-channels; this single-piece molding improved dimensional repeatability without the need for sanding the surfaces to make them flat prior to secondary bonding. Except where indicated, the flanges for beams numbers 6 and above do not contain ply drops.

The results of tests and analysis on beam configuration 3 using beams 4 and 5 showed that the stiffness and strains are in good agreement with beam theory and FEA predictions. Outside of problems with ply drop delamination, the failure modes for beams 4 and 5 were as expected, and the flange strain values in fatigue were in the range of limited coupon results for this flange material, as discussed in detail in References 5 and 12. The tests that we describe in the following sections provide a detailed evaluation of failure mode and lifetime prediction based on well-characterized materials from the DOE/MSU fatigue database $[1,2]$. 


\section{Experimental Investigation Of Beam Static and Fatigue Behavior}

\section{Introduction}

This section investigates the consistency between the coupon fatigue database and material performance in a series of beam structure tests. We ran beam static and fatigue tests in several load ranges, with several material variations differing in static and fatigue properties in the flanges and webs. We strain-gaged beams in each case in order to compare strain-lifetime relationships between the coupon database and the beams. Strains given are from the first few cycles, after which the strain gages failed because of matrix cracks. Beam configuration 3, used for all tests, was described in the previous section. The Appendix gives detailed results for each beam test.

The general objective of the beam tests in this section was to compare beam performance with the performance of the flange and web materials in coupon tests, thereby validating use of the coupon database for predicting the static and fatigue performance of structures. The beam materials were divided between triax-based laminates, with relatively poor tensile fatigue performance, and laminates with separate $0^{\circ}$ and $\pm 45^{\circ}$ layers, with relatively good fatigue performance.

\section{Material and Beam Description}

Tables 16-20 give a detailed summary of the materials, conditions, and results of each test. Further details for each test can be found in the Appendix. Beams 6-14, 22, and 23 used CDB 200 triaxbased flanges, designated material AA in Table 16 and in the database $[1,2]$. In this series flanges were 2.9-mm thick and 53-mm wide. The web used in all of the AA-flanged beams was designated material $\mathrm{CH} 10$ in the database. Material $\mathrm{CH} 10$ is 5 -mm thick with all $\pm 45^{\circ}$ layers of DB240 fabric. We define the materials in more detail in the footnotes for Tables 16-20. We performed this series of tests to determine whether the behavior of beams with AA material flanges (with poor tensile fatigue performance) was consistent with coupon behavior. Material AA is commonly used in wind turbine blade fabrication, but performs poorly in tensile fatigue because of heavy stitching of the $\pm 45^{\circ}$ layers to the $0^{\circ}$ layers [2]. (Materials that perform poorly in fatigue are easier to test in a substructure because they require less strain and load transfer to produce the desired central-gagesection failures.) Beams 15, 16, and 17 were further weakened by including 13-mm-diameter through-thickness holes in the flanges.

We provide summaries of tests of beams 18-21 and 24-33 in Table 17. These beams used DD5P material in the flanges, which is a model structural material with about $72 \%$ of the fibers in the $0^{\circ}$ direction (x-direction in Figure 8); the remainder of the material is $\pm 45^{\circ}$, as described in the footnote. With a low fiber content of $36 \%$ by volume, material DD5P has a much better tensile fatigue resistance than that of material AA, and is close to the best obtainable with fiberglass materials [2]. Figure 29(a) compares the coupon test results of tensile fatigue behavior of materials AA and DD5P; Figure 29(b) compares their behavior in compressive fatigue.

The straight lines in these and succeeding figures represent a linear trend on the semi-log plots. If 
the maximum (absolute) applied stress, $\mathrm{S}$, is normalized by the single-cycle static strength, $\mathrm{S}_{\mathrm{O}}$, the trend lines are given by:

$$
\frac{S}{S_{O}}=1-b \log N
$$

where $N$ is the cycles to failure and $b$ is the fatigue coefficient. The implications of a particular assumed trend line (linear on log-log versus linear on semi-log) are discussed in Reference 2 . The fatigue coefficient, $b$, for poor tensile fatigue performance is about 0.14 , whereas the best performance is about 0.10 [2].

For the final beam tests in this group, (see Table 18), we used various improved web materials (CH3, $\mathrm{CH} 12$, and DD5P) to increase the strain capacity in tensile fatigue of the web flange on the tensile side. These web materials include increasing amounts of $0^{\circ}$ material, as indicated in the footnotes. Figure 30(a) compares the tensile fatigue resistance of coupons of the four web materials, $\mathrm{CH} 10$, $\mathrm{CH} 3, \mathrm{CH} 12$, and DD5P; these results are discussed in detail in Reference 2.

Table 19 gives results for beams with material AA (triax) containing holes in the flanges, and Table 20 gives results for beams containing ply drops. These results will be discussed in later sections.

\section{Studies of Beams with Triax Material Flanges}

\section{Introduction}

As previously noted, triax fabric reinforcement produces relatively poor tensile fatigue performance [2]. Figure 30(b) combines the material AA data from Figures 29(a) and 29(b), comparing the tensile and compressive fatigue $\mathrm{S}-\mathrm{N}$ data. The static tensile strength exceeds the compressive strength, and the stress to produce failure is higher in tension at low cycles. At about a thousand cycles the curves cross, and failure occurs at lower stresses in tension for cycles greater than 1000 . Thus, with equal magnitude stresses and strains in both flanges, failure is expected in the beams in compression at low cycles, and tension at high cycles. The $10^{6}$ cycle tensile fatigue strain to failure of the $\mathrm{CH} 10$ material used for the web is similar to that for material AA $(0.46 \%$ for $\mathrm{CH} 10,0.50 \%$ for AA [1]). Thus, failure is expected at about the same time in the tension flange and in the web flange on the tensile side, which see about the same strain levels (because they are bonded together). The Appendix gives details of the materials in the cross section at the beginning of the section on beams with AA material flanges.

\section{Behavior of Beams}

Figure 31(a) compares the failure strain conditions for the AA flange beams with the strain-cycles data for the material AA coupons. (The solid square and triangle symbols are the measured initial strains on the tension and compression flanges, respectively; the symbol shown indicates which flange actually failed.) The static beam tests $(6,9$, and 13) resulted in compressive flange failures 
with damage in the web as well (Figure 31(a)). The measured static compressive flange strains at failure cover the range observed for the compressive coupon tests (Figure 31(a), one cycle). Figure 31(b) compares the web material $\mathrm{CH} 10$ coupon results with the beam data; the $\mathrm{CH} 10$ tensile fatigue strains are, again, similar to the beam failure strains. In order to compare coupon data with web flange strains in the beams, the beam strains are adjusted downward to 0.82 of the measured flange outside surface strains to give the strain at the outside of the web flange (assuming a linear strain variation across the beam depth).

We conducted fatigue tests with beams having the AA material flanges (without holes) for beams $7,8,9,10,11,12$, and 14. These beams all failed on the tension flange, and the results in Figure 31(a) show close agreement with the failure strains and cycles for tensile coupons of the same material, tested at $\mathrm{R}=0.1$ (the same $\mathrm{R}$ value as the beam tensile flange). The predicted shift from compressive failure at low cycles to tensile failure at high cycles is observed in the beam results only in the static compression failures compared with tensile fatigue failures; no lifetimes could be produced in fatigue between 1 and 1,000 cycles because of difficulties in controlling tests in the low cycle range. Photographs of failure details are given in the Appendix for most beams, and Figures 32 and 33 gives a combined photograph of all flanges in this series as well as several detailed photographs.

The overall results provided in Figure 31 validate use of the fatigue coupon database to predict beam structural-element lifetime for tension-dominated failures. Earlier discussion showed that the beam strains are accurately predicted by appropriate finite-element analysis, with a reasonable approximation by simple beam theory. Thus, when analyzed appropriately, the results given here confirm that these materials, when fabricated into a structural element similar to a blade, provide the static strength, tensile fatigue lifetime, and failure mode anticipated from simple coupon data. The size, flexural loading, and bonding to the web element do not compromise or complicate the material performance.

These results are for a triax material, which, although representative of blade materials, has poor fatigue resistance. This results in relatively low load transfer and low web loading, which produces flange failures. However, the stress and strain conditions producing beam failure, although lower than in subsequent beams, are more severe than expected in blade service loadings.

\section{Studies of Beams with Improved Flange and Web Materials}

\section{Introduction}

In this section we describe the development of improved materials for the flanges and webs and their application to beams. Flange materials which can withstand more severe fatigue loading tend to produce failure in other modes than flange fracture, such as adhesive failure or web failure adjacent to the flange. Because the flange and web are bonded together, the strains in each are nearly identical at the bonded plane. Thus, the web must withstand the same tensile and compressive fatigue cycling in these areas as do the flanges, while also carrying the shear loads. 


\section{Material Development and Coupon Results}

We reported earlier that the tensile fatigue resistance of triax materials, such as material AA, was very deficient as compared with laminates having separate $0^{\circ}$ and $\pm 45^{\circ}$ layers $[2,11]$. Structural laminates with about $70 \% 0^{\circ}$ material with separate layers were found to behave well in tensile fatigue only at overall fiber contents below about $42 \%$ for laminates containing a high percentage of $0^{\circ}$ layers relative to $\pm 45^{\circ}$ layers. A complete parametric study of potential structural flange materials is reported in Reference 2 .

For this study, we investigated a similar range of parameters for web materials. Again, these efforts are described in detail in Reference 2, and the data are included in the DOE/MSU database [1]. The results of the coupon study show that a potential web material must have a relatively high percentage of $0^{\circ}$ layers and low overall fiber content to approach the strain capabilities (represented by the $10^{6}$ cycle maximum strain) in tensile fatigue of the structural flange (DD5P) materials. This tends to stiffen the beams significantly, resulting in higher loads and more load-transfer problems to achieve the same flange strains.

\section{Beam Test Results}

Table 17 describes a series of beams (numbers 18-21 and 24-29) prepared with web material CH10 (all \pm 45$)$ and flange material DD5P $\left(72 \% 0^{\circ}, 36 \%\right.$ overall fiber volume content). This flange has excellent fatigue resistance in tension (see Figure 29(a)), whereas $\mathrm{CH} 10$ is a typical $\pm 45^{\circ}$ web material. The flange material coupon results [2] show tension and compression strains for $10^{6}$ cycles of $1.15 \%$ and $1.30 \%$, respectively, whereas the values for $\mathrm{CH} 10$ are $0.58 \%$ in tension and $0.64 \%$ in compression. The AA material $10^{6}$ cycle strains are $0.50 \%$ in tension and $0.95 \%$ in compression.

Figures 34 and 35 compare the beam data with flange material and web material coupon data, respectively. All of the failures were predominantly in the web, with some flange interaction. The results in Figure 35 show that the web flanges should have already cracked heavily prior to flange failure, and this appeared to be the case. Thus, most of these failures were induced in the web flange area, and agree generally with the web coupon data in Figure 35. Significant flange-web delamination near the ends of the shear stiffeners was also observed, as shown in Figure 36.

The results with web material $\mathrm{CH} 10$ were disappointing, in that failures predominantly generated from the web flange area. We decided to test several web materials with strain capability that more nearly approximated the flange material (DD5P), using the flange material itself in the web. Figure 30 (a) compares the tensile strains of the four web materials tested in tensile fatigue. Higher $0^{\circ}$ material content gives higher tensile fatigue strain capability if the overall fiber content is similar.

Table 18 gives the results for beams with DD5P flanges and $\mathrm{CH} 3, \mathrm{CH} 12$, and DD5P webs. Figures 37 and 38 give the DD5P flange/CH3 web results for beams 30-33 compared with flange and web coupon data respectively. All of the beams in this group showed a variety of delamination and web damage. The beam data in Figures 37 and 38 agree generally with the flange and web coupon data, 
but failure modes were not simple to interpret.

Beams 34 and 35 included DD5P material flanges and CH12 web material (see Table 18 and Figures 39 and 40). As indicated in Table 18, these beams produced delamination failures in the load transfer area of the load pads. The fatigue failure (beam 35) was at a strain well below either set of coupon data, as expected from the load-transfer problems.

Beams with material DD5P in the flanges and web are shown in Table 18 and Figure 41(a). The lower cycle results (beams 52 and 53) failed in the shear stiffener area (beam 53), which was then increased in thickness, and resulted in beam 52 showing compression flange buckling. Beams 51 and 54 reached close to the coupon data: we stopped the tests with only minor gage section damage; beam 54 eventually failed in the shear stiffener area. Figure 41(b) shows the tension and compression flanges of beams 51-54.

\section{Conclusions for Beams With Improved Flange and Web Materials}

Results for the beams with DD5P material flanges are not as conclusive as those for the AA material flanges. Because these DD5P flanges can withstand strains about twice as great at $10^{6}$ cycles, and many of the webs were increased in stiffness over a simple $\pm 45^{\circ}$ laminate such as $\mathrm{CH} 10$, the loadtransfer requirements were increased significantly. Thus, greater demands were put on the web in the web flange area, where the strains were the same as in the flanges. Results for Figures 34 and 35, for the material DD5P flanges and $\mathrm{CH} 10\left( \pm 45^{\circ}\right) \mathrm{web}$, show that the beams survive to a lifetime in the same range as the flange material coupons, exceeding the lifetime of the web material coupons. In most cases, the web material was heavily cracked prior to failure, leading to tensile flange delamination. Similar agreement between beams and coupons is shown in Figure 37 and 38, with a web (CH3) containing $24 \% 0^{\circ}$ material. Higher $0^{\circ}$ material contents in web materials $\mathrm{CH} 12$ and DD5P led to more load-transfer problems; however the beam data do approach the coupon results at lower loads and higher cycles (see Figure 41). The load-transfer problems are related to the particular beam design used here, although the web failure adjacent to the flange would be expected in a blade and is a meaningful result. Overall, the beam data with material DD5P flanges are consistent with web and/or flange coupon results in the absence of failures resulting from load introduction problems.

\section{Stiffness Changes}

Several of the beams were monitored for stiffness changes. Figure 42 gives stiffness change as a function of fractional lifetime for four beams. Stiffness changes were generally moderate, with the greatest changes associated with delaminations, as reported in the first section. Material coupon stiffness changes tend to be in the range of $10 \%$ to $15 \%$ until just prior to failure [2]. Changes greater than this are typically the result of structural breakdown as by delamination in the load-transfer area. Strains during fatigue were monitored by special clip gages described in Ref. [2], because bonded strain gages fail with the onset of matrix cracking. 


\section{Studies Of Structural Details}

\section{Introduction}

Wind turbine blades are comprised of large areas of structure to which the foregoing sections apply. However, they also contain unintentional flaws and necessary structural details such as ply drops and adhesive bonds. The beam test specimen provides a good context in which to consider certain structural details. This section includes results for two cases: first, the effects of severe flaws in the form of through-thickness, 13-mm diameter holes; and second, various cases of single and multiple ply drops. In each case, coupon data are presented followed by results where the detail is incorporated into beam flanges.

\section{Effects of Through-Thickness Holes}

Turbine blades are subject to damage and manufacturing flaws, and in some cases may contain bolted connections. Composite materials are relatively insensitive to notches and flaws, but still demonstrate some degree of notch sensitivity in most cases [13,14]. The most notch-sensitive composites tend to be woven biaxial fabric constructions, with finer weaves giving more notch sensitivity; in the most notch-sensitive cases, or with very large flaws, linear fracture mechanics may be applied for through-thickness flaws [13]. More commonly, stable damage development near flaws is significant, and two parameter models such as the Nuismer-Whitney model are used [14]. Sometimes, a through-thickness hole is used in laminate tests, which tends to produce a more severe strength loss than flaws that escape visual inspection. For the carbon-fiber composites that have been investigated, impact damage and resulting delamination tend to be slightly more severe than throughholes in compression.

\section{Coupon Results With Holes}

We investigated flaw sensitivity for AA triax material, which, like woven fabrics [16], was expected to exhibit more notch sensitivity than separate ply laminates. Figure 43(a) gives coupon fatigue maximum stress versus cycles to failure ( $\mathrm{S}-\mathrm{N})$ data for notched and unnotched specimens, where the notch was a central 13-mm diameter through-hole in a 51-mm-wide coupon. The stress plotted in Figure 43(a) is that in the far-field, away from the notch. Figure 43(b) gives the same data plotted for the net cross-sectional area remaining at the hole, which is about $38-\mathrm{mm}$ wide for the 51-mm overall width notched specimens. The data show moderate notch sensitivity for the static tests. The fatigue trends appear identical when the data are plotted in Figure 43(c) on a normalized basis; the unnotched and notched results are superimposed. These results are typical for those of many fiberglass laminates [13, 14]. In compression, the results are slightly more notch sensitive (see Figure 43(d)), but less notch sensitive in reverse loading (see Figure 43(e)). However, the reverse-loading case is the most fatigue sensitive for the stresses that produce failure in a given number of cycles. Figures 44 and 45 show the progression of damage and the damage in failed coupons for the tensile fatigue cases. Figure 46 shows local delamination damage for a compression coupon with no hole. 


\section{Beam Results With Holes}

We fabricated three beams with several 13-mm-diameter holes drilled through both tension and compressive flanges (see Table 19). As expected, Figure 47(a) shows that the holes did reduce the static strength and fatigue life, relative to beams without holes. Figure 47(b) confirms that the beams behave similarly to the coupons containing holes. The static-tested beam (17) and the low-cycle fatigue beam (15) failed in compression, as expected from the coupon data, although at lower stress and higher cycles, the failure shifted to the tensile flange (beam 16). Again this is consistent with the coupon predictions. The mode shift is expected by comparing Figure 43(b) with 43(d). Figure 48 shows the details of failed beams with holes and other details as given in the Appendix.

The results of tests in this section for strength, fatigue lifetime and failure mode again show consistent behavior between coupons and beam structures. Severe flaws in the form of 13-mmdiameter holes produce a moderate-strength reduction in the fatigue life of unflawed coupons. However, the far-field strain to produce failure at $10^{6}$ cycles is still in the $0.4 \%$ range, only slightly below that for the unnotched specimens. The unnotched and notched trend lines tend to converge at high cycles in tension, as reported in the literature [13].

\section{Studies of Ply Drops}

\section{Introduction}

Thickness variations are required in any structures with varying loads such as wind turbine blades. Thickness variations in laminated composite materials are accomplished by dropping plies along the length. Thus, ply drops are a structural detail common to most composite structures. This part of the study explores various aspects of ply drops, including the number of plies dropped, ply drop location, spacing, thickness, stacking sequence, geometry, and special treatment of ply drop areas. All studies were based on the DD5P laminate discussed earlier, which is a typical structural laminate with $72 \%$ $0^{\circ}$ fibers, and an overall fiber volume content of 36\%. Ply drops generate high interlaminar stresses that tend to initiate and propagate delamination cracks between plies, particularly under fatigue loading $[15,16]$. Details of specimen preparation and testing can be found in Reference 16.

\section{Coupon Tests}

Table 21 lists the laminate configurations tested with ply drops. The base laminate was material DD5P in the database [1], discussed earlier. Plies were added to this laminate and dropped in the gage section. Dropped plies are indicated by an $\left(^{*}\right)$ on the ply throughout this section. Laminate configurations designated ESA, ESB, and ESC contained a single dropped ply in the location shown (ESB is illustrated in Figure 49). ESE and ESF contained a single dropped ply, but with additional continuous plies (thicker laminate in the same DD5P arrangement) used to change the ratio of dropped to continuous plies. ESG and ESH contained two dropped plies at the same location in the thicker laminate configuration. 
Delamination growth data are given in Figures 50-52 for laminates ESA, ESB, and ESC with single ply drops. In most cases, these are typical curves out of three replications; complete data are given in Reference 18. Delamination for the exterior ply drops (ESA) occurs at much lower stress levels than for the two different interior ply drops (ESB and ESC). We anticipated this because the exterior ply drop can peel from the surface in opening mode, and has only one propagating crack between itself and the rest of the laminate; cases with internal ply drops require a crack on either side of the dropped ply to delaminate.

Figure 53 compares ESB (with a single interior ply drop) with ESF (with a single interior ply drop in a thicker laminate) and ESH (with two interior ply drops at the same location in a thicker laminate). The thicker laminate with a single ply drop (ESF) shows a reduced delamination rate relative to the thinner laminates (ESB). We expected this because the strain energy release rate is typically higher when the dropped ply is a greater fraction of the total laminate stiffness $[15,16]$. However, when two plies are dropped at an interior location in a thicker laminate (ESH), delamination is much more rapid than for a surface ply drop.

Figure 54 compares laminates with exterior ply drops. ESE, a single exterior ply drop on a thicker laminate, delaminates more rapidly than ESA, a thinner laminate. However, a thicker laminate ESG, with two plies dropped at the same location delaminates more rapidly than either ESA or ESE.

\section{Beams With Ply Drops In Flanges}

The results from the coupon tests give delamination at various stress levels, where the stress given is on the thin side of the ply drop. Finite-element runs of beams with delaminations will be carried out in the future to explore this problem in terms of strain energy release rates, but at this time coupon and beam test results are compared only in terms of the beam flange and coupon strains during fatigue.

Table 20 characterizes beams 39-42, 44 and 48-50, which contained ply drops of either ESA, ESB, ESG or ESH. As indicated in Figure 55, ESA and ESH are expected to delaminate prior to DD5P fatigue failure on the tension flange. ESB is projected to be close to delamination at fatigue failure at $10^{6}$ cycles. Figures 56 and 57 show the results of the ply drop delaminations in beams relative to coupons at comparable strain levels (strain energy release levels may differ). Although the beams and coupons delaminate in similar strain ranges, the delamination rates are significantly higher for the beams. As previously noted a more complete analysis of the beams with ply drops by FEA is planned, which may provide more consistent comparisons. We also anticipate additional ply drop testing. 


\section{Conclusions and Design Recommendations for Ply Drop Study}

We can draw some conclusions can be drawn about delamination and preventing delamination.

- For the same ply drops, thicker laminates are better for resisting delamination.

- Dropping more than one ply at the same location increases the delamination tendency.

- Internal ply drops are more resistant to delamination than external ply drops. (Single internal ply drops probably will not delaminate prior to section fatigue failure.)

- Beams with ply drops delaminate at similar strain levels, but significantly higher delamination rates than observed for coupons. 


\section{Conclusions for Overall Study}

Our main objective was to develop a beam test specimen representative of wind turbine blade primary substructure to test the validity of using the materials database and current design methodologies for predicting structural strength, stiffness, failure mode, and fatigue lifetime. We met this objective as our findings show that strength, stiffness, failure mode, and fatigue life can be predicted with acceptable accuracy as long as premature failure does not occur in the load introduction areas. (The specialized load introduction details for the beams are not representative of blades, but the general problem of load transfer at the hub and other special details of blades is of similar concern.)

Development of the beam specimen required an iterative process of design, testing, analysis, and redesign, until adequate loads could be introduced into the gage section to produce static and fatigue failures in the flanges and/or web areas. Although three-dimensional finite-element analysis was required for the detail areas, simple beam theory was in good agreement with experimental beam stiffness and strain values. Depending on the materials used, the final beam specimen (configuration 3) proved to be a very useful tool for validating strength and lifetime predictions for a variety of flange and web materials, and is serving as a test bed for on-going studies of structural details such as ply drops and adhesives, flaws, buckling, and the interaction between manufacturing and structural performance. As improved materials are developed, the beam specimen will require improved load-transfer details, as is evident with web materials containing a high $0^{\circ}$ material content (materials CH12 and DD5P).

Tests using the triax (material AA) flanges and $\pm 45^{\circ}$ (CH10) web showed good agreement between experimental and predicted results for strength, failure mode, and fatigue lifetime. As predicted, the failure mode shifted from compression at low cycles (only the static, one cycle tests could be conducted experimentally because of the very low cycles) to tensile flange failure at moderate to high cycles and lower loads. The poor tensile fatigue performance of triax fabric in coupons was equally evident in the beam structures, with good quantitative correlation on lifetimes.

The use of materials with improved fatigue resistance (material DD5P in the flanges) did raise the strain capacity of the beam in fatigue by about a factor of two, as predicted. Failures then shifted to the web flange area, which experienced severe damage, sometimes leading to delamination from the main flange. This failure mode occurred at slightly higher strains than the web material coupons could withstand (materials $\mathrm{CH} 10$ and $\mathrm{CH} 3$ ), because the web flange $\pm 45^{\circ}$ layers can deteriorate heavily before the beam fails, as compared with failure of the $0^{\circ}$ layers in the flange, which produces rapid failure. Further increases in the $0^{\circ}$ content of the web (materials $\mathrm{CH} 12$ and DD5P) resulted in premature load pad and shear stiffener failures. Although the failure modes were more complex with the material DD5P flanges, making validation of lifetime predictions more complex, the beam results did fall in the strain and lifetime range predicted by the coupon database.

The final sections of the report include results of an ongoing study that uses the beam specimen to explore the effects of flaws and structural details. A $13 \mathrm{~mm}$ diameter through - thickness drilled hole 
has been considered in the composites industry as a very severe type of flaw, worse than most flaws found in service. Coupons with holes showed moderate notch sensitivity in static tests, and similar normalized fatigue trends to unnotched coupons. Beams with holes in both flanges showed results for strength and lifetime that were consistent with the coupon data, again validating the use of coupon data for predicting structural performance.

The effects of ply drops used to taper laminate thickness on delamination growth were also studied. The coupons with ply drops experienced somewhat less rapid delamination at similar strain levels as compared with ply drops in beam flanges; however the general strain range in which significant delamination occurred was similar in each case. In addition, design guidelines for ply drop geometries are provided, which show that plies should be dropped on the interior of the laminate, one at a time. 


\section{REFERENCES}

1. Mandell, J.F.; Samborsky, D.D. (November 1995). MSU/DOE Wind Turbine Blade Composite Material Fatigue Database, available through Dr. Herbert J. Sutherland, Sandia National Laboratories, Albuquerque, NM, 87185.

2. Mandell, J.F.; Samborsky, D.D. (1997). DOE/MSU Composite Materials Fatigue Database: Test Methods, Materials, and Analysis. SAND97-3002, Albuquerque, NM: Sandia National Laboratories; available from National Technical Information Service, Springfield, VA, 22161.

3. Hedley, C.W. (April 1994). Mold Filling Parameters in Resin Transfer Molding, M.S. Thesis, Department of Chemical Engineering, Montana State University.

4. Humbert, D.R. (April 1996). Modeling of Resin Transfer Molding of Composite Materials With Oriented Unidirectional Plies, M.S. Thesis, Department of Chemical Engineering, Montana State University.

5. Combs, D.W. (March 1995). Design, Analysis and Testing of a Wind Turbine Blade Substructure, M.S. Thesis, Dept. Of Mechanical Engineering, Montana State University.

6. Gere, J.M. ; Timoshenko, S. (1984). Mechanics of Materials. Boston, Massachusetts: PWS Publishing.

7. Cook, R.; Young, W. (1985), Advanced Mechanics of Materials. New York, Macmillan Publishing Company.

8. American Institute of Steel Construction, (1986). Load \& Resistance Factor Design, American Institute of Steel Construction, Inc. ch. K, p. 79.

9. Gere, J.M. ; Timoshenko, S. (1984). Mechanics of Materials. Boston, Massachusetts: PWS Publishing. p. 354.

10. Gere, J.M.; Timoshenko, S. (1984). Mechanics of Materials. Boston, Massachusetts: PWS Publishing. p.408.

11. Mandell, J.F.; Reed, R.M. Jr.; Samborsky, D.D. (1992), "Fatigue of Fiberglass Wind Turbine Blade Materials", SAND92-7005, Albuquerque, N.M., Sandia National Laboratories, available from National Technical Information Service, Springfield, VA, 22161.

12. Mandell, J.F.; Combs, D.E.; Samborsky, D.D. (1995). Fatigue of Fiberglass Beam Substructures. Wind Energy 1995, W.D. Musial, S.M. Hock, and D.E. Berg, Eds., SED-Vol16, ASME, pp. 99 - 106. 
13. Mandell, J.F., Crack Propagation and Fracture of Composites. Proceedings of the 14th Society of Engineering Sciences, G. C. Sih, ed., Bethlehem, PA., Lehigh University., 1977.

14. Nuismer, R.J.; Whitney, J.M. (1995). Fracture Mechanics of Composites. ASTM STP 953, ASTM, Philadelphia. pp. 117-142.

15. Cairns, D.S.; Mandell, J.F.; Scott, M.E.; Macagnano, J.Z. (1997). Design Considerations for Ply Drops in Composite Wind Turbine Blades. Wind Energy 1997, AIAA/ASME, pp. 197-208.

16. Scott, M.E. (August 1997). Effects of Ply Drops on the Fatigue Resistance of Composite Materials and Structures. M.S. Thesis, Department of Chemical Engineering, Montana State University. 


\section{TABLES}

Table 1. Anticipated MSU Program Impacts: Areas of Improved Technology in Wind Turbine Blade Structures

1. Broad based materials database for constant-amplitude loading, with design-quality data for a narrower range of selected materials systems.

2. Improved materials systems for blades.

3. Validated cumulative damage law for use with spectrum loading.

4. Finite-element analysis requirements for prediction of stiffness, strength, and lifetime in typical blade structures.

5. Optimized generic structural details for typical blade features: rules of thumb, analysis, and database requirements for structural detail design, including adhesive bonding, ply delamination, and hub areas.

6. Assessment of the related effects of manufacturing and materials reinforcement details on blade structural performance and cost. Impacts of higher production rate and/or higher quality manufacturing. 
Table 2. Characteristics and Properties of Sections of Beams 1-5

C-channel Layup Schedule

\begin{tabular}{|c|c|}
\hline Channel & Layup \\
\hline$\# 1$ & $( \pm 45)_{s}$ \\
\hline$\# 2$ & $( \pm 45)_{s}$ \\
\hline Web of I-beam & {$\left[( \pm 45)_{2}\right]_{\mathrm{s}}$} \\
\hline
\end{tabular}

$v_{f}$ for C-channels

\begin{tabular}{|c|c|}
\hline C-channel Section & $\boldsymbol{v}_{\boldsymbol{f}}$ \\
\hline Web & 0.45 \\
\hline Flange & 0.38 \\
\hline
\end{tabular}

Layup Schedule and $v_{f}$ for Flat Pieces of I-beam.

\begin{tabular}{|c|c|c|c|}
\hline Part & Layup & $\boldsymbol{v}_{\boldsymbol{f}}$ & \% 0's \\
\hline Pads & {$\left[(0 / 90)_{4}\right]_{\mathrm{s}}$} & 0.45 & 50 \\
\hline Shear Stiffener & {$\left[( \pm 45)_{3}\right]_{\mathrm{s}}$} & 0.47 & 0 \\
\hline Flange 1 & {$\left[( \pm 45) /(0)_{3}\right]_{\mathrm{s}}$} & 0.48 & 67 \\
\hline $\begin{array}{c}\text { Flange 2 } \\
\text { outer section }\end{array}$ & {$\left[\right.$ c.m. $\left./(0)_{2} /( \pm 45) /(0)_{4}\right]$} & 0.42 & 77 \\
\hline $\begin{array}{c}\text { Flange 2 } \\
\text { gage section }\end{array}$ & $\left.[\text { c.m./(0) })_{2} /( \pm 45) /(0)_{2}\right]$ & 0.41 & 69 \\
\hline
\end{tabular}


Table 2. Characteristics and Properties of Sections of Beams 1 - 5 (Continued)

Orthotropic Material Properties for Composite I-beam

\begin{tabular}{|c|c|c|c|c|c|c|}
\cline { 2 - 7 } \multicolumn{1}{c|}{} & Flange 1 & \multicolumn{2}{|c|}{ Flange 2 } & \multicolumn{2}{c|}{ C-channel } & $\begin{array}{c}\text { Shear } \\
\text { Stiffener }\end{array}$ \\
\cline { 2 - 7 } & & outer & gage & flange & web & \\
\hline $\mathrm{E}_{x}, \mathrm{GPa}$ & 24.8 & 24.8 & 21.4 & 12.4 & 12.4 & 12.4 \\
\hline $\mathrm{E}_{\mathrm{y}}, \mathrm{GPa}$ & 9.0 & 9.0 & 9.7 & 12.4 & 12.4 & 12.4 \\
\hline $\mathrm{E}_{z}, \mathrm{GPa}$ & 9.0 & 9.0 & 9.7 & 8.3 & 8.3 & 8.3 \\
\hline$v_{x y}$ & 0.322 & 0.322 & 0.387 & 0.582 & 0.582 & 0.582 \\
\hline$v_{y z}$ & 0.25 & 0.25 & 0.25 & 0.25 & 0.25 & 0.25 \\
\hline$v_{x z}$ & 0.25 & 0.25 & 0.25 & 0.25 & 0.25 & 0.25 \\
\hline $\mathrm{G}_{\mathrm{xy}}, \mathrm{GPa}$ & 3.6 & 3.6 & 4.6 & 9.7 & 9.7 & 9.7 \\
\hline $\mathrm{G}_{\mathrm{yz}}, \mathrm{GPa}$ & 3.8 & 3.8 & 3.8 & 3.8 & 3.8 & 3.8 \\
\hline $\mathrm{G}_{\mathrm{xz}}, \mathrm{GPa}$ & 3.8 & 3.8 & 3.8 & 3.8 & 3.8 & 3.8 \\
\hline
\end{tabular}

Table 3. A Summary of Beam Configurations and Testing Regime

\begin{tabular}{|c|c|c|c|c|}
\hline Configuration & Beam Number & X-Section, mm & Characteristics & Test Regime \\
\hline \multirow{2}{*}{1} & 1 & \multirow{2}{*}{$76 \times 76$} & stiffener 1 & fatigue \\
\cline { 2 - 3 } \cline { 5 - 5 } & 2 & & stiffener 1 & fatigue \\
\hline 2 & 3 & $51 \times 76$ & $\begin{array}{c}\text { stiffener 1 } \\
\text { ply drops }\end{array}$ & fatigue \\
\hline \multirow{2}{*}{3} & 4 & $51 \times 76$ & $\begin{array}{c}\text { stiffener 2 } \\
\text { ply drops }\end{array}$ & fatigue \\
\cline { 2 - 2 } & 5 & & static \\
\cline { 2 - 3 } & & & &
\end{tabular}


Table 4. Test History for Beam 1

\begin{tabular}{|c|c|c|c|}
\hline Total Cycles & Cycles (Sequence) & Maximum Load (kN) & Event \\
\hline $1-100,000$ & 100,000 & 22.2 & Data \\
\hline $100,000-130,244$ & 30,244 & 44.5 & Pad Failure \\
\hline $130,244-189,533$ & 59,289 & 44.5 & Pad Failure \\
\hline $189,533-199,533$ & 10,000 & 22.2 & \\
\hline $199,503-207,030$ & 7,497 & 44.5 & Pad Failure \\
& & & Outside Rollers \\
\hline $207,030-217,030$ & 5,000 & 22.2 & Data \\
\hline $217,030-227,030$ & 10,000 & 44.5 & Failure \\
\hline $227,030-256,499$ & 29,469 & 66.7 & \\
\hline
\end{tabular}

Table 5. Summary of Cycles and Loads for Beam 1

\begin{tabular}{|c|c|}
\hline Maximum Load (kN) & Total Cycles \\
\hline 22.2 & 120,000 \\
\hline 44.5 & 107,030 \\
\hline 66.7 & 46,419 \\
\hline
\end{tabular}

Table 6. Test history for Beam 2

\begin{tabular}{|c|c|c|c|}
\hline Total Cycles & Cycles (Sequence) & Maximum Load $(\mathbf{k N})$ & Event \\
\hline 1 & 1 & & Data \\
\hline $1-10,000$ & 10,000 & 22.2 & \\
\hline $10,000-20,000$ & 10,000 & 44.5 & \\
\hline $20,000-36,950$ & 16,950 & 66.7 & Stopped \\
\hline
\end{tabular}


Table 7. Test history for Beam 3

\begin{tabular}{|c|c|c|c|}
\hline Total Cycles & Cycles (Sequence) & Maximum Load $(\mathbf{k N})$ & Event \\
\hline 0 & & & Strain Data \\
\hline $0-10,000$ & 10,000 & 22.2 & Increase Load \\
\hline $10,000-59,700$ & 49,700 & 35.6 & Ply Delamination \\
\hline $59,700-757,239$ & 697,539 & 35.6 & Test Terminated \\
\hline
\end{tabular}


Table 8. Test History (Top) and Load, Micro-strain and Cycles Summary, Beam 4. Microstrain Values are the Average Magnitudes of Tension and Compression Strain Measured at the Initiation of Each Sequence.

\begin{tabular}{|c|c|c|c|c|c|}
\hline Total Cycles & Cycles (Sequence) & \multicolumn{2}{|c|}{$\begin{array}{c}\text { Maximum Load } \\
(\mathbf{k N})\end{array}$} & \multicolumn{2}{|c|}{ Event } \\
\hline \multirow[t]{2}{*}{1} & & & & \multicolumn{2}{|c|}{ Data } \\
\hline & & & & \multicolumn{2}{|c|}{ Apply Mat } \\
\hline $2-10,000$ & 10,000 & 22 & & \multicolumn{2}{|c|}{ Increase Load } \\
\hline $10,000-500,000$ & 490,000 & 35 & & \multicolumn{2}{|c|}{ Repaired Delaminations } \\
\hline $500,000-779,102$ & 279,102 & & & \multicolumn{2}{|c|}{ Data } \\
\hline \multirow[t]{2}{*}{$779,102-1.2 \mathrm{e} 6$} & 392,227 & 3 & & \multicolumn{2}{|c|}{ Repaired Delaminations } \\
\hline & & & & \multicolumn{2}{|c|}{ Increased Load } \\
\hline \multirow[t]{3}{*}{$1.2 \mathrm{e} 6-1.3 \mathrm{e} 6$} & 171,715 & & & \multicolumn{2}{|c|}{ All Pads Failed } \\
\hline & & & & \multicolumn{2}{|c|}{ Repaired Beam } \\
\hline & & & & \multicolumn{2}{|c|}{ Increased Load } \\
\hline \multirow[t]{2}{*}{$1.3 \mathrm{e} 6-1.6 \mathrm{e} 6$} & 300,000 & 4 & & \multicolumn{2}{|c|}{ Data } \\
\hline & & & & \multicolumn{2}{|c|}{ Repaired Delaminations } \\
\hline $1.6 \mathrm{e} 6-1.76 \mathrm{e} 6$ & 160,000 & 4 & & \multicolumn{2}{|c|}{ Repaired Delaminations } \\
\hline \multirow[t]{2}{*}{$1.76 \mathrm{e} 6-1.97 \mathrm{e} 6$} & 200,000 & 4 & & \multicolumn{2}{|c|}{ Repaired Delaminations } \\
\hline & & & & \multicolumn{2}{|c|}{ Increased Load } \\
\hline $1.97 \mathrm{e} 6-2.24 \mathrm{e} 6$ & 269,977 & & & \multicolumn{2}{|c|}{ Data } \\
\hline $2.24 \mathrm{e} 6-2.26 \mathrm{e} 6$ & 16,354 & & & \multicolumn{2}{|c|}{ Beam Failed } \\
\hline $\begin{array}{l}\text { Maximum Load } \\
(\mathrm{kN})\end{array}$ & \multicolumn{2}{|c|}{$\begin{array}{l}\text { Micro-Strain (average of tension } \\
\text { and compression) }\end{array}$} & & at Load & Total Cycles \\
\hline 22.2 & \multicolumn{2}{|l|}{4040} & & 000 & 10,000 \\
\hline 35.6 & \multicolumn{2}{|l|}{6360} & & $6 \mathrm{e} 6$ & $1.17 \mathrm{e} 6$ \\
\hline 40.0 & \multicolumn{2}{|l|}{7180} & \multicolumn{2}{|c|}{171,715} & $1.34 \mathrm{e} 6$ \\
\hline 44.5 & \multicolumn{2}{|l|}{8270} & \multicolumn{2}{|c|}{631,360} & $1.97 \mathrm{e} 6$ \\
\hline 48.9 & \multicolumn{2}{|l|}{9220} & &, 735 & $2.26 \mathrm{e} 6$ \\
\hline
\end{tabular}


Table 9. Comparison of FEA, Beam Theory and Experimental Strain vs. Load Slopes, Beam 2

\begin{tabular}{|c|c|c|c|c|}
\cline { 2 - 5 } \multicolumn{1}{c|}{} & \multicolumn{2}{c|}{$\begin{array}{c}\text { Slope of Strain vs. Load Curve } \\
(\mu \in / \mathbf{k N})\end{array}$} & \multicolumn{2}{c|}{$\begin{array}{c}\text { Ratio of } \\
\text { (Slope/Experimental Slope) }\end{array}$} \\
\cline { 2 - 5 } & Tension & Compression & Tension & Compression \\
\hline FEA & 86 & 86 & 1.01 & 1 \\
\hline Classic & 87 & 87 & 1.03 & 1 \\
\hline Experimental & 85 & 86 & 1 & 1 \\
\hline
\end{tabular}

Table 10. Comparison for FEA, Beam Theory, and Average 1st Cycle Experimental Displacement and Micro-strain vs. Load Slopes, Beams 4 and 5

\begin{tabular}{|c|c|c|c|}
\cline { 2 - 4 } \multicolumn{1}{c|}{} & Avg. Slope Values & \multicolumn{2}{c|}{ Predicted Slope } \\
\cline { 2 - 4 } & & Theoretical & FEA \\
\hline Displacement & $(\mathrm{mm} / \mathrm{kN})$ & \multicolumn{2}{|c|}{$(\mathrm{mm} / \mathrm{kN})$} \\
\hline Load Point & 0.130 & 0.104 & 0.104 \\
\hline Center & 0.205 & 0.252 & 0.226 \\
\hline Micro-Strain & $(\mu \in / \mathrm{kN})$ & \multicolumn{2}{|c|}{$(\mu \in / \mathrm{kN})$} \\
\hline Tension & 185 & 200 & 198 \\
\hline Compression & 186 & 200 & 198 \\
\hline
\end{tabular}

Table 11. Ratios of Predicted Displacement and Micro-strain Slopes Over Average Experimental Slopes for Beams 4 and 5. The Experimental Slopes Listed are Those Derived from the First Cycle of Testing.

\begin{tabular}{|c|c|c|}
\cline { 2 - 3 } \multicolumn{1}{c|}{} & \multicolumn{2}{c|}{ Ratio of Slopes } \\
\cline { 2 - 3 } \multicolumn{1}{c|}{} & $\begin{array}{c}\text { (Theoretical/Avg } \\
\text { Experimental.) }\end{array}$ & $\begin{array}{c}\text { (FEA/ Average } \\
\text { Experimental) }\end{array}$ \\
\hline \multicolumn{2}{c|}{ Displacement } \\
\hline Load Point & 0.8 & 0.8 \\
\hline Center & 1.23 & 1.10 \\
\hline \multicolumn{2}{|c|}{ Micro-Strain } \\
\hline Tension & 1.08 & 1.07 \\
\hline Compression & 1.07 & 1.06 \\
\hline
\end{tabular}


Table 12. Comparison of FEA and Experimental Strain vs. Load Slopes, Beam 1

\begin{tabular}{|c|c|c|c|}
\hline & \multicolumn{2}{|c|}{$\begin{array}{l}\text { Slopes of Load vs Strain Curve } \\
\qquad \mu \in / \mathbf{k N}\end{array}$} & \multirow{2}{*}{$\begin{array}{c}\text { Ratio of Slopes } \\
\text { FEA/Experimental }\end{array}$} \\
\hline & FEA & Beam 1 & \\
\hline \multicolumn{4}{|c|}{ Tension Cycles } \\
\hline 1 & 86 & & \\
\hline 100,000 & & 76 & 1.13 \\
\hline 200,000 & & 82 & 1.04 \\
\hline \multicolumn{4}{|c|}{ Compression Cycles } \\
\hline 1 & 86 & & \\
\hline 100,000 & & 82 & 1.06 \\
\hline 200,000 & & 81 & 1.07 \\
\hline
\end{tabular}

Table 13. Comparison of FEA and Experimental Strain vs. Load Slopes, Beam 2

\begin{tabular}{|c|c|c|c|}
\cline { 2 - 4 } \multicolumn{1}{c|}{} & \multicolumn{2}{c|}{ Slopes of Load vs Strain Curve } \\
\multicolumn{1}{c|}{ FE/kN } & Ratio of Slopes \\
\cline { 2 - 4 } \multicolumn{1}{c|}{} & FEA & Beam 3 & FEA/Experimental \\
\hline \multicolumn{5}{|c|}{ Tension Cycles } \\
\hline 1 & 198 & 171 & 1.15 \\
\hline 59,700 & & 192 & 1.03 \\
\hline \multicolumn{5}{|c|}{ Compression Cycles } \\
\hline 1 & 198 & 169 & 1.15 \\
\hline 59,700 & & 171 & 1.17 \\
\hline
\end{tabular}


Table 14. Comparison of FEA, Theoretical, and Experimental Displacement vs. Load Slopes, Beams 4 and 5

\begin{tabular}{|c|c|c|c|c|c|c|c|c|}
\hline & \multicolumn{8}{|c|}{ Slope of Displacement vs Load Curves $(\mathrm{mm} / \mathbf{k N})$} \\
\hline & \multicolumn{2}{|c|}{ FEA } & \multicolumn{2}{|c|}{ Theoretical } & \multicolumn{2}{|c|}{ Beam 4} & \multicolumn{2}{|c|}{ Beam 5} \\
\hline & Load & Center & Load & Center & Piston & Center & Piston & Center \\
\hline \multicolumn{9}{|l|}{ Cycles } \\
\hline 1 & 0.104 & 0.226 & 0.104 & 0.252 & 0.136 & 0.203 & 0.124 & 0.206 \\
\hline 2 & & & & & & & 0.134 & 0.212 \\
\hline 3 & & & & & & & 0.125 & 0.203 \\
\hline $1.17 \mathrm{e} 6$ & & & & & 0.138 & 0.212 & & \\
\hline $1.97 \mathrm{e} 6$ & & & & & 0.148 & 0.226 & & \\
\hline $2.24 \mathrm{e} 6$ & & & & & 0.176 & 0.265 & & \\
\hline
\end{tabular}

Table 15. Comparison of FEA, Theoretical, and Experimental Micro-strain vs. Load Slopes, Beams 4 \& 5 .

\begin{tabular}{|c|c|c|c|c|}
\hline & \multicolumn{4}{|c|}{$\begin{array}{l}\text { Slope of Strain vs Load Curves } \\
\qquad(\mu \in / \mathbf{k N})\end{array}$} \\
\hline & FEA & Theoretical & Beam 4 & Beam 5 \\
\hline \multicolumn{5}{|c|}{ Tension Cycles } \\
\hline 1 & 198 & 200 & 185 & 186 \\
\hline 2 & & & & 188 \\
\hline 3 & & & & 185 \\
\hline $1.1 \mathrm{e} 6$ & & & 185 & \\
\hline $1.9 \mathrm{e} 6$ & & & 205 & \\
\hline $2.29 \mathrm{e} 6$ & & & 205 & \\
\hline \multicolumn{5}{|c|}{ Compression Cycles } \\
\hline 1 & 198 & 200 & 181 & 192 \\
\hline 2 & & & & 200 \\
\hline 3 & & & & 196 \\
\hline $1.1 \mathrm{e} 6$ & & & 183 & \\
\hline $1.1 \mathrm{e} 6$ & & & 192 & \\
\hline $1.1 \mathrm{e} 6$ & & & 186 & \\
\hline
\end{tabular}


Table 16. Summary of Data for Beams with Triax Flanges and Material CH10 Webs

\begin{tabular}{|c|c|c|c|c|c|c|}
\hline Beam & $\begin{array}{c}\text { Materials } \\
\text { Flange / Web }\end{array}$ & $\begin{array}{c}\text { Stiffness, K, } \\
\text { kN/m }\end{array}$ & $\begin{array}{l}\text { Max. / Min. } \\
\text { Load, kN }\end{array}$ & $\begin{array}{c}\text { Max. / Min. } \\
\text { Strain, \% }\end{array}$ & Cycles & Failure Notes \\
\hline 6 & AA / CH10 & 3,711 & 67.08 & $1.80 /-1.68$ & 1 & Compression Flange \\
\hline 7 & AA / CH10 & 3,398 & $24.5 / 2.5$ & $0.58 /-0.56$ & 492,147 & Tension Flange \\
\hline 8 & $\mathrm{AA} / \mathrm{CH} 10$ & 3,499 & $31.1 / 3.1$ & $0.79 /-0.7$ & 29,051 & Tension Flange and Web \\
\hline 9 & AA2 / CH10 & 3,556 & 59.2 & $1.78 /-1.8$ & 1 & Compression Flange \\
\hline 10 & AA2 / CH10 & 3,694 & $40.0 / 4.0$ & $1.07 /-0.97$ & 1,870 & Tension Flange \\
\hline 11 & $\mathrm{AA} / \mathrm{CH} 10$ & 3,436 & $40.0 / 4.0$ & $1.08 /-0.96$ & 4,620 & Tension Flange and Web \\
\hline 12 & AA / CH10 & 3,498 & $28.9 / 2.9$ & $0.73 /-0.68$ & 30,290 & Tension Flange \\
\hline 13 & AA / CH10 & 3,516 & 60.72 & $2.10 /-1.85$ & 1 & Compression Flange \\
\hline 14 & $\mathrm{AA} / \mathrm{CH} 10$ & 3,407 & $24.5 / 2.5$ & $0.59 /-0.58$ & 389,175 & Tension Flange \\
\hline 22 & AA / CH10 & 3,637 & $31.1 / 3.1$ & $0.84 /-0.76$ & 36,825 & Tension Flange \\
\hline 23 & AA / CH10 & 3,542 & $28.9 / 2.9$ & $0.71 /-0.64$ & 119,995 & Tension Flange \\
\hline \multicolumn{7}{|c|}{ 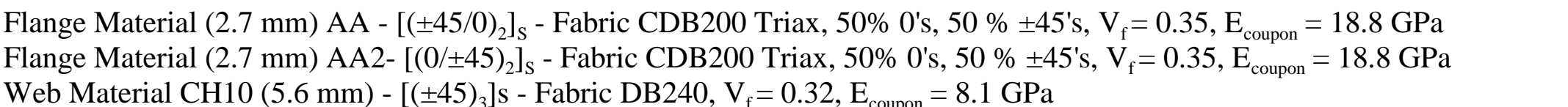 } \\
\hline
\end{tabular}


Table 17. Summary of Data for Beams with Material DD5P Flanges and Material CH10 Webs

\begin{tabular}{|c|c|c|c|c|c|c|}
\hline Beam & $\begin{array}{c}\text { Materials } \\
\text { Flange / } \\
\text { Web }\end{array}$ & $\begin{array}{c}\text { Stiffness, K, } \\
\text { kN/m }\end{array}$ & $\begin{array}{l}\text { Max. / Min. } \\
\text { Load, kN }\end{array}$ & $\begin{array}{c}\text { Max. / Min. } \\
\text { Strain, \% }\end{array}$ & Cycles & Failure Notes \\
\hline 18 & DD5P / CH10 & 4,134 & $62.3 / 6.2$ & $1.42 /-1.34$ & 9,367 & Tension Flange Delamination \\
\hline 19 & DD5P / CH10 & 4,245 & 89.18 & $1.96 /-1.82$ & 1 & Compression Flange \\
\hline 20 & DD5P / CH10 & 4,218 & $53.4 / 5.3$ & $1.09 /-1.09$ & 94,391 & Tension Flange Delamination \\
\hline 21 & DD5P / CH10 & 4,104 & $53.4 / 5.3$ & $1.14 /-0.99$ & 23,000 & Tension Flange \\
\hline 24 & DD5P / CH10 & 4,221 & 88.29 & $1.93 /-1.77$ & 1 & Compression Flange \\
\hline 25 & DD5P / CH10 & 4,305 & $62.3 / 6.2$ & $1.43 /-1.31$ & 7,636 & Compression Flange \\
\hline 26 & DD5P / CH10 & 4,355 & $57.8 / 5.8$ & $1.22 /-1.05$ & 104,407 & Compression Flange Delamination \\
\hline 27 & DD5P / CH10 & 4,069 & $53.4 / 5.3$ & $1.07 /-1.00$ & 243,876 & Tension Flange Delamination \\
\hline 28 & DD5P / CH10 & 4,142 & $44.5 / 4.4$ & $0.86 /-0.85$ & $2,000,000$ & Tension Flange Delamination \\
\hline 29 & DD5P / CH10 & 4,100 & $48.9 / 4.9$ & $0.92 /-0.96$ & 815,684 & Tension Flange Delamination \\
\hline
\end{tabular}


Table 18. Summary of Data for Beams with Material DD5P Flanges and Web Materials With Increasing $0^{\circ}$ Content

\begin{tabular}{|c|c|c|c|c|c|c|}
\hline Beam & $\begin{array}{l}\text { Materials } \\
\text { Flange / } \\
\text { Web }\end{array}$ & $\begin{array}{c}\text { Stiffness, K, } \\
\text { kN/m }\end{array}$ & $\begin{array}{l}\text { Max. / Min. } \\
\text { Load, kN }\end{array}$ & $\begin{array}{c}\text { Max. / Min. } \\
\text { Strain, \% }\end{array}$ & Cycles & Failure Notes \\
\hline 30 & DD5 / CH3 & 4,345 & $62.3 / 6.2$ & $1.20 /-1.05$ & 5,741 & Web \\
\hline 31 & DD5 / CH3 & 4,764 & $53.4 / 5.3$ & $0.92 /-0.89$ & $2,030,240$ & Tension Flange Delamination \\
\hline 32 & DD5 / CH3 & 4,639 & $53.4 / 5.3$ & $0.86 /-0.73$ & 783,153 & Load pad, Flanges still good \\
\hline 33 & DD5 / CH3 & 4,606 & $53.4 / 5.3$ & $0.94 /-0.93$ & $3,200,000$ & Web / Tension Flange Delamination \\
\hline 34 & DD5 / CH12 & 4,990 & 83.26 & $1.92 /-1.69$ & 1 & Compression Flange and Web \\
\hline 35 & DD5 / CH12 & 4,347 & $62.3 / 6.2$ & $1.04 /-1.02$ & 9,771 & Web failure \\
\hline 51 & DD5 / DD5 & 4,867 & $53.4 / 5.3$ & $0.76 /-0.75$ & $3,000,000$ & Run out \\
\hline 52 & DD5 / DD5 & 5,145 & $62.3 / 6.2$ & $0.93 /-0.89$ & 62,843 & Compression flange buckling \\
\hline 53 & DD5 / DD5 & 4,901 & $62.3 / 6.2$ & $0.94 /-0.89$ & 8,700 & Web / shear stiffener failure \\
\hline 54 & DD5 / DD5 & 4,951 & $62.3 / 6.2$ & $0.88 /-0.88$ & $2,744,704$ & Web / shear stiffener failure \\
\hline \multicolumn{7}{|c|}{$\begin{array}{l}\text { Flange / web Material }(3.0 \mathrm{~mm}) \text { DD5P-(0/ } \pm 45 / 0)_{\mathrm{s}}-\text { Fabric 0's- D155 }(72 \%), \pm 45 \text { 's }-\mathrm{DB} 120(28 \%), \mathrm{V}_{\mathrm{f}}=0.36, \mathrm{E}_{\text {coupon }}=23.6 \mathrm{GPa} \\
\text { Web Material }(4.2 \mathrm{~mm}) \mathrm{CH} 3-( \pm 45 / 0 / \pm 45)_{\mathrm{s}}-\text { Fabric 0's- D155 }(24 \%), \pm 45 \text { 's }-\mathrm{DB} 240(76 \%), \mathrm{V}_{\mathrm{f}}=0.36, \mathrm{E}_{\text {coupon }}=16.8 \mathrm{GPa} \\
\text { Web Material }(3.0 \mathrm{~mm}) \mathrm{CH} 12-( \pm 45 / 0 / \pm 45)_{\mathrm{S}}-\text { Fabric 0's- D155 }(39 \%), \pm 45 \text { s }-\mathrm{DB} 120(61 \%), \mathrm{V}_{\mathrm{f}}=0.34, \mathrm{E}_{\text {coupon }}=17.7 \mathrm{GPa}\end{array}$} \\
\hline
\end{tabular}


Table 19. Summary of Data for Beams with Triax Flanges Containing $13 \mathrm{~mm}$ Diameter Through-Thickness Holes and Material CH10 Webs

\begin{tabular}{|c|c|c|c|c|c|c|}
\hline Beam & $\begin{array}{c}\text { Materials } \\
\text { Flange / Web }\end{array}$ & $\begin{array}{c}\text { Stiffness, K, } \\
\mathbf{k N} / \mathbf{m}\end{array}$ & $\begin{array}{c}\text { Max. / Min. } \\
\text { Load, kN }\end{array}$ & $\begin{array}{c}\text { Max. / Min. } \\
\text { Strain, \% }\end{array}$ & Cycles & Failure Notes \\
\hline 15 & $\mathrm{AA}($ holes $) / \mathrm{CH} 10$ & 3,260 & $31.1 / 3.1$ & $0.83 /-0.78$ & 2,772 & Compression Flange \\
\hline 16 & $\mathrm{AA}($ holes $) / \mathrm{CH} 10$ & 3,340 & $24.5 / 2.5$ & $0.58 /-0.53$ & 40,448 & Tension Flange \\
\hline 17 & $\mathrm{AA}($ holes $) / \mathrm{CH} 10$ & 3,350 & 46.97 & $1.3 /-1.08$ & 1 & Compression Flange \\
\hline
\end{tabular}


Table 20. Summary of Data For Beams with Ply Drops in Flanges With Material CH12 Webs

\begin{tabular}{|c|c|c|c|c|c|c|}
\hline Beam & $\begin{array}{c}\text { Materials } \\
\text { Flange / Web }\end{array}$ & Stiffness, K, kN/m & $\begin{array}{c}\text { Max. / Min } \\
\text { Load, kN }\end{array}$ & $\begin{array}{c}\text { Max. / Min. } \\
\text { Strain, } \%\end{array}$ & Cycles & Failure Notes \\
\hline 39 & ESA / CH12 & 4,804 & $35.6 / 3.6$ & $0.62 /-0.64$ & $1,225,650$ & ESA ply drop delamination \\
\hline 40 & ESB / CH12 & 4,787 & $35.6 / 3.6$ & $0.96 /-0.85$ & 264,137 & Compression flange delamination \\
\hline 41 & ESG / CH12 & 5,213 & $49.0 / 4.9$ & $0.74 /-0.76$ & 13,997 & ESG ply drop delamination \\
\hline 42 & ESG / CH12 & 5,524 & $35.6 / 3.6$ & $0.55 /-0.54$ & 436,508 & ESG ply drop delamination \\
\hline 44 & ESA / CH12 & 4,527 & $35.6 / 3.6$ & $0.57 /-0.58$ & 600,000 & ESA ply drop delamination \\
\hline 48 & ESA / CH12 & 4,650 & $35.6 / 3.6$ & $0.66 /-0.67$ & 72,000 & ESA ply drop delamination \\
\hline 49 & ESH / CH12 & 6,625 & $57.8 / 5.8$ & $0.76 /-0.73$ & 25,500 & ESH ply drop delamination \\
\hline 50 & ESH / CH12 & 6,054 & $48.9 / 4.9$ & $0.63 /-0.63$ & 204,000 & ESH ply drop delamination \\
\cline { 2 - 6 } & \multicolumn{2}{|c|}{$88.2(\mathrm{r})$} & --- & 1 & Compression flange \\
\hline
\end{tabular}


Table 21. Laminate Configurations with Ply Drops

\begin{tabular}{|c|c|c|c|c|c|}
\hline \multicolumn{6}{|c|}{ Laminate Configurations and Specification } \\
\hline Laminate & Lay-up & $\begin{array}{c}\mathbf{E}_{\mathbf{x}} \\
(\mathbf{G P a})\end{array}$ & $\mathbf{V}_{\mathbf{f}}$ & $\begin{array}{c}\text { Average } \\
\text { thickness }(\mathbf{m m}) \\
\text { Thick/Thin }\end{array}$ & Comments \\
\hline ESA & {$\left[\mathbf{0}^{*} /(0 / \pm 45 / 0)_{\mathrm{s}}\right]$} & 2.39 & 0.35 & $3.81 / 3.09$ & Single exterior ply drop \\
\hline ESB & $0\left[\left(\mathbf{0}^{*} / \pm 45 / 0\right)_{s}\right]$ & 2.48 & 0.35 & $3.70 / 3.00$ & Single interior ply drop \\
\hline ESC & {$\left[0 / \pm 45 / 0 / \mathbf{0}^{*}\right]_{\mathrm{s}}$} & 2.42 & 0.35 & $3.60 / 3.02$ & Single center ply drop \\
\hline ESE & {$\left[\mathbf{0}^{*}(0 / \pm 45 / 0)_{3}\right]$} & 3.05 & 0.40 & $4.52 / 3.81$ & $\begin{array}{c}\text { Thicker laminate, Single } \\
\text { external ply drop }\end{array}$ \\
\hline ESF & {$\left[0\left(\mathbf{0}^{*} / \pm 45 / 0\right)_{3}\right]$} & 3.33 & 0.40 & $4.70 / 4.06$ & $\begin{array}{c}\text { Thicker laminate, Single } \\
\text { internal ply drop }\end{array}$ \\
\hline ESG & $\begin{array}{c}{\left[\mathbf{0}_{2}^{*} /\right.} \\
\left.(0 / \pm 45 / 0)_{3}\right]\end{array}$ & 3.26 & 0.39 & $4.95 / 3.81$ & $\begin{array}{c}\text { Thicker laminate, Two } \\
\text { external ply drops }\end{array}$ \\
\hline ESH & $\begin{array}{c}{\left[0 / \mathbf{0}^{*}\right.} \\
\left.\left(\mathbf{0}^{*} / \pm 45 / 0\right)_{3}\right]\end{array}$ & 3.45 & 0.39 & $4.70 / 3.55$ & $\begin{array}{c}\text { Thicker laminate, Two } \\
\text { internal ply drops }\end{array}$ \\
\hline
\end{tabular}

\footnotetext{
"Indicates the ply or plies dropped (not repeated or symmetrical, just the ply indicated).
} 


\section{FIGURES}

CONSTANT AMPLITUDE, STATIC AND FATIGUE LOADING:

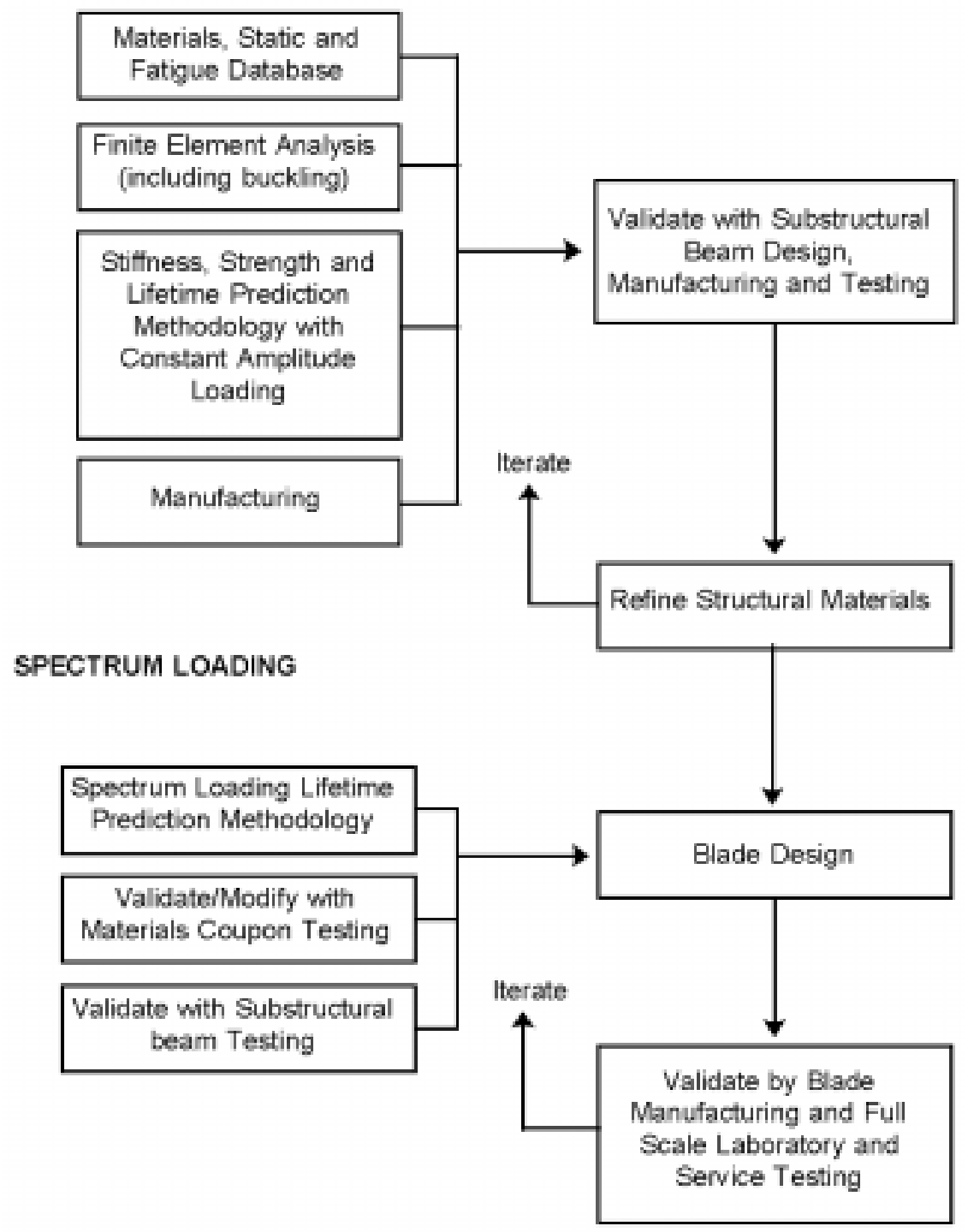

Figure 1. Overall iterative program for wind turbine blade structural optimization at MSU. 


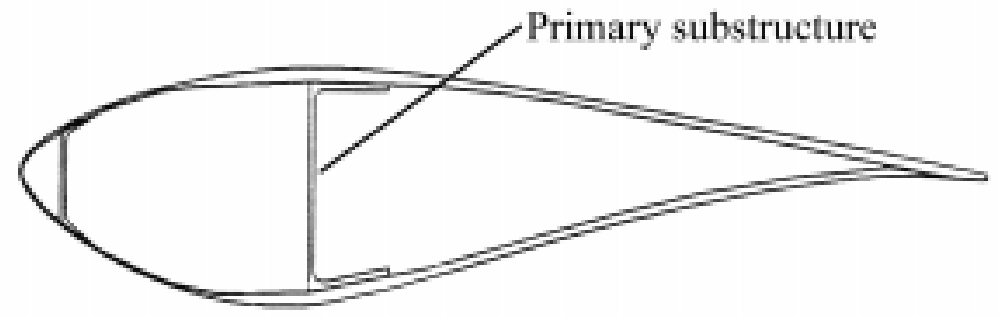

Figure 2. Cross section of NREL 9.6 meter airfoil. 

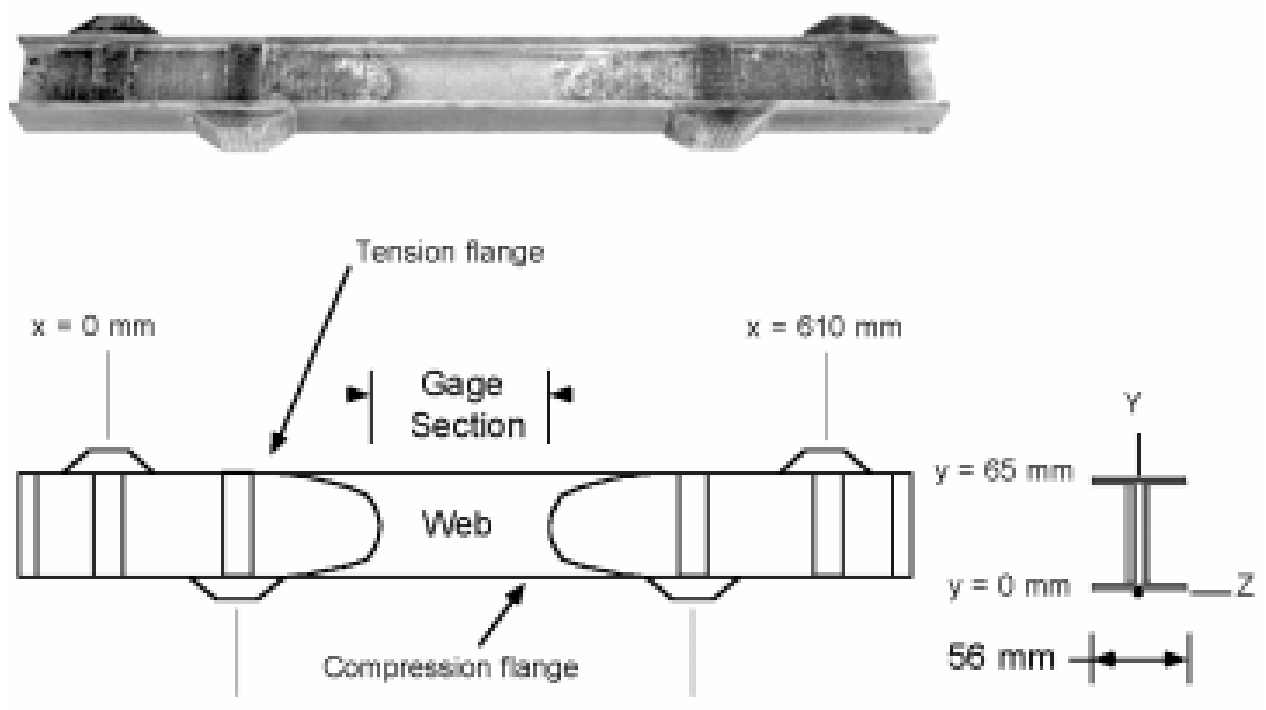

$x=114 \mathrm{~mm} \quad \mathrm{x}=495 \mathrm{~mm}$

Side View

End View

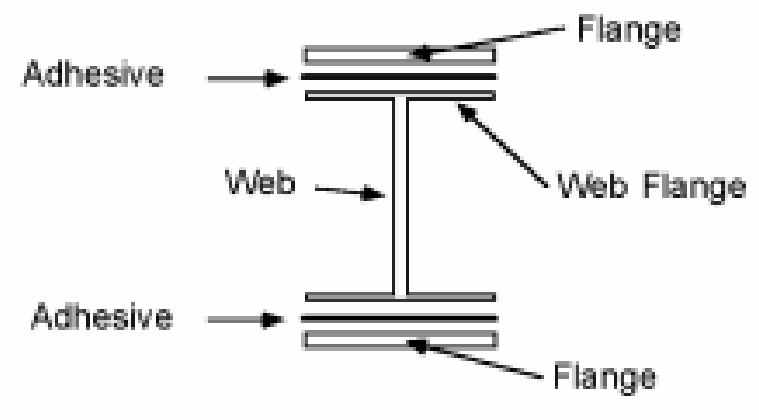

Beam Gage Section Exploded End View

Figure 3. Sketch and photograph of composite I-beam (configuration 3). 


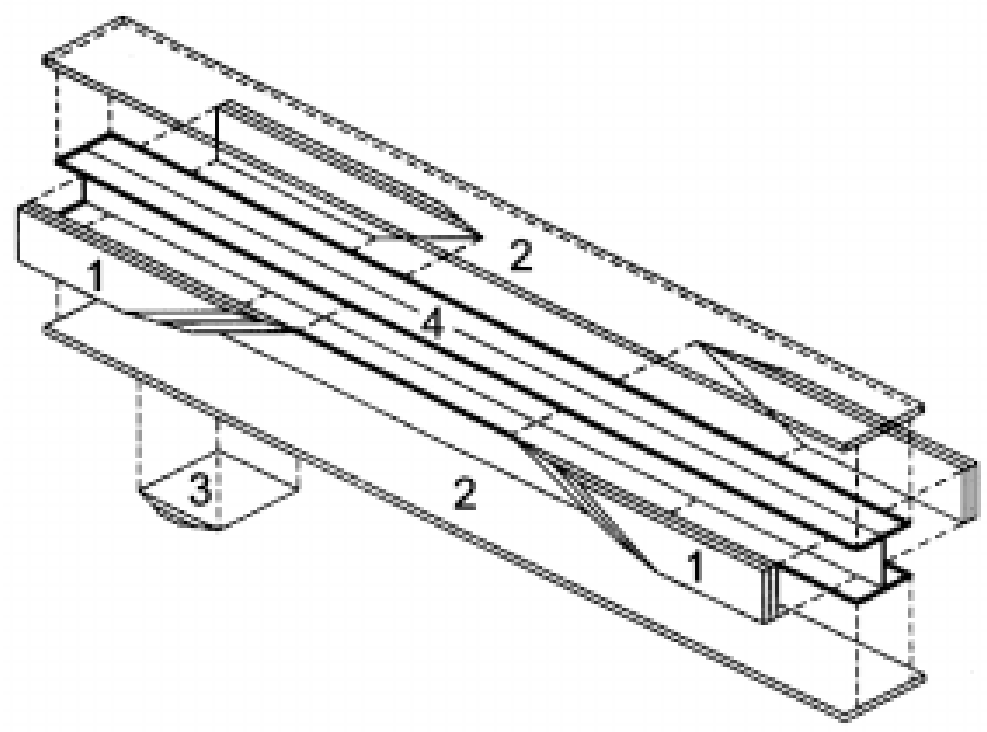

Figure 4. I-beam assembly: 1. Stiffeners, 2. Flanges, 3. Loading pads, 4. Back-to-back bonded C-channels for web.

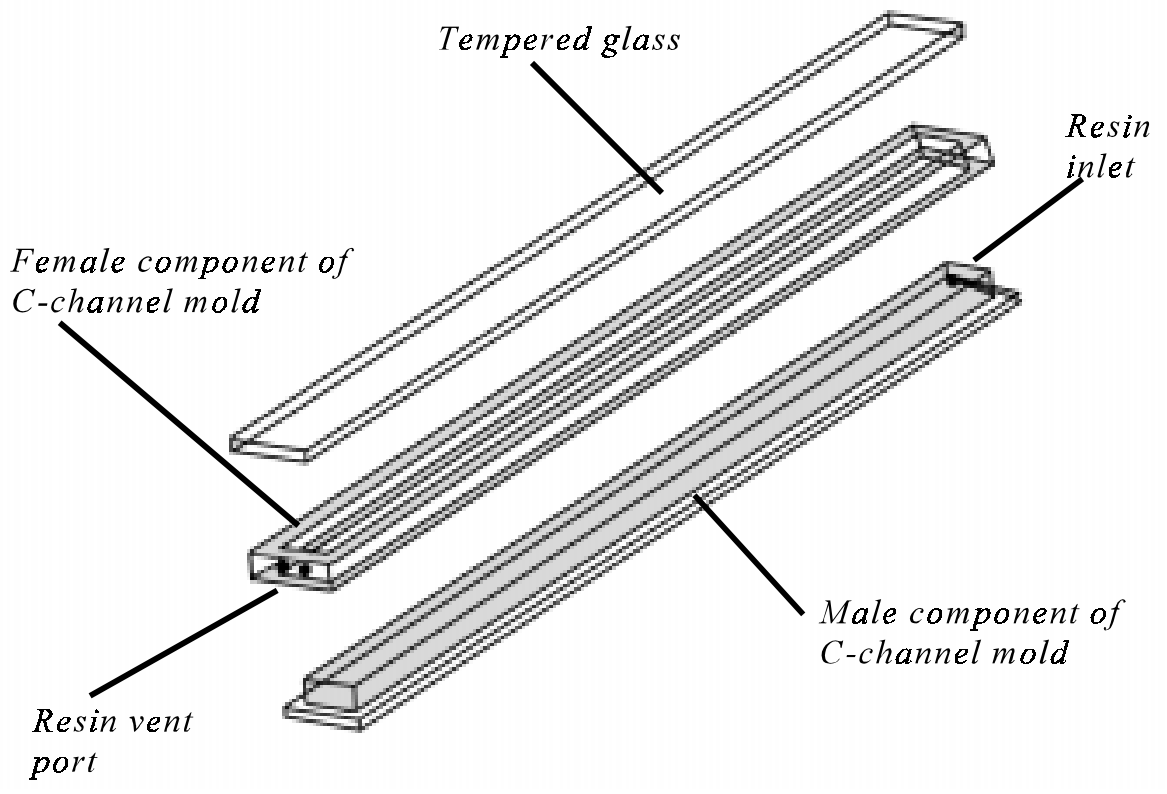

Figure 5. Three-dimensional view of C-channel mold. 


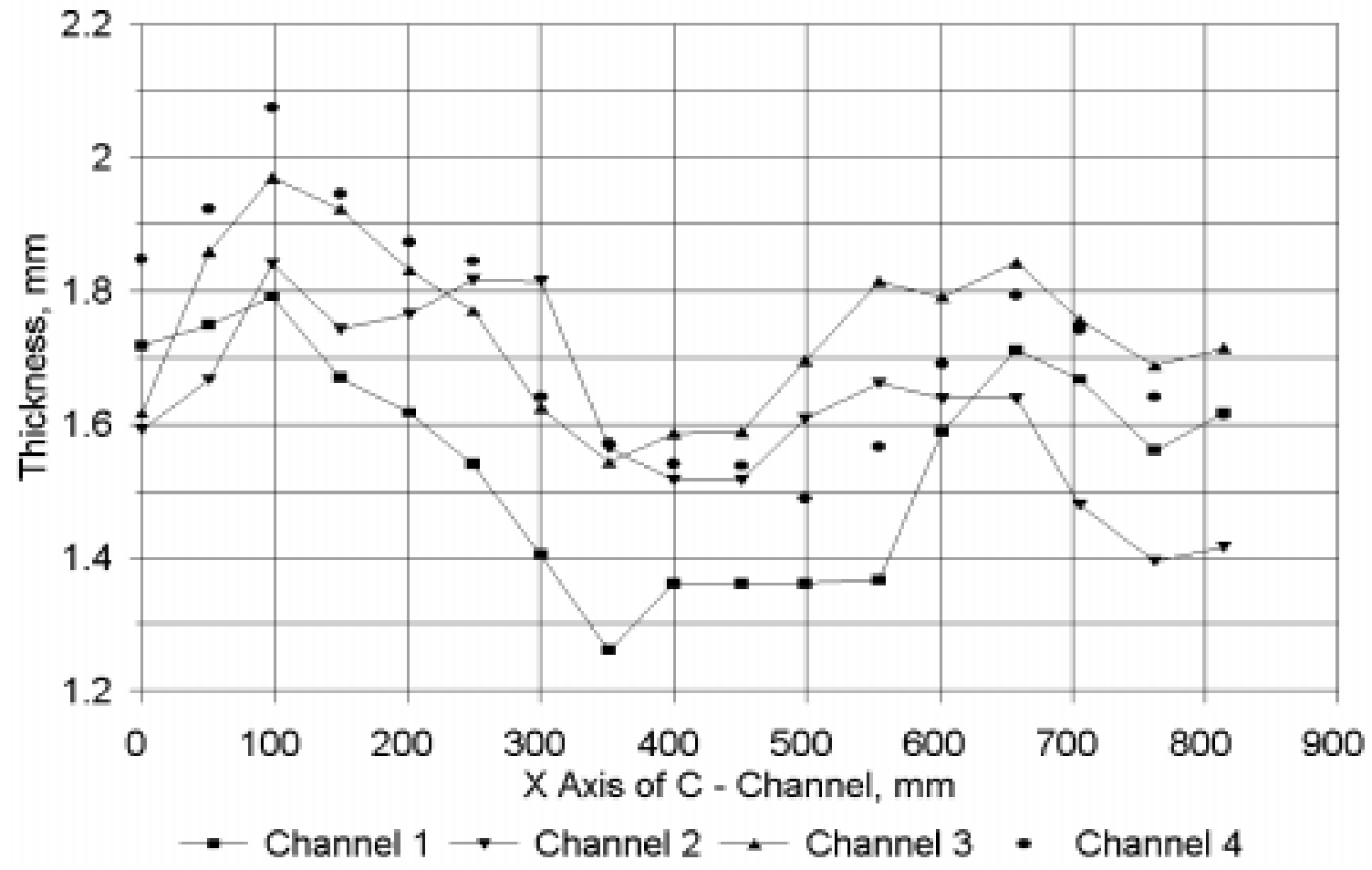

Figure 6. Thickness variation in C-channels. 


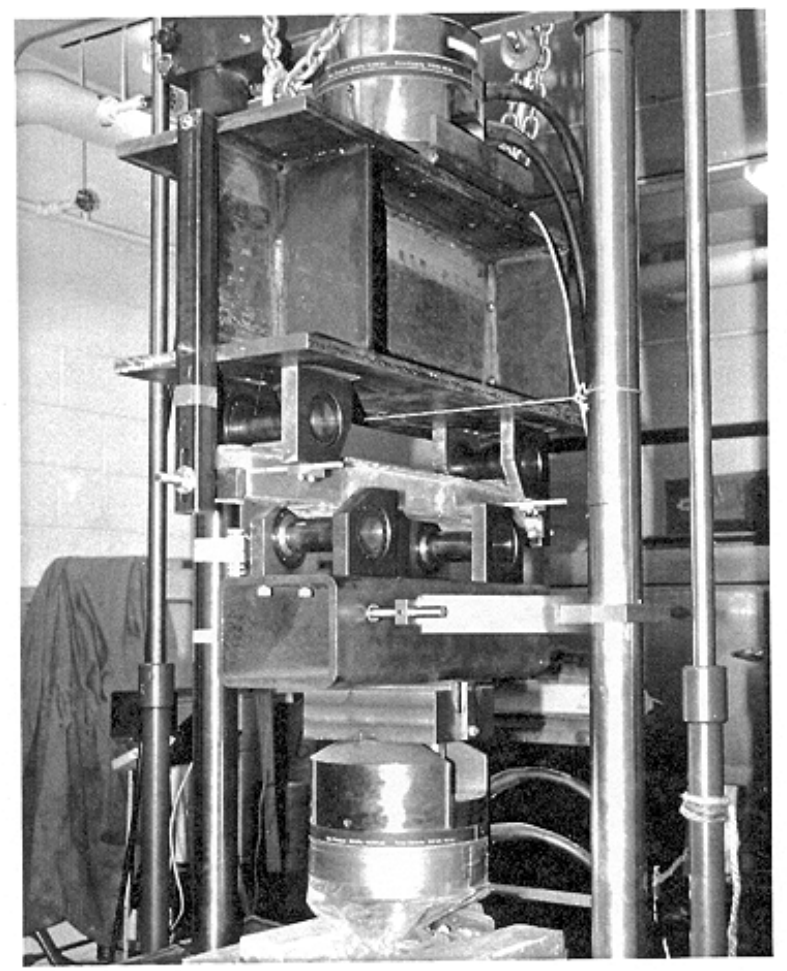

(a)

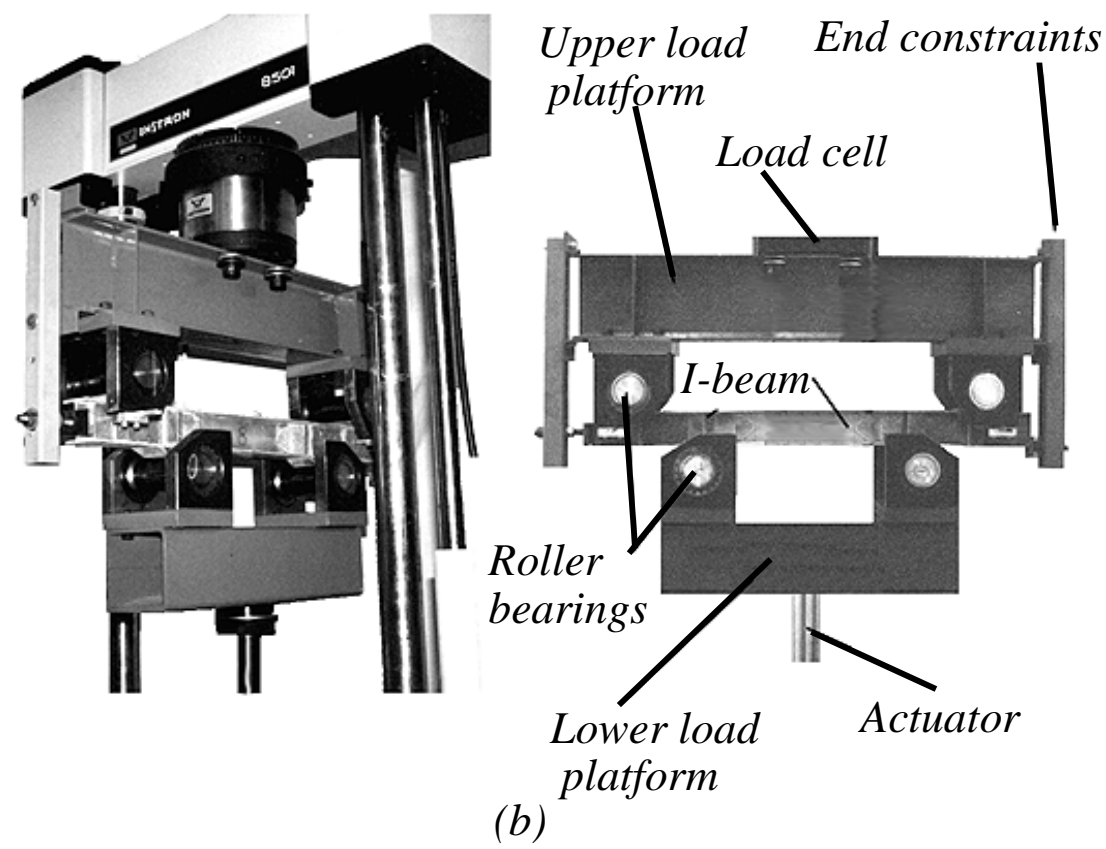

Figure 7. Four-point loading fixture in (a) MTS and (b) Instron testing machines. 

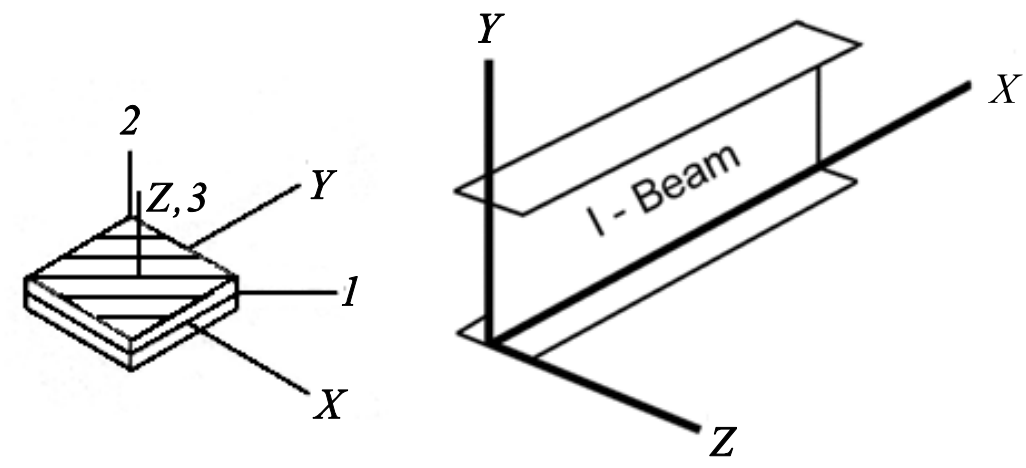

$0^{O}$ direction $=X$ in laminate designations

Figure 8(a). Laminate and beam coordinate systems.
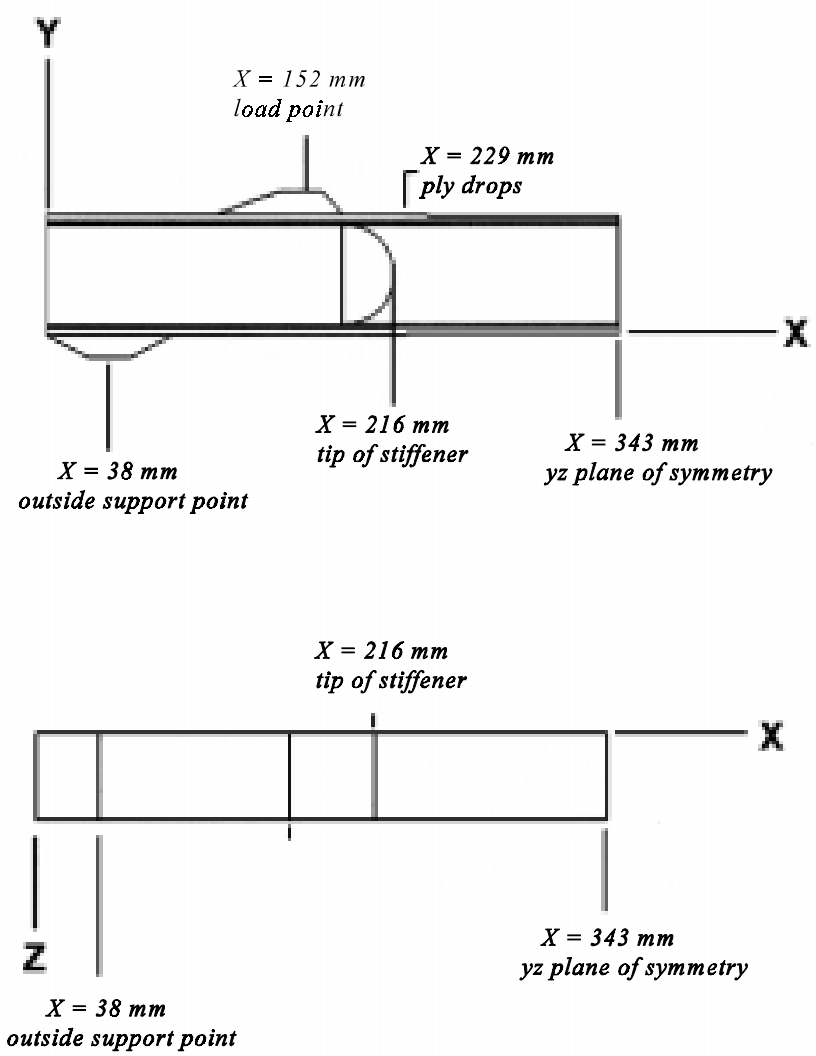

Figure 8(b). Alignment of FEA coordinate system. 


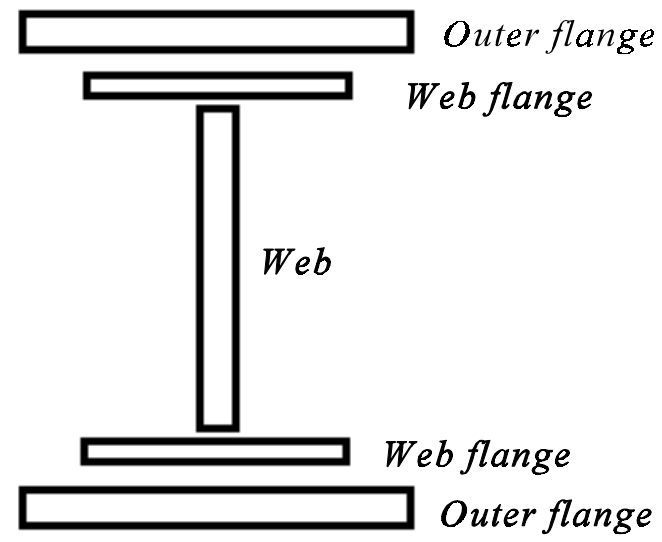

Figure 9. Geometric and elastic entities for composite I-beam.

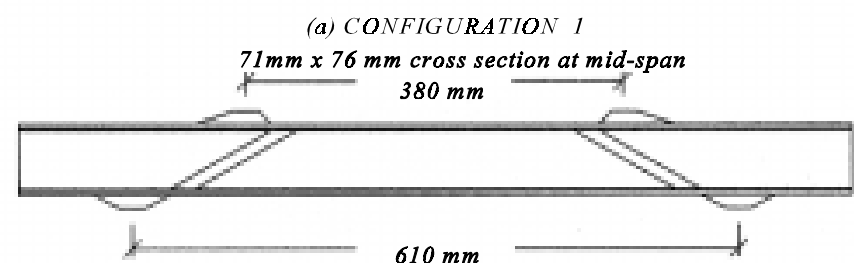

(b) CONFIGURATION 2

$70 \mathrm{~mm} \times 51 \mathrm{~mm}$ cross section at mid-span (includes ply drops as shown in (c))

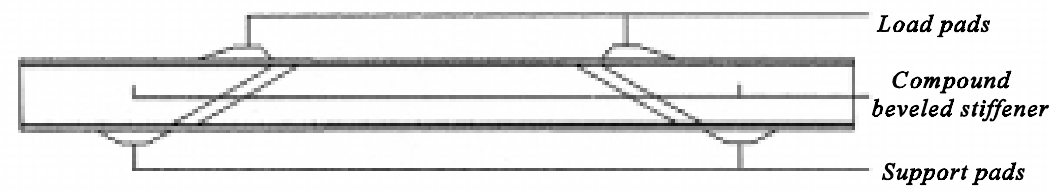

(c) CONFIGURATION 3

$70 \mathrm{~mm} \times 51 \mathrm{~mm}$ cross section at mid-span

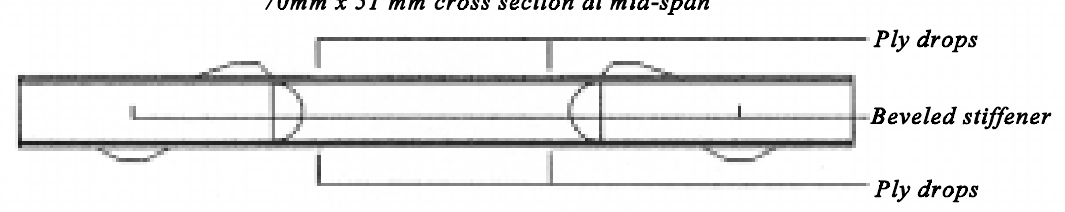

Figure 10. Beam configurations. 


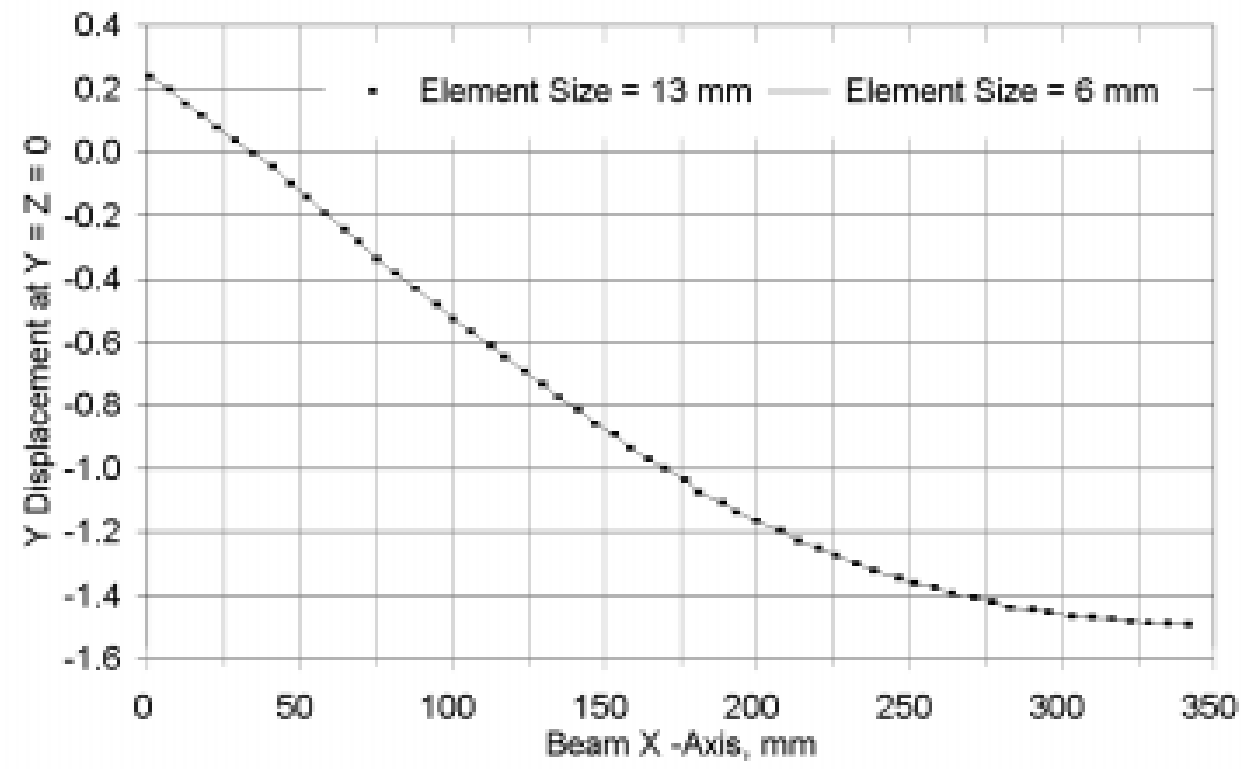

Figure 11. Convergence of FEA solution for configuration 1 (Beams 1 and 2). 


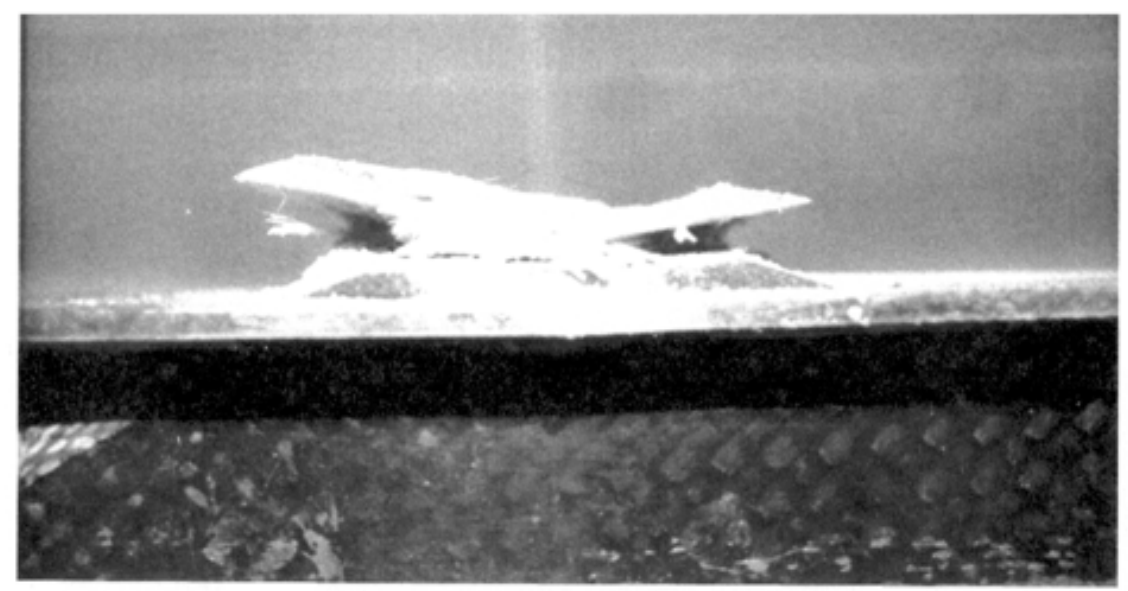

(a)

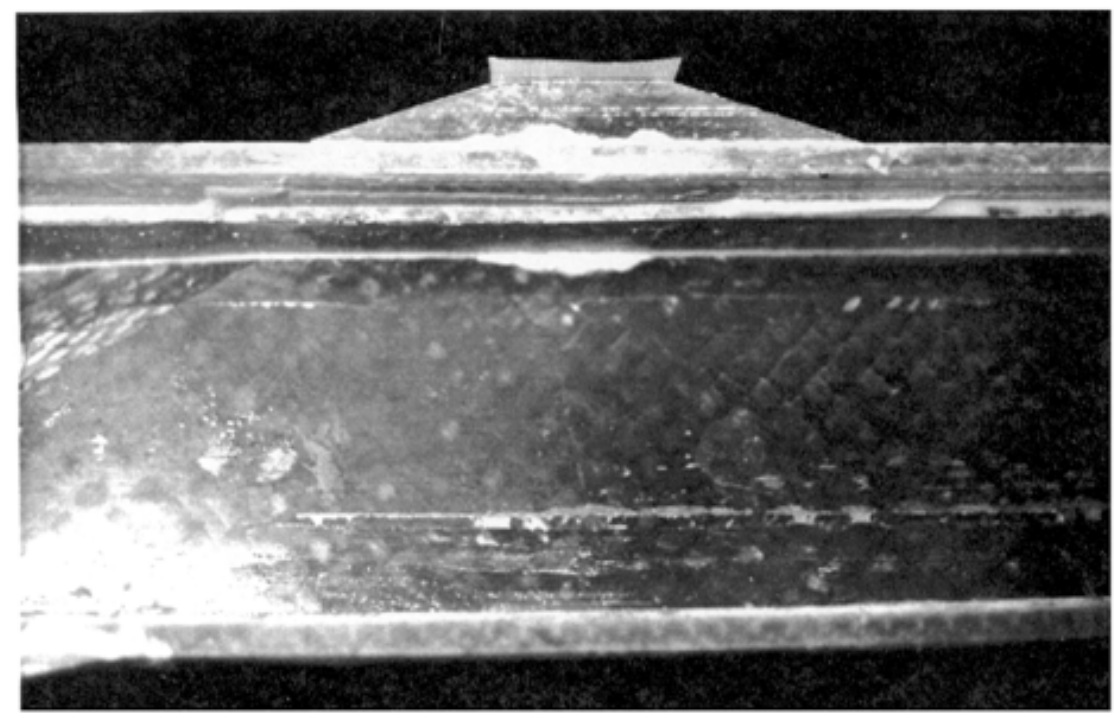

(b)

Figure 12. (a) Load pad damage and compression damage zone, tension side of Beam 1. (b) Adhesive failure of Beam 2. 


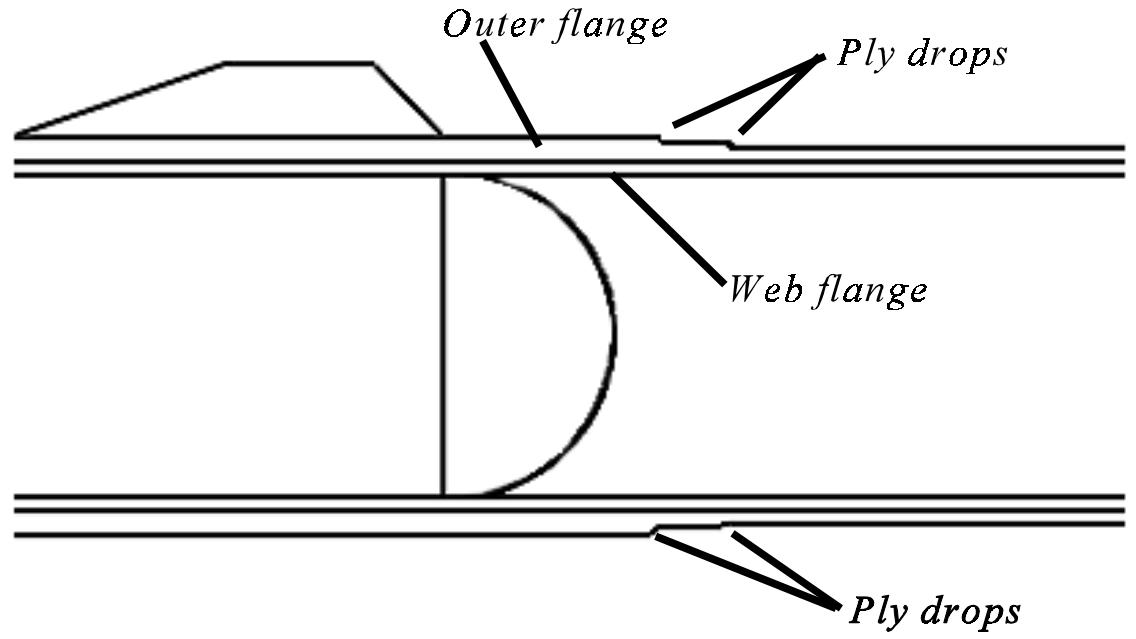

Figure 13. Ply drops, configuration 3, xy plane.

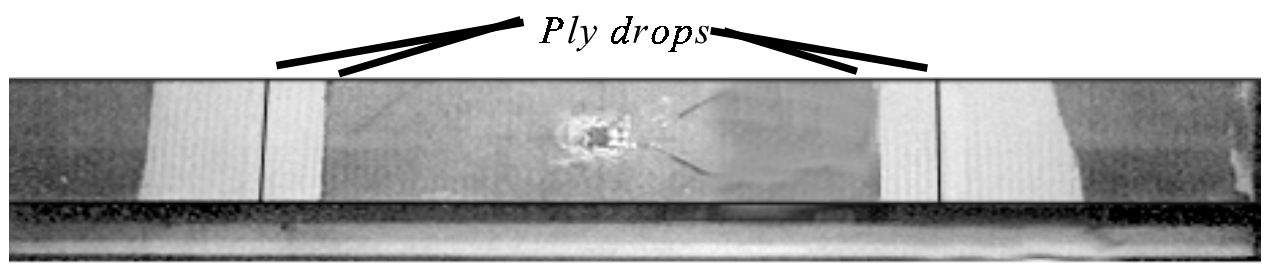

Figure 14. Delamination of ply drops, beam 3. 


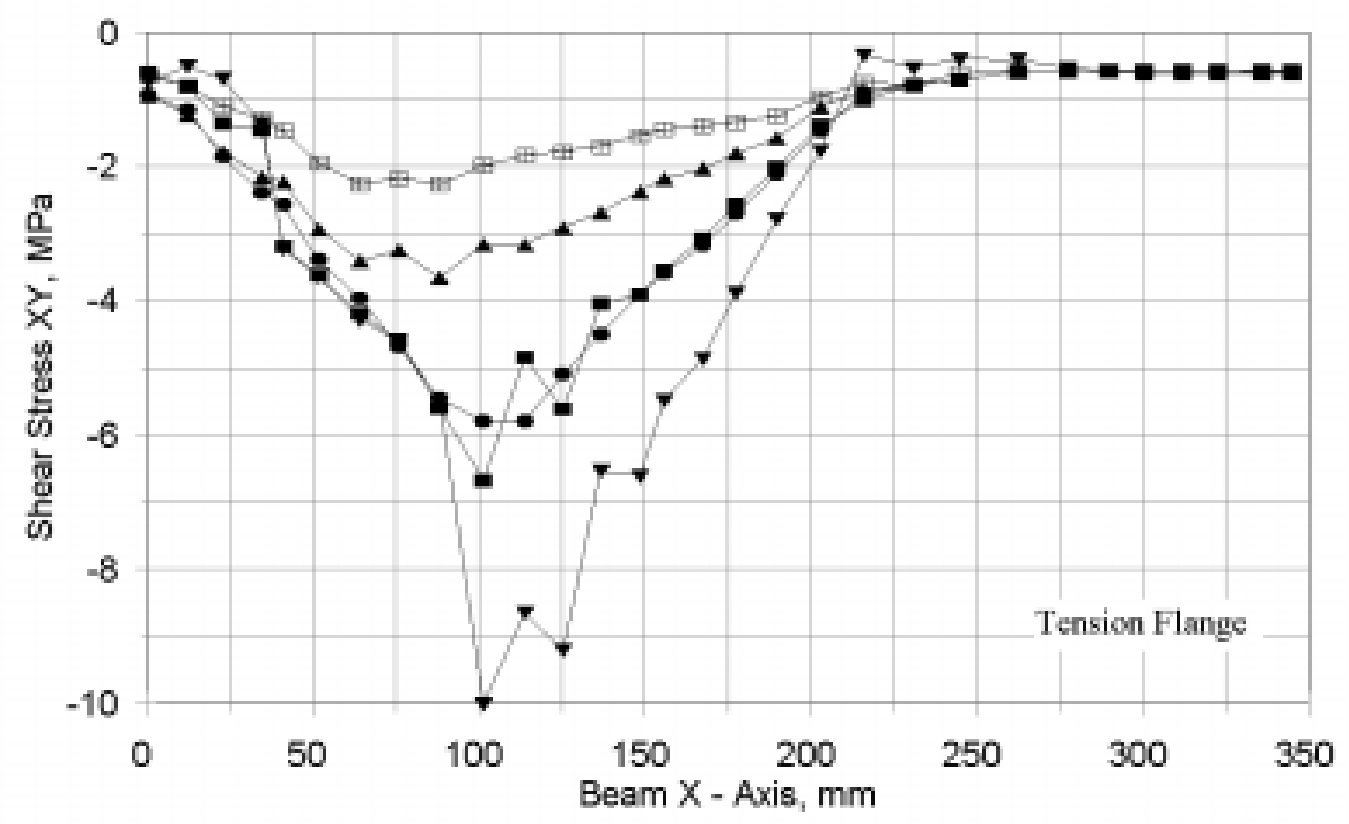

$-z=0 \mathrm{~mm} \rightarrow \mathrm{z}=3 \mathrm{~mm} \rightarrow \mathrm{z}=10 \mathrm{~mm}-\mathrm{z}=18 \mathrm{~mm}-\mathrm{m}-\mathrm{z}=25 \mathrm{~mm}$

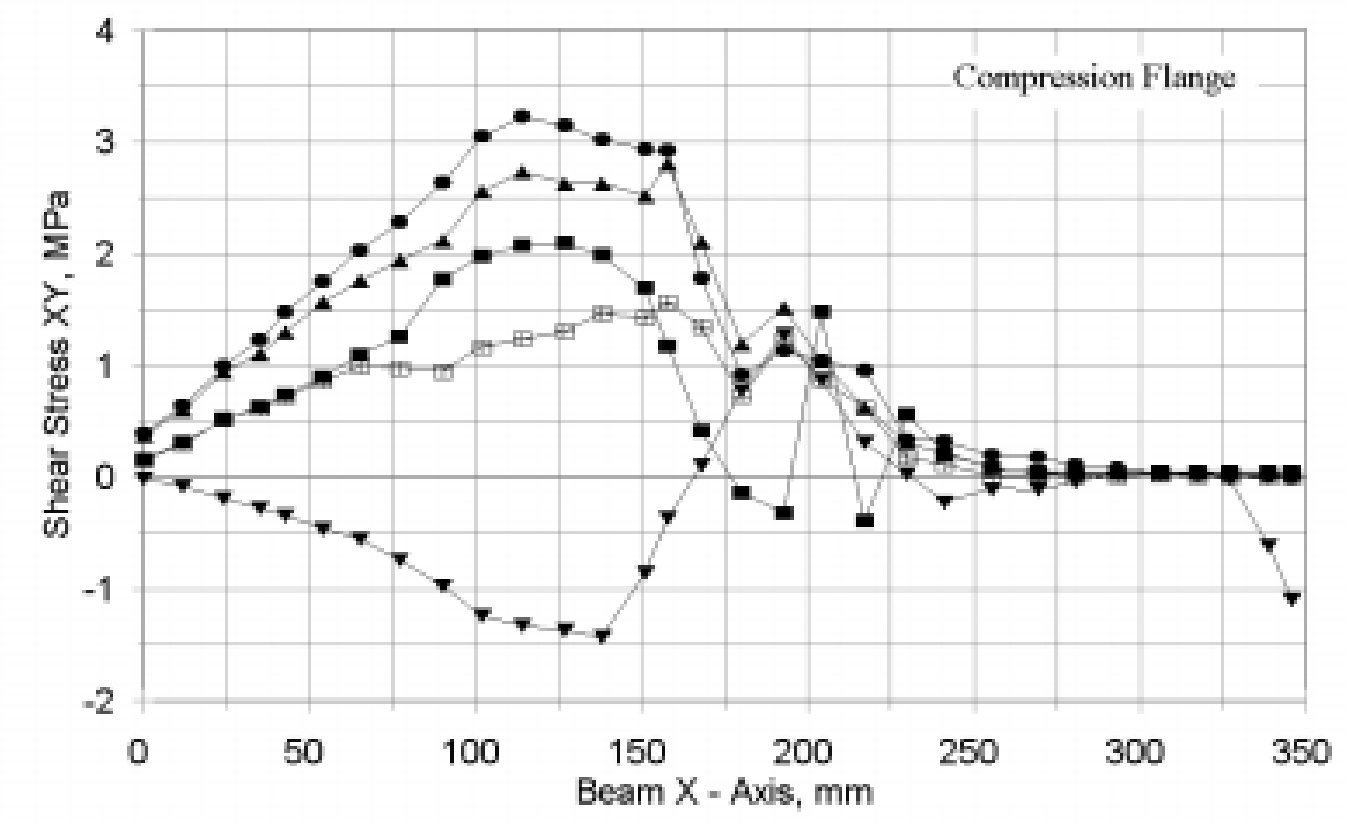

$-Z=0 \mathrm{~mm} \rightarrow-Z=3 \mathrm{~mm} \longrightarrow Z=10 \mathrm{~mm} \longrightarrow z=18 \mathrm{~mm}-Z=25 \mathrm{~mm}$

Figure 15. Shear stress XY at the adhesive interface of flanges, configuration 2. 


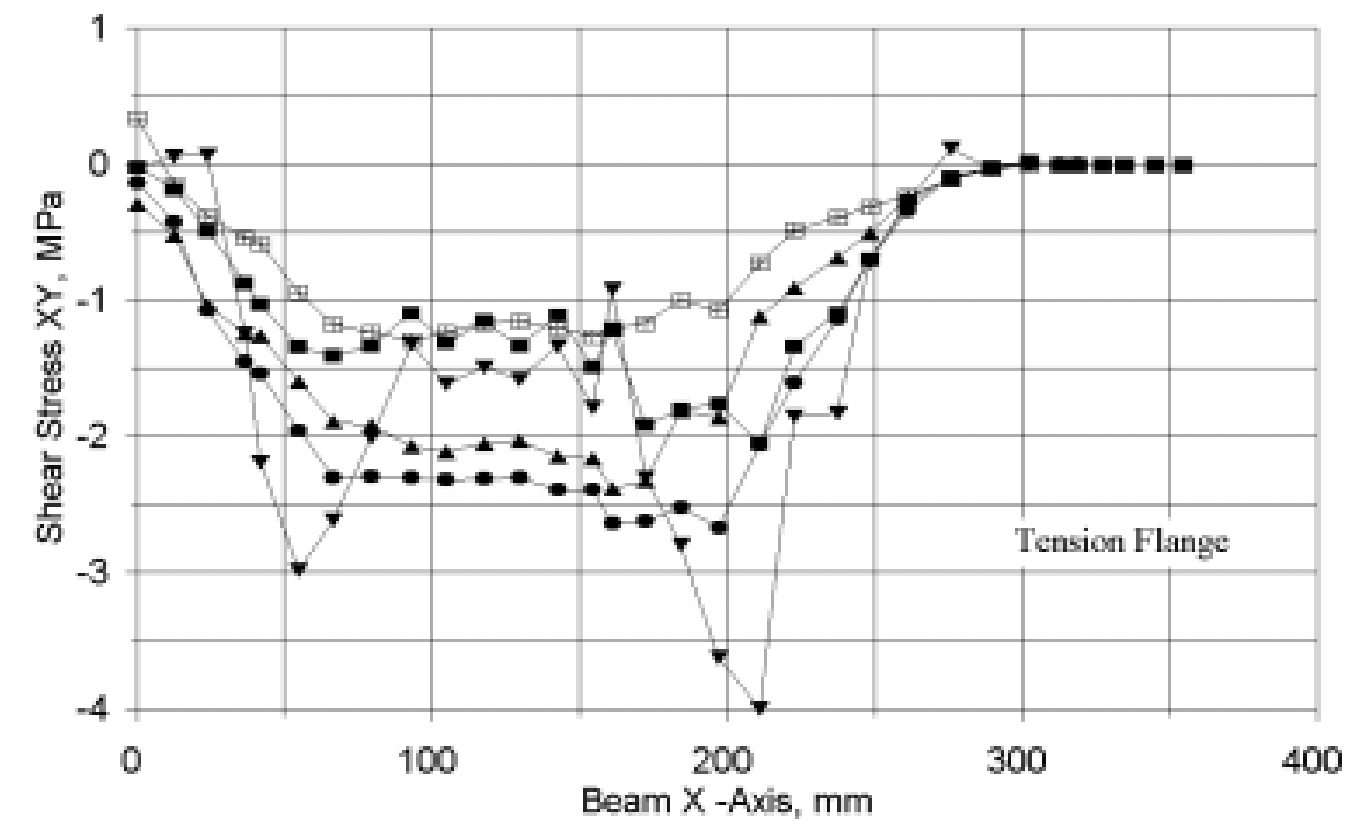

- $z=0 \mathrm{~mm} \rightarrow \mathrm{Z}=3 \mathrm{~mm} \rightarrow \mathrm{z}=10 \mathrm{~mm}-\mathrm{z}=18 \mathrm{~mm}-\mathrm{D}-\mathrm{z}=25 \mathrm{~mm}$

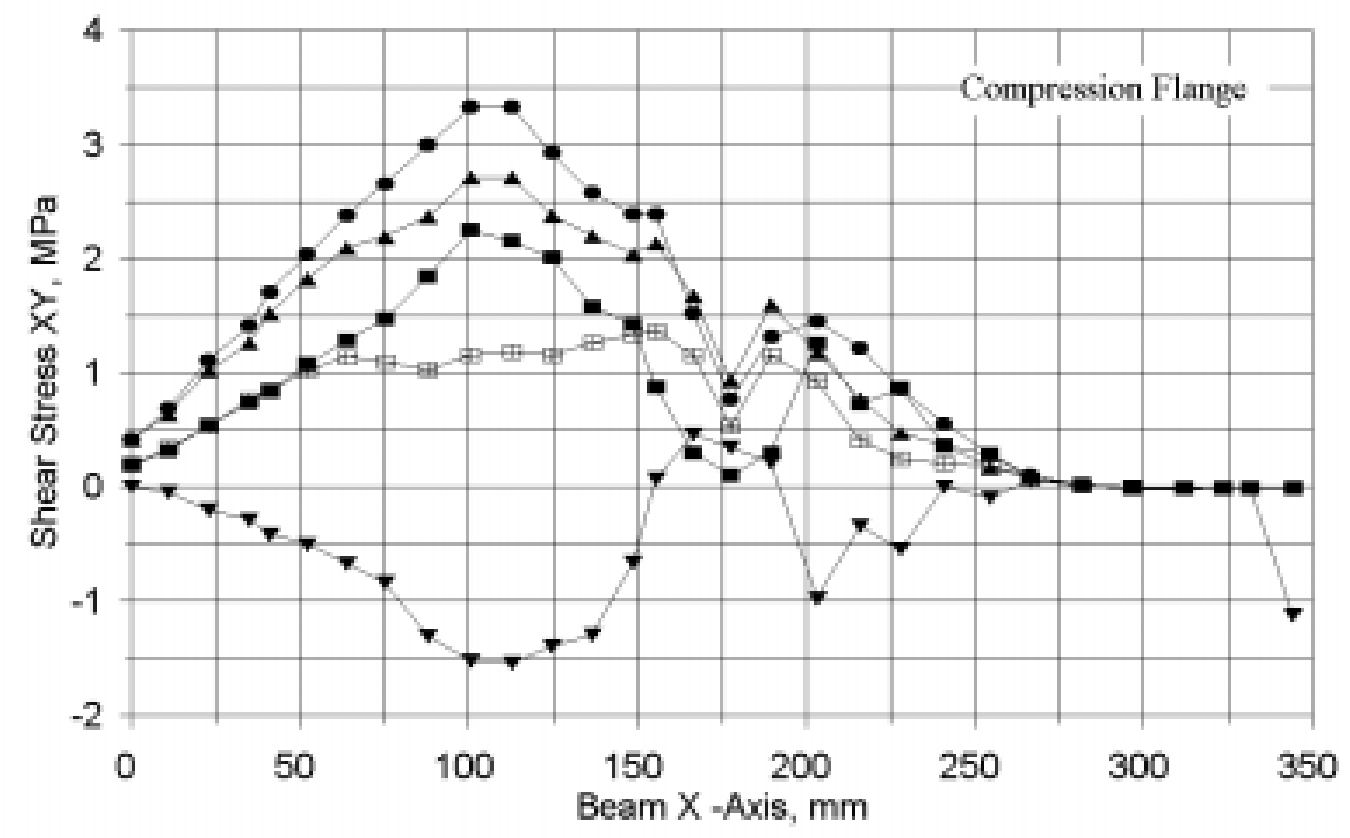

$-Z=0 \mathrm{~mm} \rightarrow Z=3 \mathrm{~mm} \rightarrow Z=10 \mathrm{~mm} \rightarrow Z=18 \mathrm{~mm} \rightarrow-Z=25 \mathrm{~mm}$

Figure 16. Shear stress XY at the adhesive interface of flanges, configuration 3. 

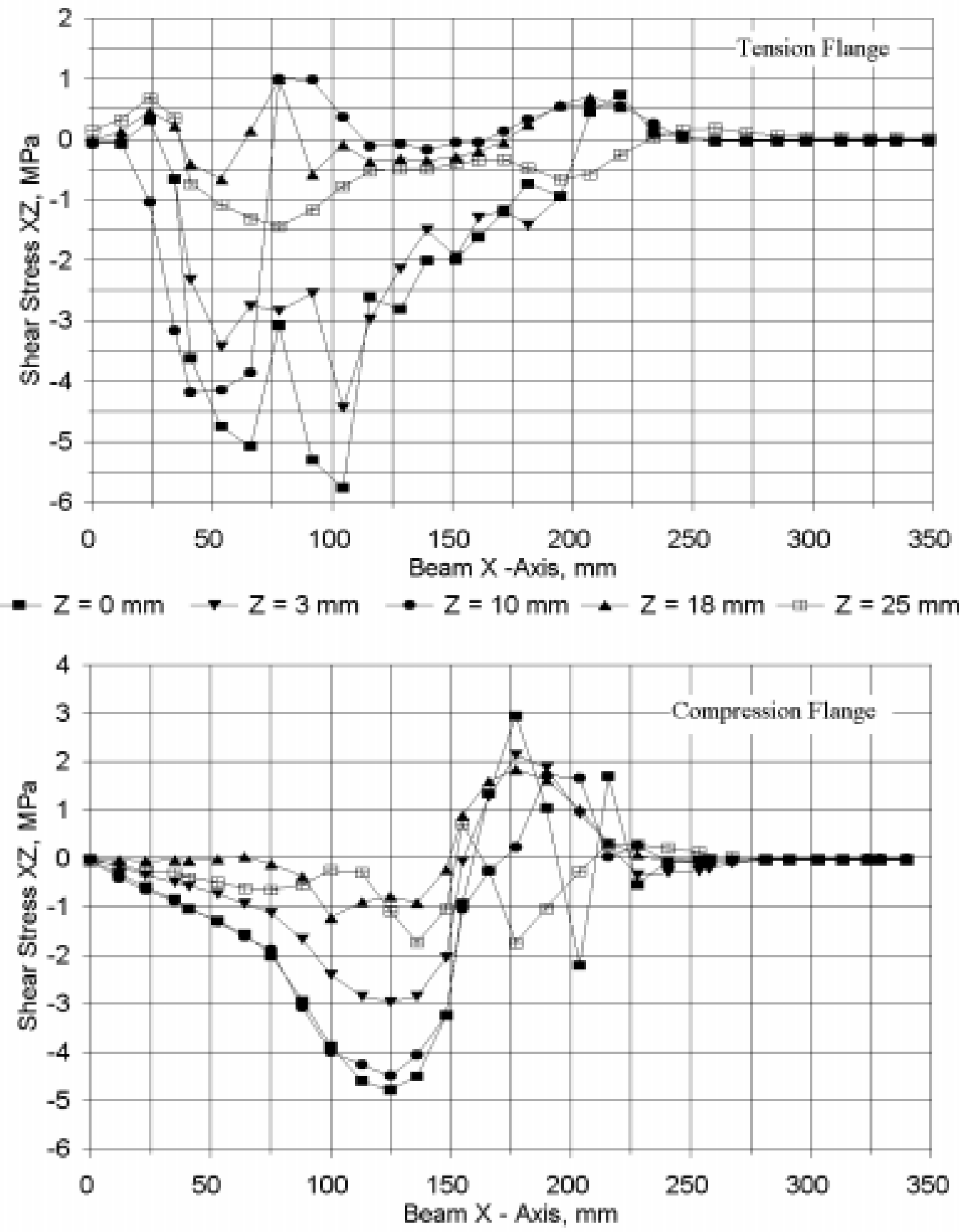

$-Z=0 \mathrm{~mm} \rightarrow Z=3 \mathrm{~mm} \rightarrow Z=10 \mathrm{~mm} \rightarrow Z=18 \mathrm{~mm} \rightarrow Z=25 \mathrm{~mm}$

Figure 17. Shear stress $X Z$ at the adhesive interface of flanges, configuration 2. 


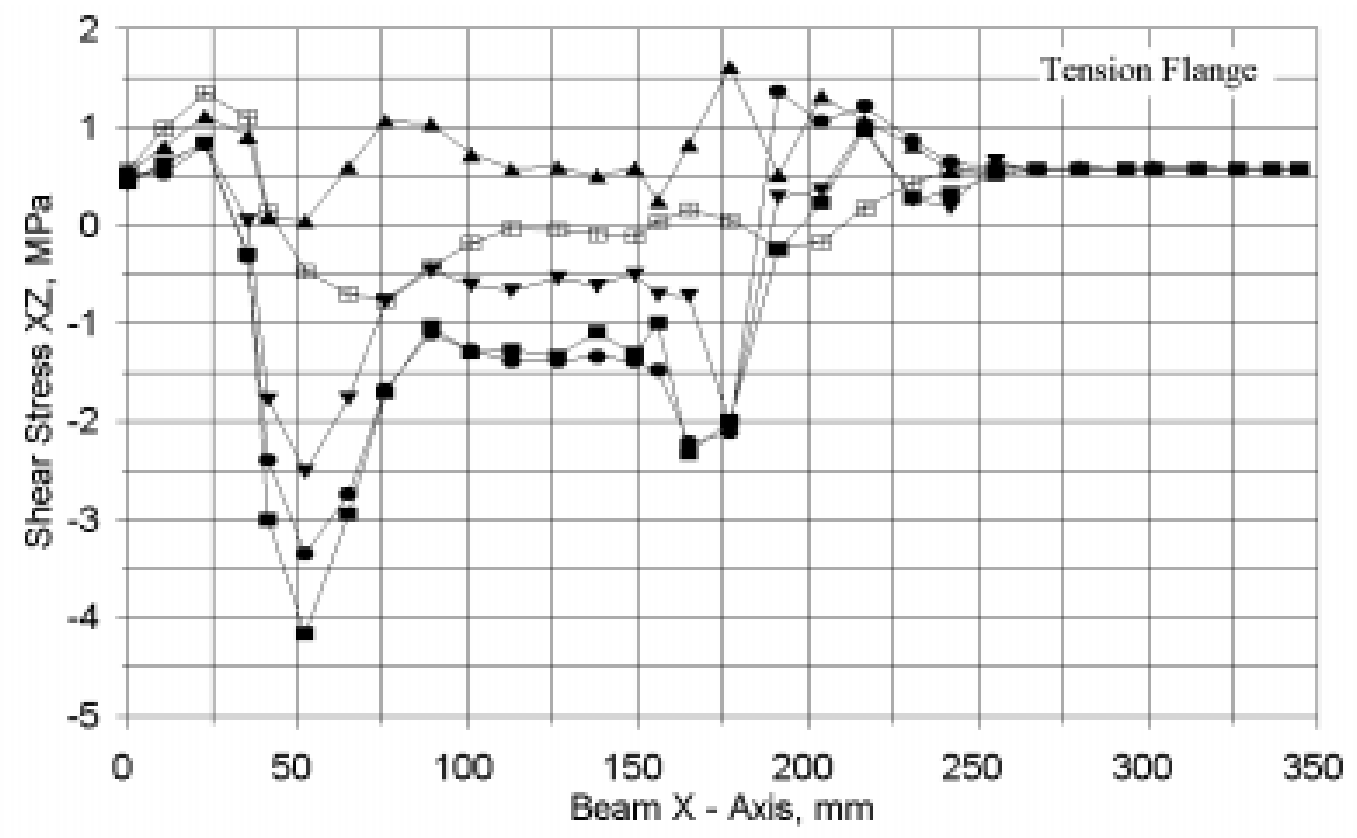

$-Z=0 \mathrm{~mm} \rightarrow Z=3 \mathrm{~mm} \longrightarrow Z=10 \mathrm{~mm} \rightarrow Z=18 \mathrm{~mm}-Z=25 \mathrm{~mm}$

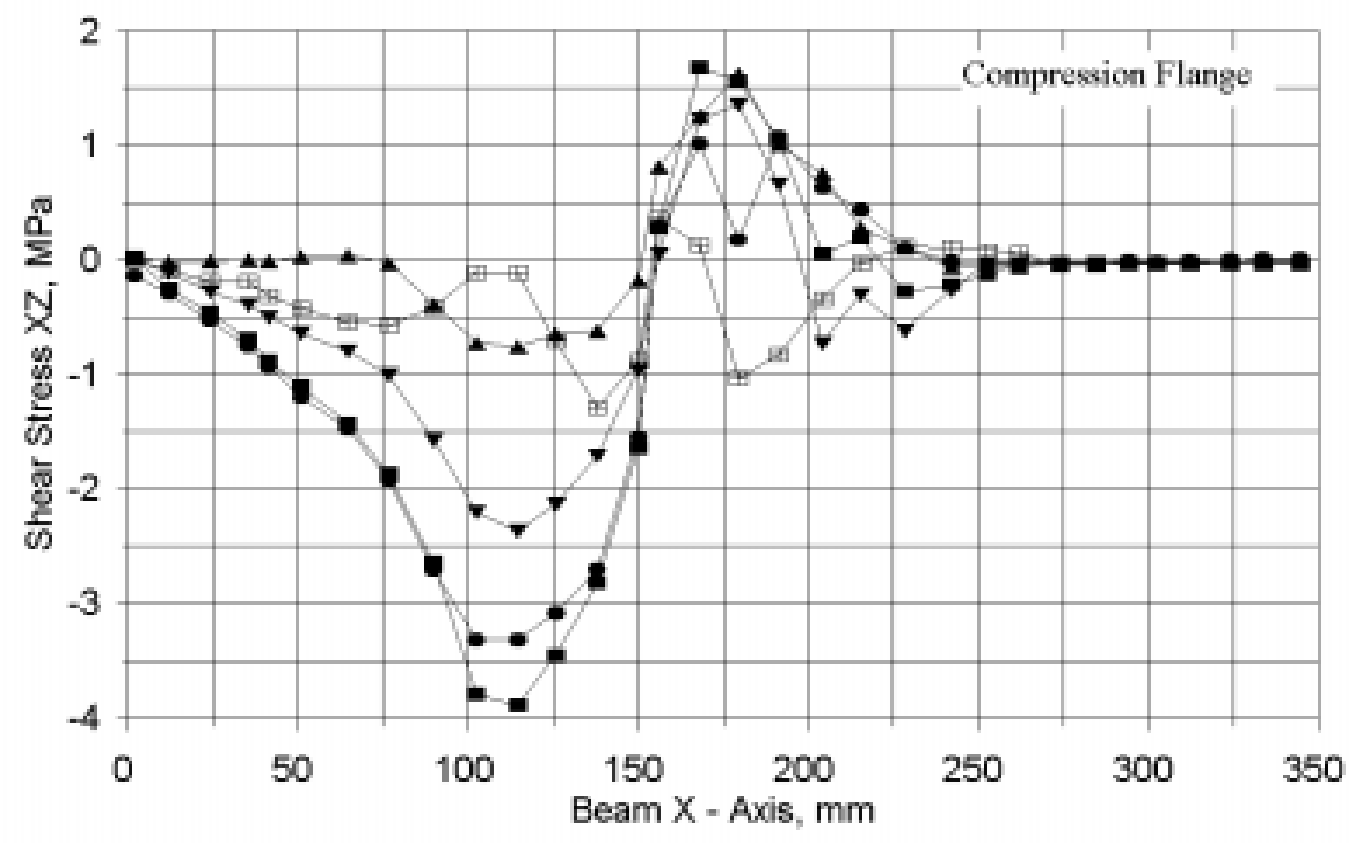

$-z=0 \mathrm{~mm} \rightarrow z=3 \mathrm{~mm} \longrightarrow z=10 \mathrm{~mm} \bullet z=18 \mathrm{~mm} \rightarrow z=25 \mathrm{~mm}$

Figure 18. Shear stress $\mathrm{XZ}$ at the adhesive interface of flanges, configuration 3. 


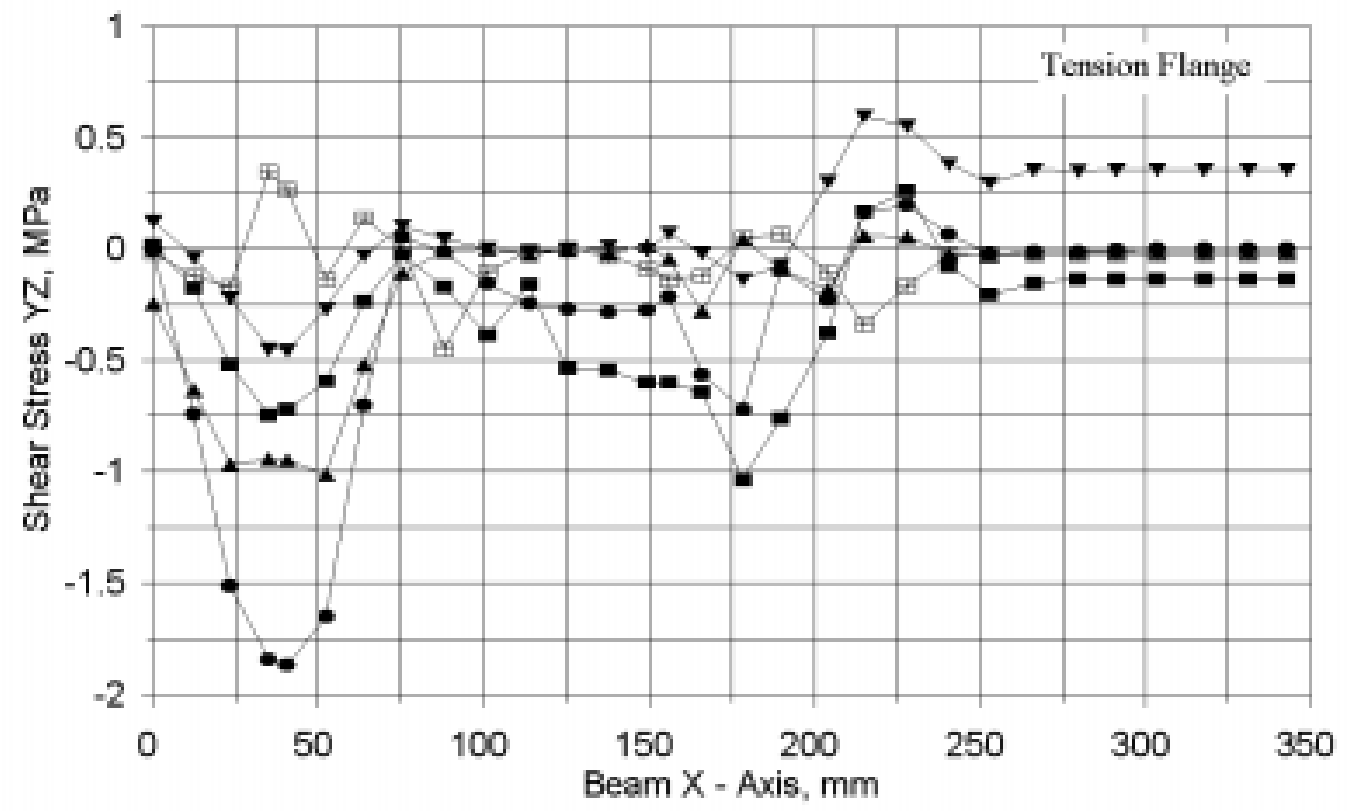

$-Z=0 \mathrm{~mm} \rightarrow Z=3 \mathrm{~mm} \rightarrow Z=10 \mathrm{~mm} \rightarrow Z=18 \mathrm{~mm} \rightarrow Z=25 \mathrm{~mm}$

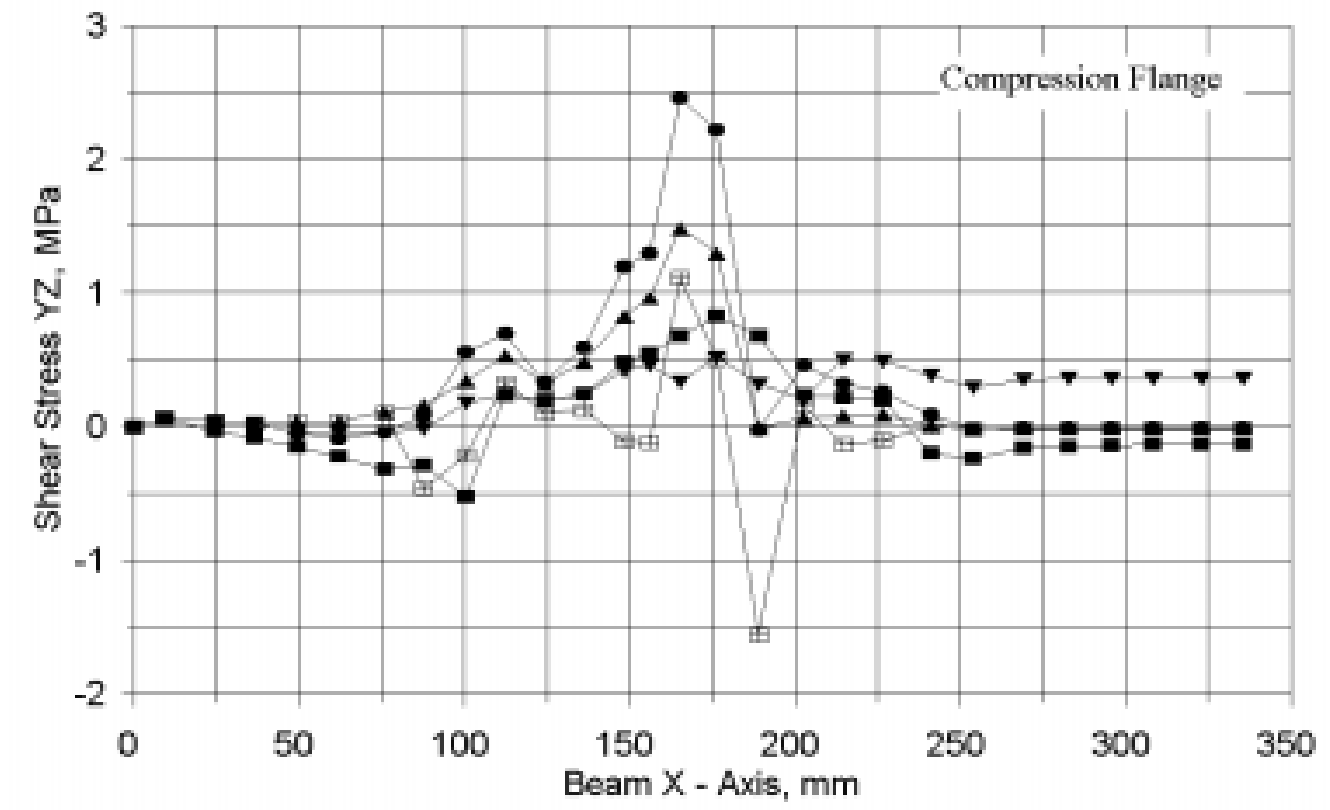

$-z=0 \mathrm{~mm} \rightarrow Z=3 \mathrm{~mm} \rightarrow Z=10 \mathrm{~mm} \rightarrow z=18 \mathrm{~mm} \boxplus z=25 \mathrm{~mm}$

Figure 19. Shear stress $\mathrm{YZ}$ at the adhesive interface of flanges, configuration 3. 

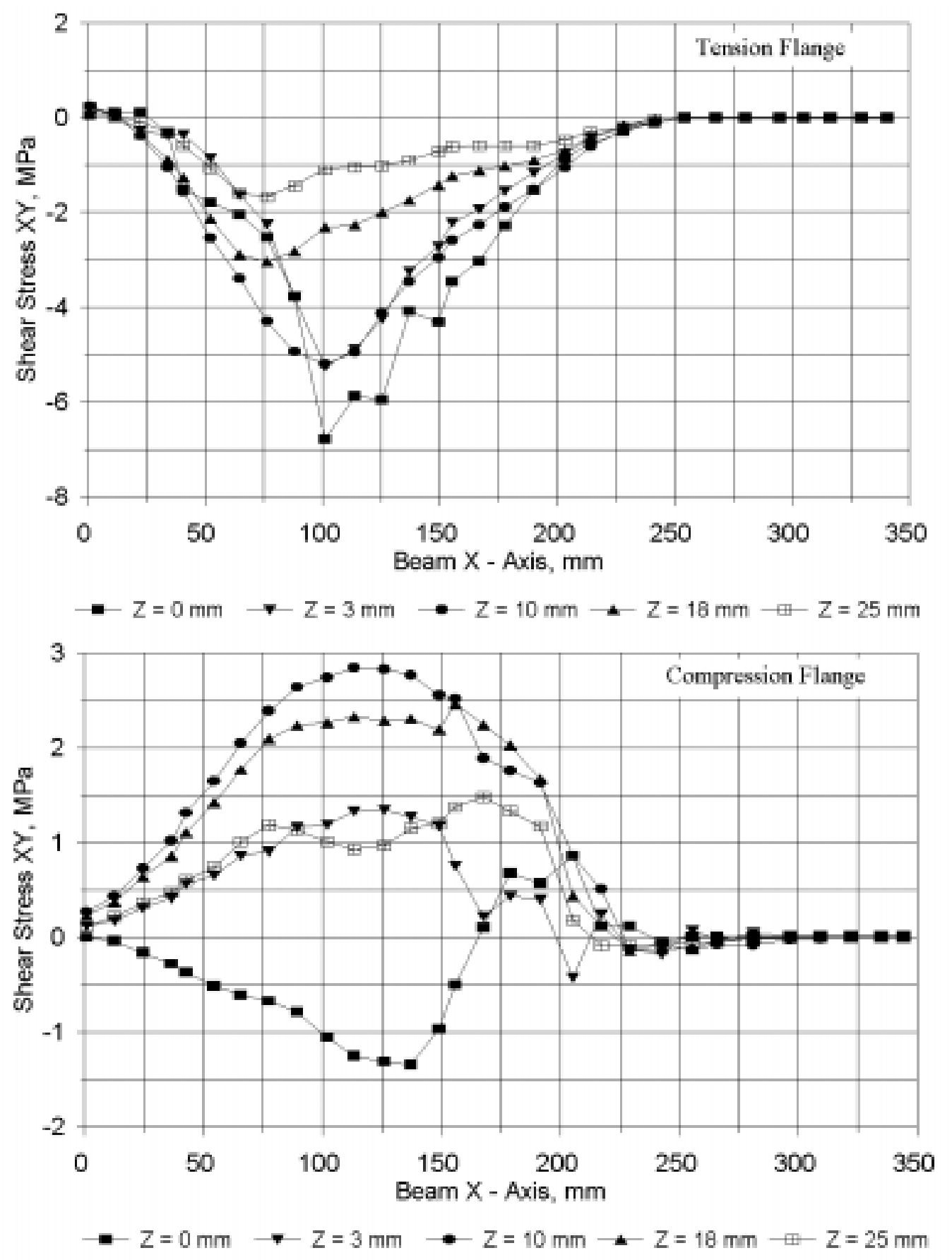

Figure 20. FEA Shear stress XY at flange interface, configuration 2, with isotropic material properties. 


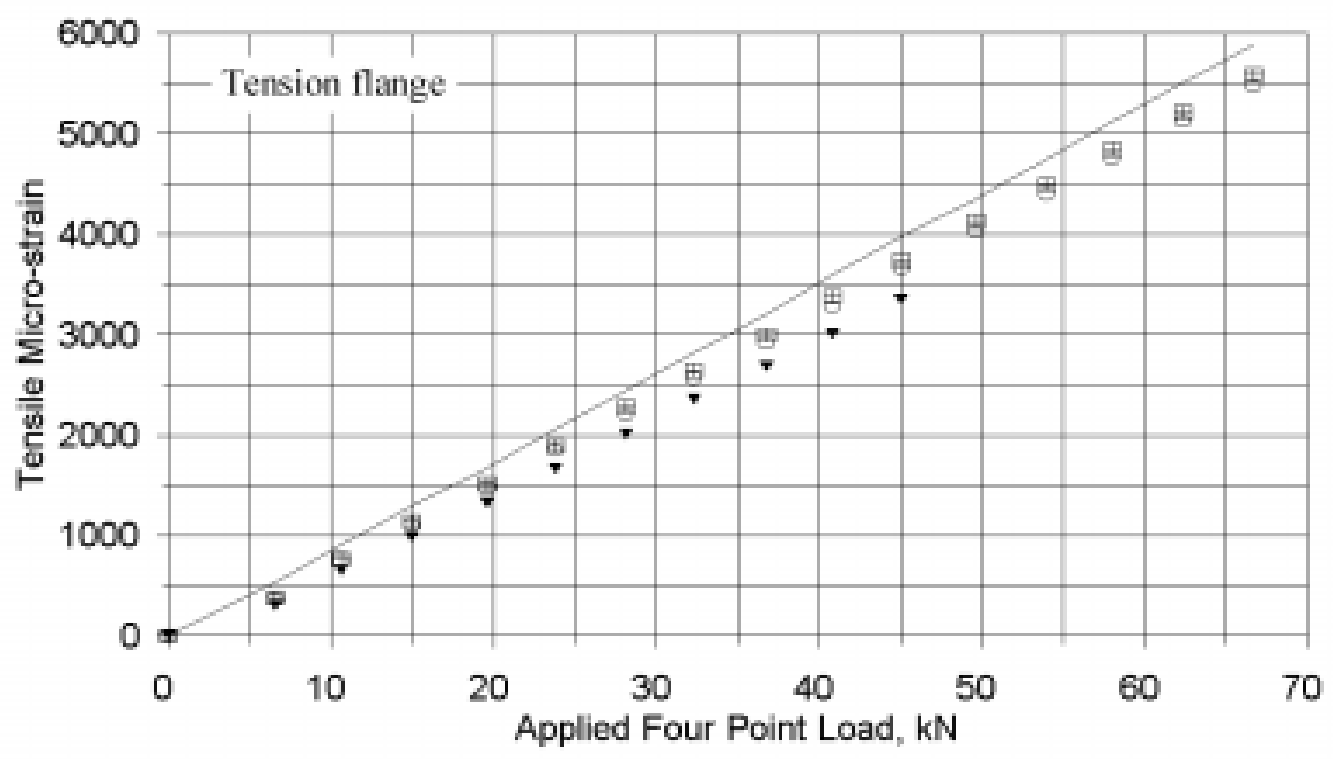

\section{FEA $\rightarrow$ Beam 1, 100,000 cycles}

- Beam 1,200,000 cycles Beam 2, 1 cycle

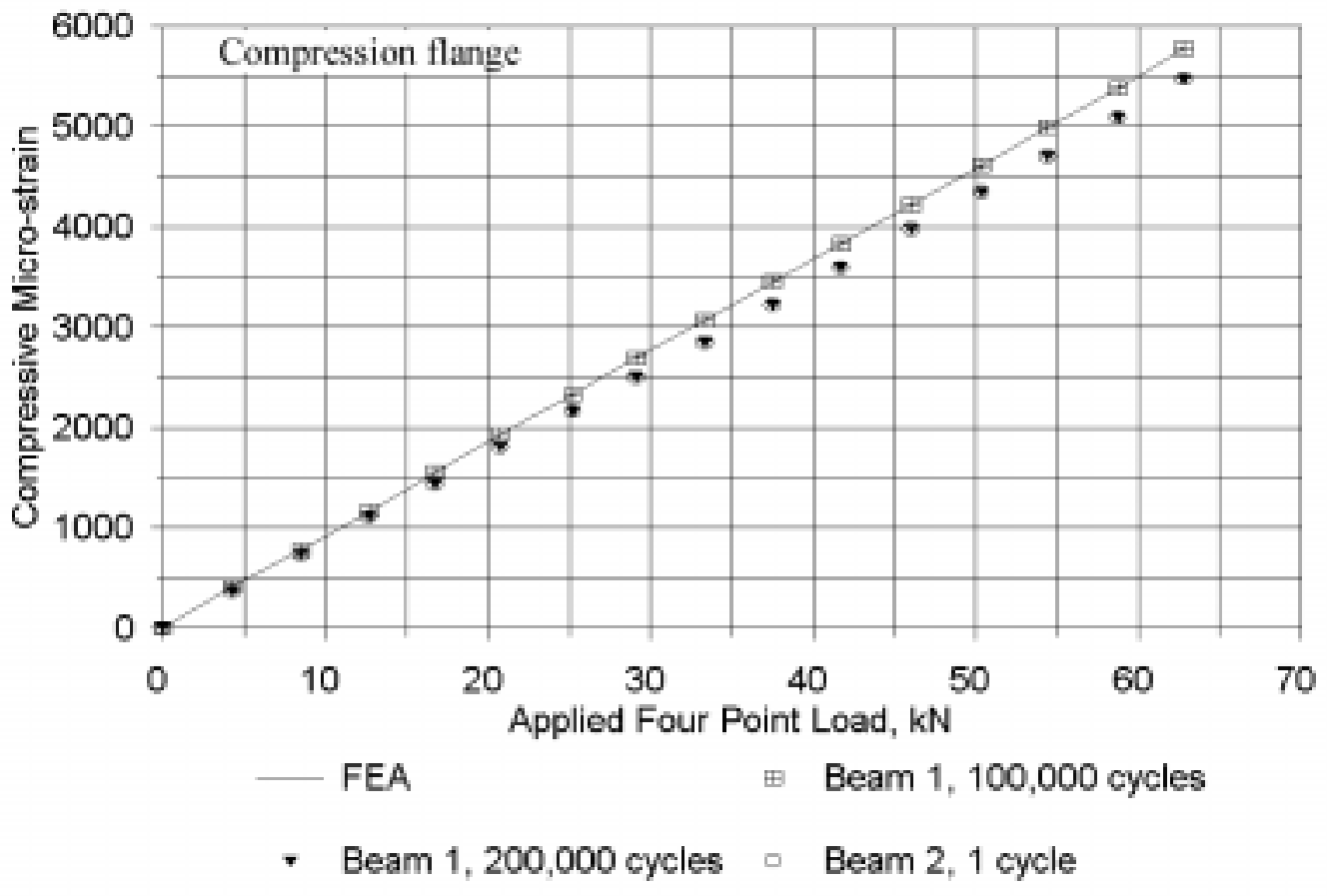

Figure 21. FEA and experimental strain versus load data, beams 1 and 2. 

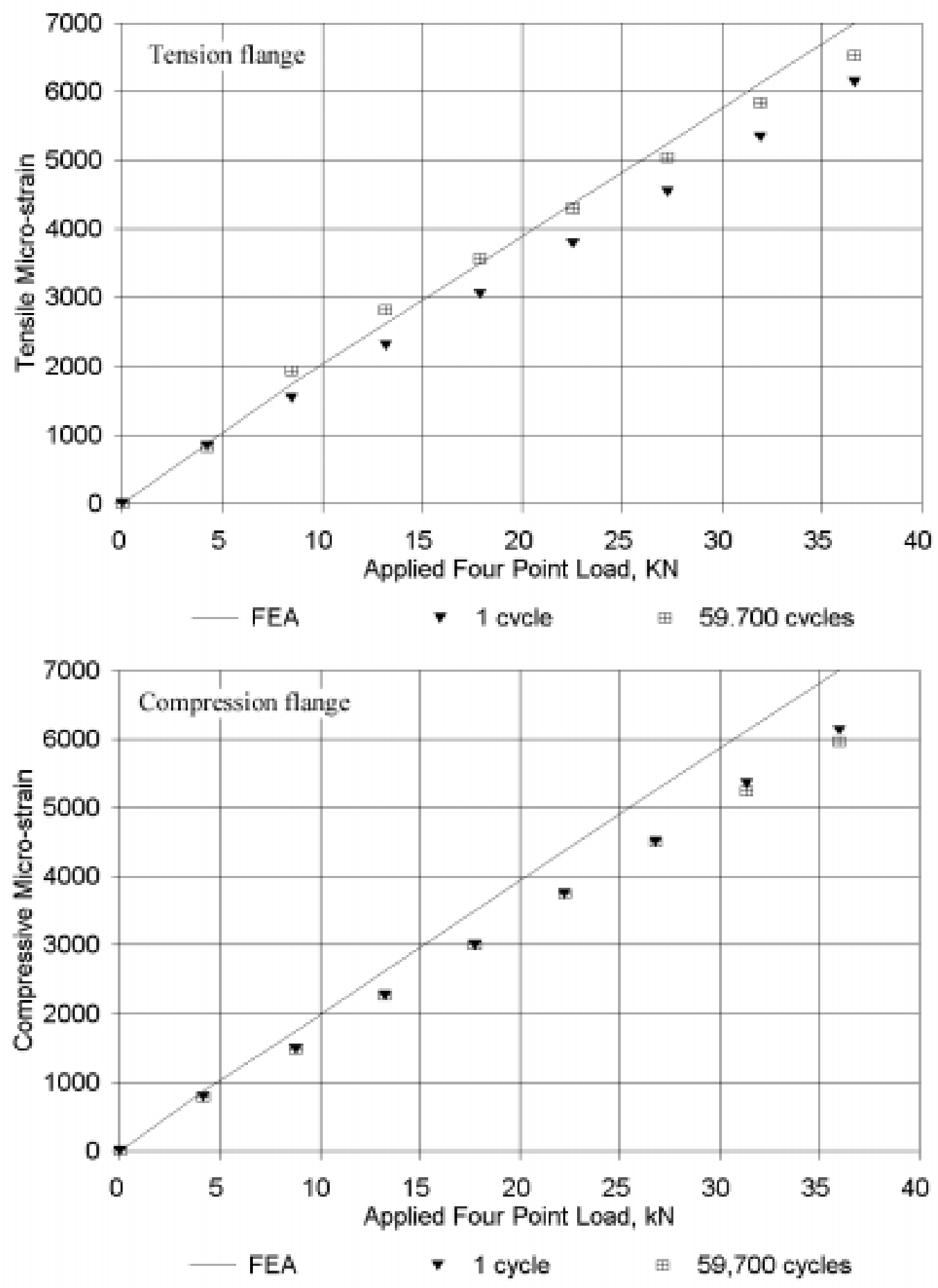

Figure 22. FEA and experimental strain versus load data, beam 3. 


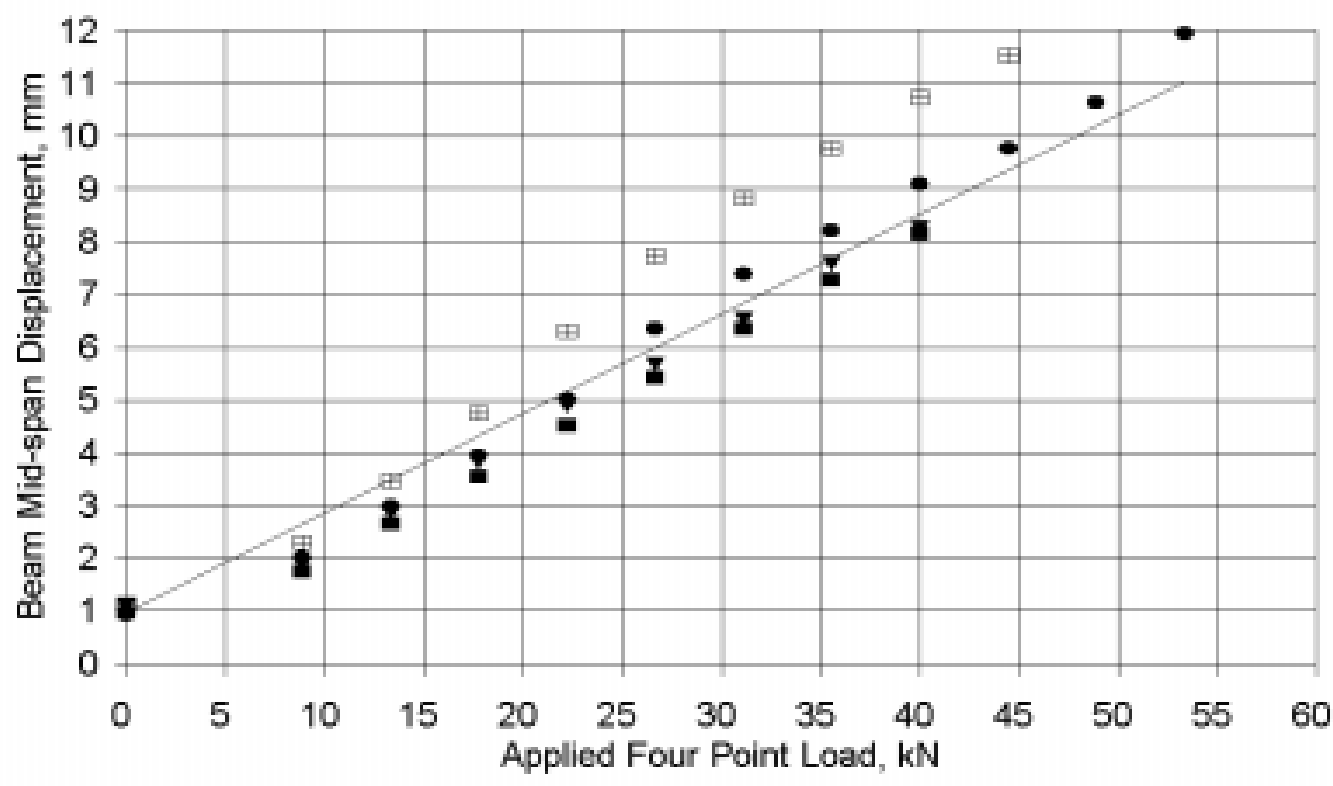

FEA

- 1 cycle

- $1,170,000$ cycles

- $1,970,000$ cycles $\boxplus 2,240,000$ cycles

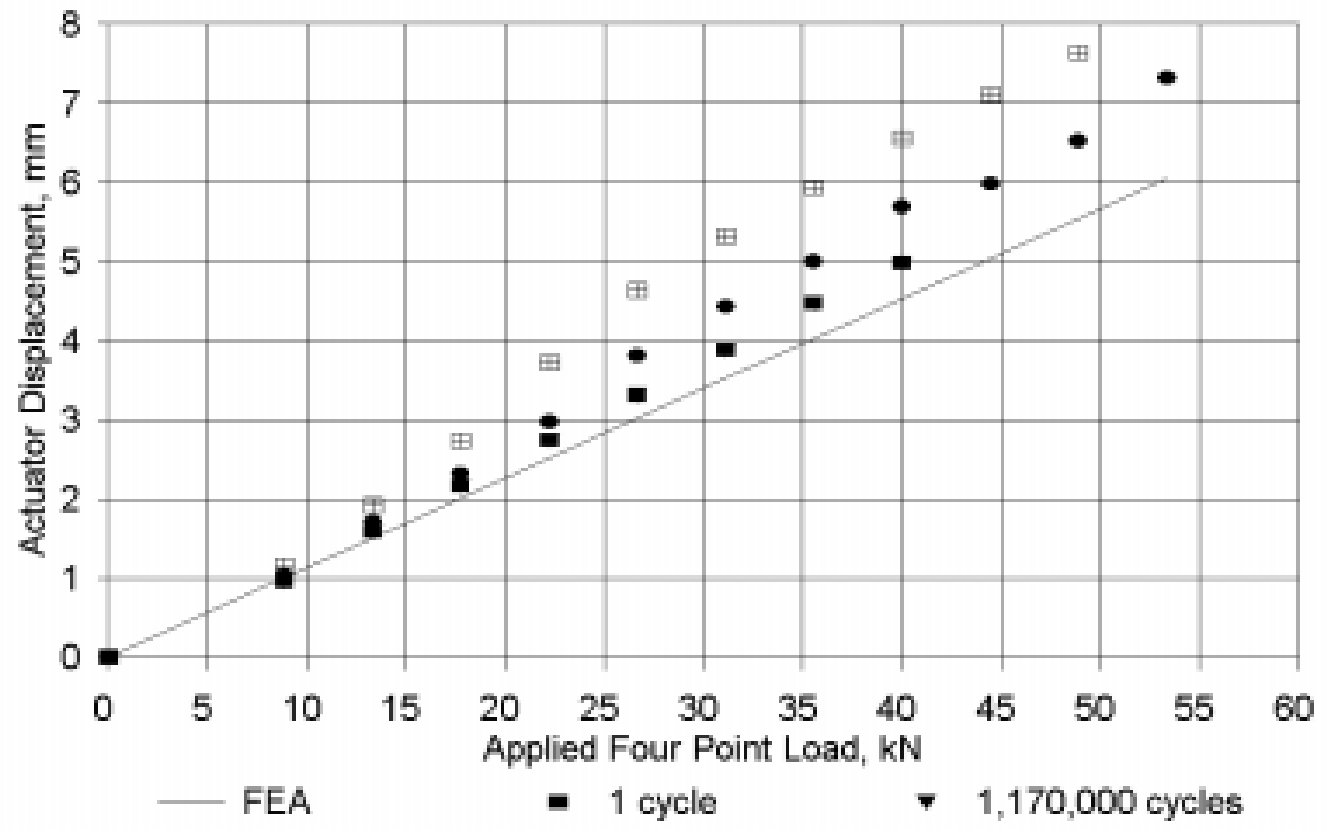

- $1,970,000$ cycles $\boxplus 2,240,000$ cycles

Figure 23. Center point and actuator displacement versus load, beam 4. 


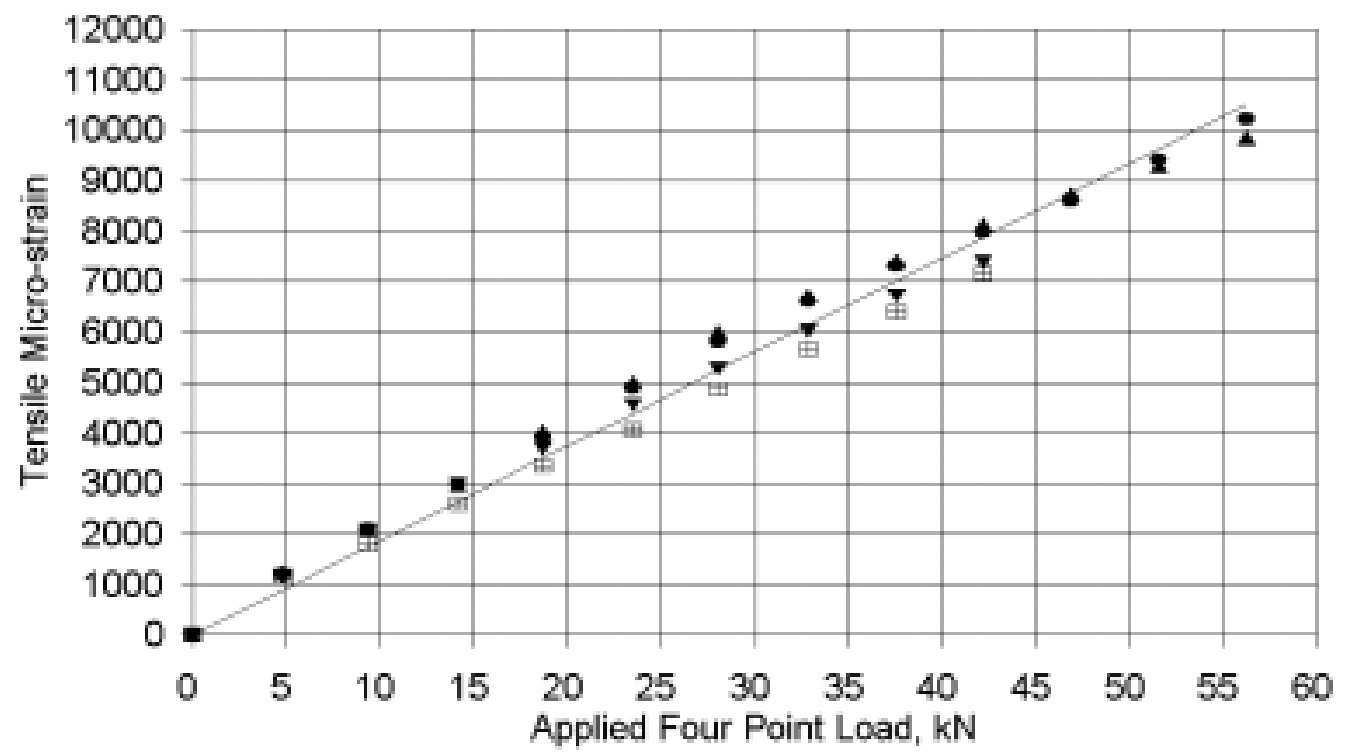

FEA

\# 1 Cycle

- 1,170,000 Cycles

- $1,970,000$ Cycles $42,240,000$ Cycles

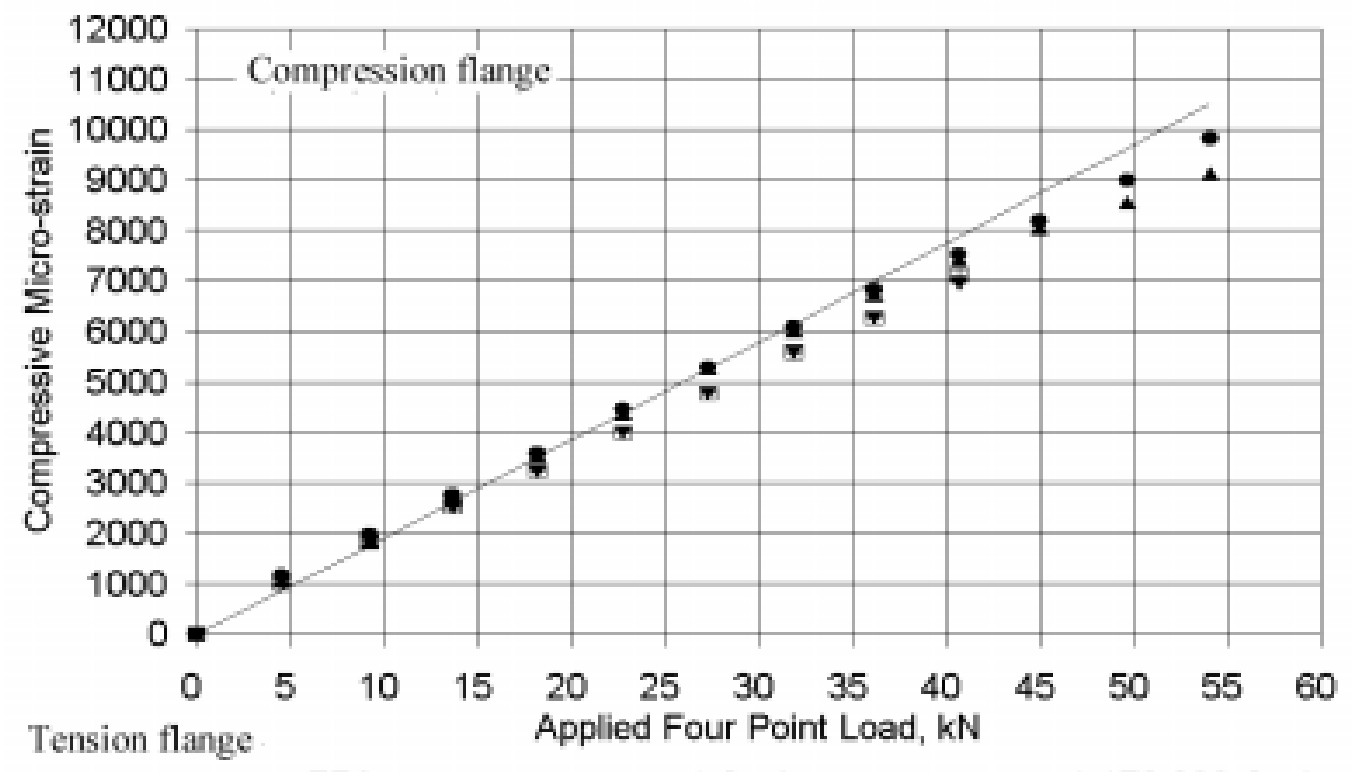

FEA

in 1 Cycle

- $1,170,000$ Cycles

- $1,970,000$ Cycles $42,240,000$ Cycles

Figure 24. FEA and experimental strain versus load data, beam 4. 

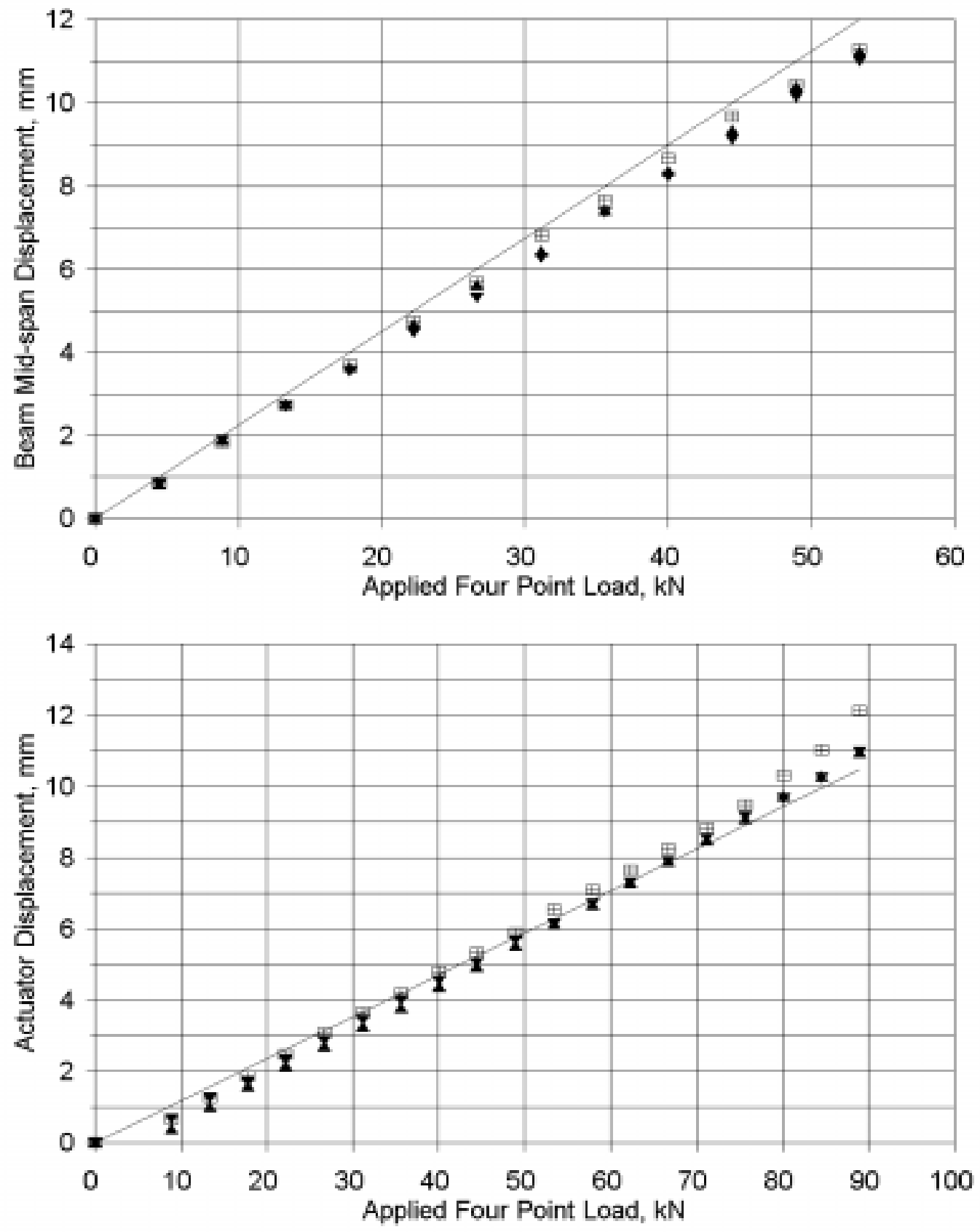

FEA \ 1st Test $\boxplus$ 2nd Test $~ 3$ rd Test

Figure 25. FEA and experimental displacement versus load results, beam 5. 

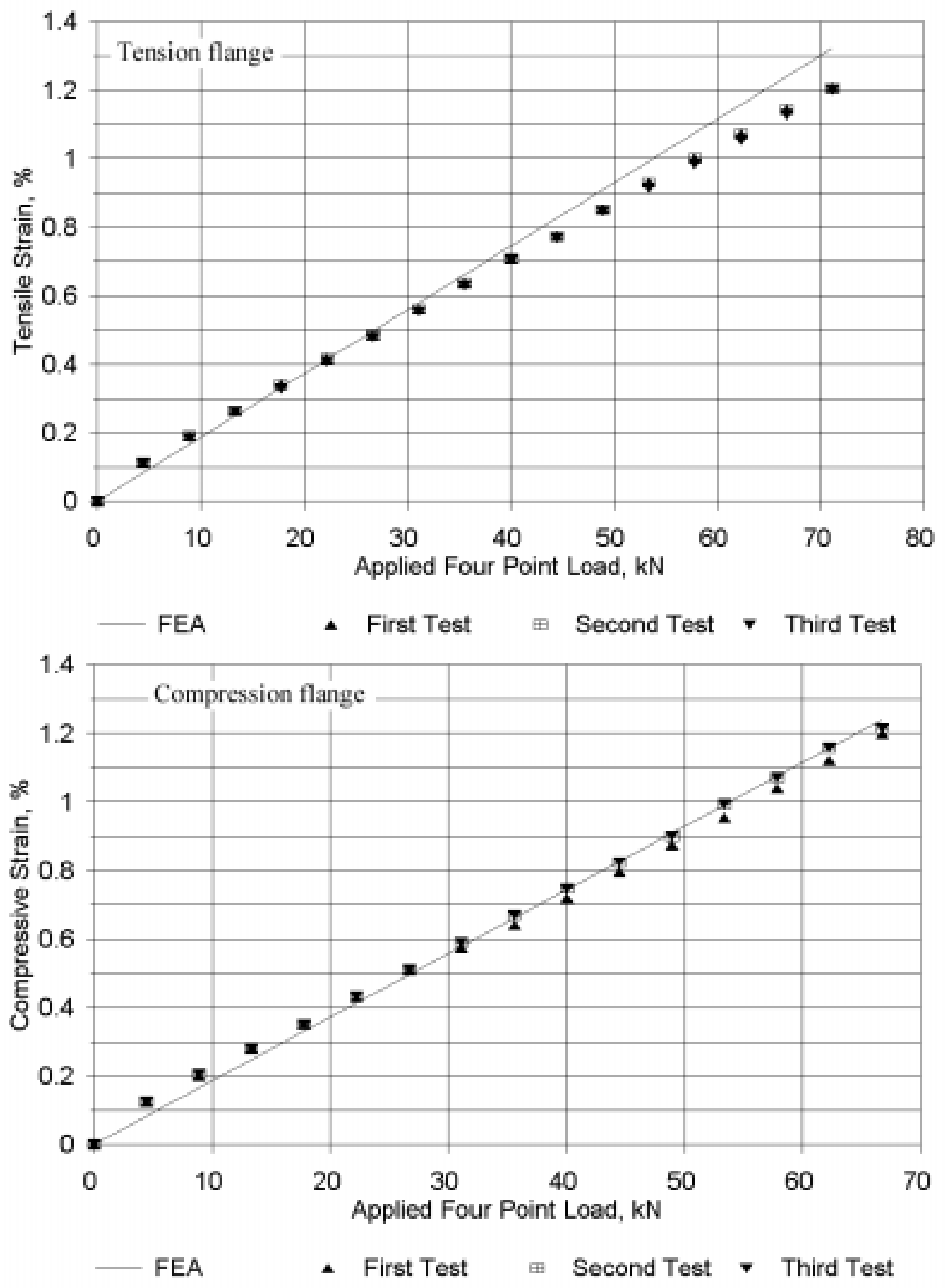

Figure 26. FEA and experimental strain versus load results, beam 5 . 


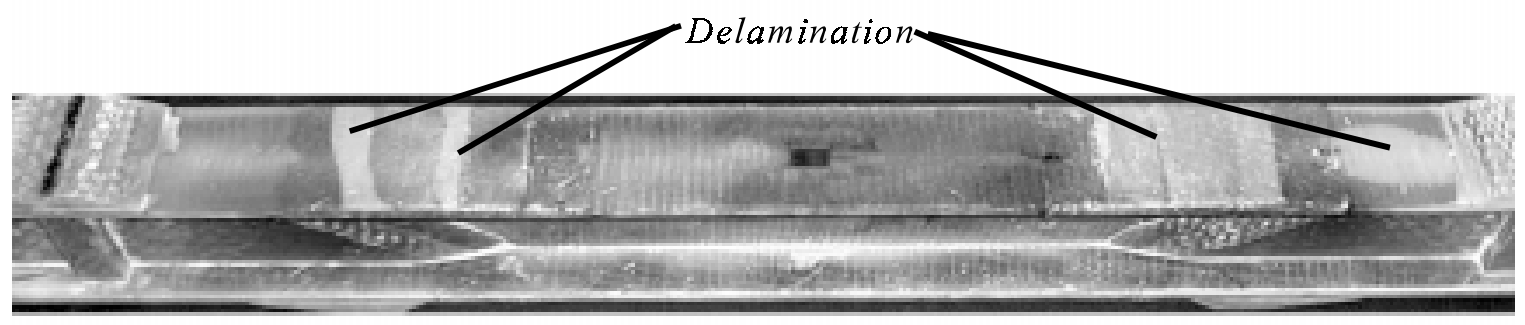

Figure 27. Accumulated damage on inner surface of tension flange, $\pm 45^{\circ}$ plies, 2.26 million cycles, beam 4 .

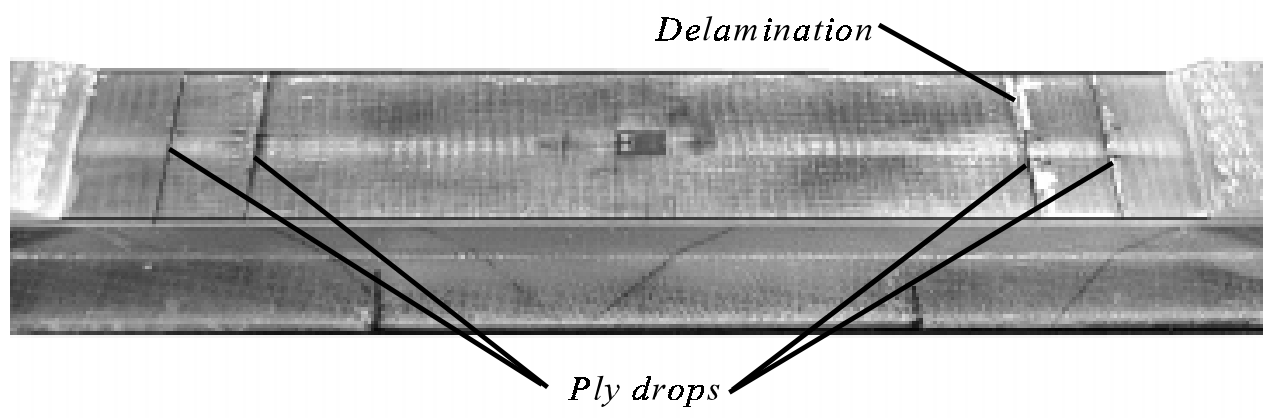

Figure 28. Outer surface of compression flange, 2.26 million cycles, beam 4 . 


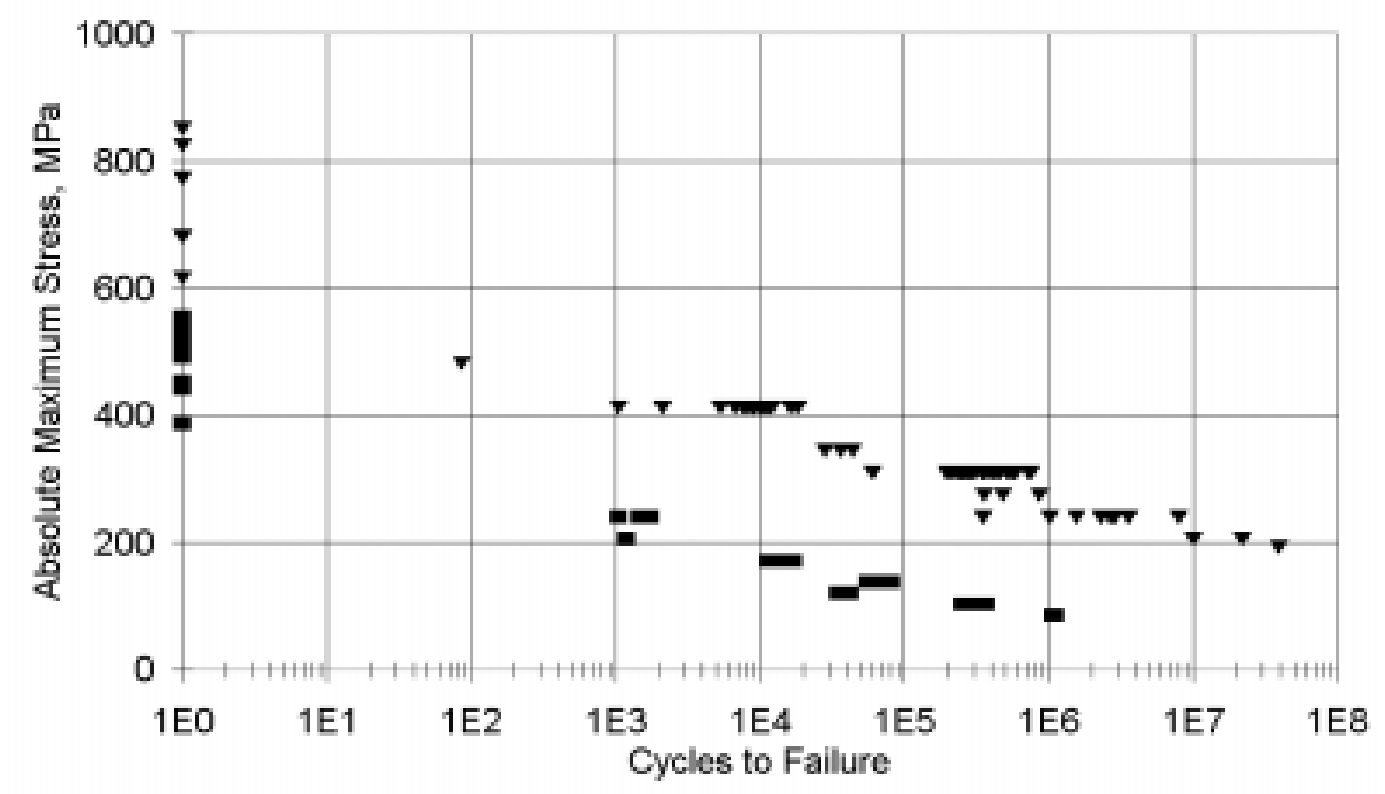

- Material Aa $\mathbf{\text { Material DO5P }}$

Figure 29(a). Fatigue data for materials AA and DD5P, $R=0.1$.

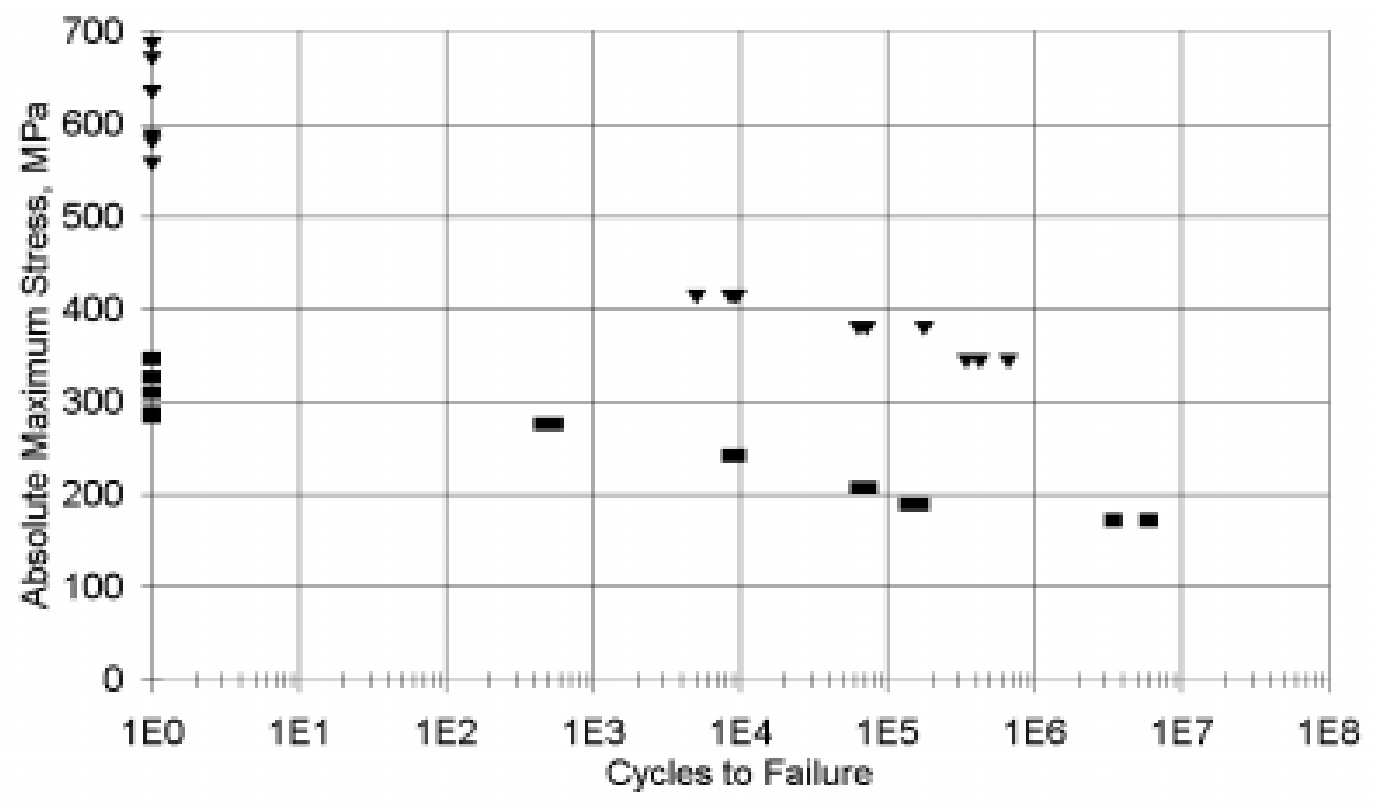

- Material AA - Material DDSP

Figure 29(b). Fatigue data for materials AA and DD5P, $R=10$. 


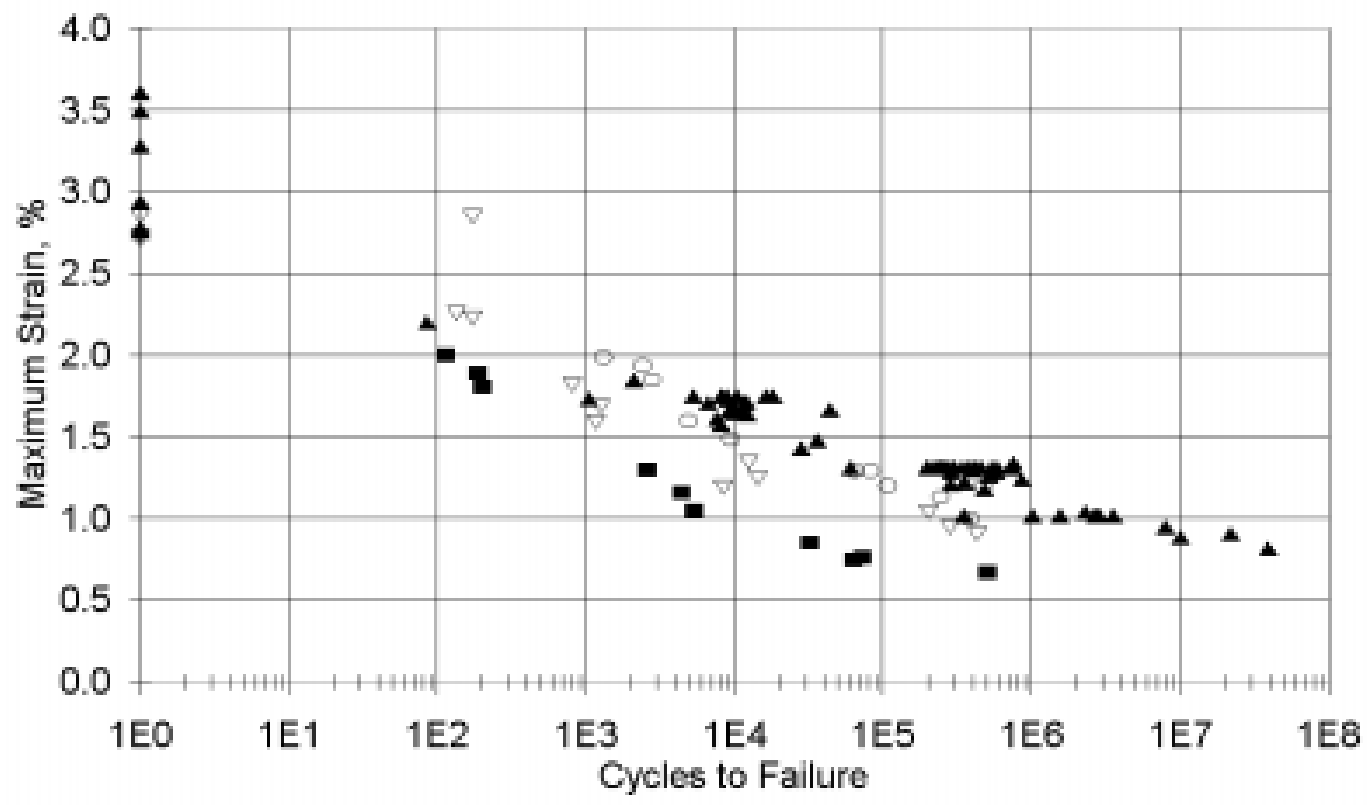

- Material $\mathrm{CH}_{10} \nabla$ Material $\mathrm{CH} 3 \triangleright$ Material $\mathrm{CH} 12 \backsim$ Material DD5P

Figure 30(a). Fatigue data for materials CH3, CH10, CH12 and DD5P, R = 0.1.

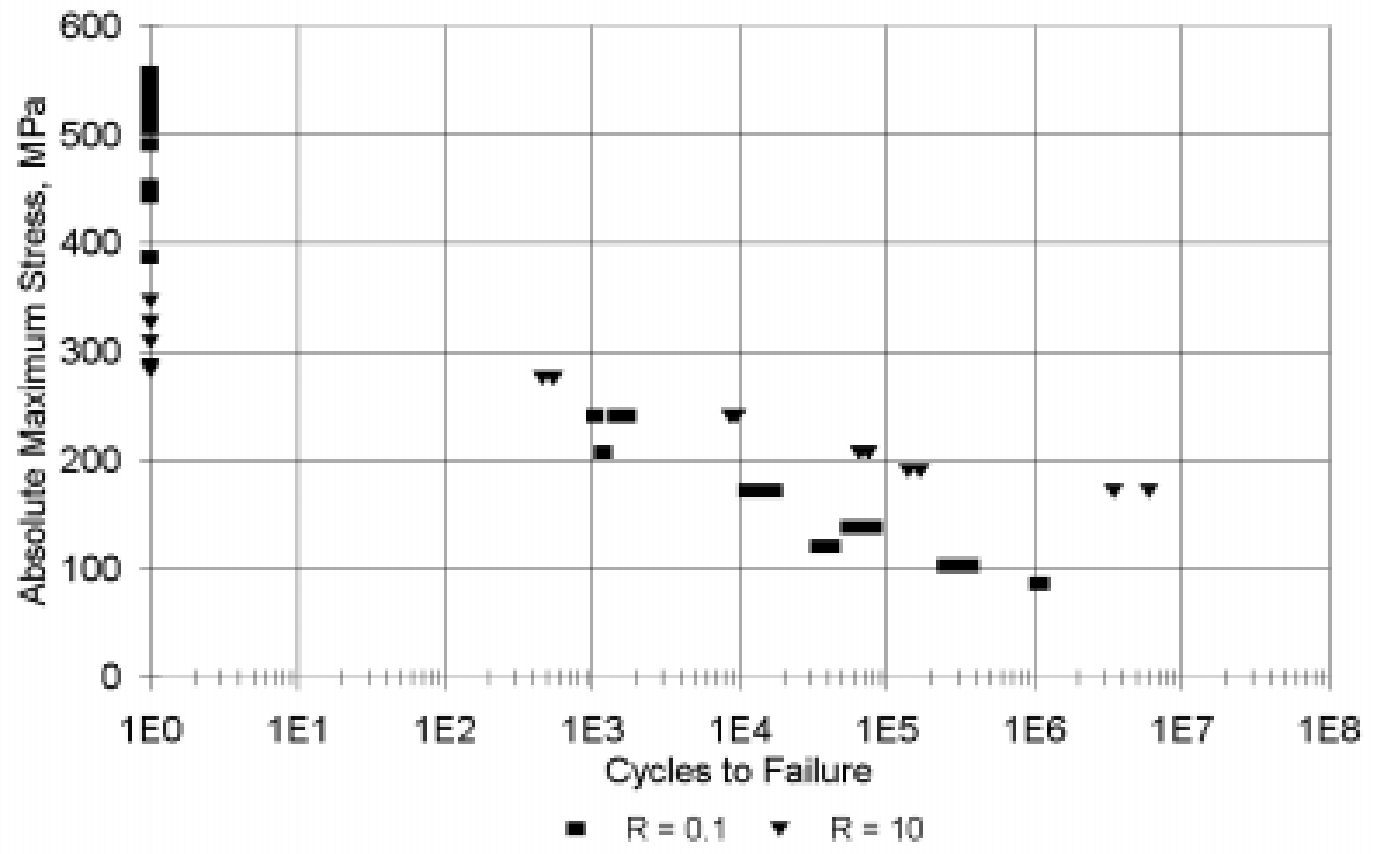

Figure 30(b). Fatigue data for material AA, $R=0.1$ and 10 . 


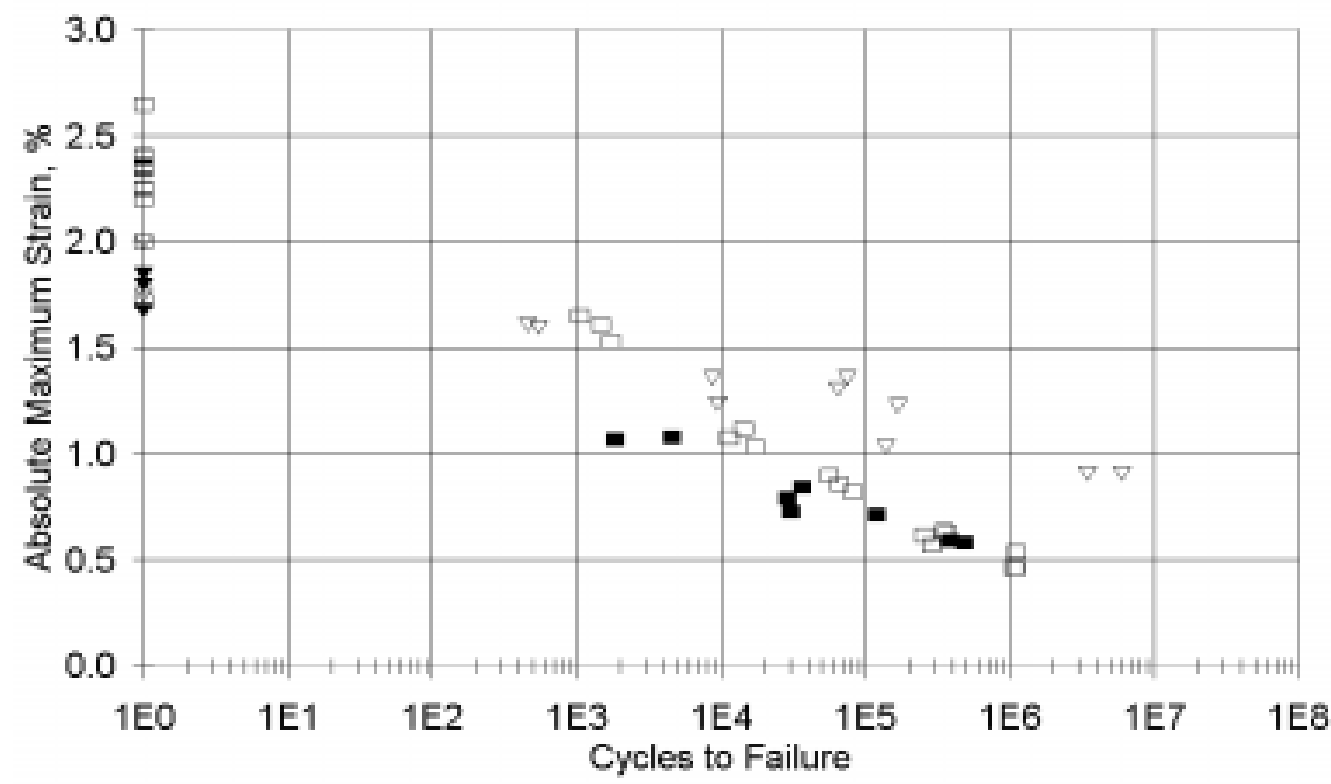

- Material AA Tension Coupons, $\mathrm{R}=0.1 \quad \nabla \quad$ Material AA Compression Coupons, $\mathrm{R}=10$

- Beam Tension Flange Failure $\quad$ Beam Compression Flange Failure

Figure 31(a). Beams $6-14,22$ and 23 with material AA flanges and material CH10 web compared with material AA coupon fatigue data.

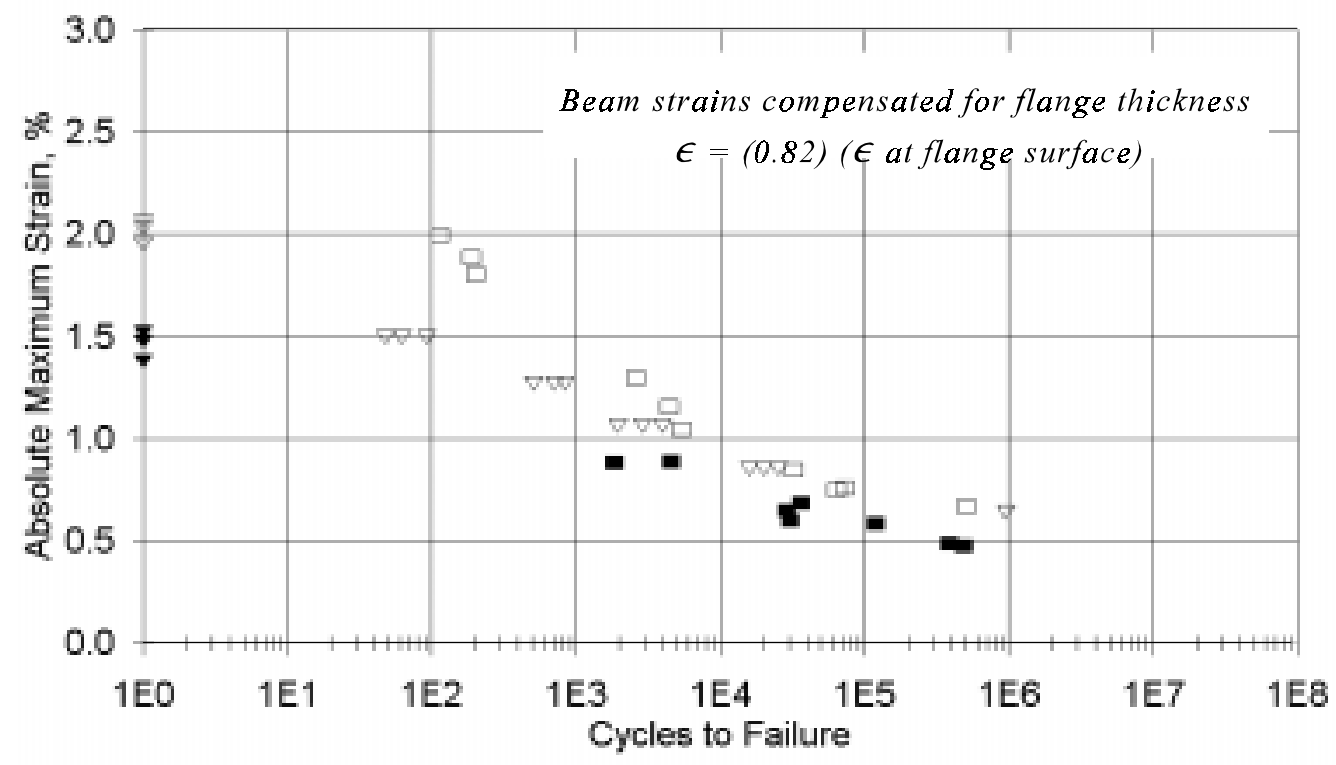

$\begin{array}{lll}\square \text { Material } \mathrm{CH} 10 \text { Tension Coupons, R=0.1 } & \nabla \text { Material CH10 Compression Coupons, R=10 } \\ \text { - Beam Tension Flange Failure } & \text { - Beam Compression Flange Failure }\end{array}$

Figure 31(b). Beams 6 - 14, 22 and 23 with material AA flanges and material CH10 web Compensated for flange thickness compared with material CH10 coupon fatigue data. 

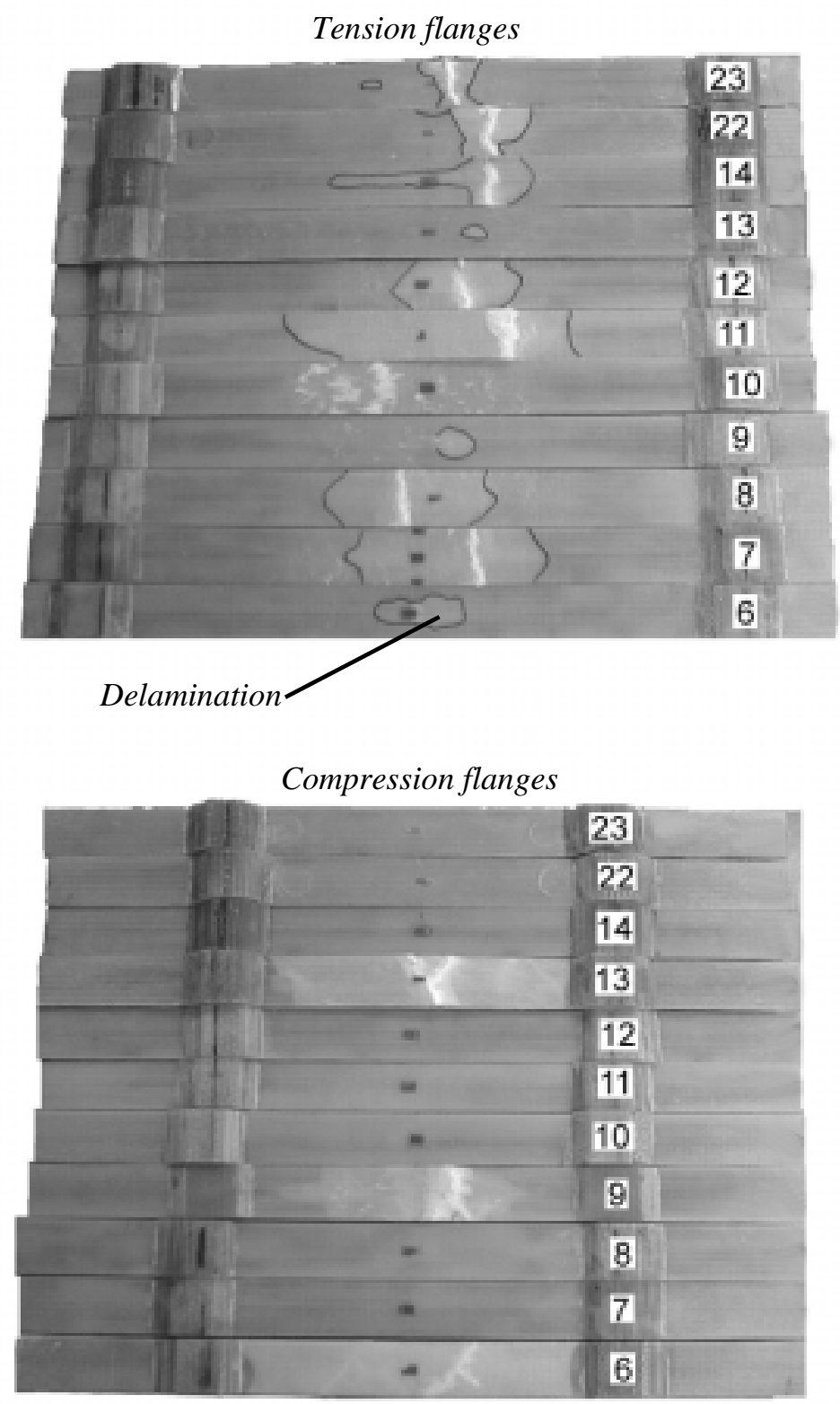

Figure 32. Tensile and compressive flanges of failed beams with material AA flanges and material $\mathrm{CH} 10$ webs. 


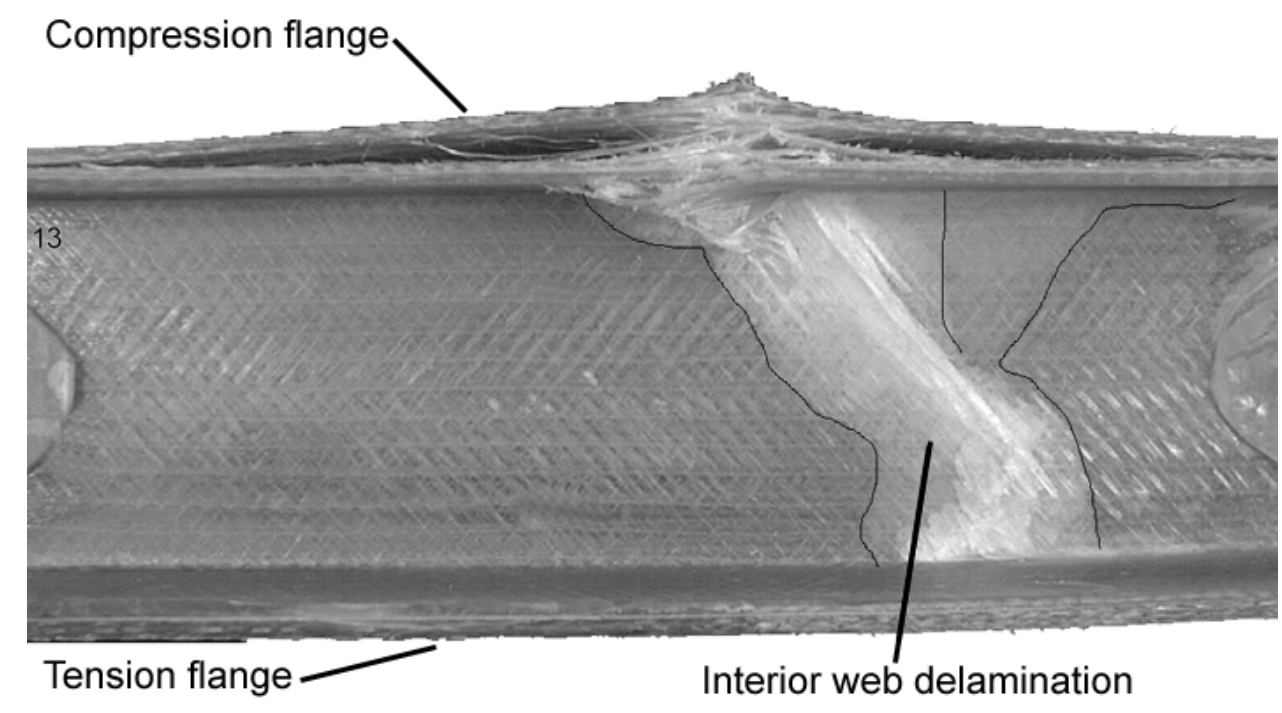

Figure 33(a). Beam 13 static compression flange failure.

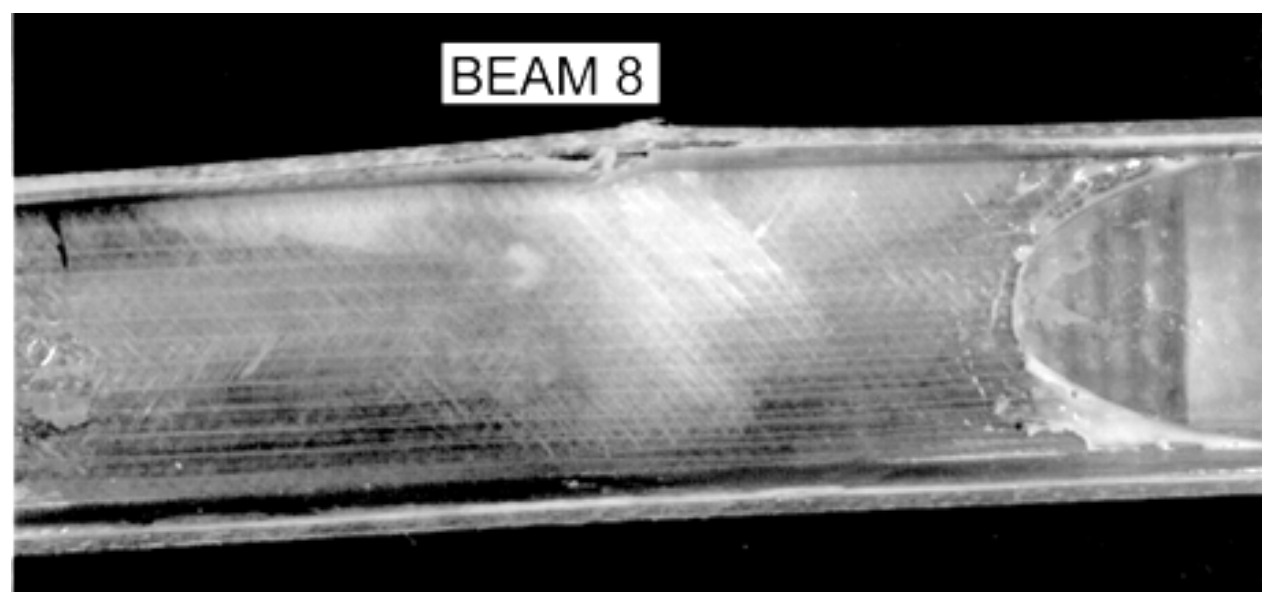

Figure 33(b). Beam 8 tension flange failure. 


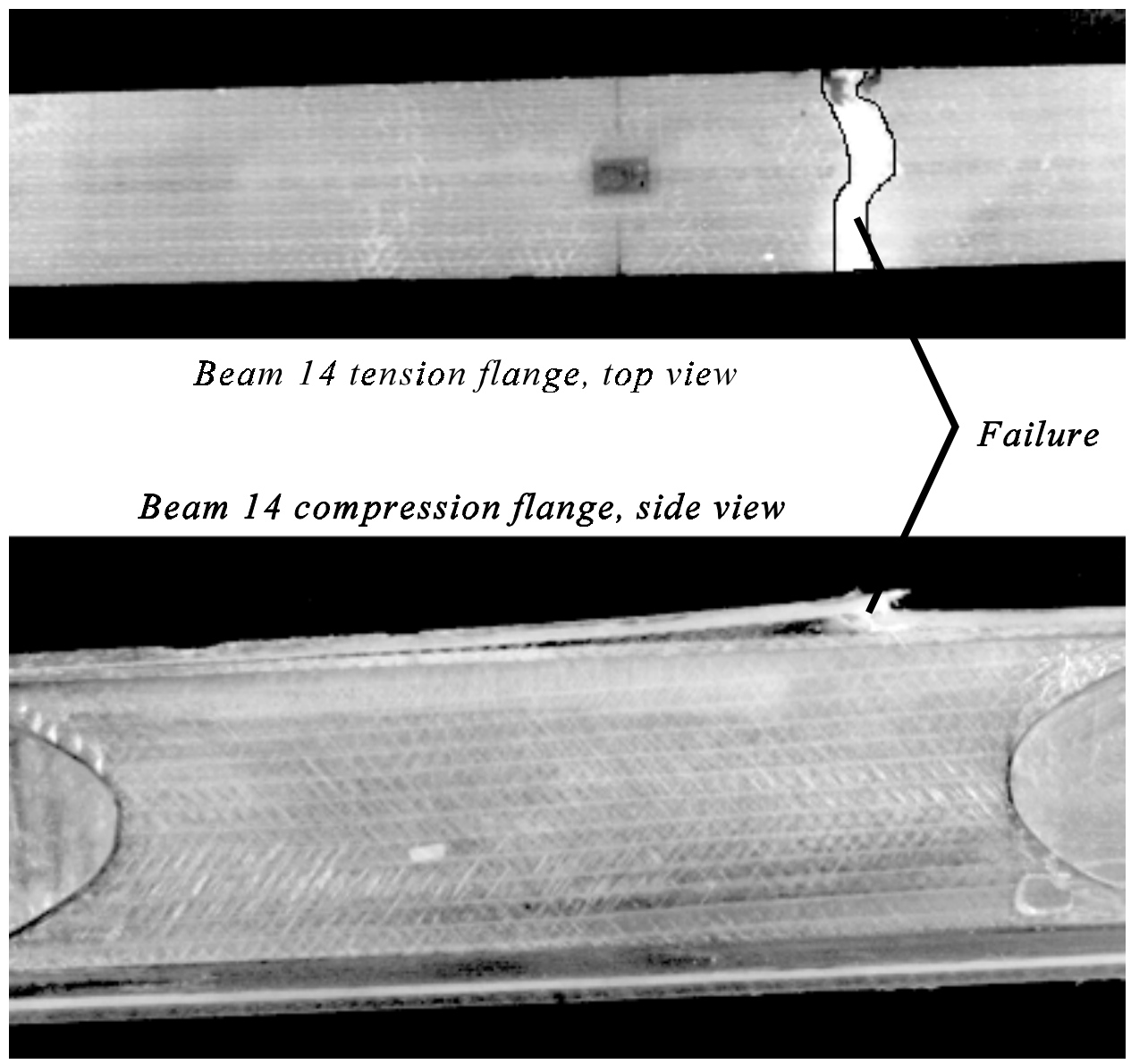

Figure 33(c). Beam 14 tension flange fatigue failure. 


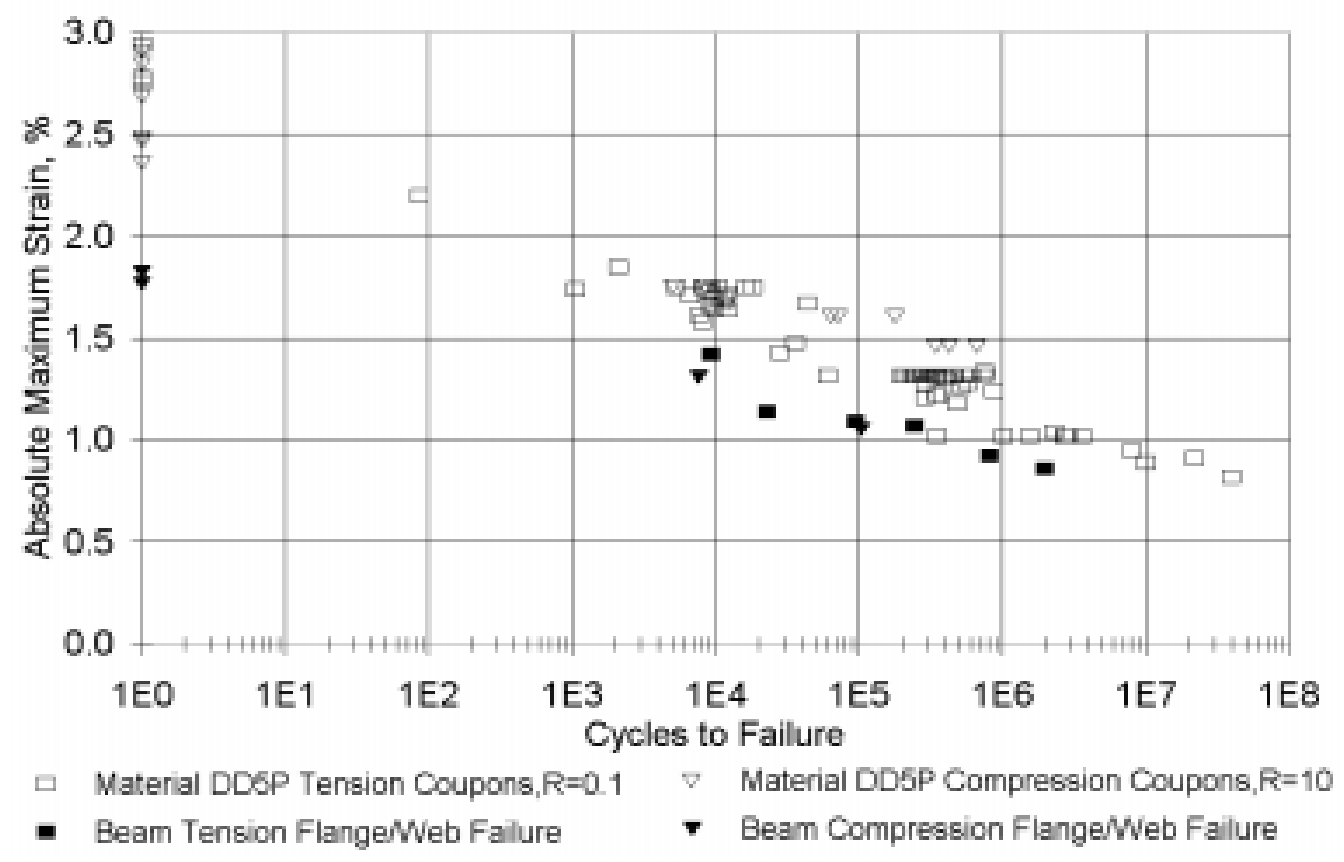

Figure 34. Beams 18 - 21 and 24 - 29 with material DD5P flanges and material CH10 web compared with material DD5P coupon fatigue data.

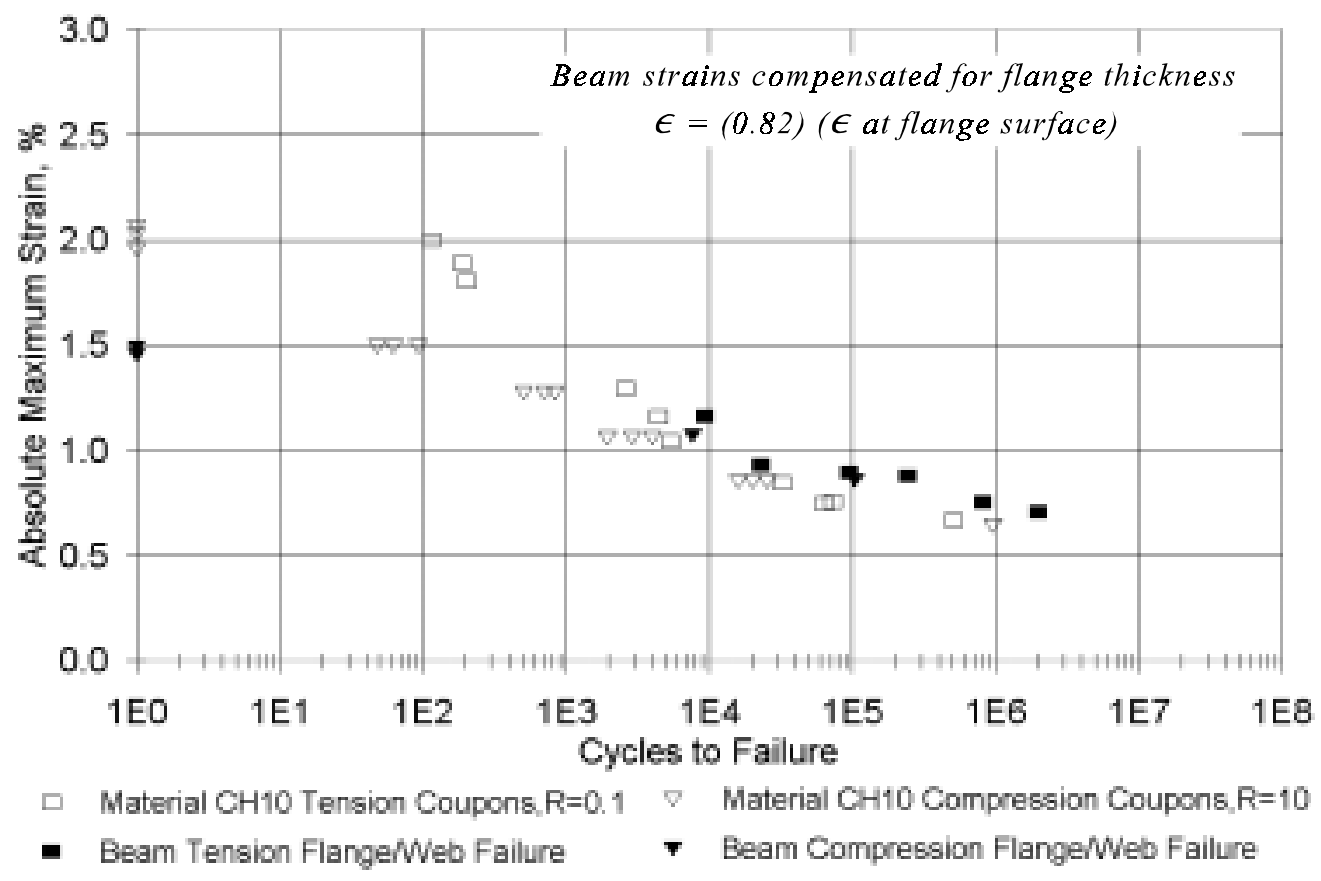

Figure 35. Beams 18 - 21 and 24 - 29 with material DD5P flanges and material CH10 web compensated for flange thickness compared with material CH10 coupon fatigue data. 


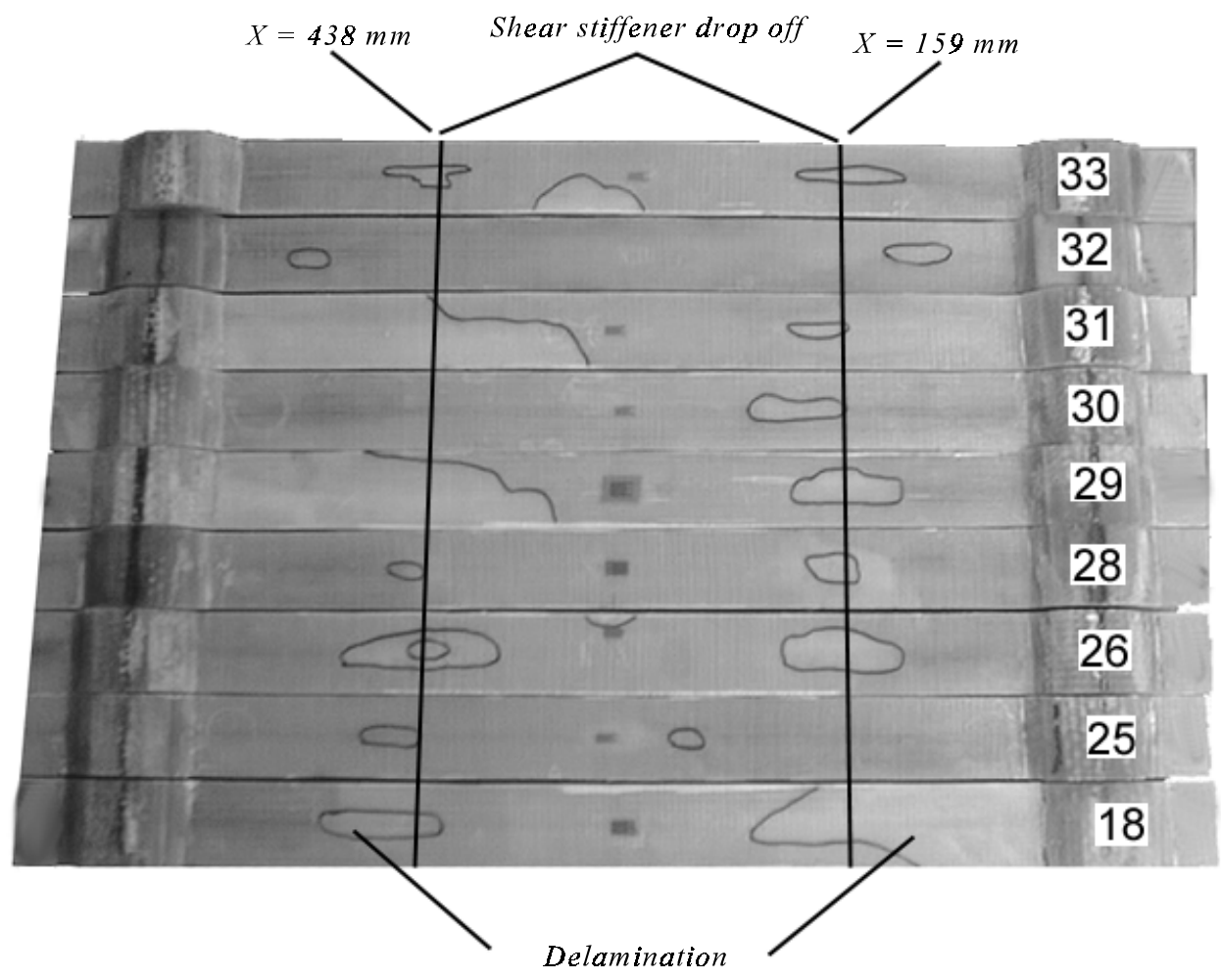

Figure 36. Tension flanges of failed beams with material DD5P flanges and material $\mathrm{CH} 3$ webs. 


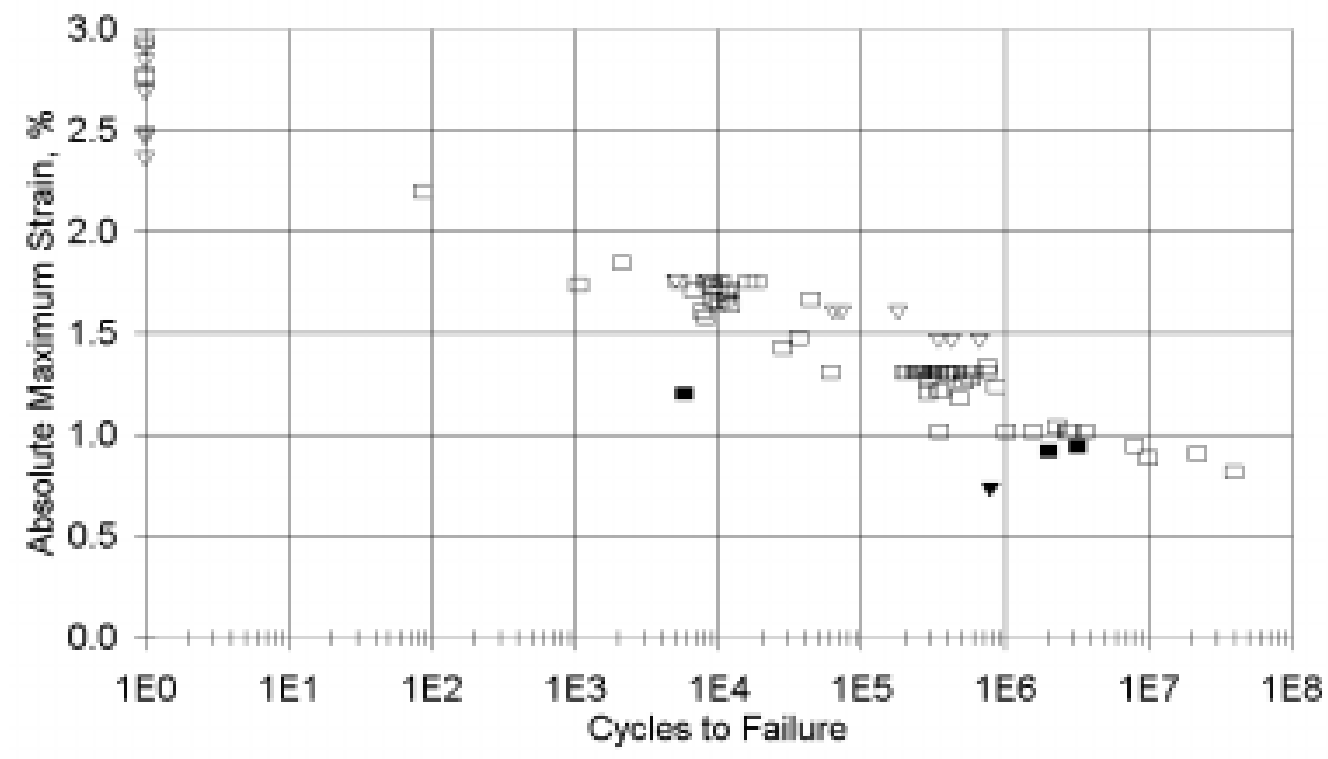

- Material DD5P Tension Coupons, $\mathrm{R}=0.1 \quad \nabla \quad$ Material DD5P Compression Coupons, $\mathrm{R}=10$

- Beam Tension Flange/Web Failure . Beam Compression Flange/Web Failure

Figure 37. Beams 30 - 33 with material DD5P flanges and material $\mathrm{CH3}$ web compared with DD5P coupon fatigue data.

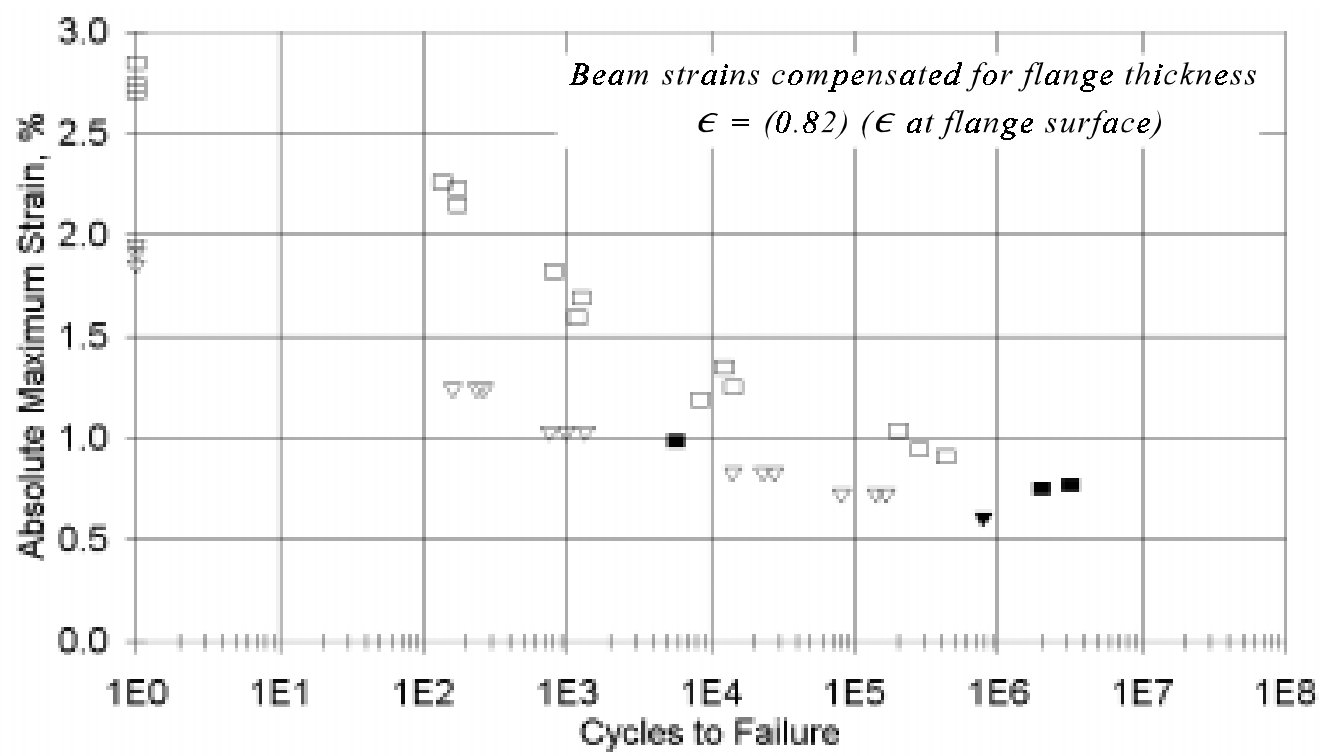

- Material $\mathrm{CH} 3$ Tension Coupons, $\mathrm{R}=0.1 \quad \nabla$ Material $\mathrm{CH} 3$ Compression Coupons, $\mathrm{R}=10$

- Beam Tension FlangeWeb Failure - Beam Compression Flange $W_{\text {- }}$ - Failure

Figure 38. Beams 30 - 33 with material DD5P flanges and material CH3 web compensated for flange thickness compared with $\mathrm{CH3}$ coupon fatigue data. 


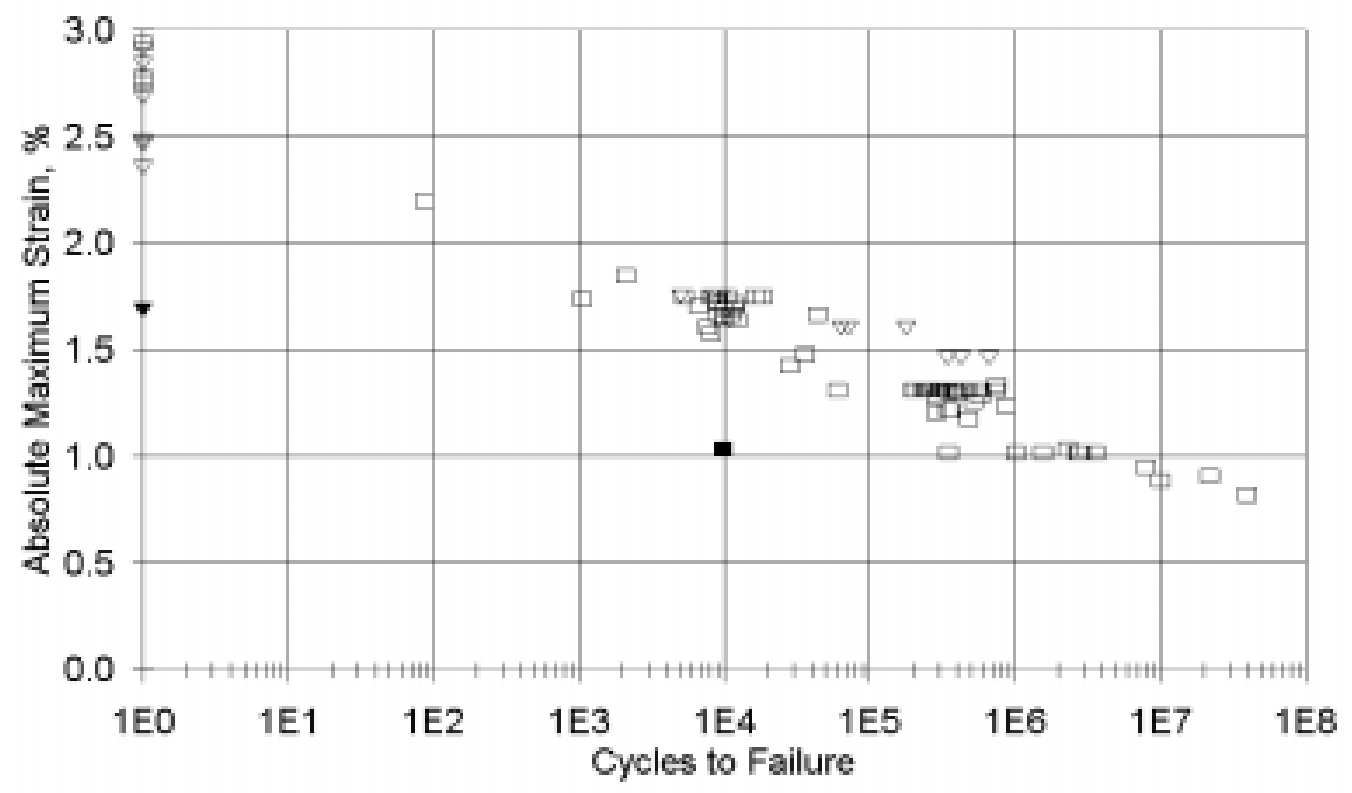

$\square$ Material DD6P Tension Coupons, $R=0.1 \quad \nabla \quad$ Material DO5P Compression Coupons, $R=10$

- Beam Tension FlangerWeb Failure - Beam Compression FlangeNWeb Failure

Figure 39. Beams 34 and 35 with material DD5P flanges and material CH12 web compared with material DD5P coupon fatigue data.

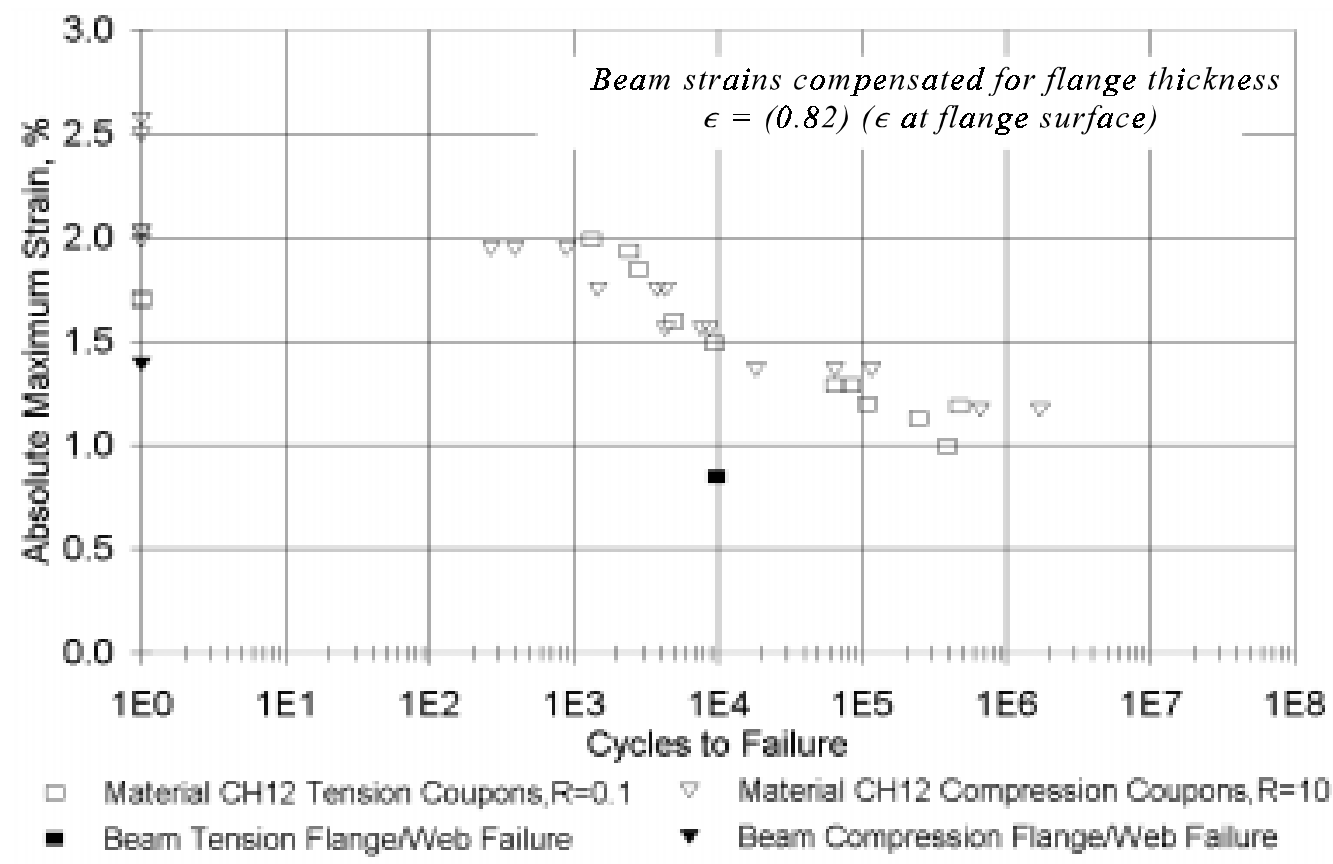

Figure 40. Beams 34 and 35 with material DD5P flanges and material CH12 web compensated for flange thickness compared with material $\mathrm{CH12}$ coupon fatigue data. 


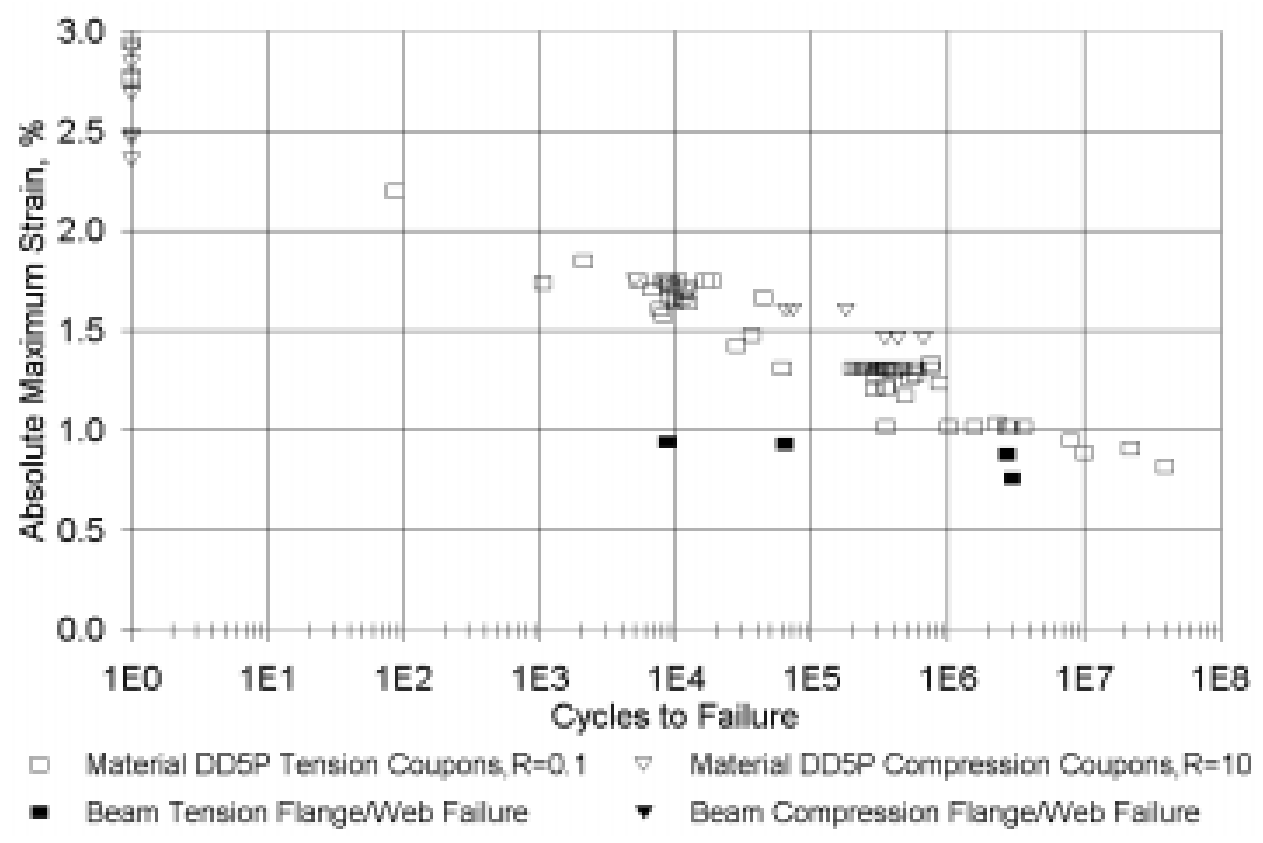

Figure 41(a). Beams 51 - 54 with material DD5P flanges and web compared with material DD5P coupon fatigue data.
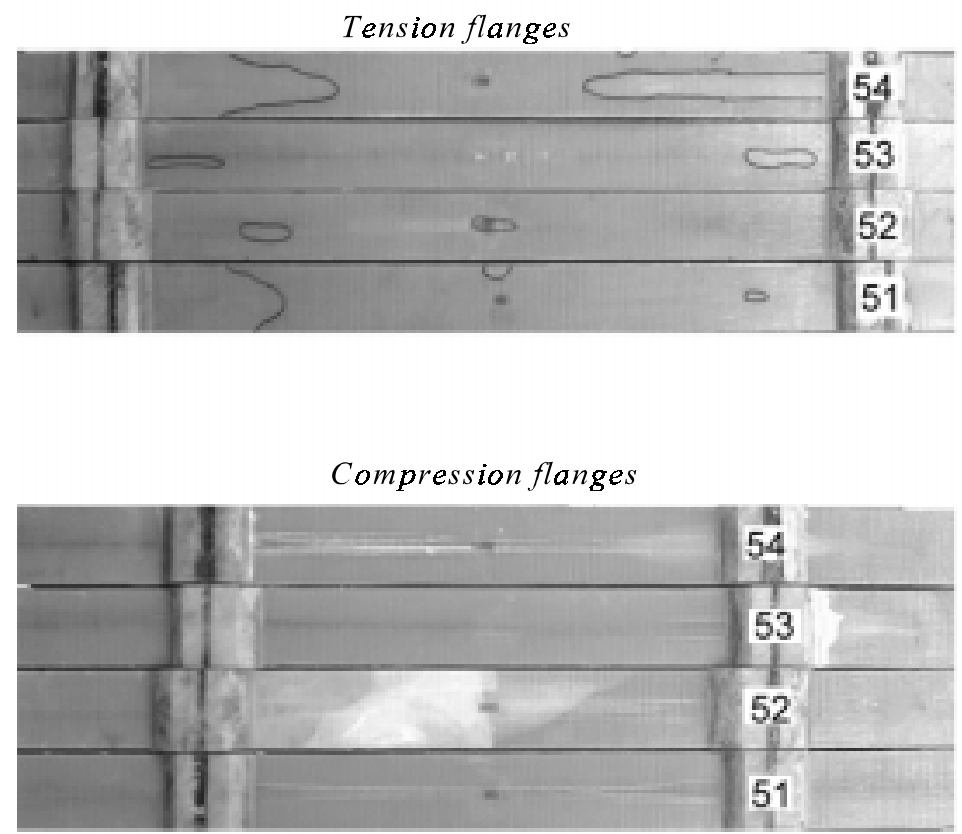

Figure 41(b). Tension and compression flanges of failed beams with material DD5P flanges and webs. 


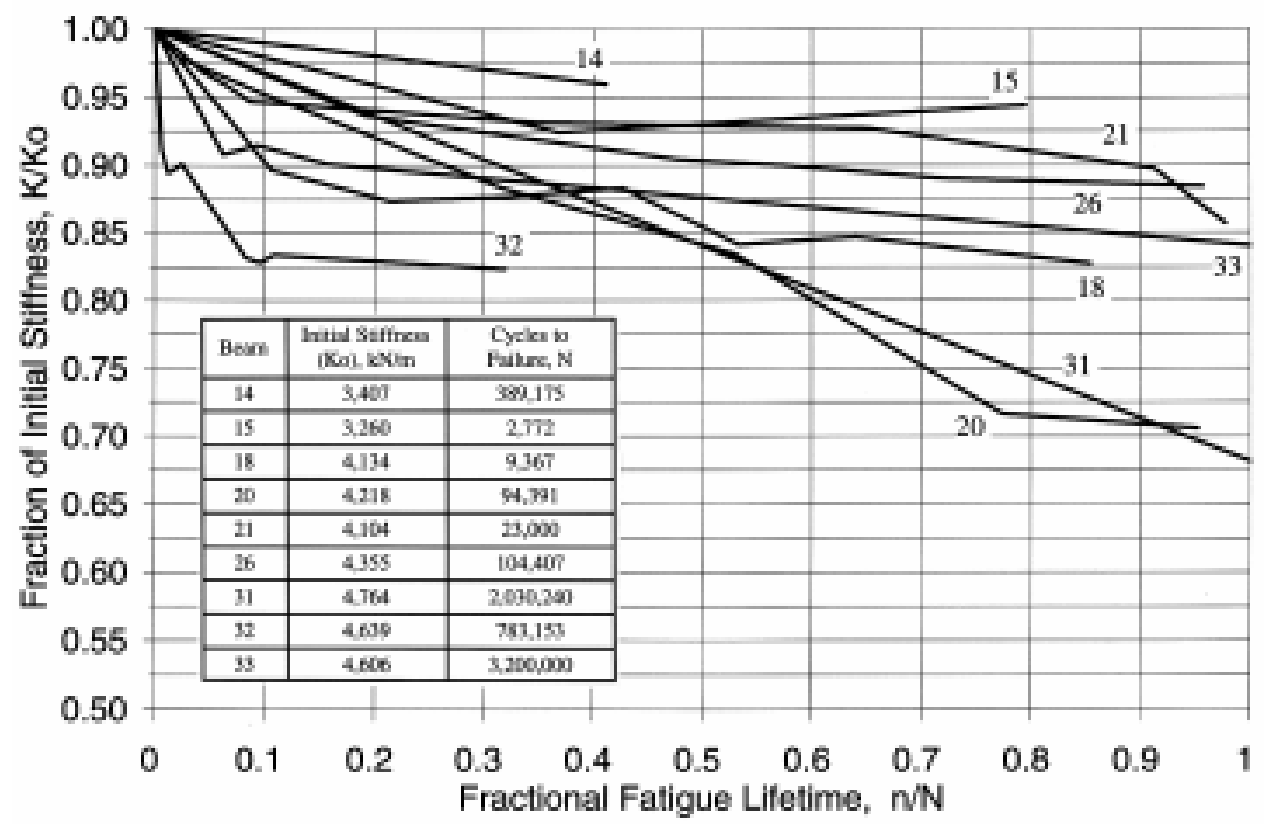

Figure 42. Beam stiffness versus lifetime.

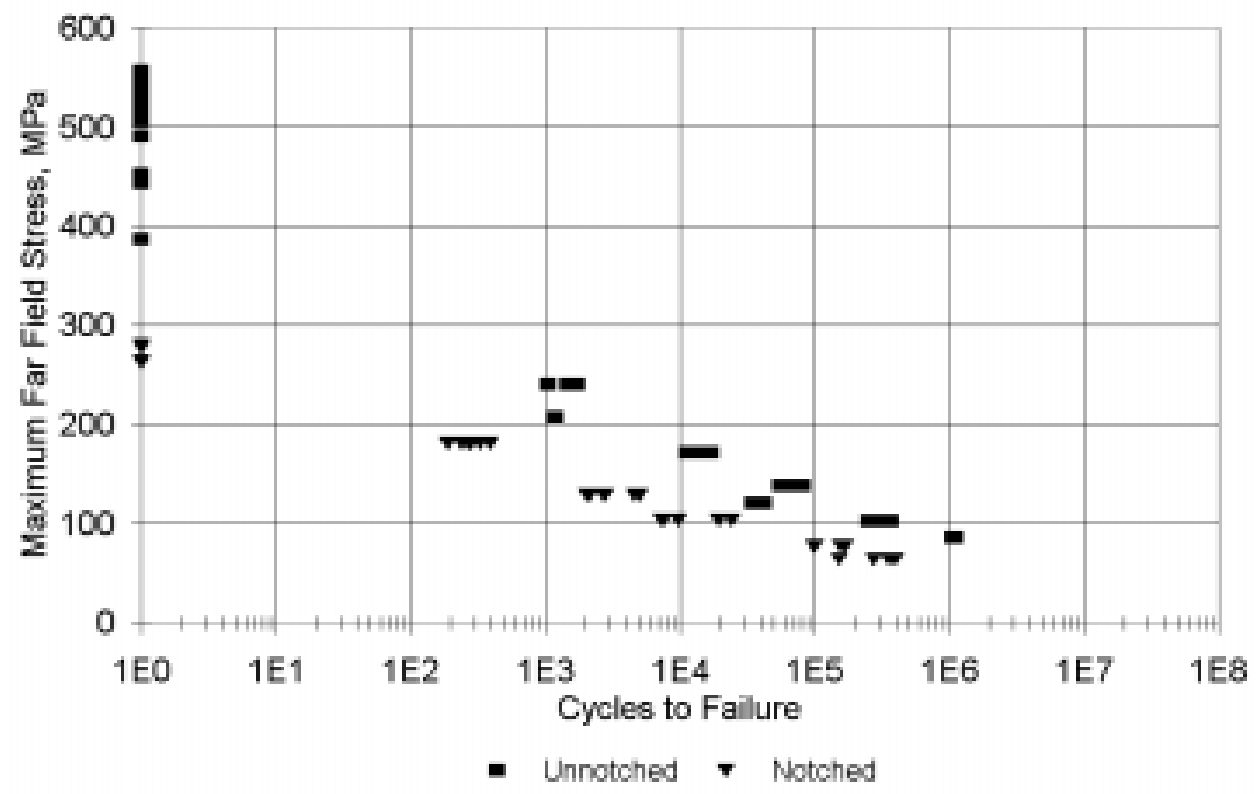

Figure 43(a). Tensile fatigue data for material AA coupons with and without a $13 \mathrm{~mm}$ diameter hole, $R=0.1$. 


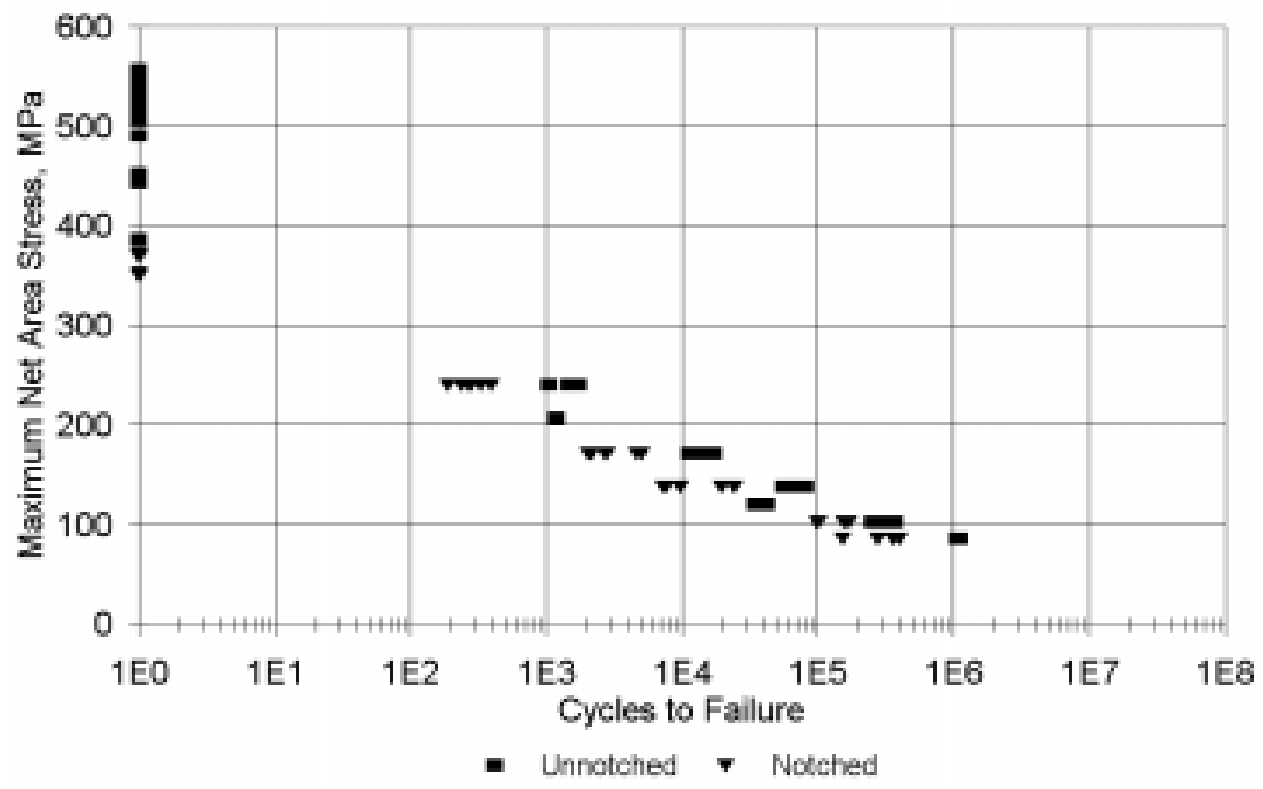

Figure 43(b). Tensile fatigue data for material AA coupons with and without a $13 \mathrm{~mm}$ diameter hole, $R=0.1$.

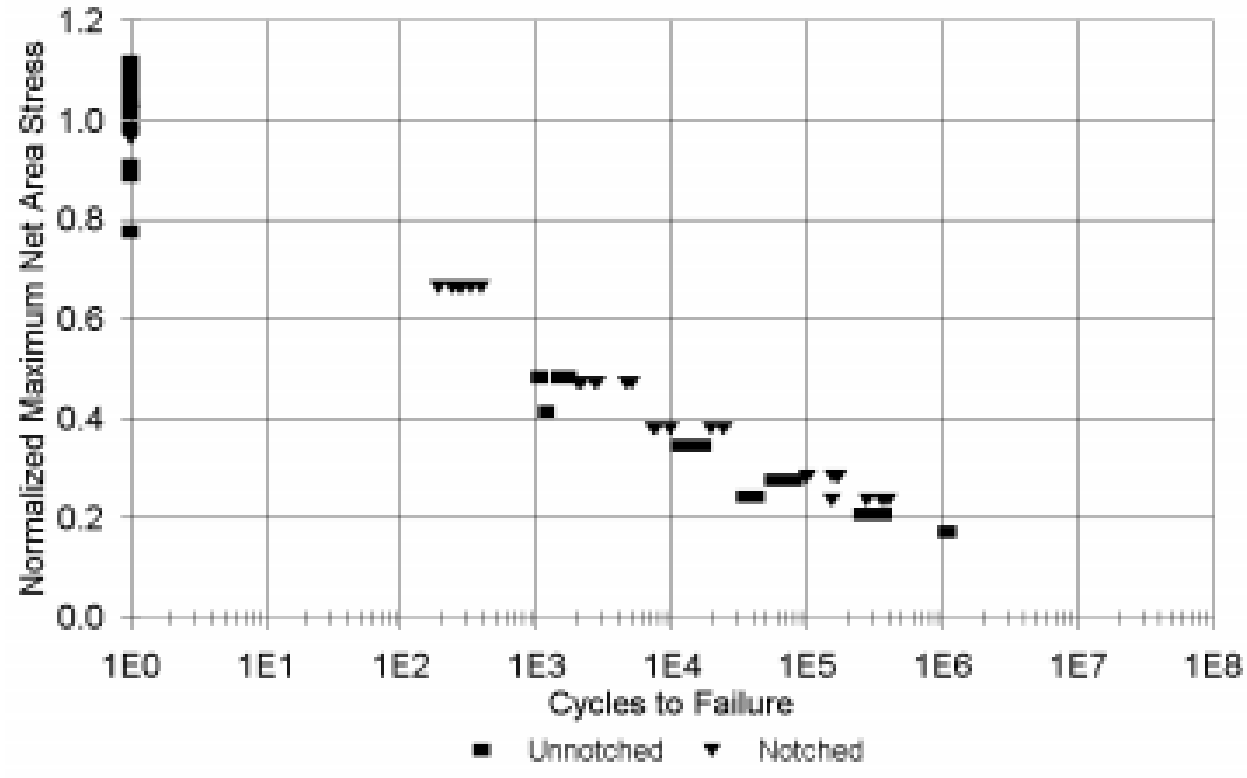

Figure 43(c). Normalized tensile fatigue data for material AA coupons with and without a $13 \mathrm{~mm}$ diameter hole, $R=0.1$. 


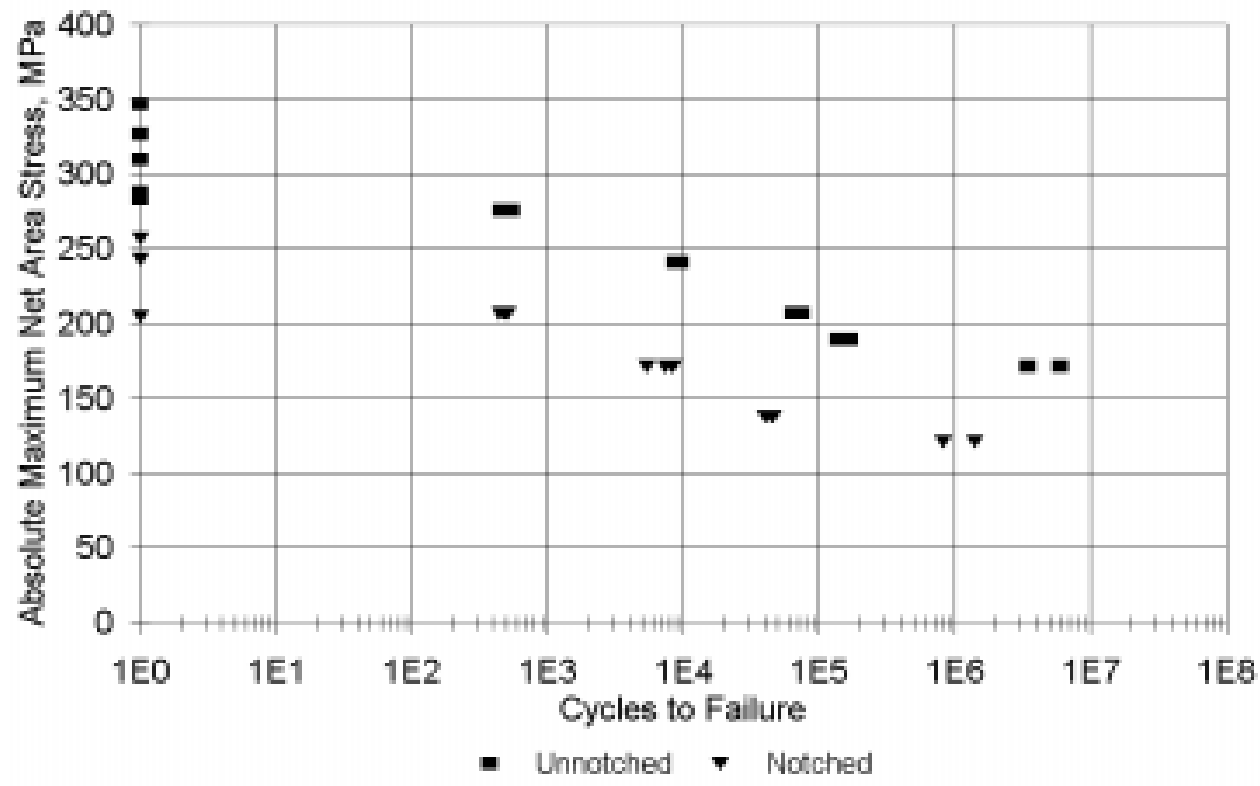

Figure 43(d). Compressive fatigue data for material AA coupons with and without a $13 \mathrm{~mm}$ diameter hole, $R=10$.

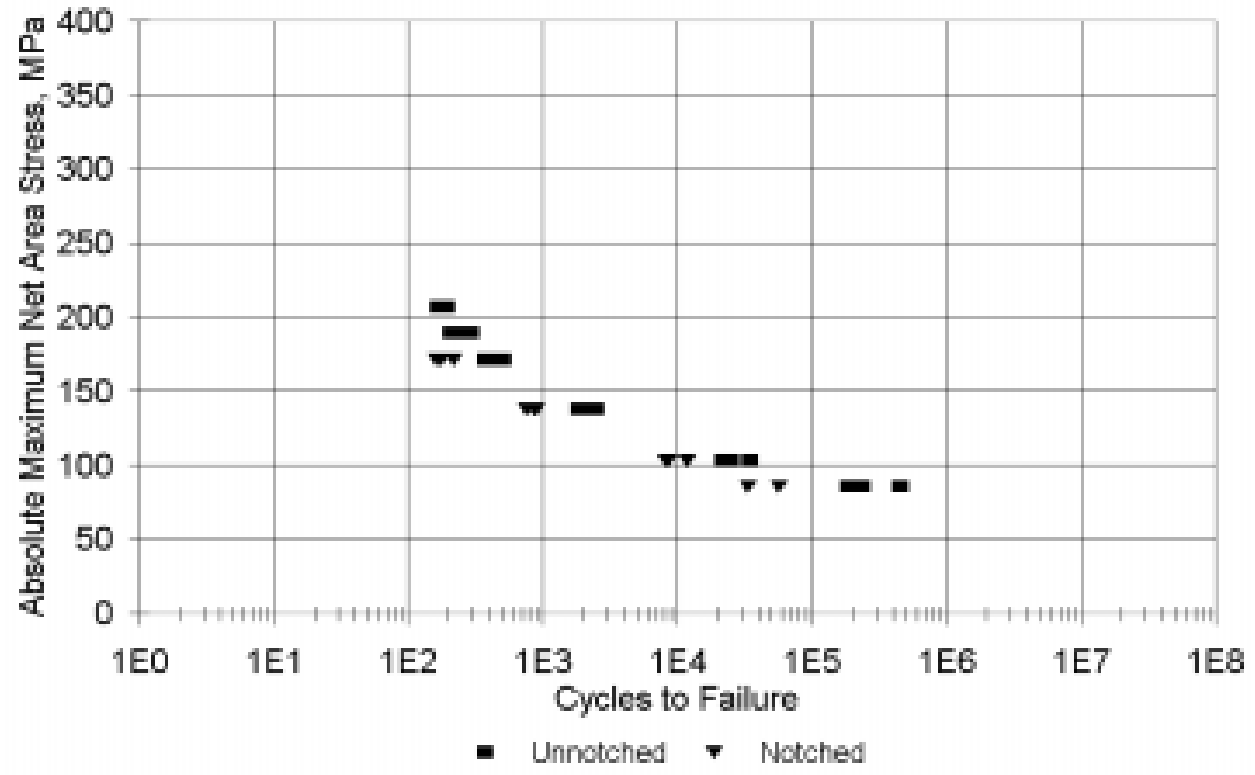

Figure 43(e). Fatigue data for material AA coupons with and without a $13 \mathrm{~mm}$ diameter hole, $R=-1$. 


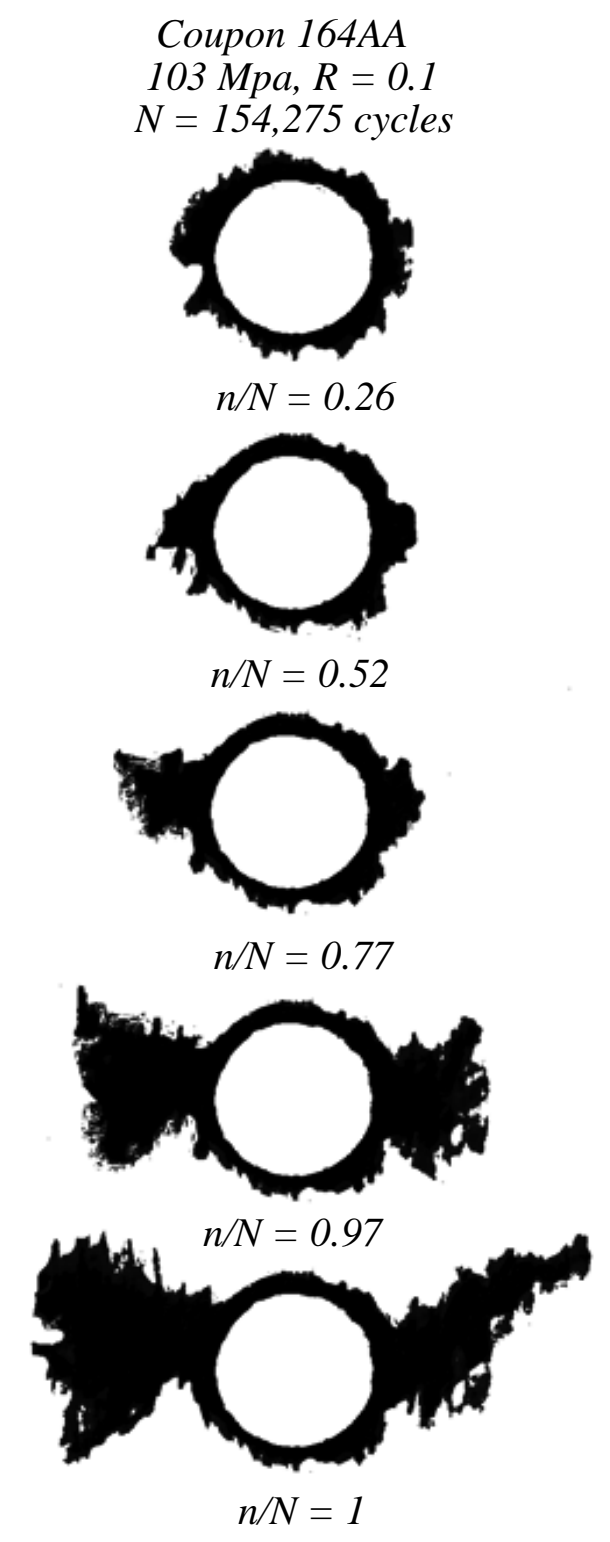

Figure 44. Damage around the $13 \mathrm{~mm}$ diameter hole vs. fatigue lifetime. 


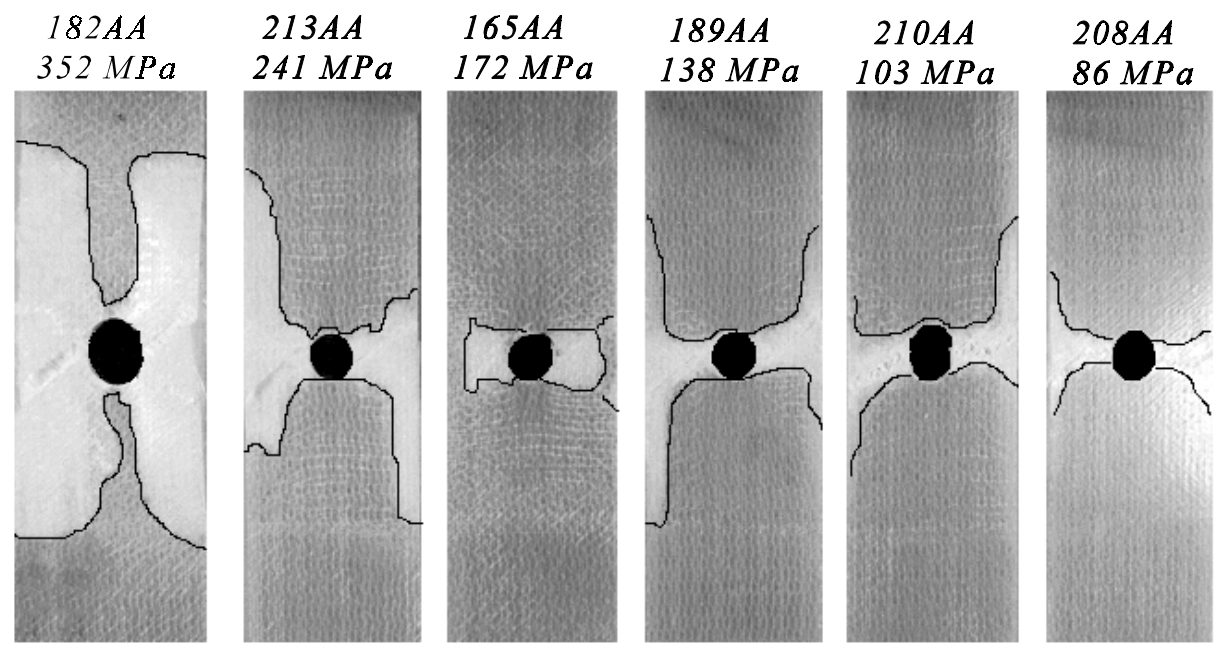

Figure 45. Photograph of damage around the $13 \mathrm{~mm}$ diameter hole at different stress levels, $R=0.1$.

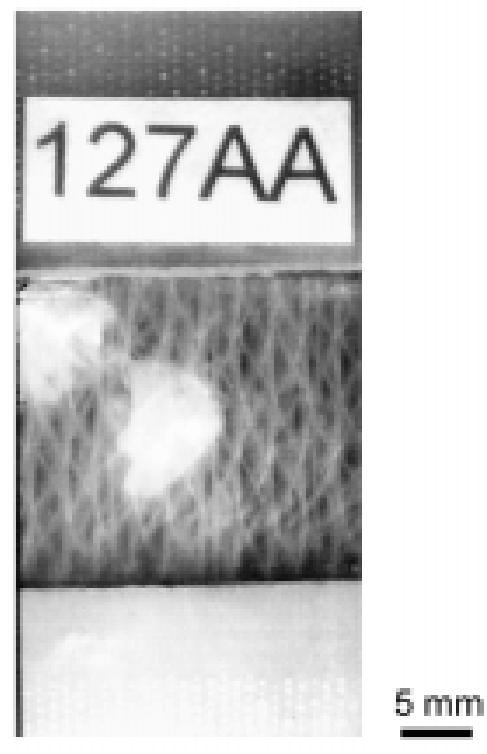

Figure 46. Delamination on a compression fatigue coupon. 


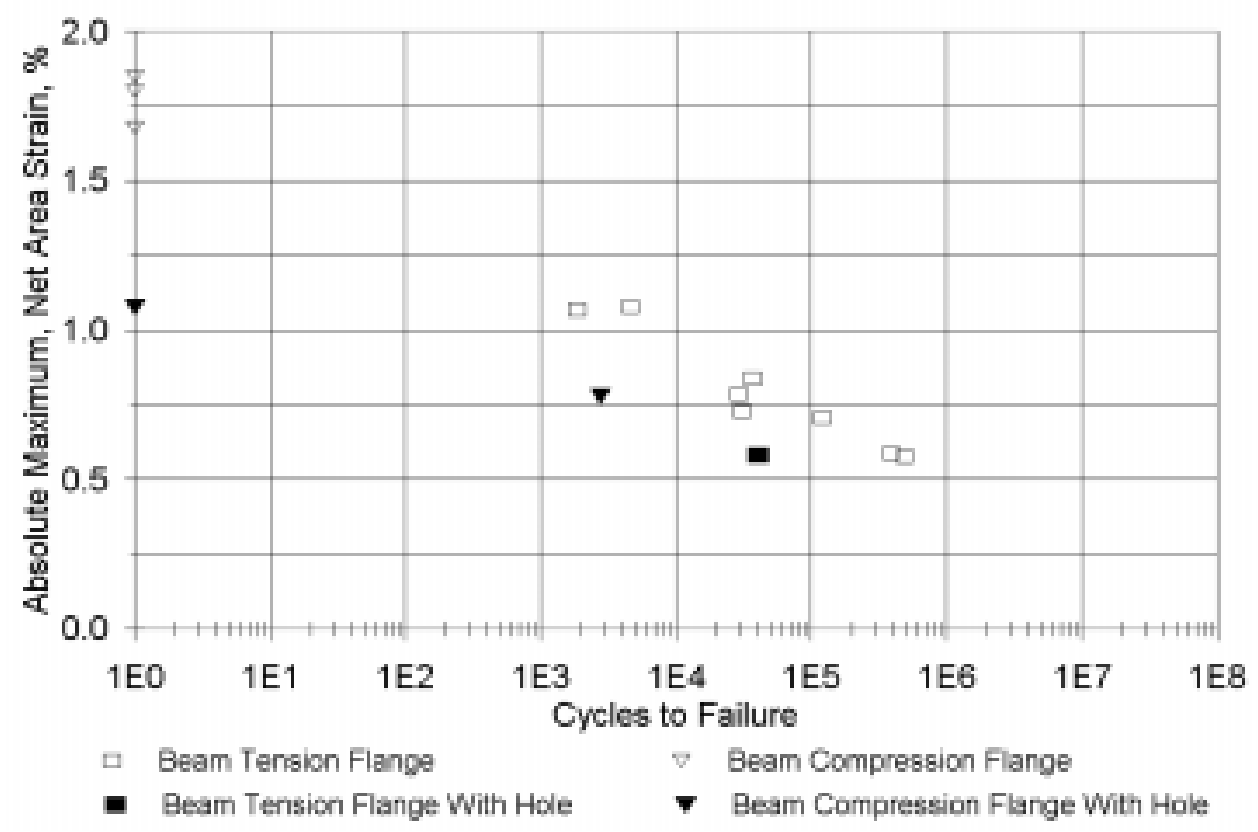

Figure 47(a). Comparison of AA material flange beams without holes to AA beams with $13 \mathrm{~mm}$ diameter holes in the flanges.

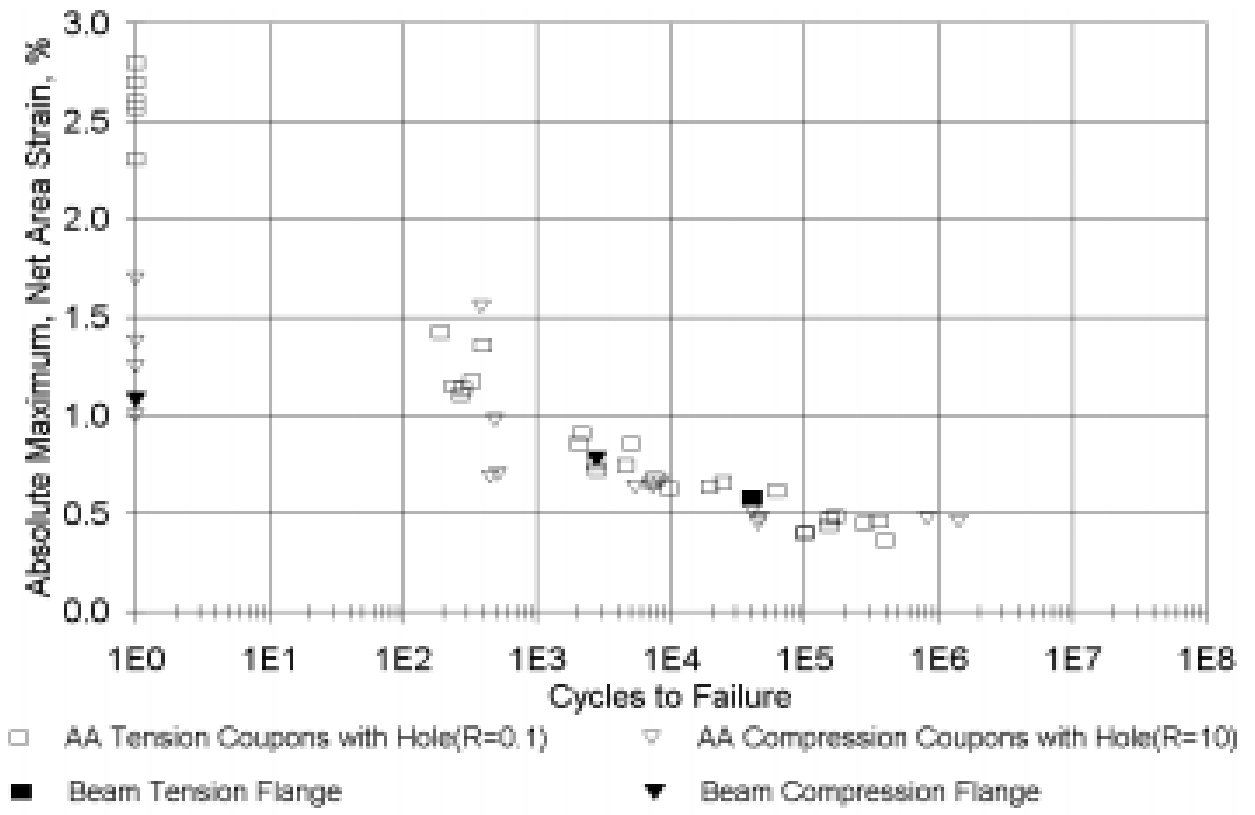

Figure 47(b). Comparison of AA material flange beams with holes to AA material coupons with $13 \mathrm{~mm}$ diameter holes. 
Beam 15 Compression flange

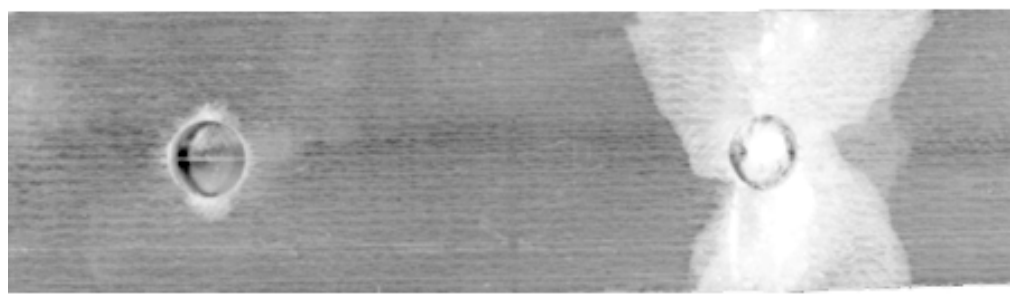

Beam 15 side view

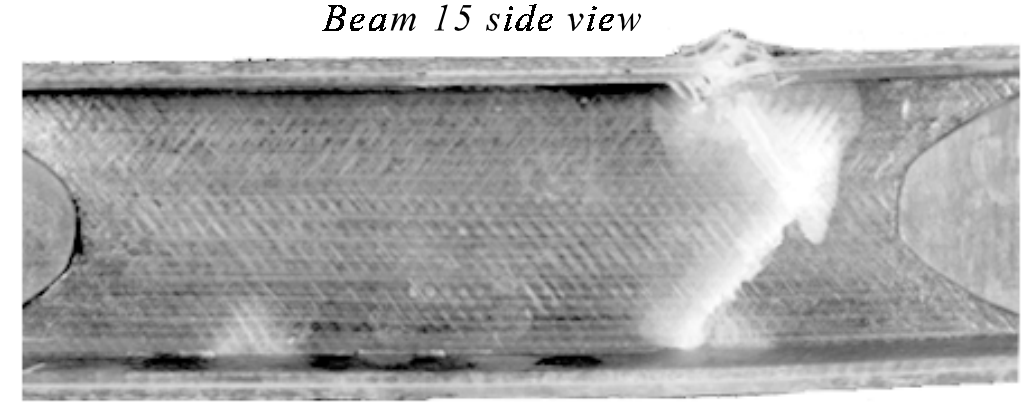

Figure 48. Beam 15 with holes, static compression flange failure.

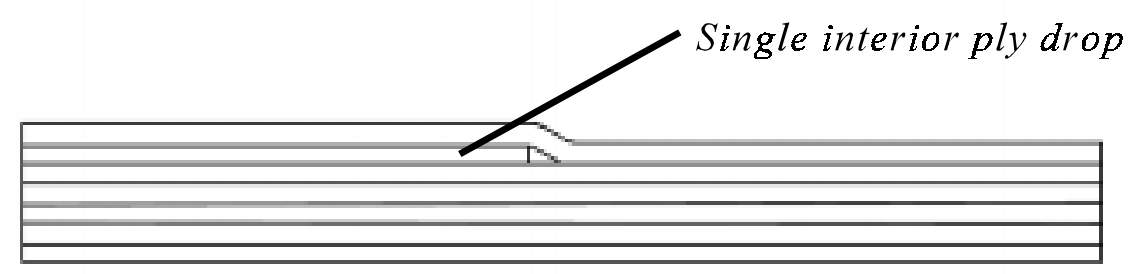

Figure 49. ESB Laminate. 


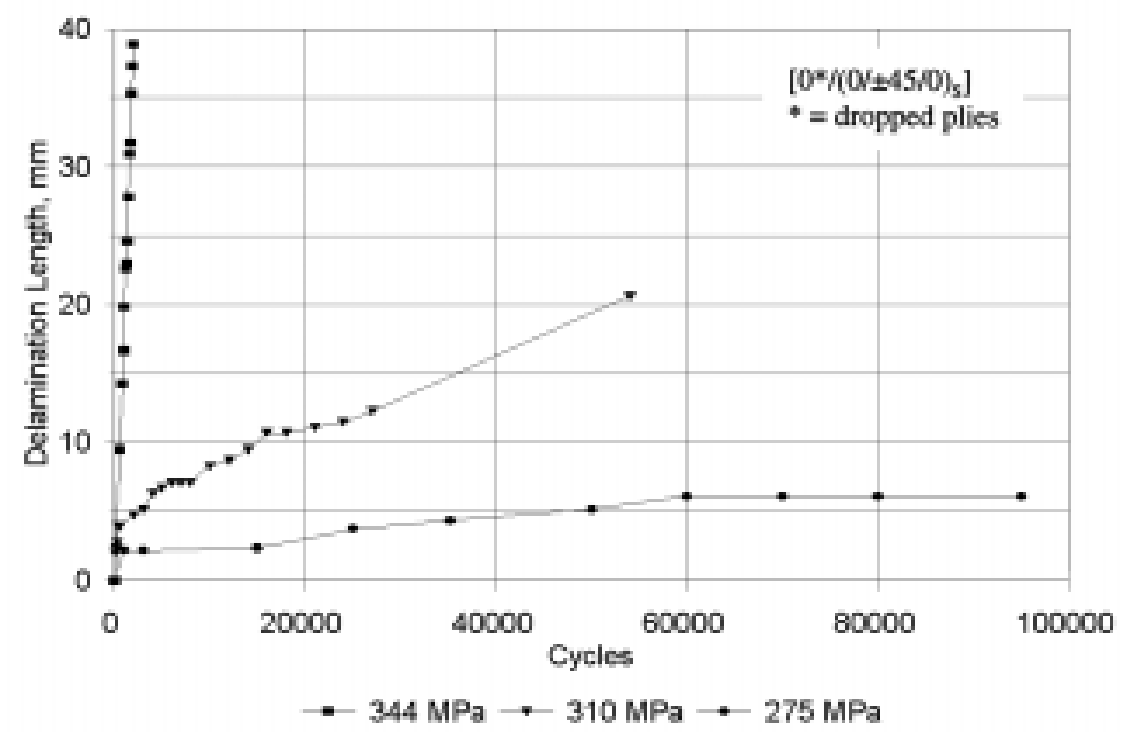

Figure 50. Delamination length vs. cycles for ESA (single exterior $0^{\circ}$ ply drop) laminate, $\mathbf{R}=\mathbf{0 . 1}$.

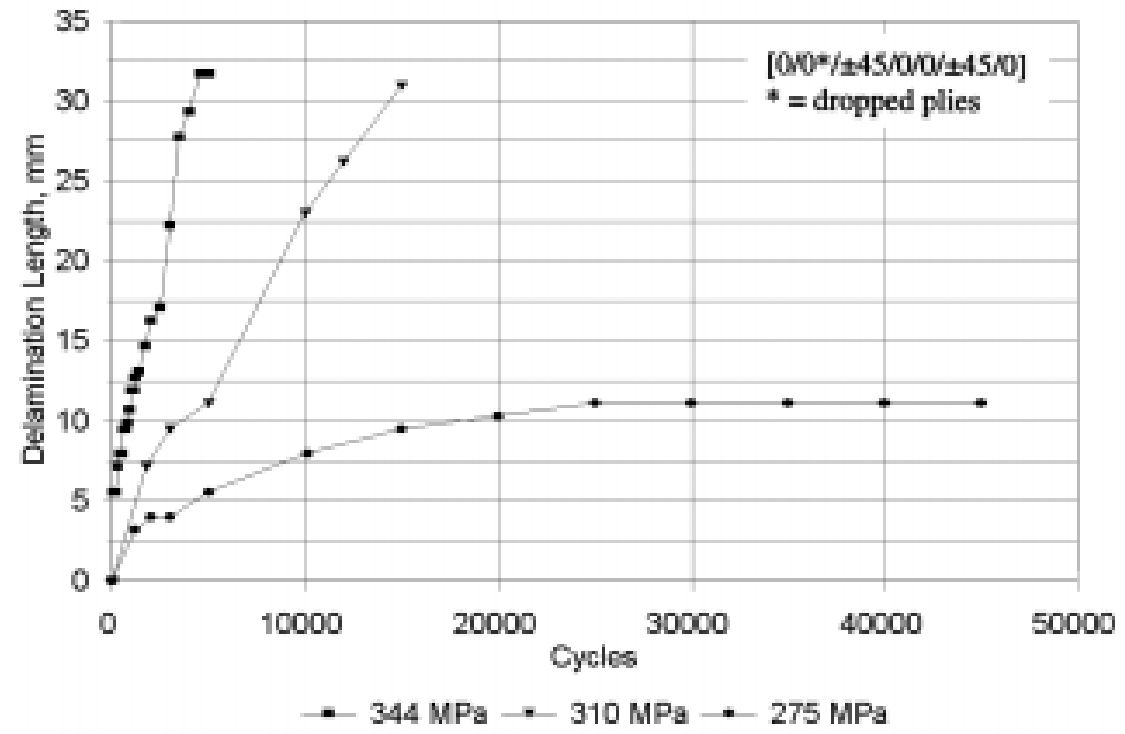

Figure 51. Delamination length vs. cycles for ESB (single interior $0^{\circ}$ ply drop) laminate, $\mathbf{R}=\mathbf{0 . 1}$. 


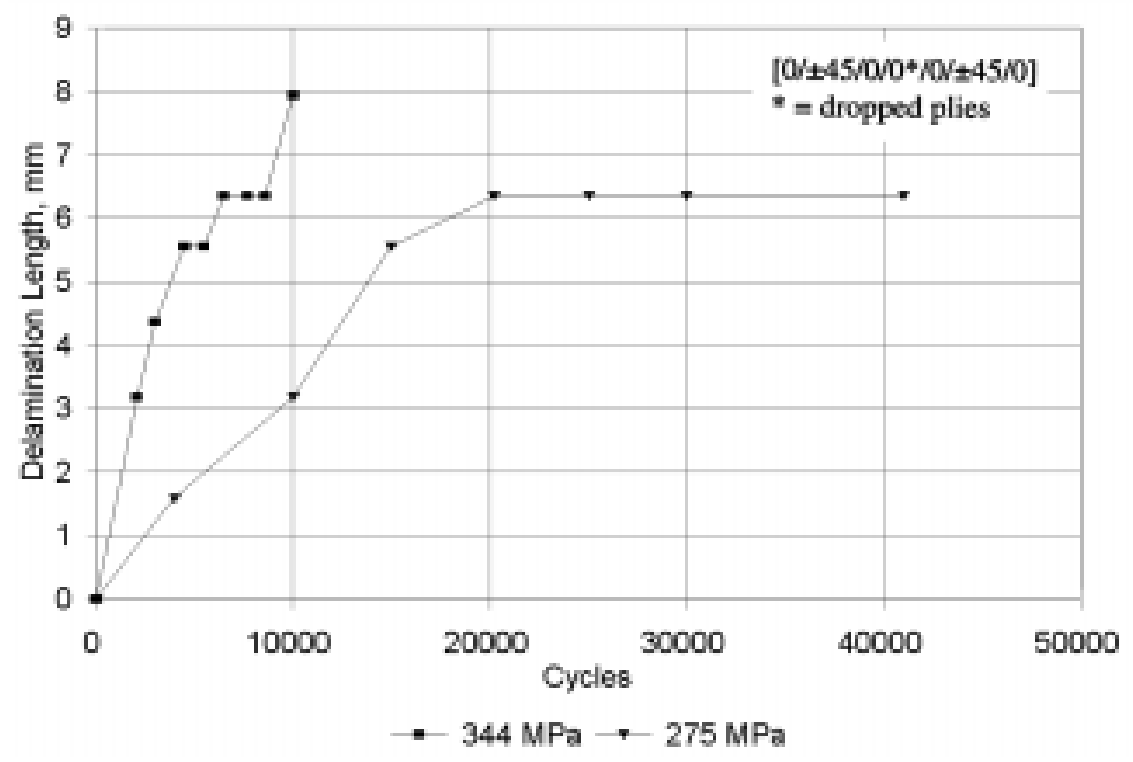

Figure 52. Delamination length vs. cycles for ESC (single center interior $0^{\circ}$ ply drop) laminate, $R=0.1$.

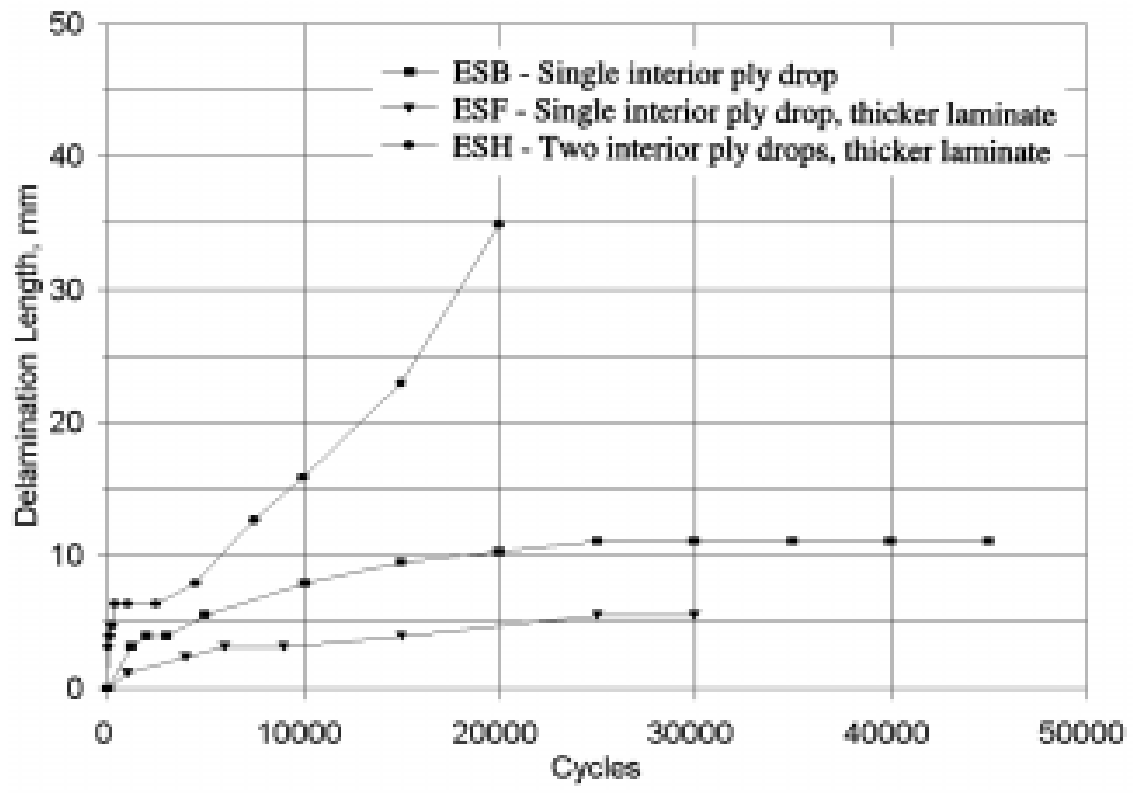

Figure 53. Delamination length vs. cycles for ESB, ESH, ESF (all interior $0^{\circ}$ ply drop) laminates at a maximum running stress of $275 \mathrm{MPa}, \mathrm{R}=0.1$. 


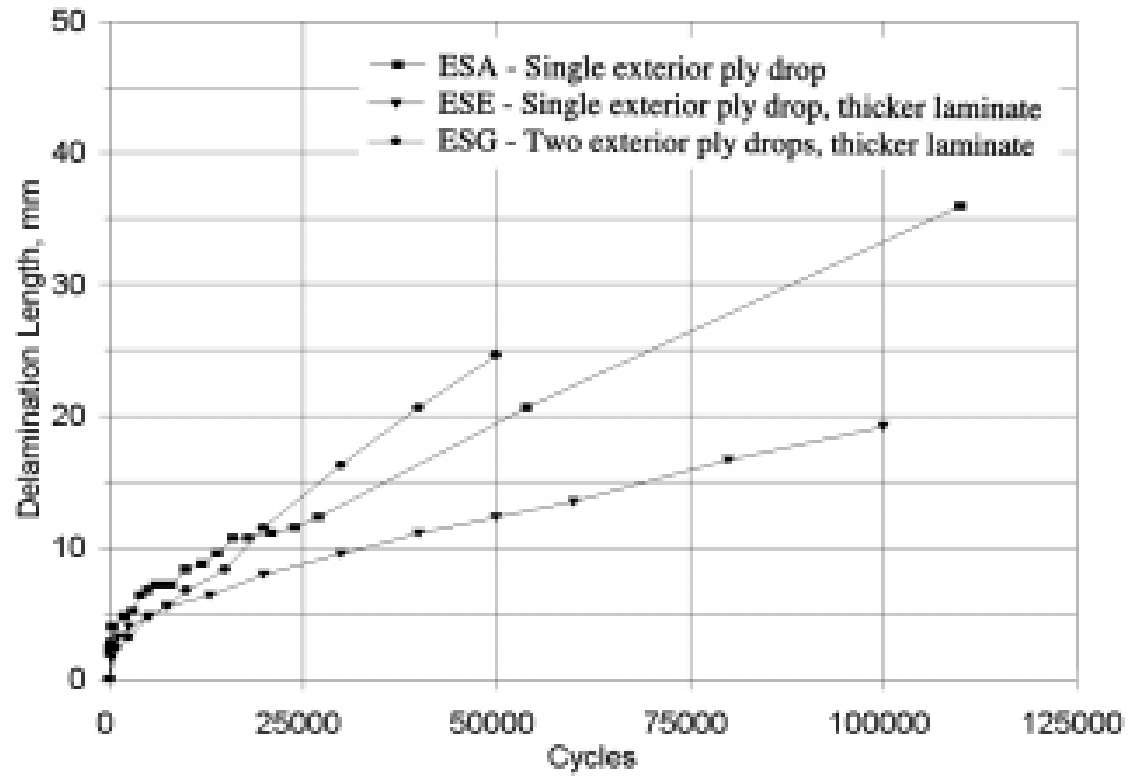

Figure 54. Delamination length vs. cycles for ESA, ESG, ESE (all exterior $0^{\circ}$ ply drop) laminates at a maximum running stress of $275 \mathrm{MPa}, \mathrm{R}=\mathbf{0 . 1}$.

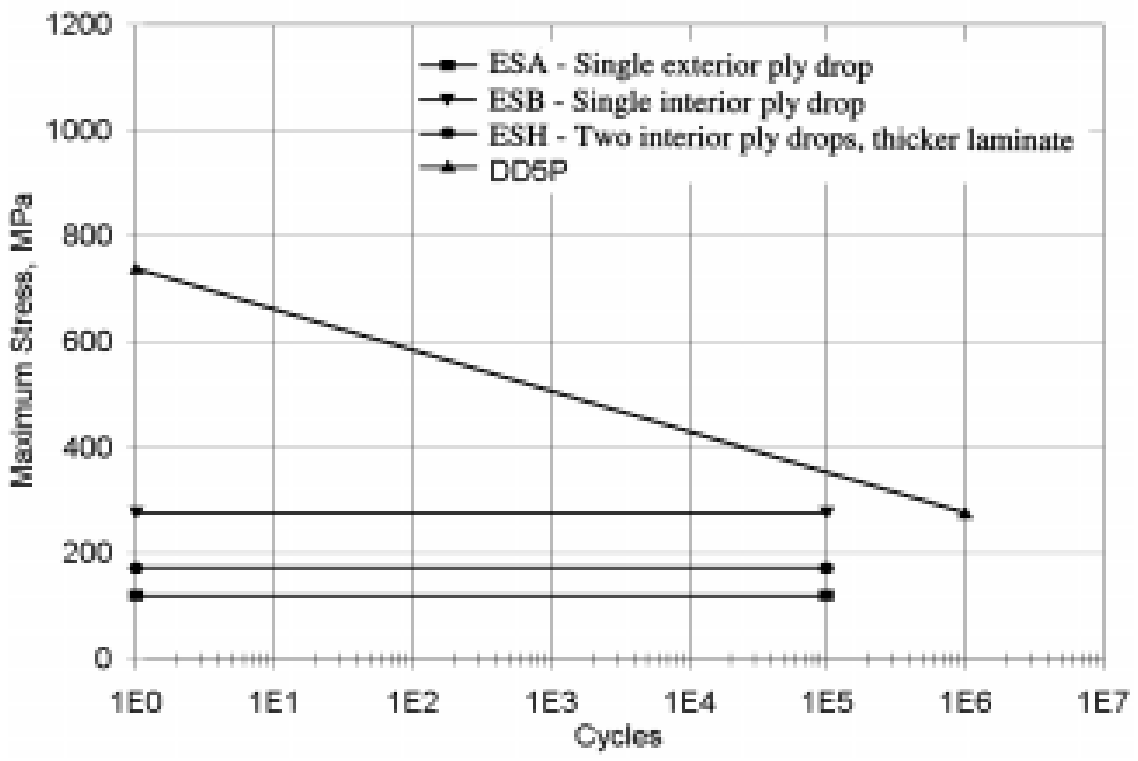

Figure 55. Tapered beam flange with ply drops, $R=0.1$. 


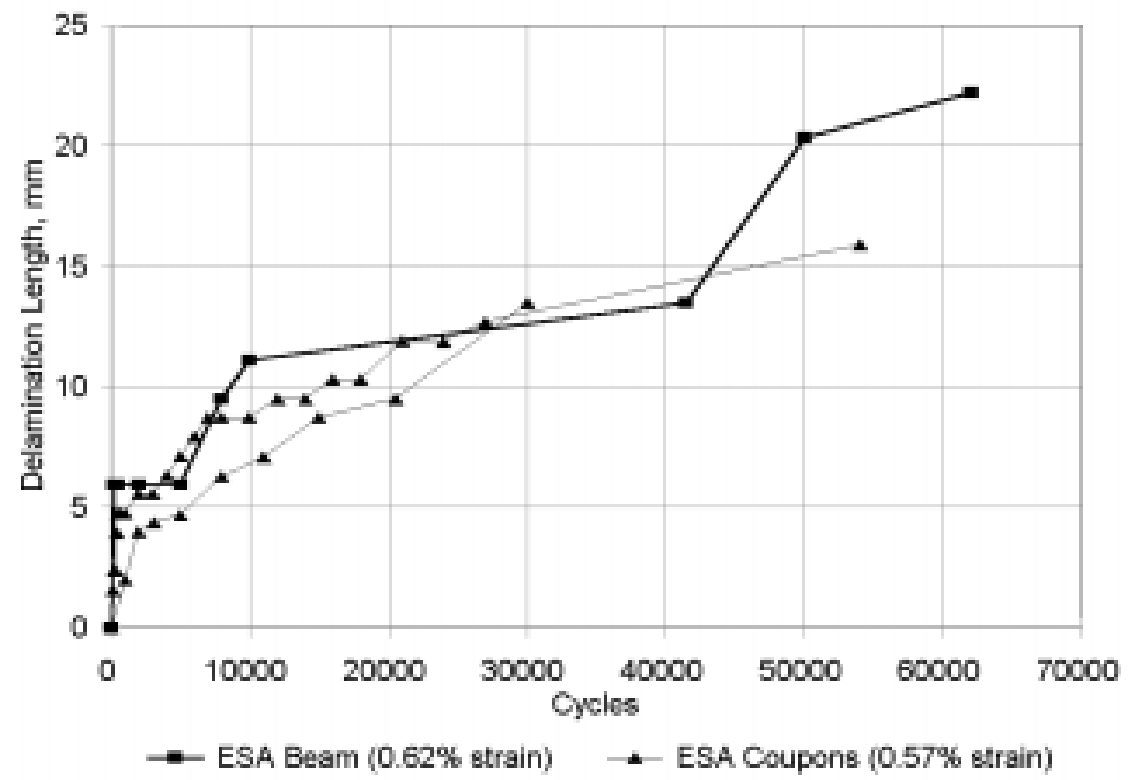

Figure 56. Beam (tension flange) vs. coupon data $(R=0.1)$ for ESA (single exterior $0^{\circ}$ ply drop), $R=0.1$.

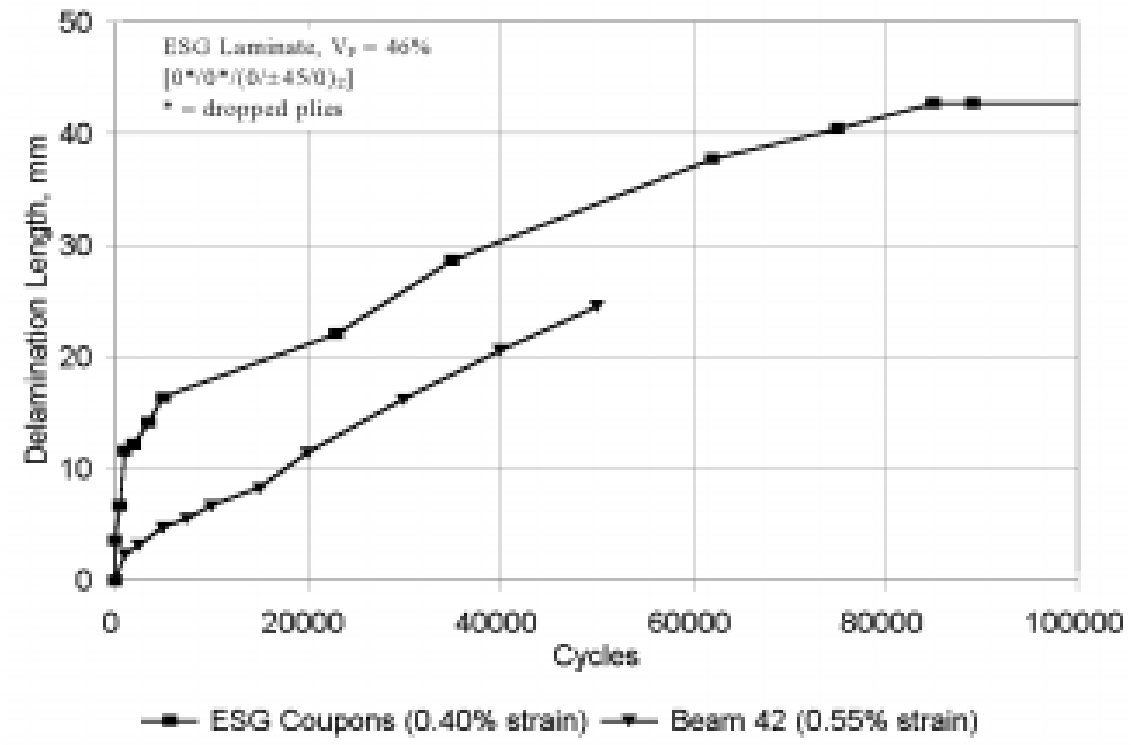

Figure 57. Delamination length vs. cycles for tension flange ESG laminate with two exterior ply drops compared with coupon data. 


\section{APPENDIX}

INDIVIDUAL BEAM TEST DETAILS FOR BEAMS NUMBERS 6 AND HIGHER

Page

Beams With AA Material (Triax) Flanges and CH10 Material Web . . . . . . . . . 91

Beam $6 \ldots \ldots \ldots \ldots$. . . . . . . . . . . . . . . . . . . . . . . .

Beam $7 \ldots \ldots \ldots \ldots$

Beam $8 \ldots \ldots \ldots \ldots \ldots \ldots$

Beam $9 \ldots \ldots \ldots \ldots \ldots 1$

Beam $10 \ldots \ldots \ldots \ldots 10 \ldots \ldots \ldots$

Beam $11 \ldots \ldots \ldots \ldots 10 \ldots \ldots$

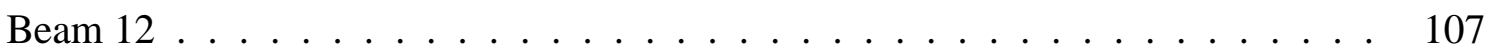

Beam $13 \ldots \ldots \ldots \ldots \ldots$

Beam $14 \ldots \ldots \ldots \ldots \ldots \ldots$

Beam $22 \ldots \ldots \ldots \ldots \ldots \ldots \ldots \ldots$

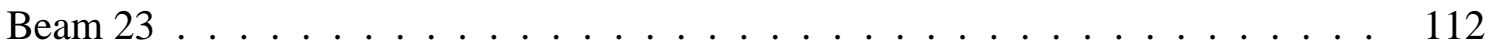

Beams With Improved Flange and Web Materials . . . . . . . . . . . . . . . 113

Beams With DD5P Material Flanges and CH10 Material Webs . . . . . . . . . . 113

Beam $18 \ldots \ldots \ldots \ldots \ldots$. . . . . . . . . . . . . . . . . . . . . . . . . . . . . . . . . . . . . .

Beam $19 \ldots \ldots \ldots \ldots \ldots \ldots \ldots \ldots \ldots$

Beam $20 \ldots \ldots \ldots \ldots \ldots \ldots \ldots \ldots$

Beam $21 \ldots \ldots \ldots \ldots \ldots \ldots$

Beam $24 \ldots \ldots \ldots \ldots \ldots \ldots \ldots$

Beam $25 \ldots \ldots \ldots \ldots \ldots \ldots \ldots$

Beam $26 \ldots \ldots \ldots \ldots \ldots \ldots \ldots \ldots \ldots$

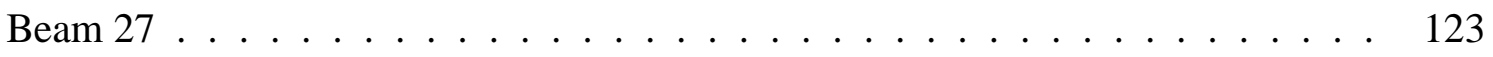

Beam $28 \ldots \ldots \ldots \ldots \ldots \ldots$

Beam $29 \ldots \ldots \ldots \ldots \ldots$

Beams With DD5P Material Flanges and CH3 Material Webs . . . . . . . . . . . 126

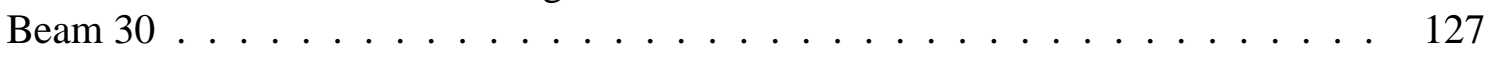

Beam $31 \ldots \ldots \ldots \ldots \ldots \ldots \ldots$

Beam $32 \ldots \ldots \ldots \ldots \ldots$

Beam $33 \ldots \ldots \ldots \ldots \ldots$

Beams With DD5P Material Flanges and CH5 Material Webs . . . . . . . . . 131

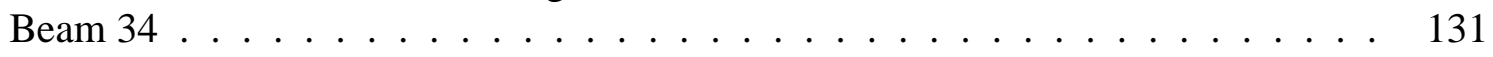

Beam $35 \ldots \ldots \ldots \ldots \ldots \ldots$

Beams With DD5P Material Flanges and DD5P Material Webs . . . . . . . . 135

Beam $51 \ldots \ldots \ldots \ldots \ldots \ldots \ldots \ldots$

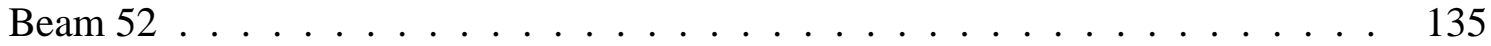

Beam $53 \ldots \ldots \ldots \ldots \ldots \ldots \ldots \ldots$

Beam $54 \ldots \ldots \ldots \ldots \ldots \ldots \ldots \ldots \ldots$ 


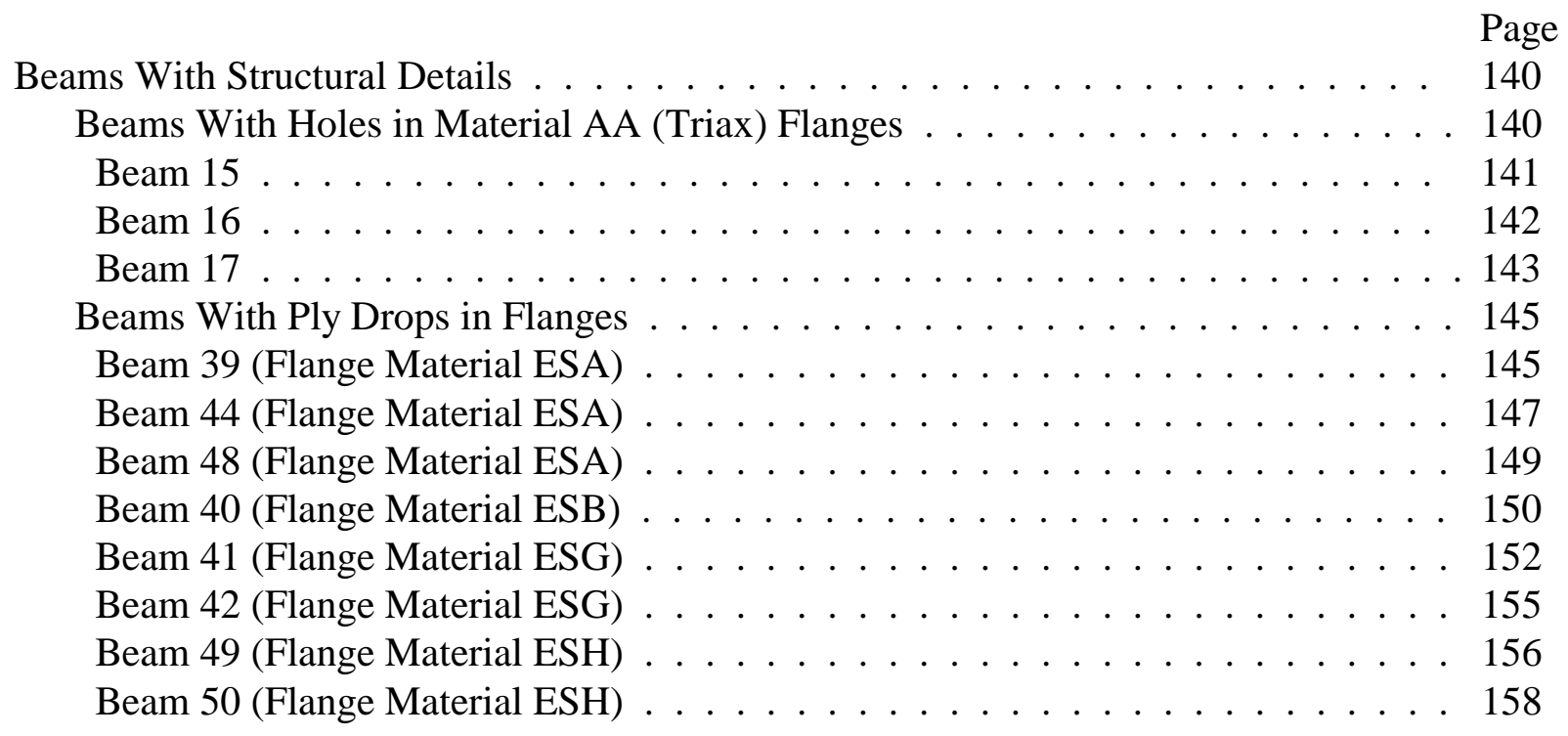




\section{AA Material (Triax) Flanges and CH10 Web Material}

Beams 6 through 17, 22 and 23 all had Material AA (CDB200 Triax fabric) flanges, $\mathrm{V}_{\mathrm{F}}=0.42$, consisting of a lay up of $\left(\left( \pm 45^{\circ} / 0^{\circ}\right)_{2}\right)_{S}$, except for Beams 9 and 10, which had the lay up reversed $\left(\left(0^{\circ} / \pm 45^{\circ}\right)_{2}\right)_{\mathrm{S}}$. The description of the I - Beam flange lay up and ply numbering scheme for these beams is outlined in Tables 22 and 23. The web was CH10 material, $\left(\left( \pm 45^{\circ}\right)_{3}\right)_{\mathrm{S}}$ with DB240 fabric.

\section{BEAM 6}

Beam 6 was tested statically to failure. The beam was loaded under actuator displacement control at a rate of $0.25 \mathrm{~mm} / \mathrm{s}$ until failure, which involved a total ramp time of 74 seconds. An initial beam stiffness of $3,711 \mathrm{kN} / \mathrm{m}$ was measured. As the beam was loaded, the compression flange started to twist along the $\mathrm{X}$ - axis, prior to final compressive failure of the compression flange. The total amplitude of this twist was approximated at 6 to $8 \mathrm{~mm}$ prior to failure and the onset of this twisting occurred at approximately 90 to $95 \%$ of the ultimate load. This twisting was also evident in the failed beam as one side of the beam flange had fragmented $\pm 45^{\circ}$ strands pointing up, while the other side of the flange had the fragmented strands pointing down. Figures 58 and 59 show the failed beam. Further examination of the buckled compression flange indicated that the outside $0^{\circ}$ ply (ply 3, Table 22) delaminated first from the adjacent $+45^{\circ}$ layer (ply 4, Table 22). This delamination arrested at $\mathrm{x}=267 \mathrm{~mm}$, which was evident by the white damage band in the outside plies at this point. It was not evident where the delamination started. From this initial arrest at $x=267 \mathrm{~mm}$, the delamination continued to grow towards both inside compressive load pads at $x=152 \mathrm{~mm}$ and $\mathrm{x}=464 \mathrm{~mm}$.

The web had multiple delaminations under the initial flange failure site generated after the flange failure. Some delamination spots are visible at $x=191,267,343$ and $394 \mathrm{~mm}$, at the compression flange - web intersection that could be buckling nodal points. No shear stiffener, torsional stiffener or tension flange damage or delaminations were visible. The load - flange absolute maximum strain graph is shown in Figure 60 and indicates a maximum tension flange strain of 1.80\% and a minimum compression flange strain of $-1.6 \%$ which occurred at an ultimate applied load of $67.08 \mathrm{kN}$ at a maximum mid-span deflection of $22 \mathrm{~mm}$. 
Table 22. Ply Reference Notation for Beams 6 through 9, 12 through 17, 22 and 23.

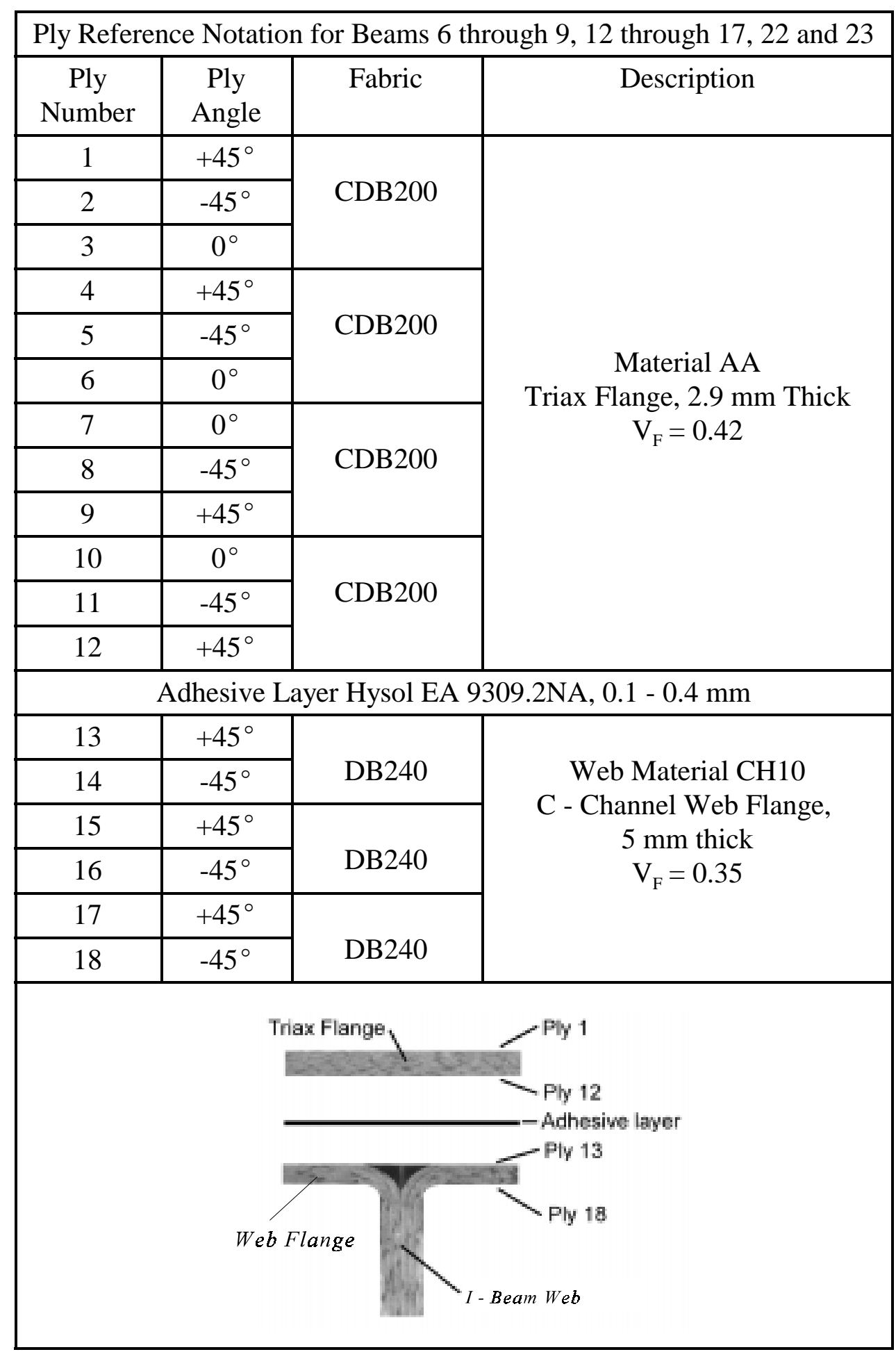


Table 23. Ply Reference Notation for Beams 10 and 11.

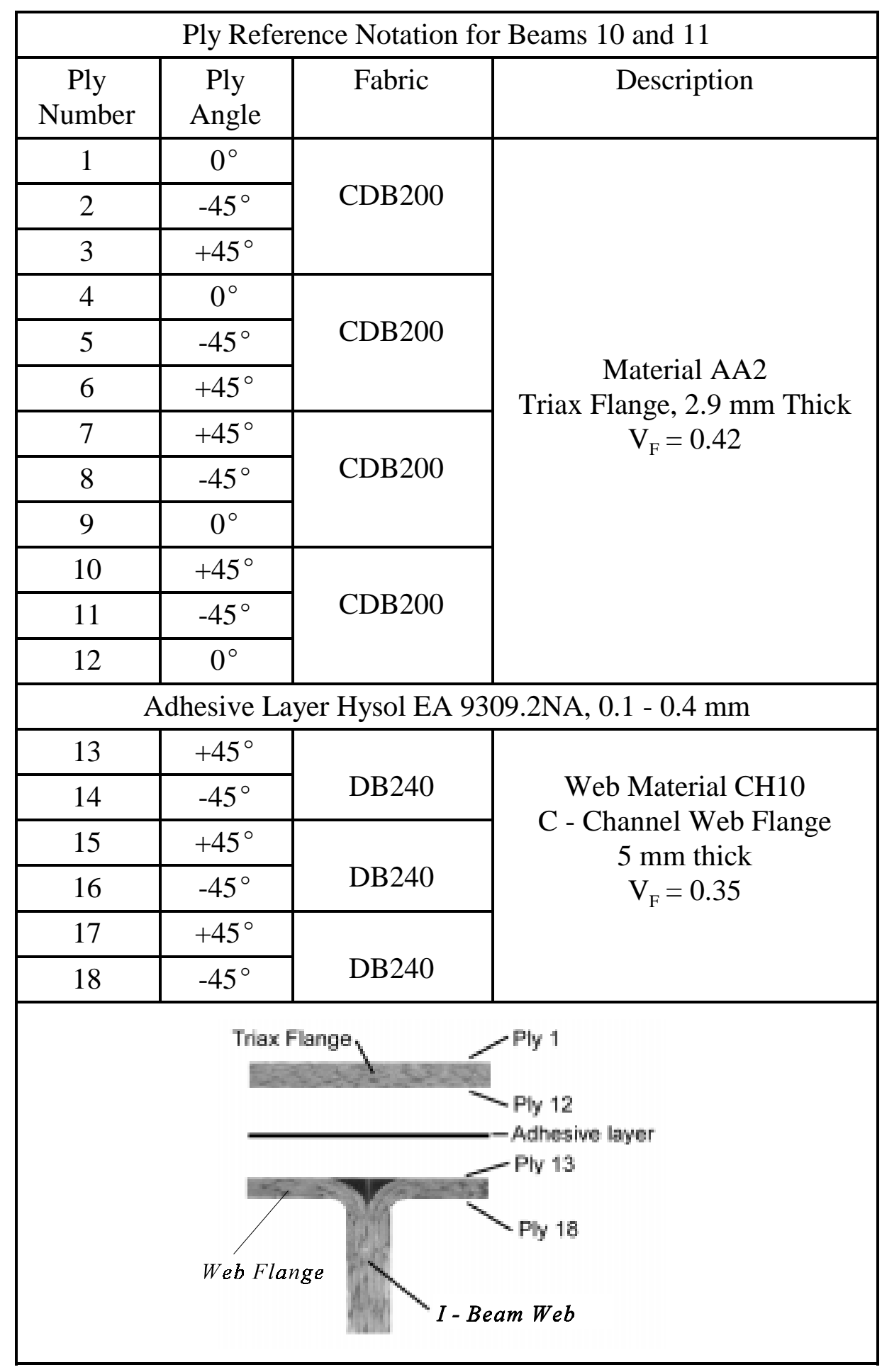




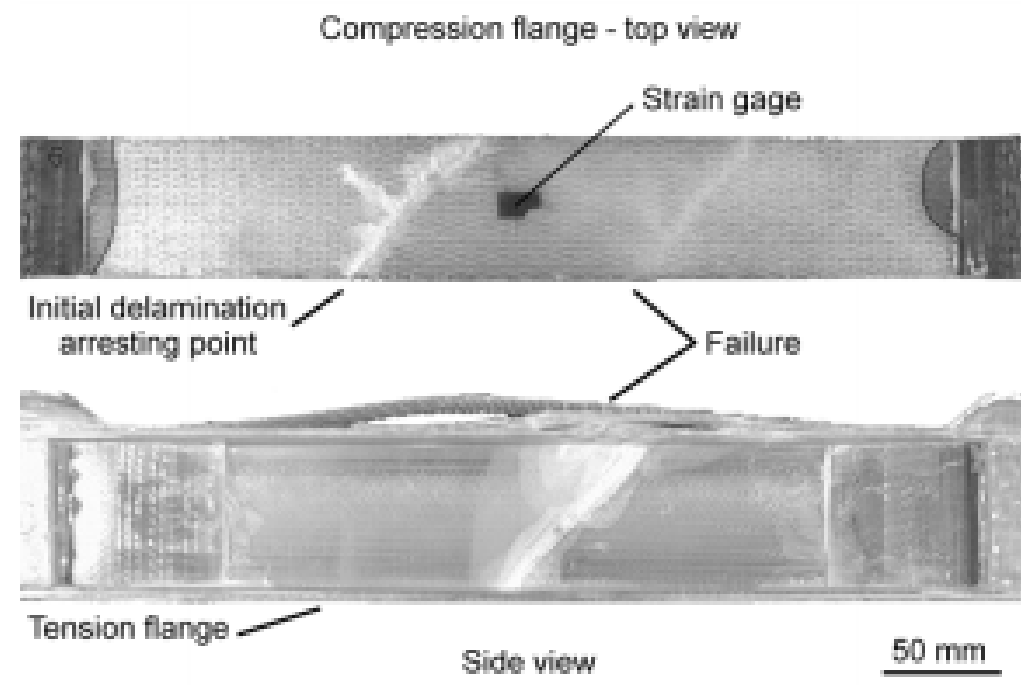

Figure 58. Beam 6.

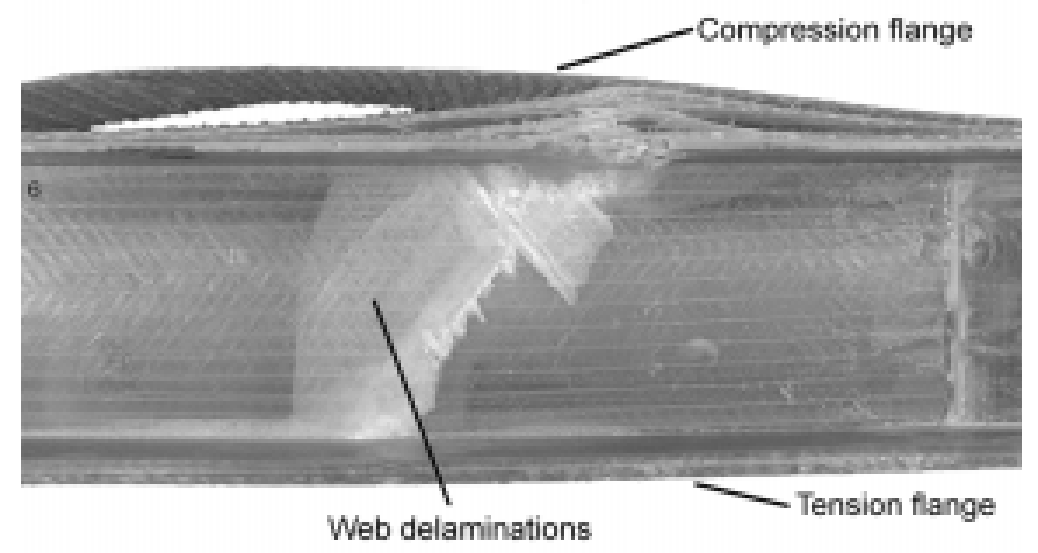

Figure 59. Beam 6. 


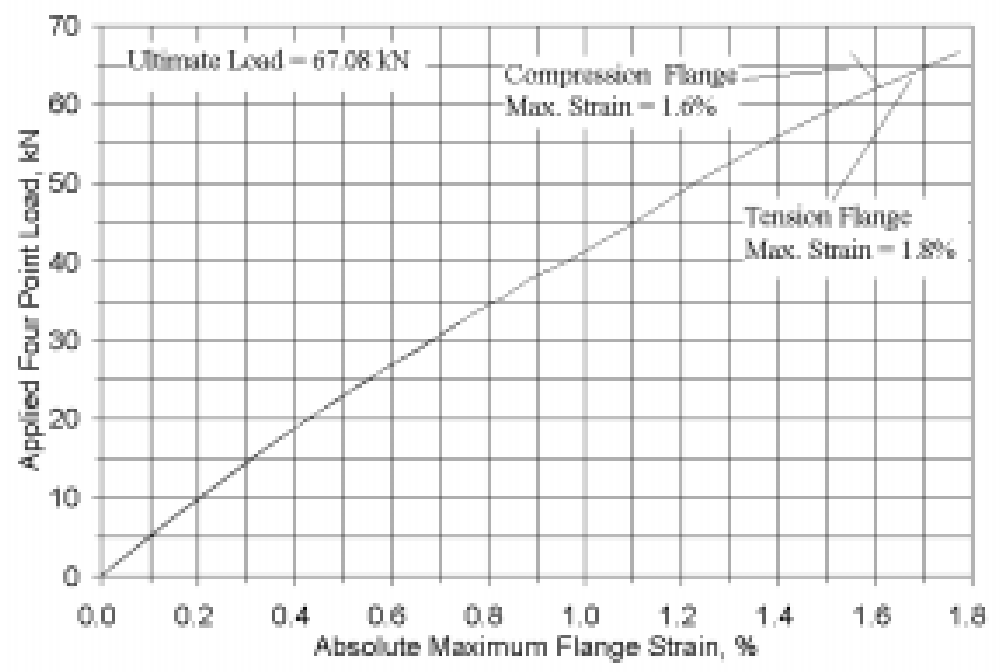

Figure 60. Load vs. maximum flange strain, beam 6, static test.

\section{BEAM 7}

Beam number 7 was fatigued at a rate of $5 \mathrm{~Hz}$ under sinusoidal load control with a maximum load of $24.5 \mathrm{kN}$ and a minimum load of $2.5 \mathrm{kN}$. The maximum load produced an initial maximum tension flange strain of $0.58 \%$ and a minimum compression flange strain of $-0.56 \%$. The initial beam stiffness was measured as $3,398 \mathrm{kN} / \mathrm{m}$. The tensile flange had two additional strain gages on the flange edges to determine the strain distribution across the flange. At a static load of $27 \mathrm{kN}$, the center strain gage indicated $0.680 \%$ strain, while the edge gages indicated $0.640 \%$ and $0.632 \%$ for a combined average strain of $0.651 \%$. With the center strain gage directly over the web and the two other gages on the relatively flexible edges, this strain distribution is fairly uniform with only a $\pm 4 \%$ change across the flange width. Initially, the beam was loaded to $32 \mathrm{kN}$ with readings taken from all the strain gages, including a delta strain gage rosette $\left(0^{\circ} / 120^{\circ} / 240^{\circ}\right)$ centered $9 \mathrm{~mm}$ ahead of one of the shear stiffeners on the neutral axis of the beam. The strain rosette (Omega Engineering, Inc. SG-3/350/RY11) was utilized to determine the nature of the strains ahead of the stiffener, which was a point of damage on the initial beams (1-5) and to also aid in finite element modeling of the beam.

The initial loading versus flange strain graph is shown in Figure 61 and is typical of all the other triax beams. Both the tension and compression flange indicate the same load - strain slope. The maximum absolute flange strain versus fatigue cycles is shown in Figure 62. The stiffness of the beam decreases during the fatigue test due to matrix cracking and delamination, and under load control, the maximum strain in the beam must increase during the fatigue test. The apparent increase in actuator amplitude, maximum stroke minus minimum stroke, is shown in Figure 63 and is typical of all the beams tested. The initial strain rosette data is graphically shown in Figure 64. The shear stress $9 \mathrm{~mm}$ ahead of the shear stiffener was calculated from this data and is shown in Figure 65. The shear stress is small, but present on the neutral axis of the beam at this point. During the fatigue test, white spots started to form at random locations on the tension flange. These damage nucleation locations involved fiber delamination and fiber breakage involving the stitching cross over points 
in the fabrics.

As the fatigue test continued, the damage sites increased in size and some damage spots coalesced to form failure lines. These sites continued to grow until the worst damage site extended across the tensile flange that caused final failure of the tension flange at 492,147 cycles. The failure site occurred at $x=356 \pm 5 \mathrm{~mm}$ and is shown in Figures 66 and 67.

The flange damage was very localized, while the delamination of the entire flange from the I-beam preform extended from $\mathrm{x}=260$ to $\mathrm{x}=406 \mathrm{~mm}$ and was due to the flange failure. The delamination in the beam occurred between the $+45^{\circ}$ (ply 12, Table 22) and the adhesive, and between the $\pm 45^{\circ}$ plies (plies 15,16, Table 22). The failure also caused delaminations to extend $16 \mathrm{~mm}$ down into the shear web. No shear stiffener, torsional stiffener or compression flange damage or delaminations were visible. The Instron 8501 displacement interlocks were set so that any actuator travel $\pm 3 \mathrm{~mm}$ above the nominal fatigue running displacement would stop the fatigue test and limit any post failure damage from being generated. This procedure was observed for all the beams.

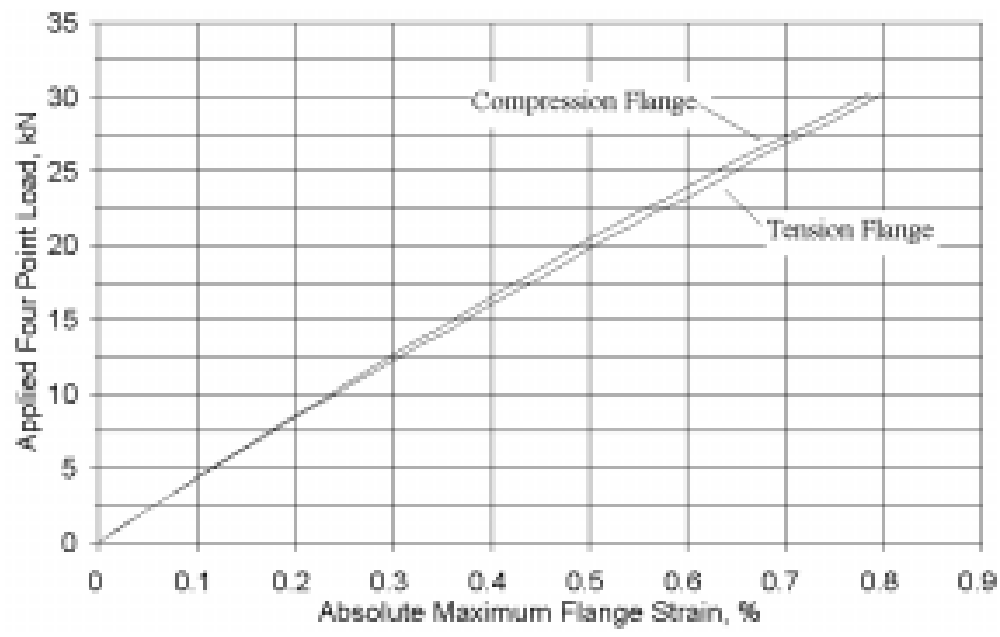

Figure 61. Load vs. maximum flange strain, beam 7, initial loading. 


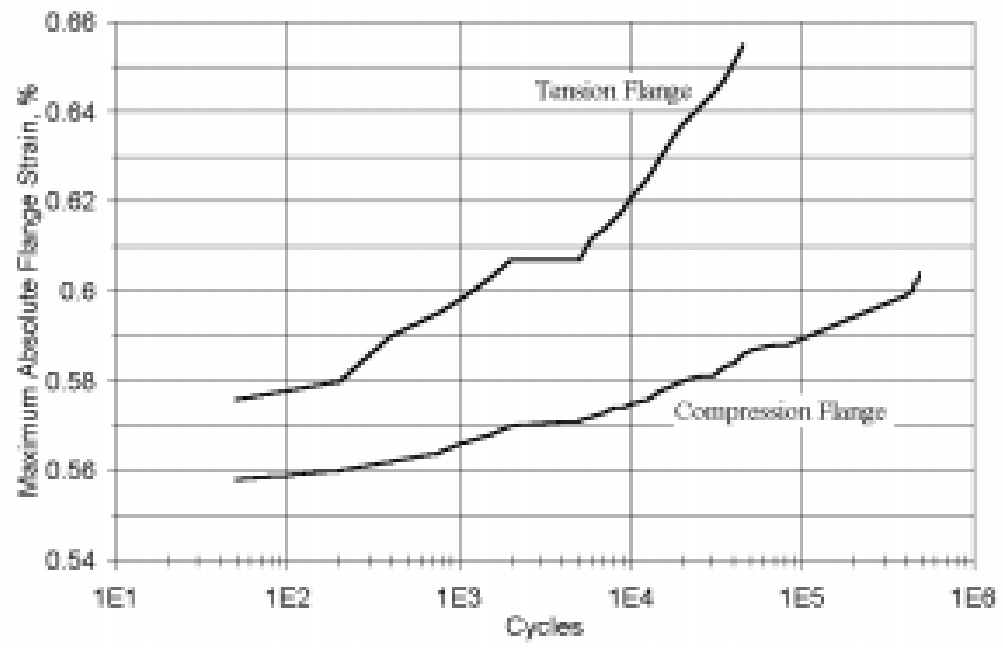

Figure 62. Maximum flange strain, beam 7. initial loading.

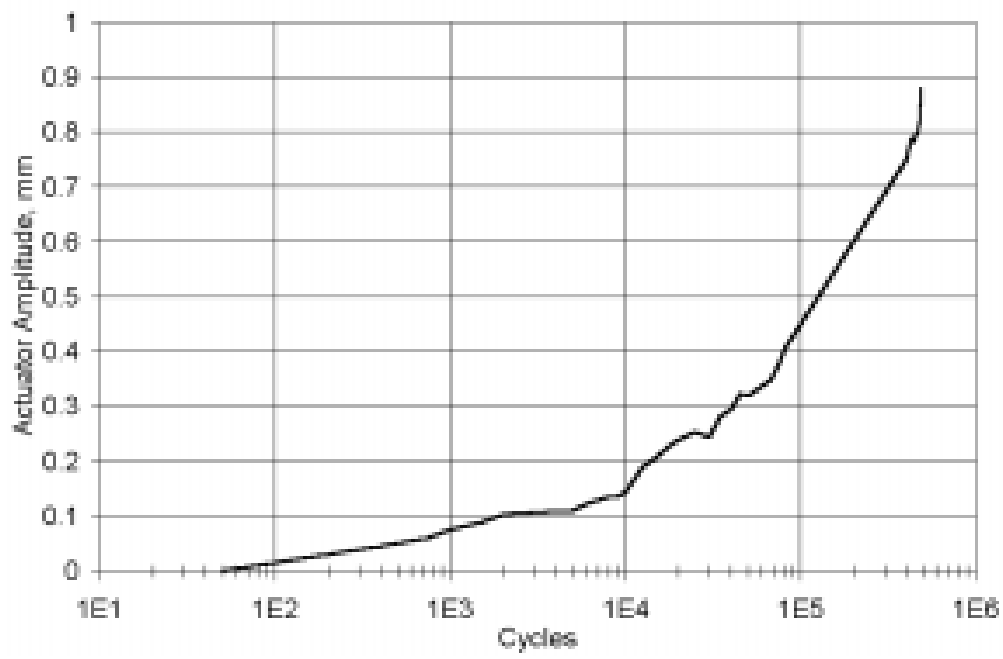

Figure 63. Actuator amplitude vs. cycles, beam 7. 


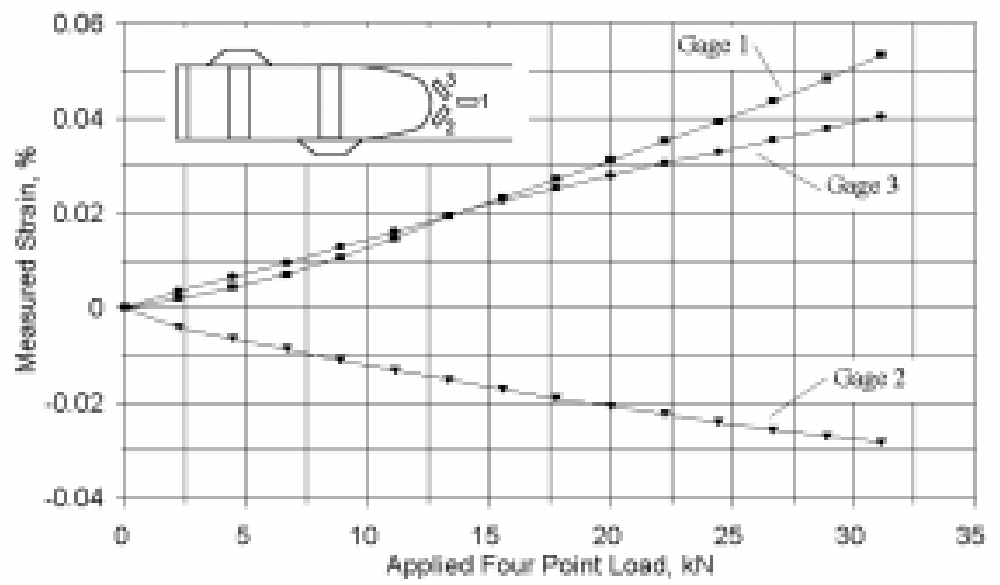

Figure 64. Load vs. strain for beam 7, delta strain gage rosette on web.

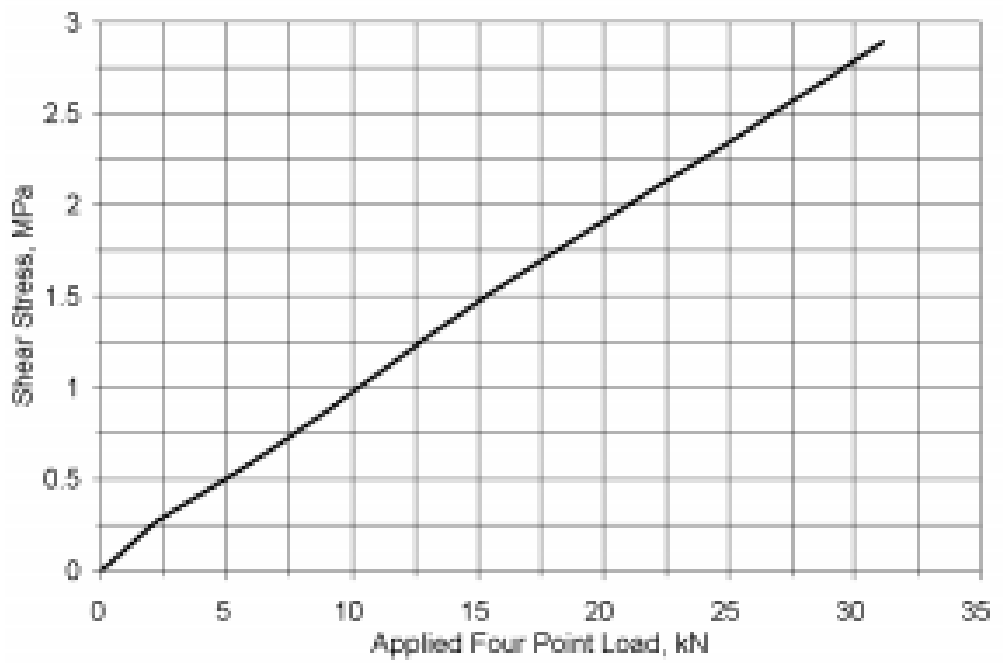

Figure 65. Load vs. web shear stress for beam 7, $9 \mathbf{~ m m}$ ahead of shear stiffener. 


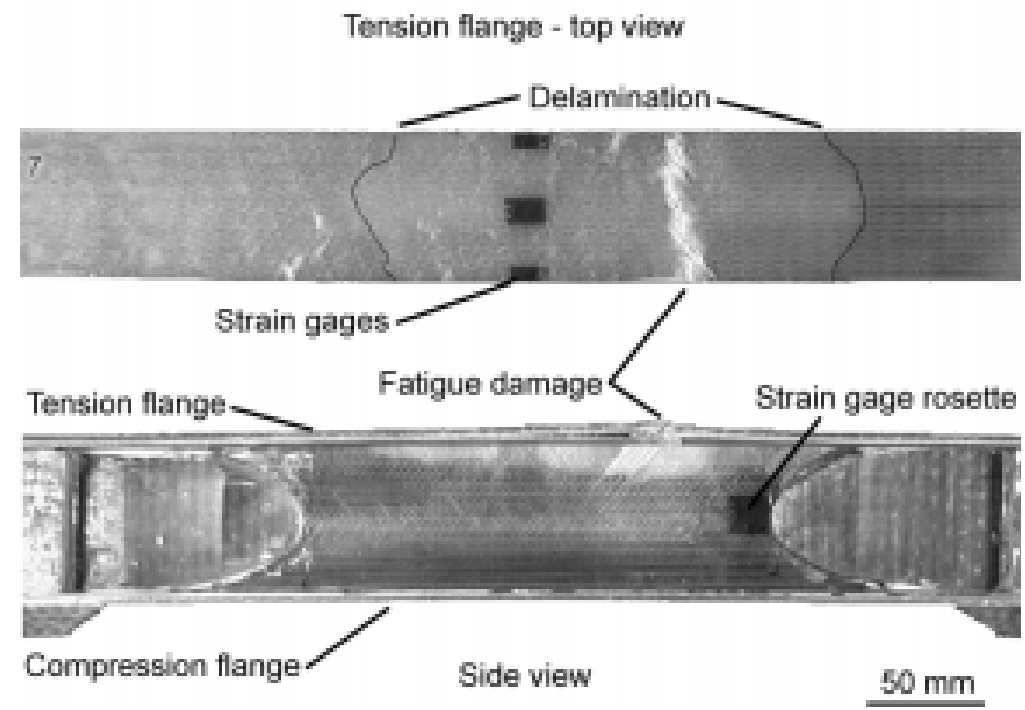

Figure 66. Beam 7.

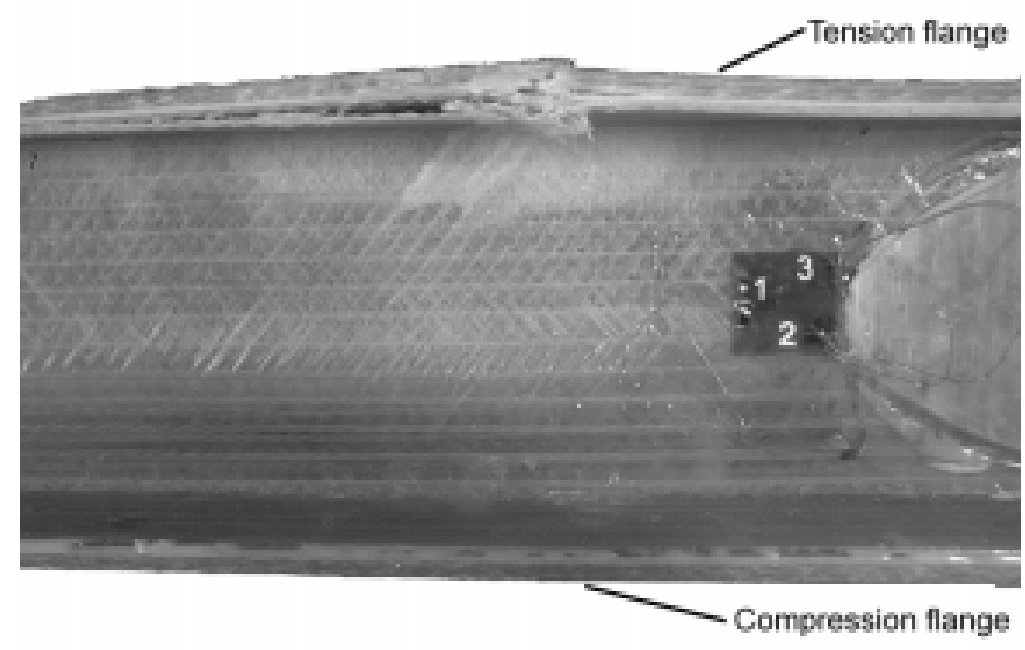

Figure 67. Beam 7. 


\section{BEAM 8}

Beam number 8 was fatigued at a rate of $2 \mathrm{~Hz}$ with a maximum load of $31.1 \mathrm{kN}$ and a minimum load of $3.1 \mathrm{kN}$. The maximum load produced an initial maximum tension flange strain of $0.79 \%$ and a minimum compression flange strain of $-0.70 \%$. The initial beam stiffness was measured as 3,499 $\mathrm{kN} / \mathrm{m}$. As with Beam 7, white damage spots were generated on the tension flange during the fatigue test.

At 29,051 cycles, the tensile flange failed and separated at $x=324 \pm 9 \mathrm{~mm}$, which caused the flange to delaminate from the preform between $\mathrm{x}=255$ to $\mathrm{x}=368 \mathrm{~mm}$ and is shown in Figures 68 and 69 . The delamination involved extensive fiber bridging between the inside flange $+45^{\circ}$ (ply 12 , Table 22) and the adhesive on the preform. This beam was fatigued at a higher strain than Beam 7 and thus had more internal strain energy stored in it prior to failure, which is apparent by the amount of damage generated in the web as compared to Beam 7. The web delamination extended $45 \mathrm{~mm}$ from the tension flange and was located at $\mathrm{x}=324 \pm 44 \mathrm{~mm}$. No shear stiffener, torsional stiffener or compression flange damage or delaminations were visible.

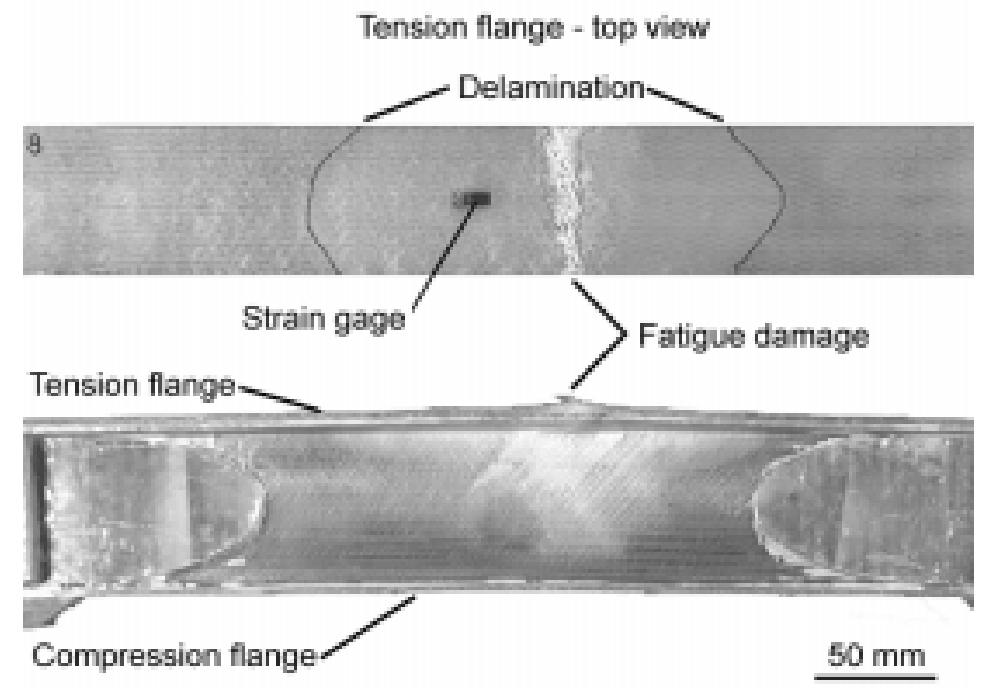

Figure 68. Beam 8.

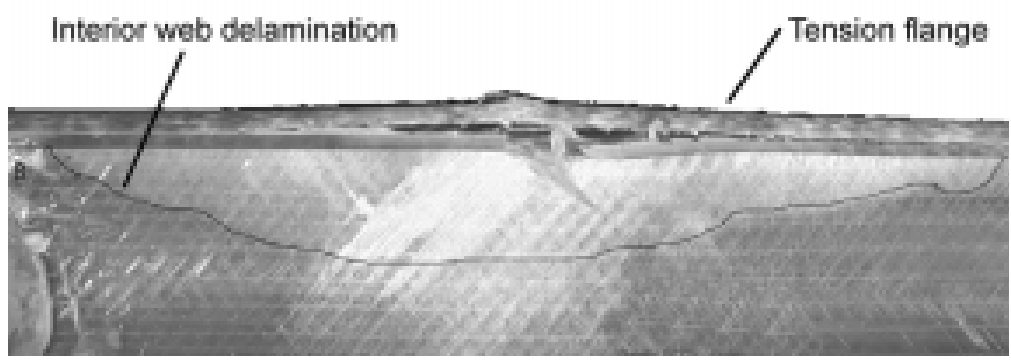

Figure 69. Beam 8. 


\section{BEAM 9}

Beam 9 involved a static test. The beam was loaded under actuator displacement control at a rate of $0.25 \mathrm{~mm} / \mathrm{s}$ until failure, which involved a total ramp time of 43 seconds. An initial beam stiffness of 3,556 kN/m was measured. Beams 9 and 10 were constructed with the $0^{\circ}$ plies on the outside (Material AA2) of the flange rather than the $+45^{\circ}$ (Material AA). This layup reversal did not significantly affect the stiffness of the beam when compared to the other beams. It was apparent, after the static test, that there was substantial fiber waviness in the fabric that caused the beam to fail prematurely. Curved fiber tows, with a radius of 4 to $5 \mathrm{~mm}$, turned white as they delaminated from the material around them on both the tension and compression flanges. Figures 70 and 71 show the failed beam. The ultimate load that the beam held was $59.2 \mathrm{kN}$ and corresponded to a maximum tension flange strain of $1.78 \%$ and a minimum compression flange strain of $-1.80 \%$. The load versus maximum strain graph is shown in Figure 72. The buckling failure of the compression flange occurred at two sites: $x=260 \pm 6 \mathrm{~mm}$ on the flange and $\mathrm{x}=298 \pm 10 \mathrm{~mm}$ on the preform. Delamination of the flange from the web flange occurred from $\mathrm{x}=203$ to $\mathrm{x}=419 \mathrm{~mm}$ and was between the adhesive layer and $0^{\circ}$ (ply 12, Table 23) ply and also between the $0^{\circ}$ (ply 12 , Table 23 ) and $-45^{\circ}$ (ply 11, 23) plies. The delamination also heavily affected the web, $\mathrm{x}=260 \mathrm{~mm}$ to $\mathrm{x}=356$ $\mathrm{mm}$, as the web delaminated fully between the interior $-45^{\circ}$ plies and also placed a spot delamination in the adhesive region on the tension flange. No shear stiffener, torsional stiffener or other tension flange damage or delaminations were visible.

\section{BEAM 10}

Beam number 10 was fatigued at a rate of $1 \mathrm{~Hz}$ with a maximum load of $40.0 \mathrm{kN}$ and a minimum load of $4.0 \mathrm{kN}$. The maximum load produced an initial maximum tension flange strain of $1.07 \%$ and a minimum compression flange strain of $-0.97 \%$. The initial beam stiffness was measured as 3,694 $\mathrm{kN} / \mathrm{m}$. The initial hysteresis of the beam is shown in Figure 73. As with Beam 9, the fiber waviness caused premature damage to be generated on the tension flange. The test was stopped after 1,870 cycles due to the amount of damage present on the tension flange and the white delaminated regions had reached both sides of the flange at $\mathrm{x}=349 \pm 13 \mathrm{~mm}$. The beam stiffness was checked after the 1,870 cycles and equaled $3,384 \mathrm{kN} / \mathrm{m}$, which was $92 \%$ of the initial stiffness. The failure site will probably occur at $\mathrm{x}=254 \pm 12 \mathrm{~mm}$ due to the amount of accumulated damage in the $0^{\circ}$ plies across the tension flange. No shear stiffener, torsional stiffener or compression flange damage or delaminations were visible at the end of the test. The failed beam is shown in Figure 74. 


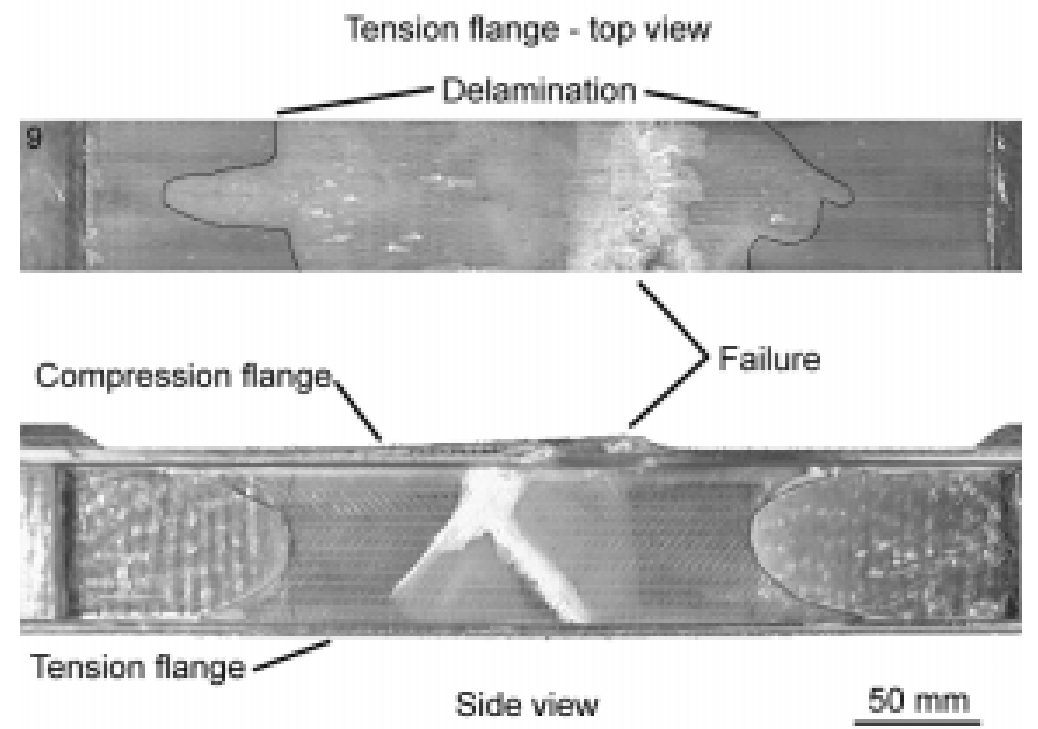

Figure 70. Beam 9.

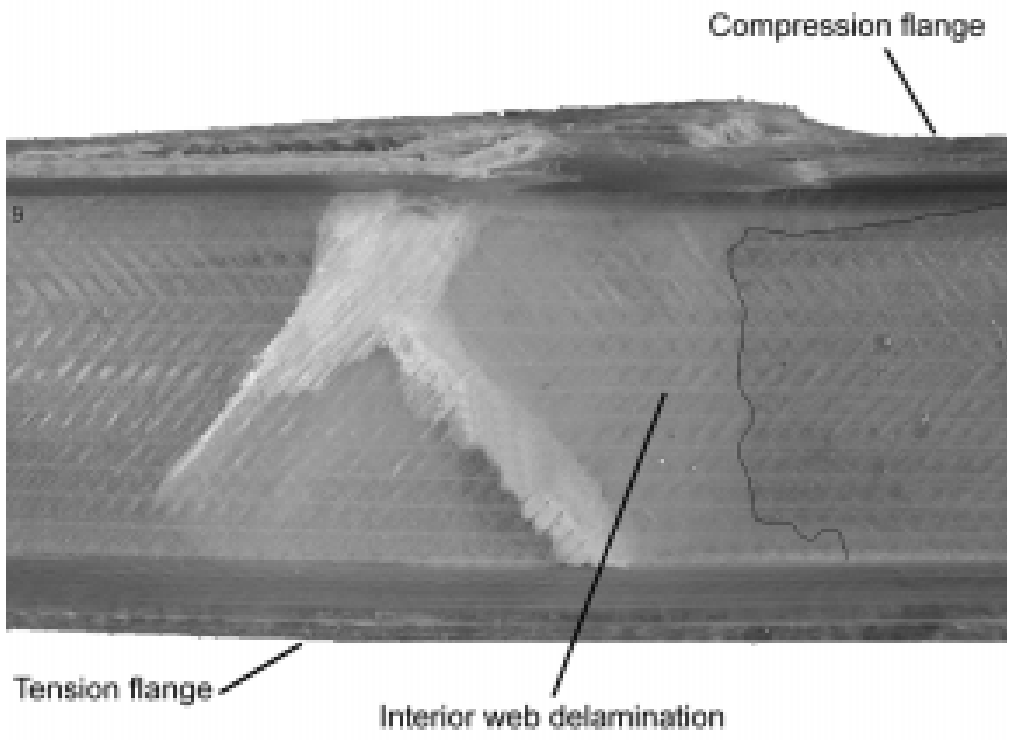

Figure 71. Beam 9. 


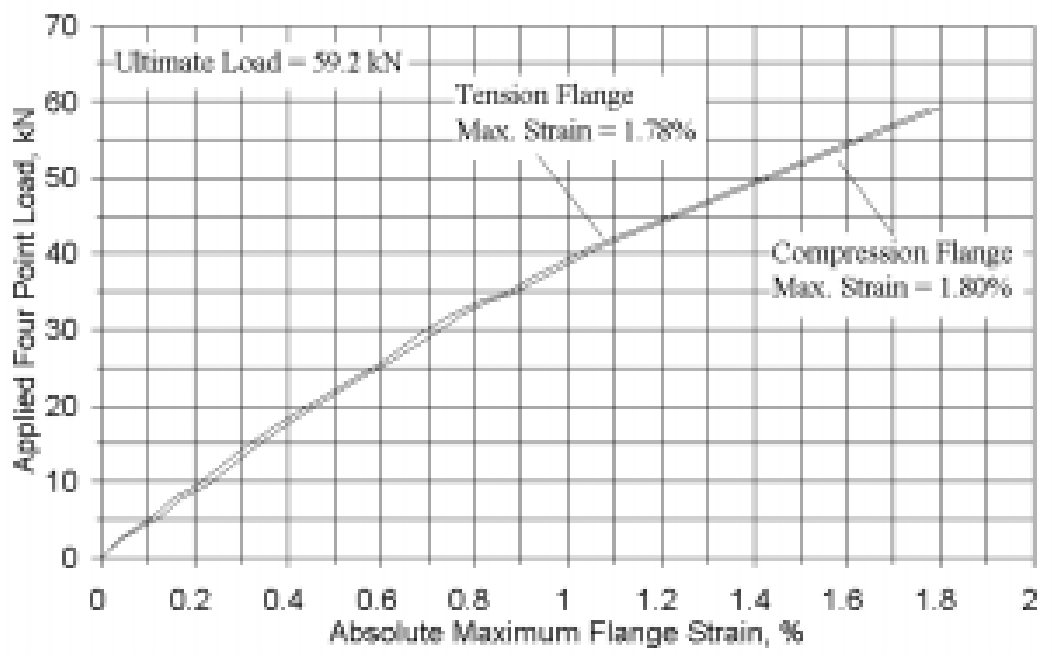

Figure 72. Load vs. maximum flange strain beam 9, static test.

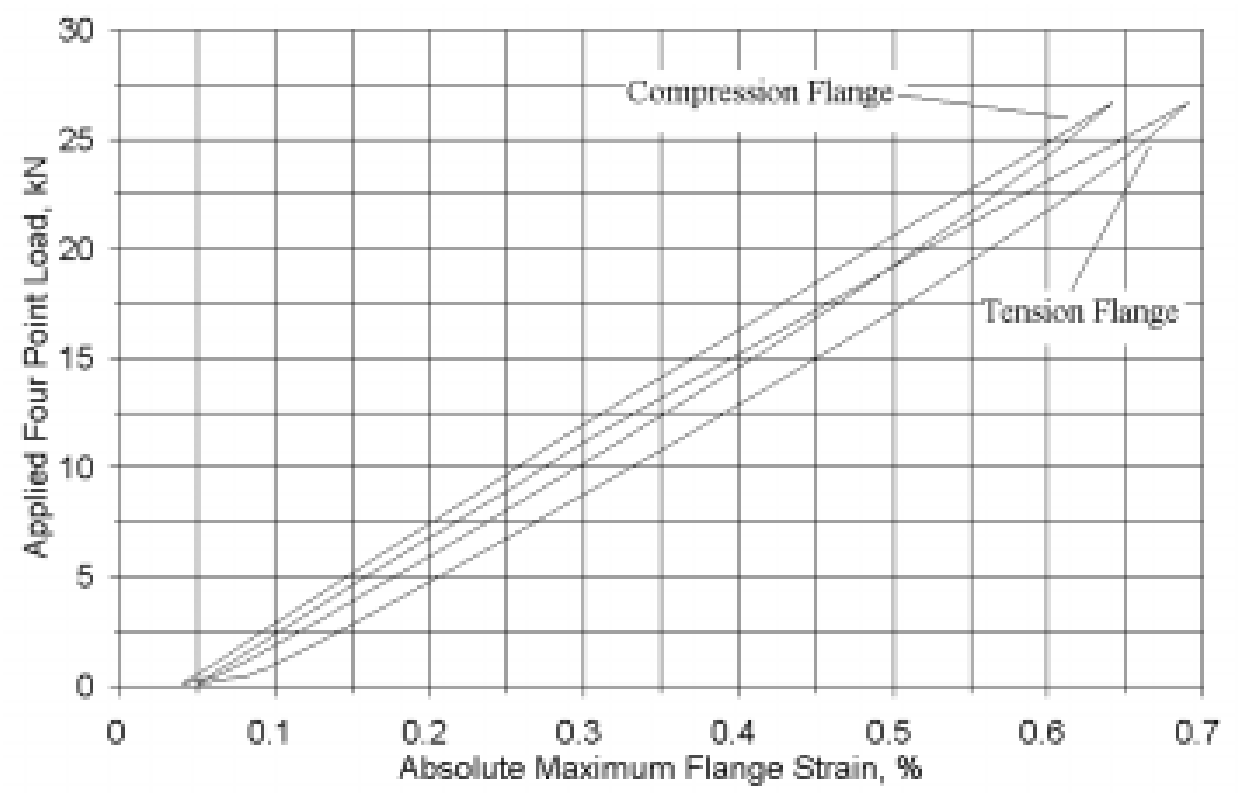

Figure 73. Initial hysteresis of beam 10. 


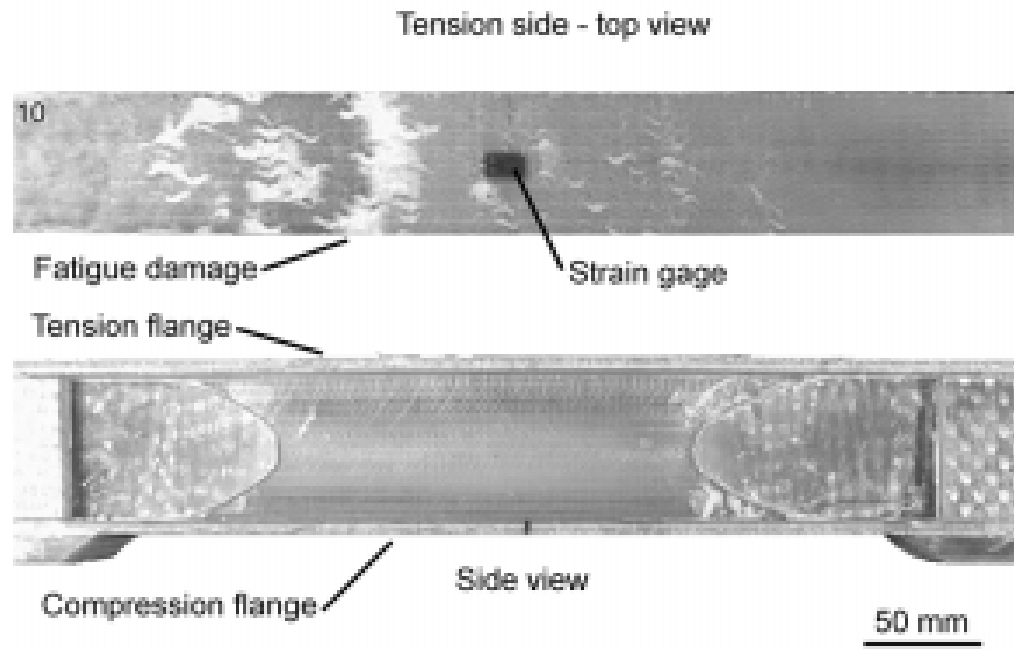

Figure 74. Beam 10.

\section{BEAM 11}

Beam number 11 was fatigued at a rate of $1 \mathrm{~Hz}$ with a maximum load of $40.0 \mathrm{kN}$ and a minimum load of $4.0 \mathrm{kN}$. The maximum load produced an initial maximum tensile flange strain of $1.08 \%$ and a minimum compressive flange strain of $-0.96 \%$. The initial beam stiffness was measured as 3,436 $\mathrm{kN} / \mathrm{m}$. The fatigue test was stopped after 3,100 cycles to check the stiffness of the beam. The stiffness had decreased to $3,061 \mathrm{kN} / \mathrm{m}$ which was $89 \%$ of the initial stiffness. Figure 75 shows the initial beam stiffness and the stiffness after 3,100 cycles. The fatigue test was resumed and the beam failed after 4,620 cycles with a tension flange failure. The maximum flange strain versus fatigue cycles is shown in Figure 76. The offset in the graph at 3,100 cycles is due to the unloading of the beam for the stiffness check. Prior to failure, numerous white damage nucleation sites were evident on the tension flange.

Final failure of the flange occurred at $\mathrm{x}=381 \pm 17 \mathrm{~mm}$ and was very localized with some tearing of the top $\pm 45^{\circ}$ plies (ply 1 and 2, Table 22), which was noticed just prior to final failure. Delamination of the tensile flange occurred between the polyester matrix and the $+45^{\circ}$ ply (ply 13 , Table 22) on the web flange with multiple amounts of fiber bridging and was located at $x=229$ to $\mathrm{x}=400 \mathrm{~mm}$. Some delamination in the web was present and was caused by the flange failure. Figures 77 and 78 show the failed beam. No shear stiffener, torsional stiffener or compression flange damage or delaminations were visible. The load pads were manufactured as three separate plates that were then adhesively bonded together to get the required $12 \mathrm{~mm}$ load pad height. The upper most plate of this load pad assembly had partially delaminated in the adhesive interface from the rest of the pad. It is hypothesized that the adhesive layer was not thick enough to resist the applied compression loading on these pads. All four pads show the same partial delamination problem, but this did not influence the beam performance during the test. 


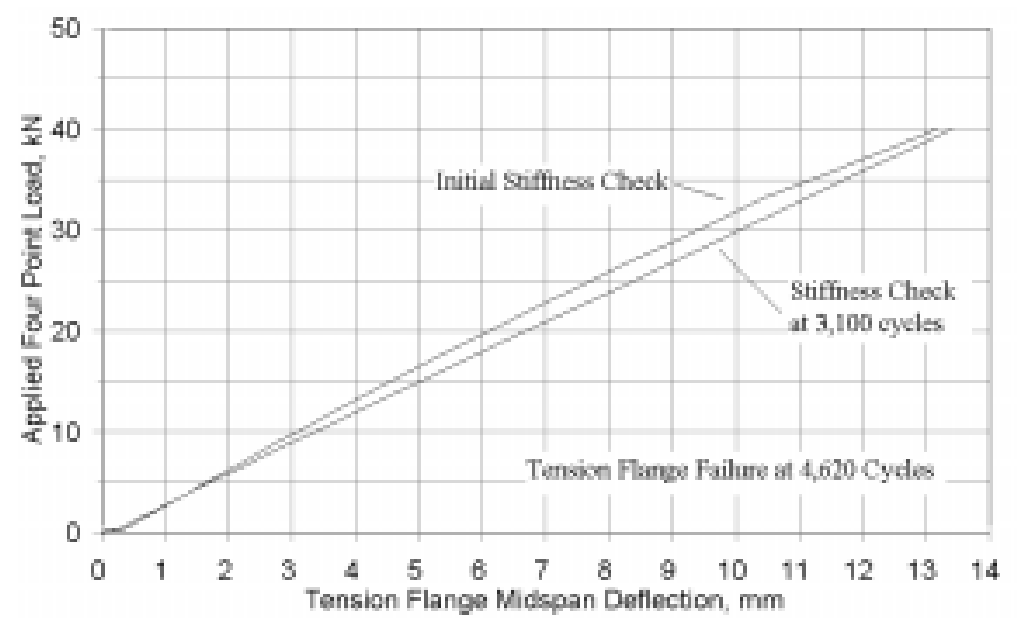

Figure 75. Load vs. flange midspan deflection, beam 11.

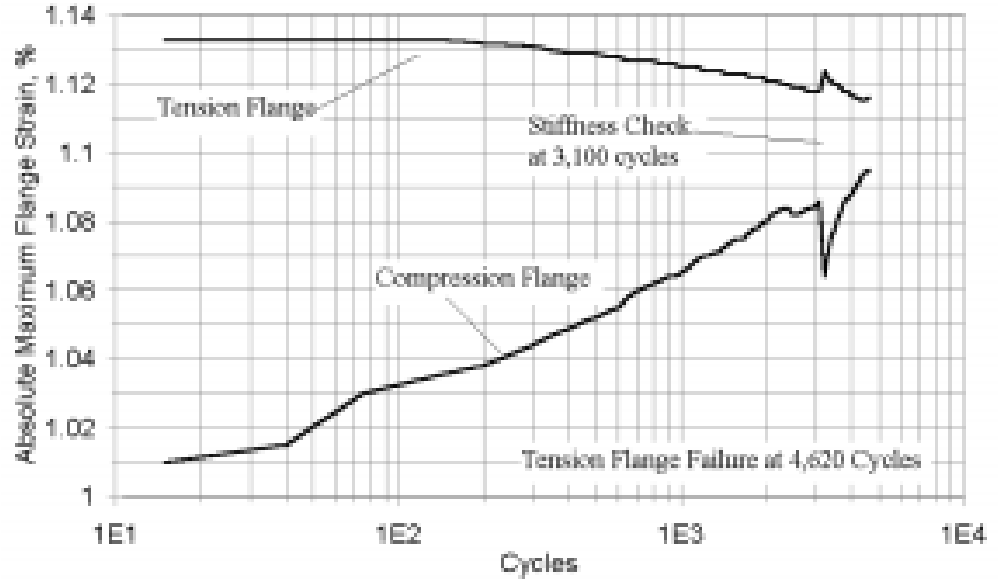

Figure 76. Absolute maximum flange fatigue strain vs. cycles, beam 11 . 
Tension flange - top view

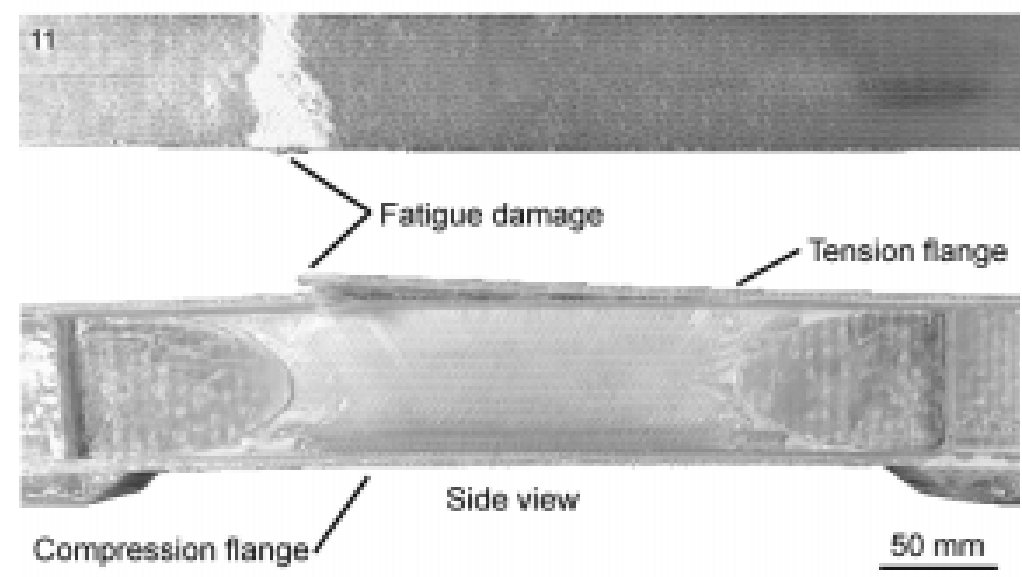

Figure 77. Beam 11.

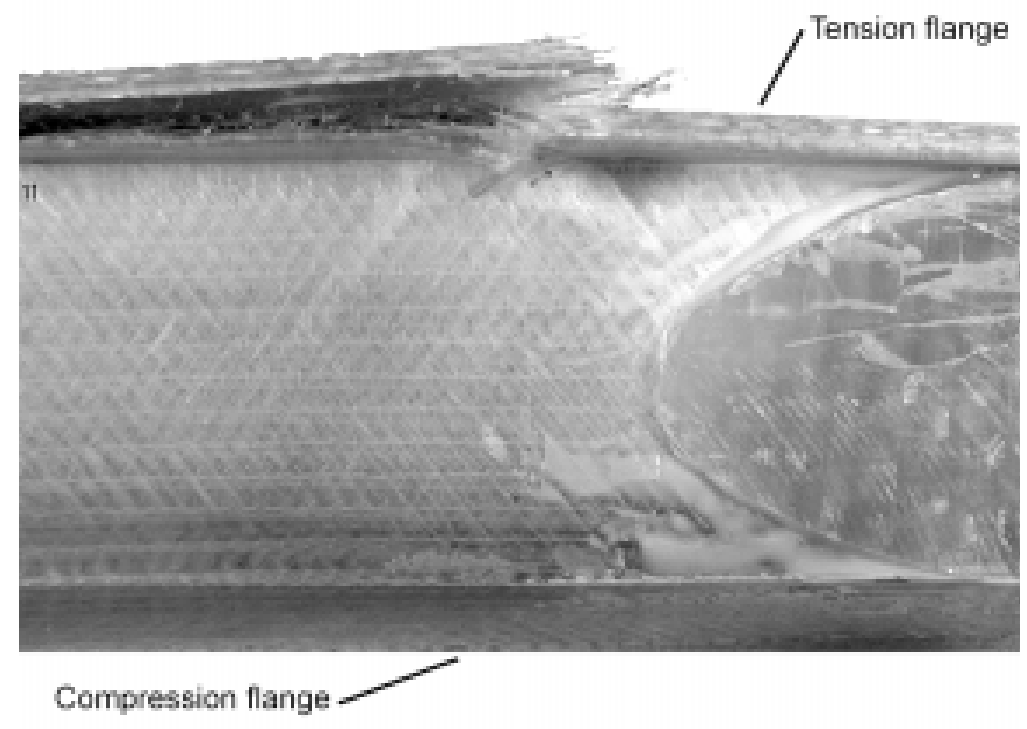

Figure 78. Beam 11. 


\section{BEAM 12}

Beam number 12 was fatigued at a rate of $2 \mathrm{~Hz}$ with a maximum load of $28.9 \mathrm{kN}$ and a minimum load of $2.9 \mathrm{kN}$. The maximum load produced an initial maximum tension flange strain of $0.73 \%$ and a minimum compression flange strain of $-0.68 \%$. The initial beam stiffness was measured as 3,498 $\mathrm{kN} / \mathrm{m}$. As with the other beams, numerous white damage nucleation spots appeared on the tension flange during the fatigue test. These damaged areas grew and coalesced until the damage spanned across the flange.

The final failure site started at one edge of the flange and grew to the other edge. After 30,290 cycles, the beam failed on the tension flange at $x=336 \mathrm{~mm}$ and is shown in Figure 79. The flange delaminated between the adhesive and the $+45^{\circ}$ ply (ply 12, Table 22) from $x=279$ to $x=394 \mathrm{~mm}$ and contained multiple fiber bridging sites. The tension flange delamination traveled $45 \mathrm{~mm}$ into the web directly under the failure site. Some other minor cracks were evident on the flanges of the preform as the $\pm 45^{\circ}$ fabrics did not completely fill the C-channel mold, and thus created a matrix rich region on the flange edge, which cracked and segmented. These cracks were on the order of 10 $\mathrm{mm}$ in length, $5 \mathrm{~mm}$ wide and were located over the shear stiffener area of the beam. The load pads showed the same minor delamination problem as in Beam 11. Both these manufacturing flaws did not seem to cause any problems with the performance of the beam during the test. Otherwise, no shear stiffener, torsional stiffener or compression flange damage or delaminations were visible.

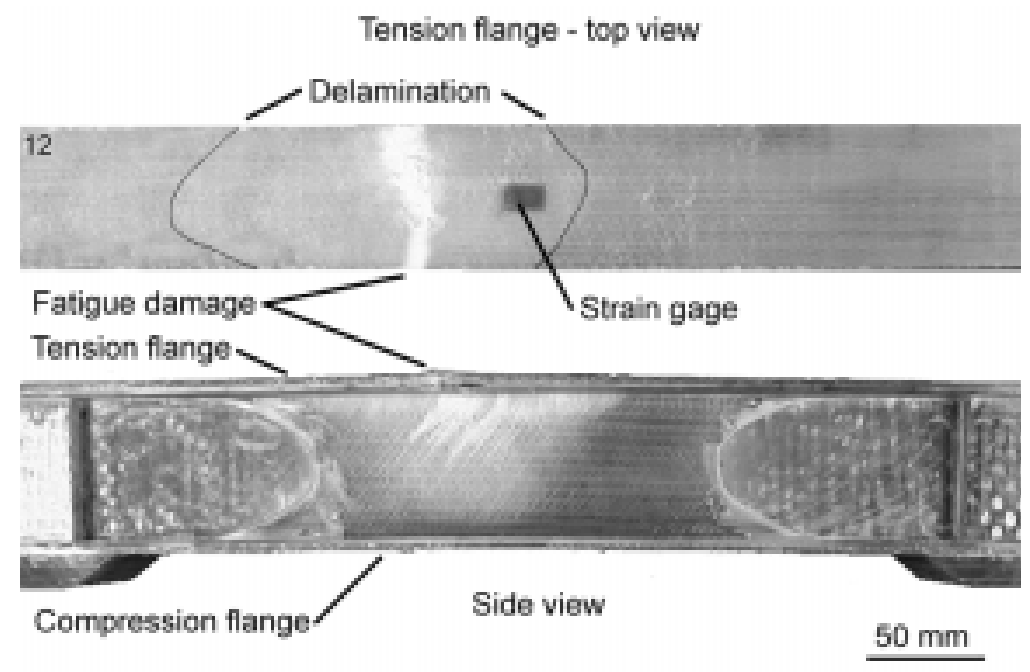

Figure 79. Beam 12. 


\section{BEAM 13}

Beam 13 involved a static test. The beam was loaded under actuator displacement control at a rate of $0.51 \mathrm{~mm} / \mathrm{s}$ until failure, which involved a total ramp time of 21 seconds. An initial beam stiffness of $3,516 \mathrm{kN} / \mathrm{m}$ was measured. The ultimate load was $60.72 \mathrm{kN}$ and corresponded to a maximum tension flange strain of $2.10 \%$, a minimum compression strain of $-1.85 \%$ and a maximum mid-span deflection of $17 \mathrm{~mm}$. The load versus maximum strain graph is shown in Figure 80. The beam failed in the compression flange at $\mathrm{x}=330 \pm 25 \mathrm{~mm}$ with delaminations between the $0^{\circ}$ (ply 10, Table 22) and +45 plies (ply 11,22) over the distance of $x=165 \mathrm{~mm}$ to $\mathrm{x}=457 \mathrm{~mm}$. The failed beam is shown in Figures 81 and 82 . The failure at $x=330 \mathrm{~mm}$ caused the web to delaminate towards the tension flange under this failure point, causing an additional delamination spot under the tension flange. No shear stiffener, torsional stiffener or other tension flange damage or delaminations were visible.

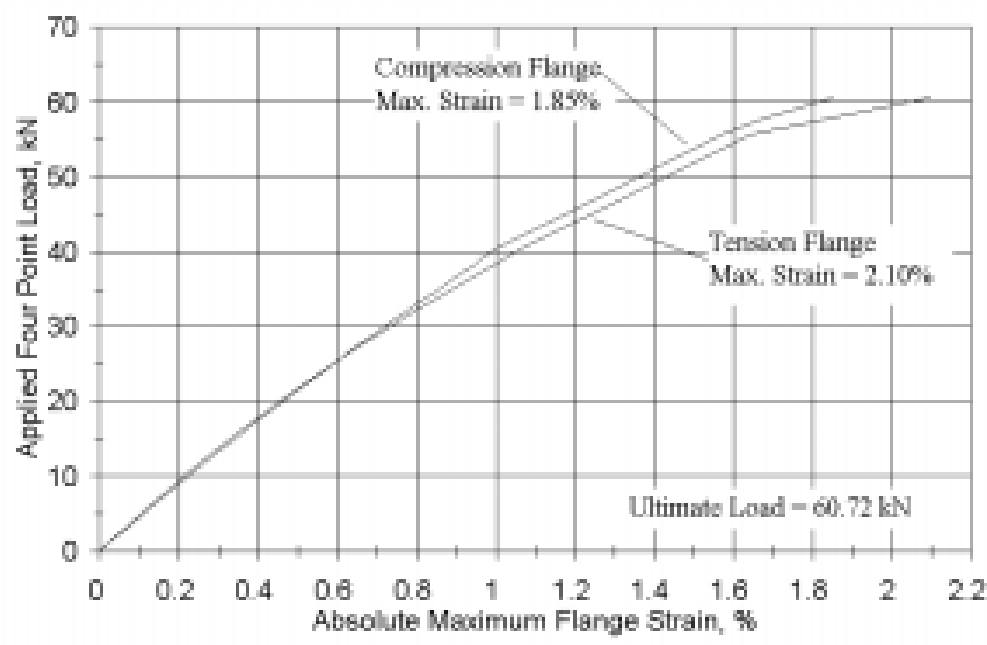

Figure 80. Load vs. maximum flange strain, beam 13, static test. 
Compression flange - top view

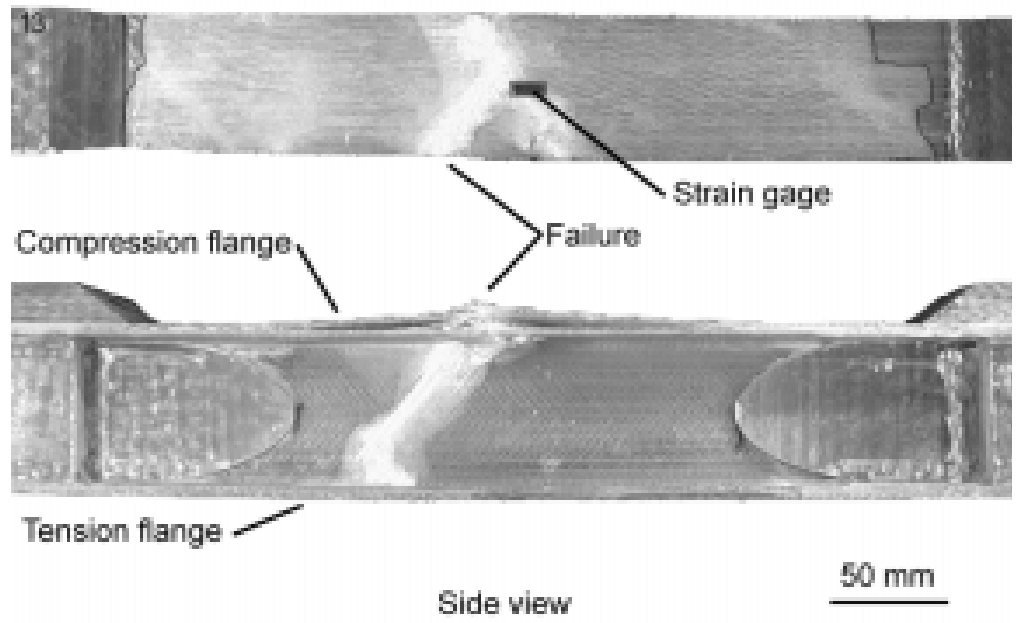

Figure 81. Beam 13.

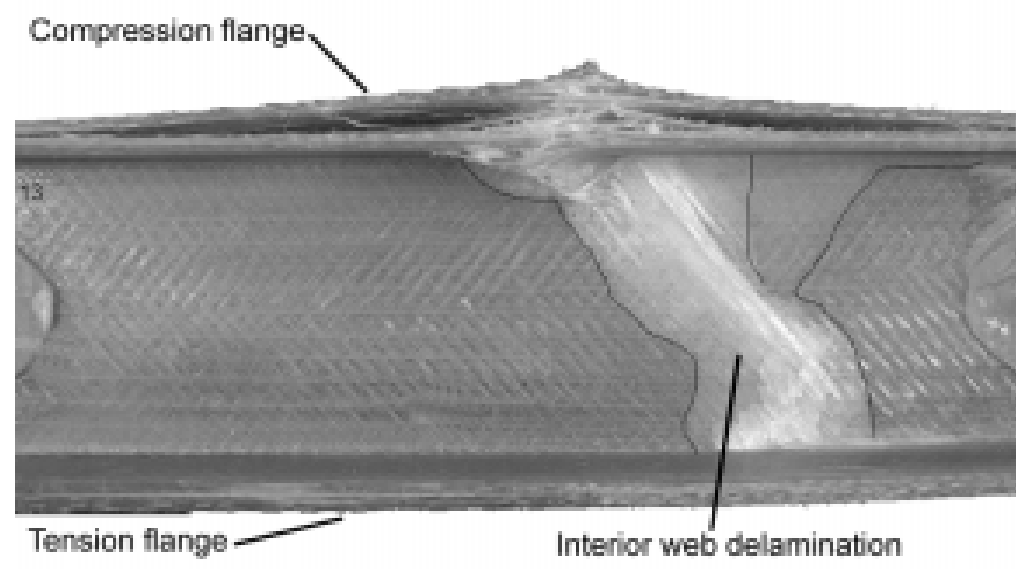

Figure 82. Beam 13. 


\section{BEAM 14}

Beam number 14 was fatigued at a rate of 5 to $10 \mathrm{~Hz}$ with a maximum load of $24.5 \mathrm{kN}$ and a minimum load of $2.5 \mathrm{kN}$. The maximum load produced an initial maximum tension flange strain of $0.59 \%$ and a minimum compression flange strain of $-0.58 \%$. The initial beam stiffness was measured as $3,407 \mathrm{kN} / \mathrm{m}$. The fatigue test was stopped after 160,000 cycles to check the stiffness, which had reduced to $3,271 \mathrm{kN} / \mathrm{m}$ or $96 \%$ of the initial stiffness. After 389,175 cycles the tension flange failed at $\mathrm{x}=248 \pm 6 \mathrm{~mm}$. The damage started at the edge of the flange and grew across the flange until final failure. The failure caused a delamination from $\mathrm{x}=229 \mathrm{~mm}$ to $\mathrm{x}=394 \mathrm{~mm}$ and was between the $+45^{\circ}$ ply (ply 16, 22) and the $-45^{\circ}$ ply (ply 17, Table 22) in the web flange. Figure 83 shows the failed beam. This delamination extended $10 \mathrm{~mm}$ down into the web. No shear stiffener, torsional stiffener or compressive flange damage or delaminations were visible.

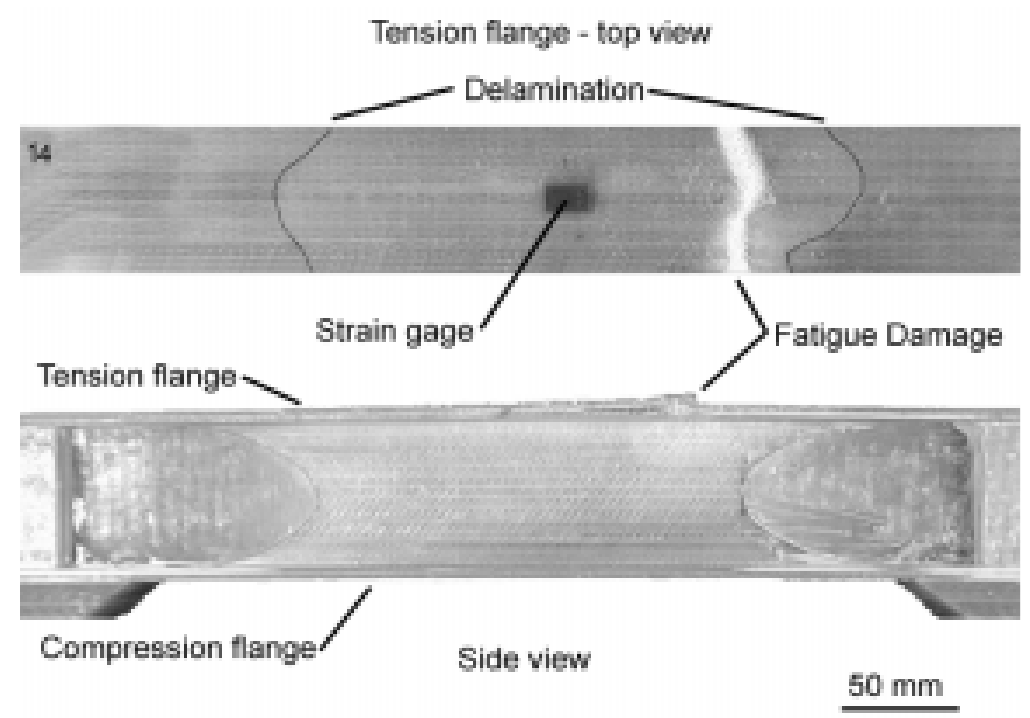

Figure 83. Beam 14. 


\section{BEAM 22}

Beam number 22 was fatigued at a rate of $5 \mathrm{~Hz}$ with a maximum load of $31.1 \mathrm{kN}$ and a minimum load of $3.1 \mathrm{kN}$. The maximum load produced an initial maximum tension flange strain of $0.84 \%$ and a minimum compression flange strain of $-0.76 \%$. The initial beam stiffness was measured as 3,637 $\mathrm{kN} / \mathrm{m}$. This beam had two acoustic emission sensors on the tension flange centered at $\mathrm{x}=70$ and $543 \mathrm{~mm}$ and two on the compression flange centered at $\mathrm{x}=178$ and $432 \mathrm{~mm}$. The acoustic emission testing was performed with Dr. Al Beattie from Sandia National Laboratory. This beam showed less white damage sites on the tension flange than the previous beams during the fatigue test. Final failure occurred on the tension flange at $\mathrm{x}=368 \pm 10 \mathrm{~mm}$ with a delamination between the $+45^{\circ}$ ply (ply 11 , Table 22) and the $-45^{\circ}$ ply (ply 12, Table 22). The delamination was between $x=330$ and 406 $\mathrm{mm}$ and grew $25 \mathrm{~mm}$ into the web. The failed beam is shown in Figure 84. No shear stiffener, torsional stiffener or compression flange damage or delaminations were visible.

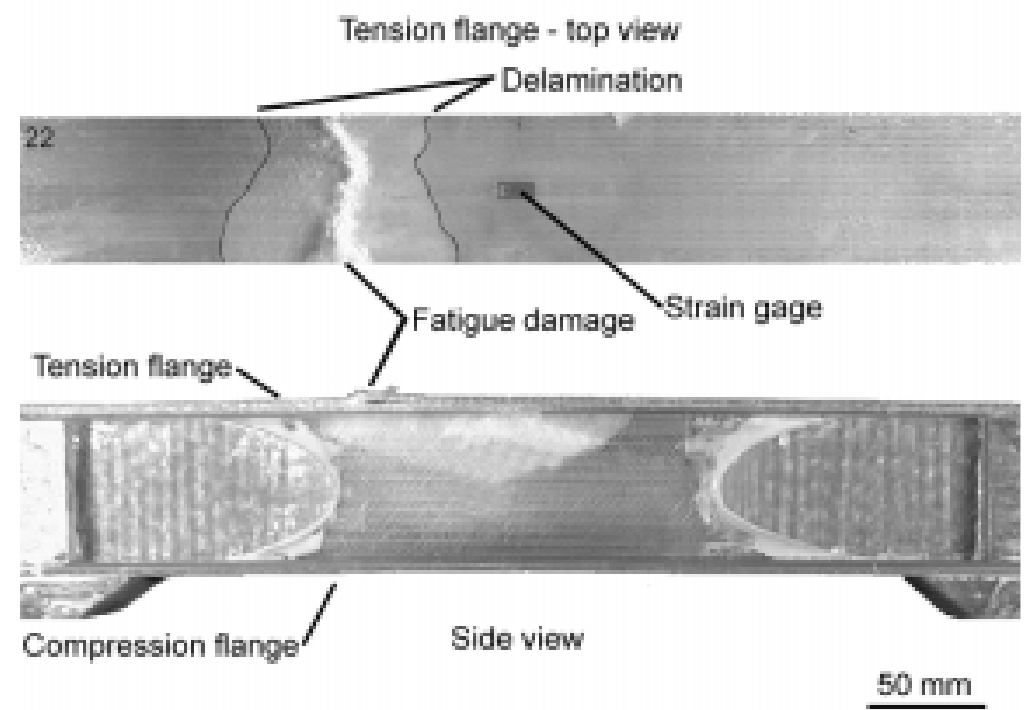

Figure 84. Beam 22. 


\section{BEAM 23}

Beam number 23 was fatigued at a rate of $5 \mathrm{~Hz}$ with a maximum load of $28.9 \mathrm{kN}$ and a minimum load of $2.9 \mathrm{kN}$. The maximum load produced an initial maximum tension flange strain of $0.71 \%$ and a minimum compression flange strain of $-0.64 \%$. The initial beam stiffness was measured as 3,542 $\mathrm{kN} / \mathrm{m}$. This beam also had two acoustic emission sensors on the tension flange centered at $\mathrm{x}=64$ and $543 \mathrm{~mm}$ and two on the compression flange centered at $\mathrm{x}=178$ and $438 \mathrm{~mm}$. The beam failed in the tensile flange after 119,995 cycles. The failure site was at $\mathrm{x}=318 \pm 10 \mathrm{~mm}$ and created a delamination between the adhesive and the $+45^{\circ}$ ply (ply 13,22) of the preform from $\mathrm{x}=292$ to $\mathrm{x}$ $=356 \mathrm{~mm}$. This delamination extended $18 \mathrm{~mm}$ down into the web. The web flange had a matrix rich region on the edge of the flange between $x=279$ and $x=470 \mathrm{~mm}$ and had a maximum depth towards the web of $8 \mathrm{~mm}$. The failed beam is shown in Figure 85. The failure site of the tensile flange was within this matrix rich region and it is believed that the initial delamination was nucleated at this edge and between the adhesive and the preform. Although this beam went 89,705 cycles longer than Beam 12, it is assumed that this had some minor effect on the performance of the test, but not a large enough effect to be considered a structurally flawed beam. No shear stiffener, torsional stiffener or compression flange damage or delaminations were visible.

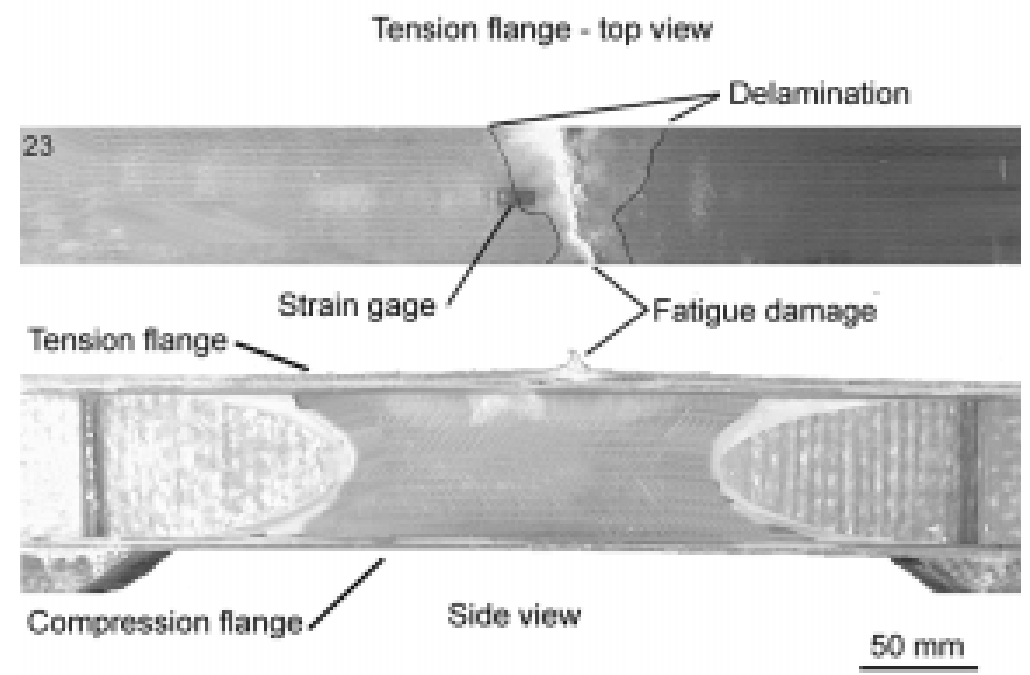

Figure 85. Beam 23. 


\section{Beams With Improved Flange and Web Materials}

\section{Beams with DD5P Material Flanges and CH10 Web Material}

Beams 18 through 21 and 24 through 29 all had DD5P flange material, $\mathrm{V}_{\mathrm{F}}=0.36$, consisting of a lay up of $\left(0^{\circ} \pm 45^{\circ} / 0^{\circ}\right)_{\mathrm{s}}$. The description of the I - beam flange layup and ply numbering scheme for these beams is outlined in Table 24 .

Table 24. Ply Reference Notation for Beams 18 - 21 and 24 - 29.

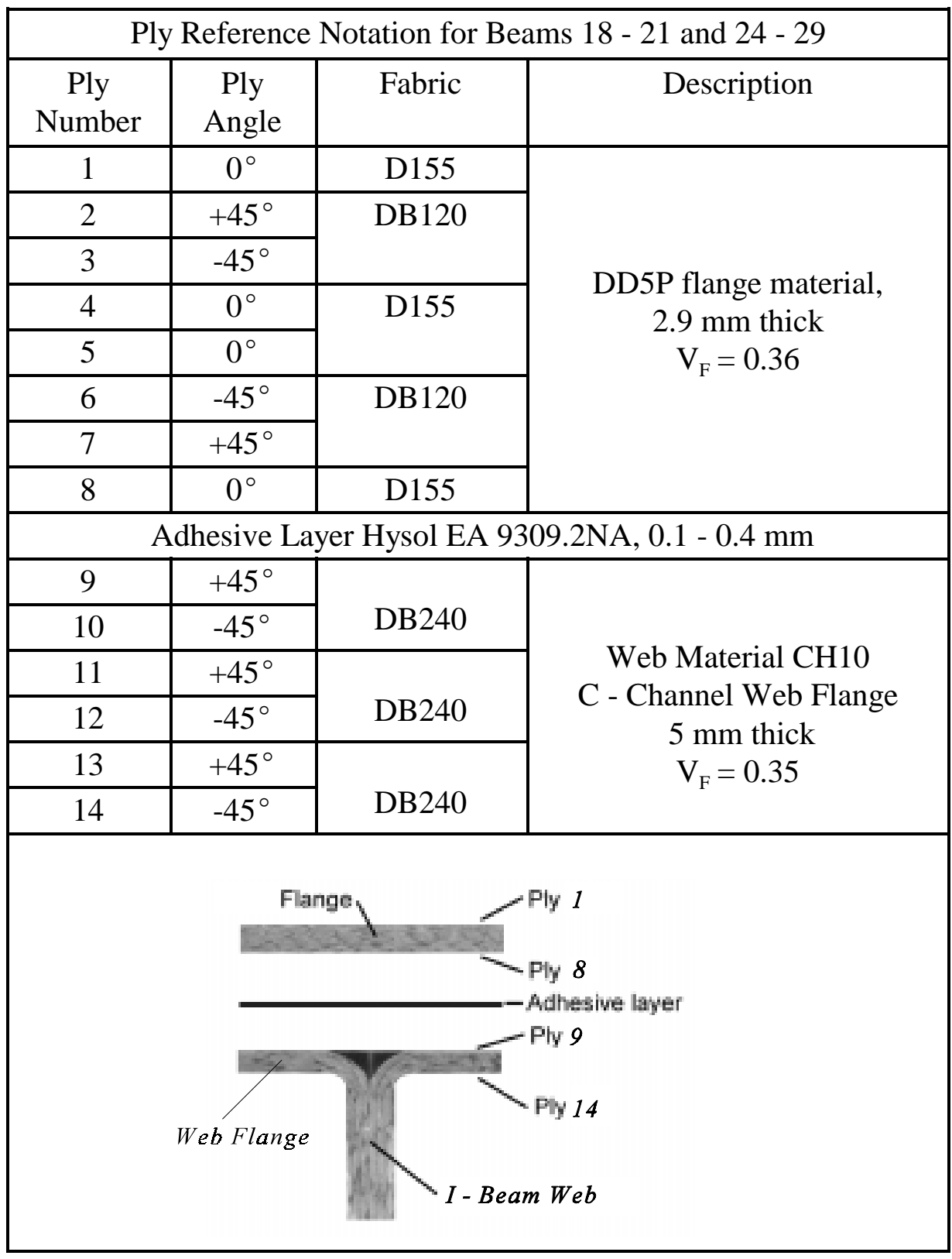




\section{BEAM 18}

Beam number 18 was fatigued at a rate of $1 \mathrm{~Hz}$ under sinusoidal load control with a maximum load of $62.3 \mathrm{kN}$ and a minimum load of $6.3 \mathrm{kN}$. The maximum load produced an initial maximum tension flange strain of $1.42 \%$ and a minimum compression flange strain of $-1.34 \%$. The initial beam stiffness was measured as $4,134 \mathrm{kN} / \mathrm{m}$. During the fatigue test, it was evident from the $0^{\circ}$ fiber bundles delaminating from the flange surface that the DD5P flange material had been manufactured with a $2^{\circ}$ to $3^{\circ}$ angle. This angle caused the $0^{\circ}$ edge terminated fibers to delaminate, starting from the flange edge and growing inward along the fiber bundle axis. This damage was confined to 4 to $6 \mathrm{~mm}$ from the flange edges and involved both the tension and compression flanges. The beam stiffness was checked throughout the test and is summarized in Table 25. As the fatigue test progressed, the tension flange started to delaminate from the $\mathrm{C}$ - channel between the $0^{\circ}$ ply (ply 8 , Table 24) and the $+45^{\circ}$ ply (ply 7, Table 24). This initial delamination started in the center of the beam and was located directly above the tapered shear stiffeners, $x=165 \mathrm{~mm}$ and $\mathrm{x}=457 \mathrm{~mm}$. This delamination grew until the test was stopped after 9,367 cycles. At this point, the delamination extended from $\mathrm{x}=127 \mathrm{~mm}$ to $\mathrm{x}=571 \mathrm{~mm}$, but had not completely traveled across the width of the flange. The compression flange had some transverse tensile cracks under the edges of the web and extended from $\mathrm{x}=152$ to $457 \mathrm{~mm}$. There was also major flange damage at $\mathrm{x}=381$ to $432 \mathrm{~mm}$, directly below the tapered shear stiffener, that was $18 \mathrm{~mm}$ wide. This damage involved broken $0^{\circ}$ on the surface and delaminations throughout the thickness of the flange. The web had delaminations extending into the shear stiffeners, but otherwise the center web, $x=215$ to $x=394 \mathrm{~mm}$, had no other noticeable damage. One shear stiffener showed cracking at $x=444 \pm 12 \mathrm{~mm}$ on the tension flange side and was involved with the web delamination underneath. The failed beam is shown in Figure 86.

Table 25. Beam 18 Stiffness vs. Cycles.

\begin{tabular}{|c|c|c|c|}
\hline Cycles & $\begin{array}{c}\text { Stiffness } \\
(\mathrm{K}), \mathrm{kN} / \mathrm{m}\end{array}$ & $\begin{array}{c}\text { Ratio } \\
(\mathrm{K} / 4,134)\end{array}$ & $\begin{array}{c}\mathrm{n} / \mathrm{N} \\
\mathrm{N}=9,367\end{array}$ \\
\hline 0 & 4,134 & 1 & -- \\
\hline 1,000 & 3,714 & 0.90 & 0.11 \\
\hline 2,000 & 3,619 & 0.88 & 0.21 \\
\hline 3,000 & 3,632 & 0.88 & 0.32 \\
\hline 4,000 & 3,659 & 0.88 & 0.43 \\
\hline 5,000 & 3,486 & 0.84 & 0.53 \\
\hline 6,000 & 3,509 & 0.85 & 0.64 \\
\hline 8,000 & 3,428 & 0.83 & 0.85 \\
\hline 9,367 & 3,150 & 0.76 & 1 \\
\hline
\end{tabular}




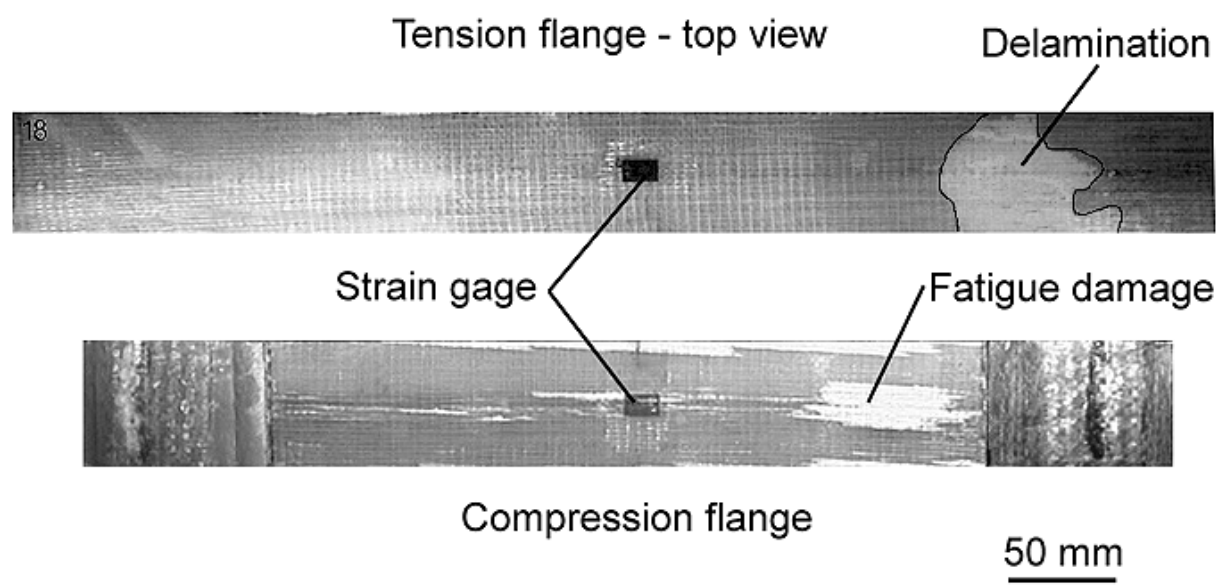

Figure 86. Beam 18.

\section{BEAM 19}

Beam 19 involved a static test. The beam was loaded under actuator displacement control at a rate of $0.05 \mathrm{~mm} / \mathrm{s}$ until failure, which involved a total ramp time of 208 seconds and a total mid-span deflection of $13 \mathrm{~mm}$. An initial beam stiffness of $4,245 \mathrm{kN} / \mathrm{m}$ was measured. As with the other static tests, the compression flange twisted prior to final failure. This twisting was also evident in the failed beam as one side of the beam flange had fragmented glass $0^{\circ}$ and $\pm 45^{\circ}$ tows pointing up, while the other side of the flange had the fragmented glass tows pointing down. The compression flange failed at $\mathrm{x}=305 \pm 15 \mathrm{~mm}$ with multiple delaminations throughout the flange thickness. The compression flange delaminated between the $0^{\circ}$ ply (ply 5,24$)$ and $-45^{\circ}$ ply (ply 6, Table 24) from $x=305$ to 457 $\mathrm{mm}$. The flange also delaminated between the 0 ply (ply 8, Table 24) and the adhesive from $\mathrm{x}=158$ to $305 \mathrm{~mm}$. The failure caused a delamination to travel into the web and created two spot delaminations on the tension flange in the adhesive layer. One shear stiffener showed some delamination at its tapered tip. No other shear stiffener, torsional stiffener or other tension flange damage or delaminations were visible. A maximum tension flange strain of $1.96 \%$ and a minimum compression flange strain of $-1.82 \%$, which occurred at a ultimate applied load of $89.18 \mathrm{kN}$, is shown in Figure 87. The failed beam is shown in Figure 88.

\section{BEAM 20}

Beam number 20 was fatigued at a rate of $4 \mathrm{~Hz}$ under sinusoidal load control with a maximum load of $53.4 \mathrm{kN}$ and a minimum load of $5.3 \mathrm{kN}$. The maximum load produced an initial maximum tension flange strain of $1.09 \%$ and a minimum compression flange strain of $-1.09 \%$. The initial beam stiffness was measured as $4,218 \mathrm{kN} / \mathrm{m}$. The beam stiffness was checked throughout the test and is summarized in Table 26 . The flanges of the beam showed the same $0^{\circ}$ fiber misalignment, $2^{\circ}$ to $3^{\circ}$ , as in Beam number 18 and affected the edges of the flanges. The beam failed after 94,391 cycles due to the tension flange delaminating from the $\mathrm{C}$ - channel involving the $0^{\circ}$ ply (ply 8, Table 24), the adhesive layer and the $\pm 45^{\circ}$ ply (ply 9, Table 24). This delamination was located between $\mathrm{x}=$ 
-75 to $521 \mathrm{~mm}$. Along with the edge $0^{\circ}$ fiber delamination, the compression flange also had transverse tension cracks from $\mathrm{x}=178$ to $445 \mathrm{~mm}$ on the flange located beneath the outside edge of the web. The web had delaminations extending $25 \mathrm{~mm}$ into the web towards the compression flange. The failed beam is shown in Figures 89 and 90.

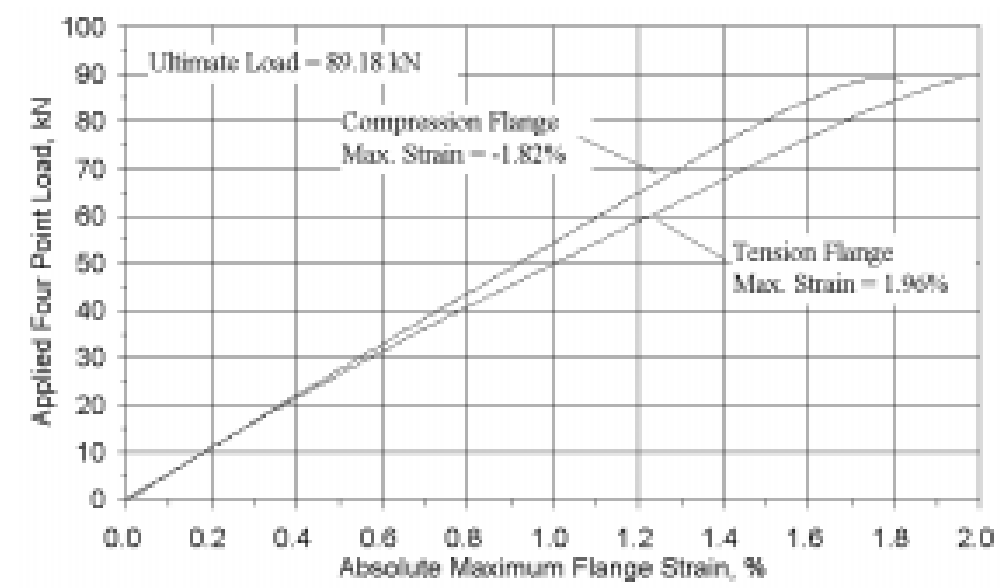

Figure 87. Load vs. maximum flange strain, beam 19, static test.

Tension flange - top view
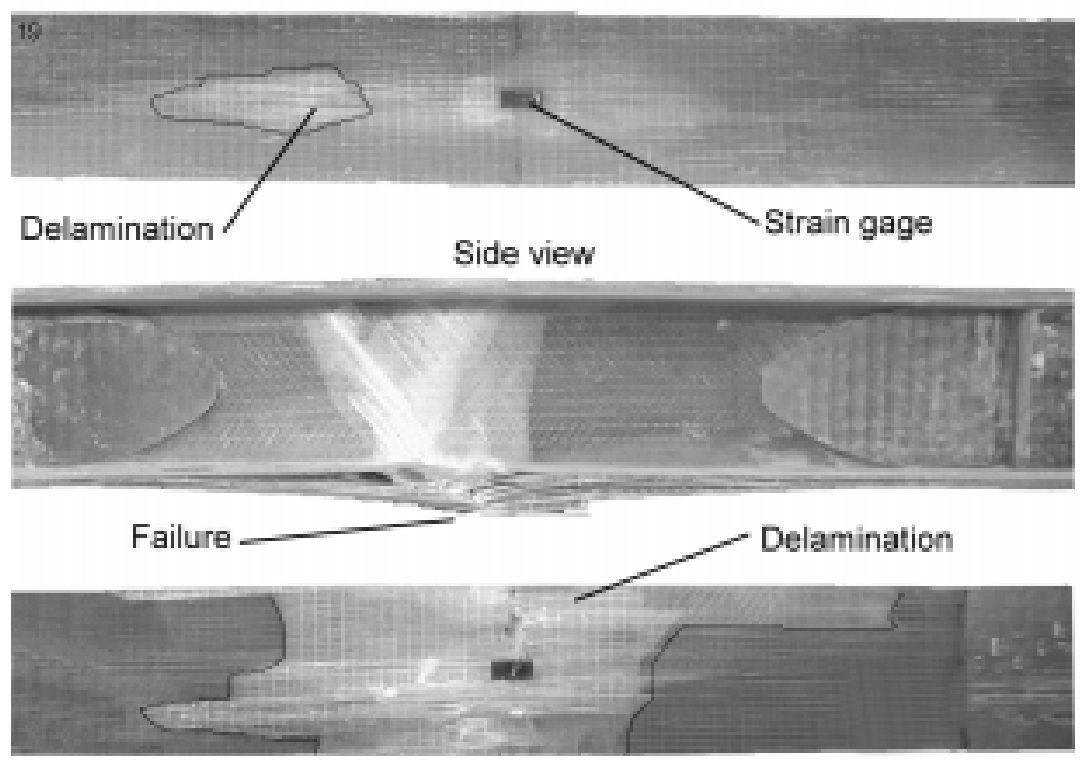

Compression flange

$50 \mathrm{~mm}$

Figure 88. Beam 19.

Table 26. Beam 20 Stiffness vs. Cycles. 


\begin{tabular}{|c|c|c|c|}
\hline Cycles & $\begin{array}{c}\text { Stiffness } \\
(\mathrm{K}), \mathrm{kN} / \mathrm{m}\end{array}$ & $\begin{array}{c}\text { Ratio } \\
(\mathrm{K} / 4,218)\end{array}$ & $\begin{array}{c}\mathrm{n} / \mathrm{N} \\
\mathrm{N}=94,391\end{array}$ \\
\hline 0 & 4,218 & 1 & --- \\
\hline 2,000 & 4,133 & 0.98 & 0.02 \\
\hline 10,000 & 4,009 & 0.95 & 0.11 \\
\hline 30,000 & 3,726 & 0.88 & 0.32 \\
\hline 50,000 & 3,522 & 0.83 & 0.53 \\
\hline 73,000 & 3,022 & 0.72 & 0.77 \\
\hline 90,000 & 2,978 & 0.71 & 0.95 \\
\hline
\end{tabular}

Tension flange - top view

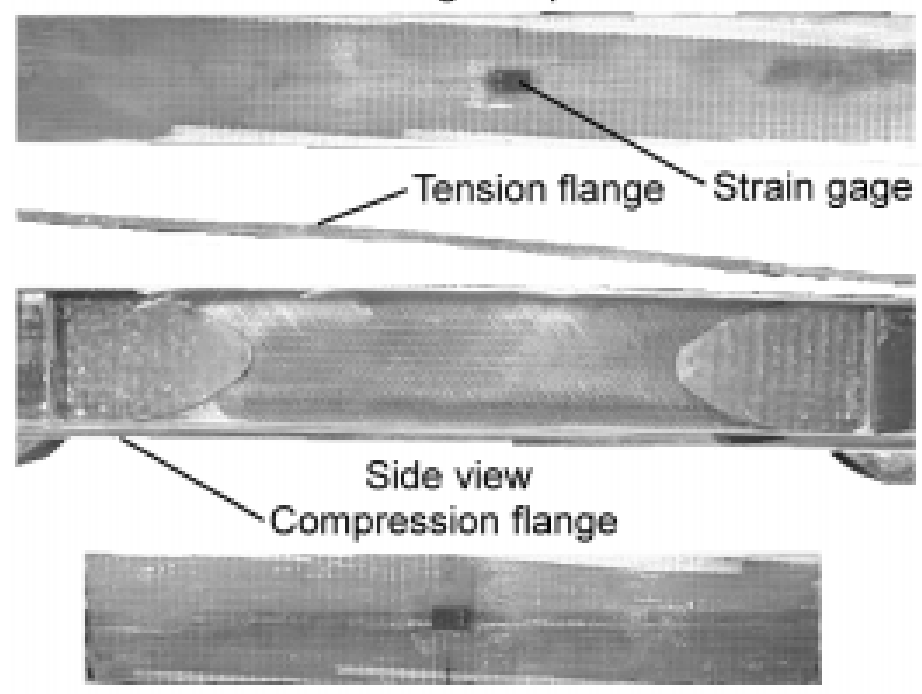

Compression flange

$\underline{50 \mathrm{~mm}}$

Figure 89. Beam 20. 


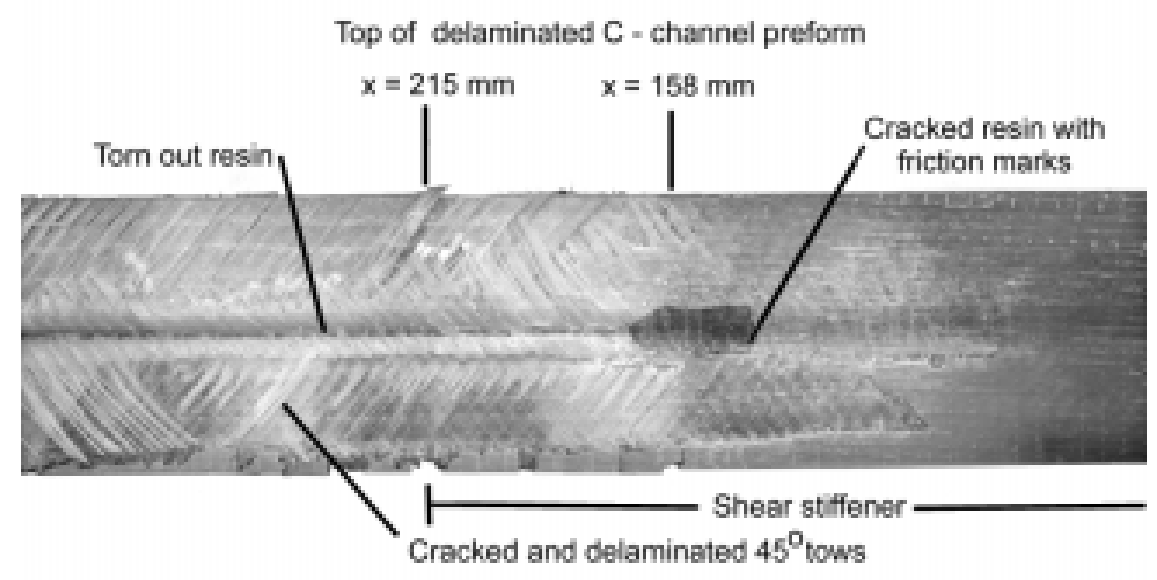

Figure 90. Beam 20.

\section{BEAM 21}

Beam number 21 was fatigued at a rate of $2 \mathrm{~Hz}$ under sinusoidal load control with a maximum load of $53.4 \mathrm{kN}$ and a minimum load of $5.3 \mathrm{kN}$. The maximum load produced an initial maximum tension flange strain of $1.14 \%$ and a minimum compression flange strain of $-0.99 \%$. The initial beam stiffness was measured as $4,110 \mathrm{kN} / \mathrm{m}$. The beam stiffness was checked throughout the test and is summarized in Table 27. This beam had a edge flaw on the tension flange edge at $\mathrm{x}=400 \pm 5 \mathrm{~mm}$ and was $1 \mathrm{~mm}$ deep. This flaw was large enough to start flange delamination from the $\mathrm{C}$ - channel between the $0^{\circ}$ ply (ply 8, Table 24) and the adhesive. After 23,000 cycles, the flange damage was $13 \mathrm{~mm}$ wide and extended from $\mathrm{x}=342 \mathrm{~mm}$ to $440 \mathrm{~mm}$. The delamination extended towards the web and $5 \mathrm{~mm}$ down into it. The compression flange had some transverse tension cracks centered about the web. No shear stiffener, torsional stiffener or other compression flange damage or delaminations were visible. The beam is shown in Figure 91.

\section{BEAM 24}

Beam 24 involved a static test. The beam was loaded under actuator displacement control at a rate of $0.075 \mathrm{~mm} / \mathrm{s}$ until failure, which involved a total ramp time of 190 seconds and a total mid-span deflection of $20 \mathrm{~mm}$. An initial beam stiffness of 4,221 kN/m was measured. The beam had four acoustic emission sensors on the flanges: two on the tension flange centered at $x=76$ and $549 \mathrm{~mm}$, and two on the compression flange centered at $\mathrm{x}=165$ and $432 \mathrm{~mm}$. A maximum tension flange strain of $1.93 \%$ and a minimum compression flange strain of $-1.77 \%$ that occurred at a ultimate applied load of $88.29 \mathrm{kN}$. As with the other static tests, the compression flange twisted prior to final failure. This twisting was also evident in the failed beam as both sides of the beam flange had fragmented glass $0^{\circ}$ and $\pm 45^{\circ}$ tows pointing up. This was a different mode of buckling than the other beams had shown. The compression flange failed at $\mathrm{x}=320 \pm 10 \mathrm{~mm}$ with multiple delaminations throughout the flange thickness. The compression flange delaminated between the $0^{\circ}$ ply (ply 5, Table 24) and $-45^{\circ}$ ply (ply 6, Table 24) from $\mathrm{x}=146$ to $437 \mathrm{~mm}$. The failure caused 
delaminations to travel through the web and into the tension flange adhesive layer. Transverse tension cracks were present on the tension flange from $\mathrm{x}=250$ to $458 \mathrm{~mm}$. The failed beam is shown in Figure 92. No shear stiffener, torsional stiffener or other tension flange damage or delaminations were visible.

Table 27. Beam 21 Stiffness vs. Cycles.

\begin{tabular}{|c|c|c|c|}
\hline Cycles & $\begin{array}{c}\text { Stiffness } \\
(\mathrm{K}), \mathrm{kN} / \mathrm{m}\end{array}$ & $\begin{array}{c}\text { Ratio } \\
(\mathrm{K} / 4,110)\end{array}$ & $\begin{array}{c}\mathrm{n} / \mathrm{N} \\
\mathrm{N}=23,000\end{array}$ \\
\hline 0 & 4,110 & 1 & --- \\
\hline 1,000 & 3,984 & 0.97 & 0.04 \\
\hline 1,500 & 3,943 & 0.96 & 0.07 \\
\hline 2,000 & 3,893 & 0.95 & 0.09 \\
\hline 8,000 & 3,830 & 0.93 & 0.35 \\
\hline 15,000 & 3,811 & 0.93 & 0.65 \\
\hline 21,000 & 3,689 & 0.90 & 0.91 \\
\hline 22,500 & 3,523 & 0.86 & 0.98 \\
\hline
\end{tabular}

Tension flange - top view

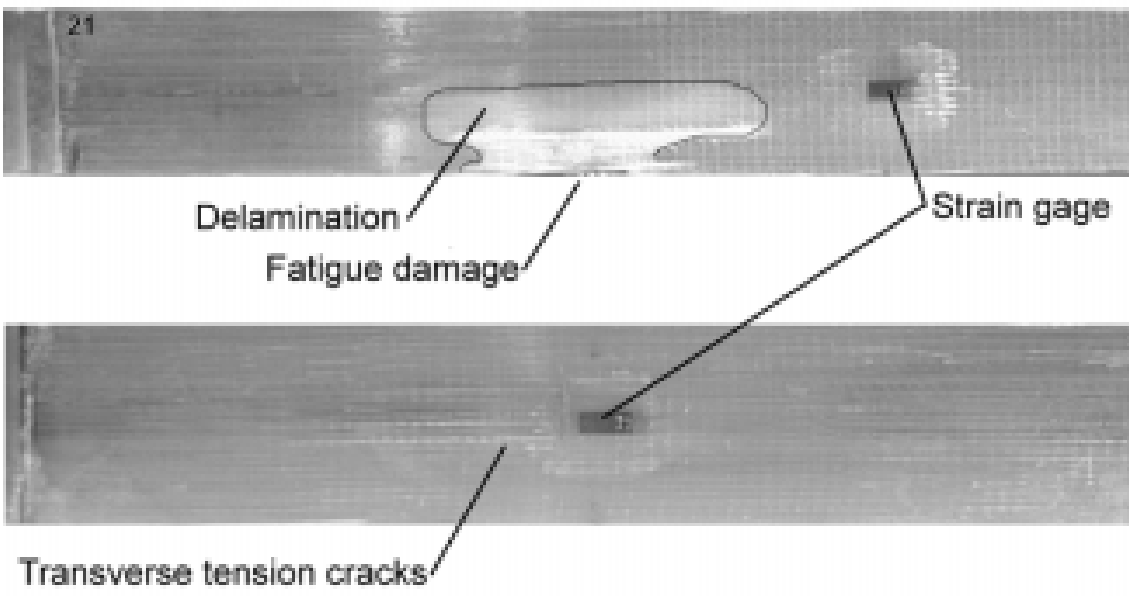

Compression flange

$50 \mathrm{~mm}$

Figure 91. Beam 21. 
Tension flange - top view

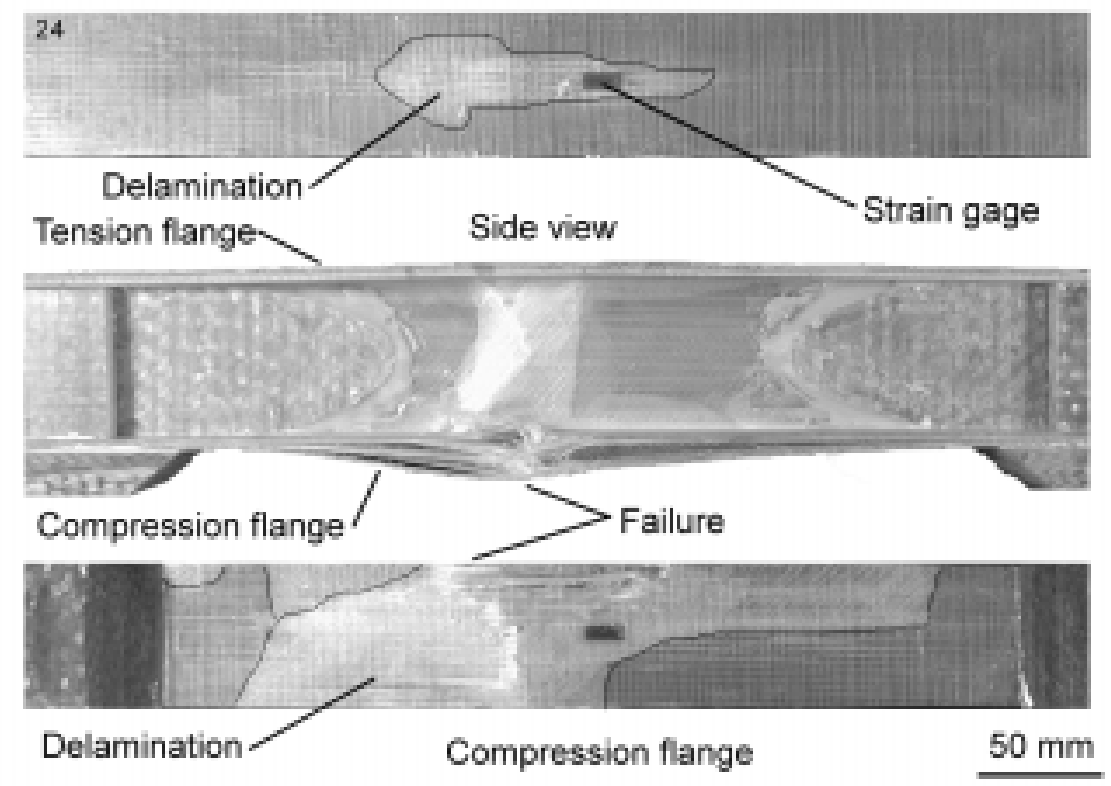

Figure 92. Beam 24.

\section{BEAM 25}

Beam number 25 was fatigued at a rate of $2 \mathrm{~Hz}$ under sinusoidal load control with a maximum load of $62.3 \mathrm{kN}$ and a minimum load of $6.2 \mathrm{kN}$. The maximum load produced an initial maximum tension flange strain of $1.43 \%$ and a minimum compression flange strain of $-1.13 \%$. The initial beam stiffness was measured as $4,305 \mathrm{kN} / \mathrm{m}$. The beam had four acoustic emission sensors on the flanges: two on the tension flange centered at $\mathrm{x}=63$ and $533 \mathrm{~mm}$, and two on the compression flange centered at $x=170$ and $430 \mathrm{~mm}$. After 7,636 cycles, the compression flange failed at $x=229 \pm 13$ $\mathrm{mm}$. A loud pop was heard one cycle prior to failure and it is suspected that a partial delamination grew to a point where it compromised the stability of the compression flange, lowering the strength of the beam to below the maximum fatigue stress. The final failure of the beam indicates a twisting of the compression flange at failure. The flange delamination extended from $\mathrm{x}=170$ to $432 \mathrm{~mm}$ and involved all the $0^{\circ}$ to $45^{\circ}$ interfaces and the adhesive layer. The delamination traveled into the web towards the tension flange and created two spot delaminations. Transverse tension cracks were also present on the tension flange over the web. It is not known if these transverse cracks were present prior to flange failure. No shear stiffener, torsional stiffener or other tension flange damage or delaminations were visible. The failed beam is shown in Figure 93. 


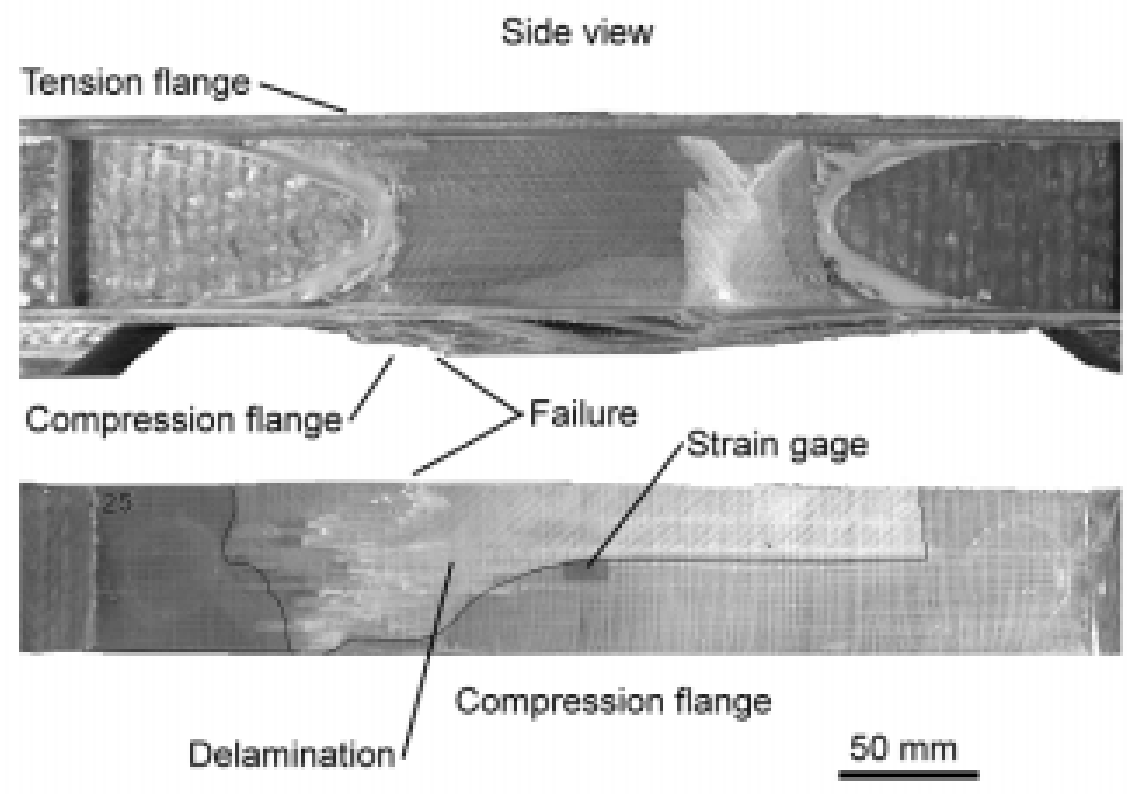

Figure 93. Beam 25.

\section{BEAM 26}

Beam number 26 was fatigued at a rate of $2 \mathrm{~Hz}$ under sinusoidal load control with a maximum load of $57.8 \mathrm{kN}$ and a minimum load of $5.8 \mathrm{kN}$. The maximum load produced an initial maximum tension flange strain of $1.22 \%$ and a minimum compression flange

strain of $-1.05 \%$. The initial beam stiffness was measured as $4,355 \mathrm{kN} / \mathrm{m}$. The beam stiffness was checked throughout the test and is summarized in 28. After 104,407 cycles, the beam failed by compression flange delamination and shear stiffener failure. Shear failure of the compression flange occurred at $\mathrm{x}=133 \mathrm{~mm}$. This was under the compression flange load pad. The compression flange delaminated between the $0^{\circ}$ ply (ply 8,24) and the adhesive layer. Delamination of the tension flange above the shear stiffeners, $x=178$ and $428 \mathrm{~mm}$, was noticed at 10,000 cycles and continued to grow until failure. The beam is shown in Figure 94. All shear stiffeners showed some signs of delamination from the web. 
Table 28. Beam 26 Stiffness vs. Cycles.

\begin{tabular}{|c|c|c|c|}
\hline Cycles & $\begin{array}{c}\text { Stiffness } \\
(\mathrm{K}), \mathrm{kN} / \mathrm{m}\end{array}$ & $\begin{array}{c}\text { Ratio } \\
(\mathrm{K} / 4,355)\end{array}$ & $\begin{array}{c}\mathrm{n} / \mathrm{N} \\
\mathrm{N}=104,407\end{array}$ \\
\hline 0 & 4,355 & 1 & --- \\
\hline 20,000 & 4,078 & 0.94 & 0.19 \\
\hline 50,000 & 3,939 & 0.91 & 0.48 \\
\hline 60,000 & 3,919 & 0.90 & 0.57 \\
\hline 75,000 & 3,878 & 0.89 & 0.72 \\
\hline 100,000 & 3,853 & 0.89 & 0.96 \\
\hline
\end{tabular}

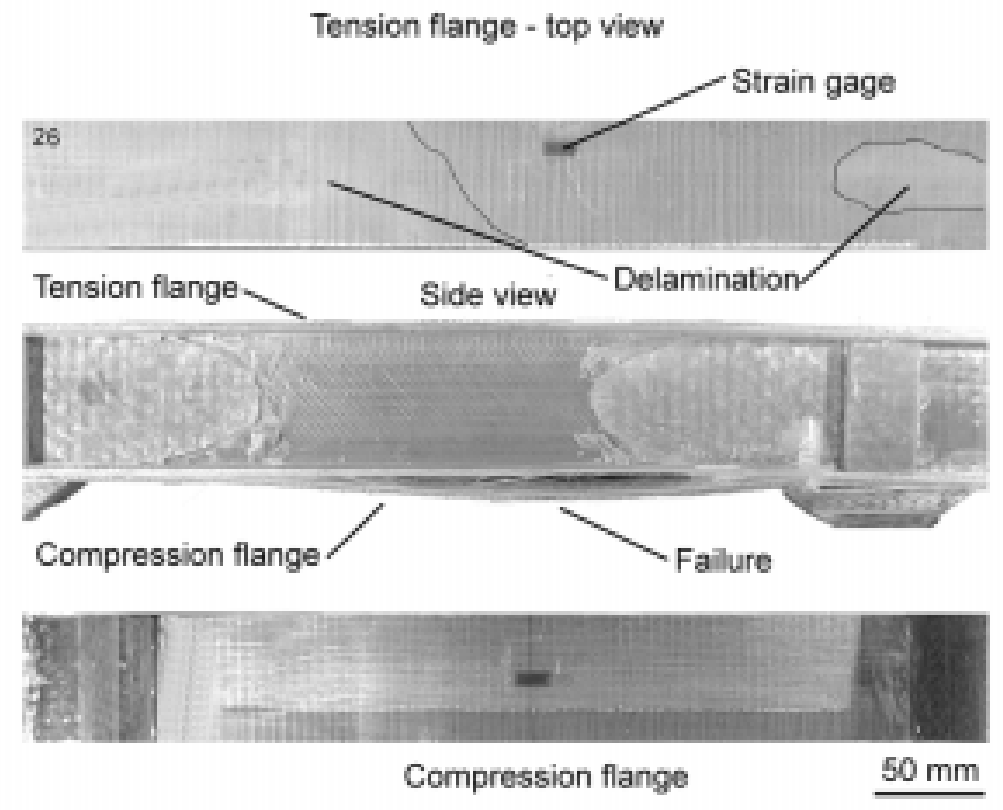

Figure 94. Beam 26. 


\section{BEAM 27}

Beam number 27 was fatigued at a rate of $3 \mathrm{~Hz}$ under sinusoidal load control with a maximum load of $53.4 \mathrm{kN}$ and a minimum load of $5.3 \mathrm{kN}$. The maximum load produced an initial maximum tension flange strain of $1.07 \%$ and a minimum compression flange strain of $-1.00 \%$. The initial beam stiffness was measured as 4,069 $\mathrm{kN} / \mathrm{m}$. As with the other DD5P beams, two tension flange delamination spots started over the tapered shear stiffener area, $\mathrm{x}=178$ and $445 \mathrm{~mm}$. These spots grew during the fatigue test until the delamination was under a tension flange load pad. After 243,876 cycles, the tension flange delaminated. The delamination involved the adhesive layer and the adjacent $0^{\circ}$ and $45^{\circ}$ plies and was from $\mathrm{x}=-75$ to $483 \mathrm{~mm}$. Some transverse cracks were present on both the tensile and compression flanges prior to failure. The shear stiffeners under the delamination show some damage, but it is not known if this was present prior to failure. The web also has delaminations extending $15 \mathrm{~mm}$ down towards the compression flange. The failed beam is shown in Figure 95.

Tension flange - top view

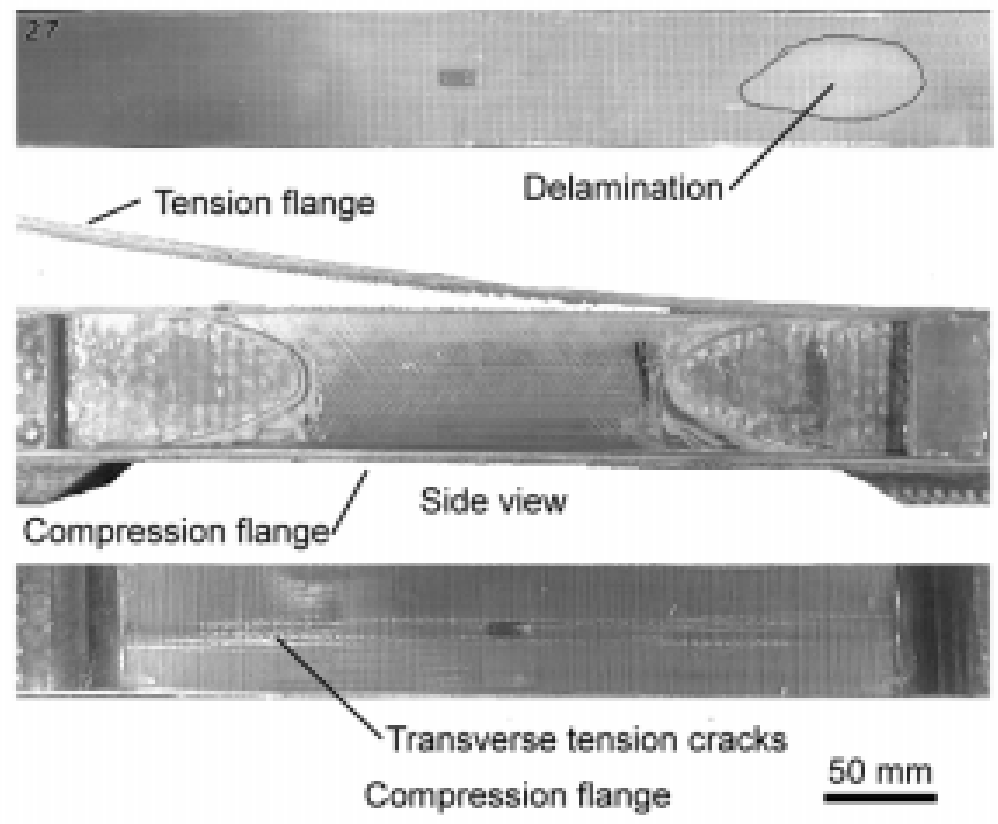

Figure 95. Beam 27. 


\section{BEAM 28}

Beam number 28 was fatigued at a rate of 5 to $12 \mathrm{~Hz}$ under sinusoidal load control with a maximum load of $44.5 \mathrm{kN}$ and a minimum load of $4.4 \mathrm{kN}$. The maximum load produced an initial maximum tension flange strain of $0.86 \%$ and a minimum compression flange strain of $-0.85 \%$. The initial beam stiffness was measured as $4,142 \mathrm{kN} / \mathrm{m}$. Tension flange delamination spots started to develop over the tapered shear stiffener area, $x=178$ and $445 \mathrm{~mm}$, after approximately 600,000 cycles. After $2,000,000$ cycles, the beam was stopped and the only damage present was the delamination between the tension flange and the adhesive layer. This is shown in Figure 96. The compression flange has two transverse tension cracks, $\mathrm{x}=406$ to $445 \mathrm{~mm}$ extending under the load pad. No shear stiffener, torsional stiffener or other flange damage or delaminations were visible.

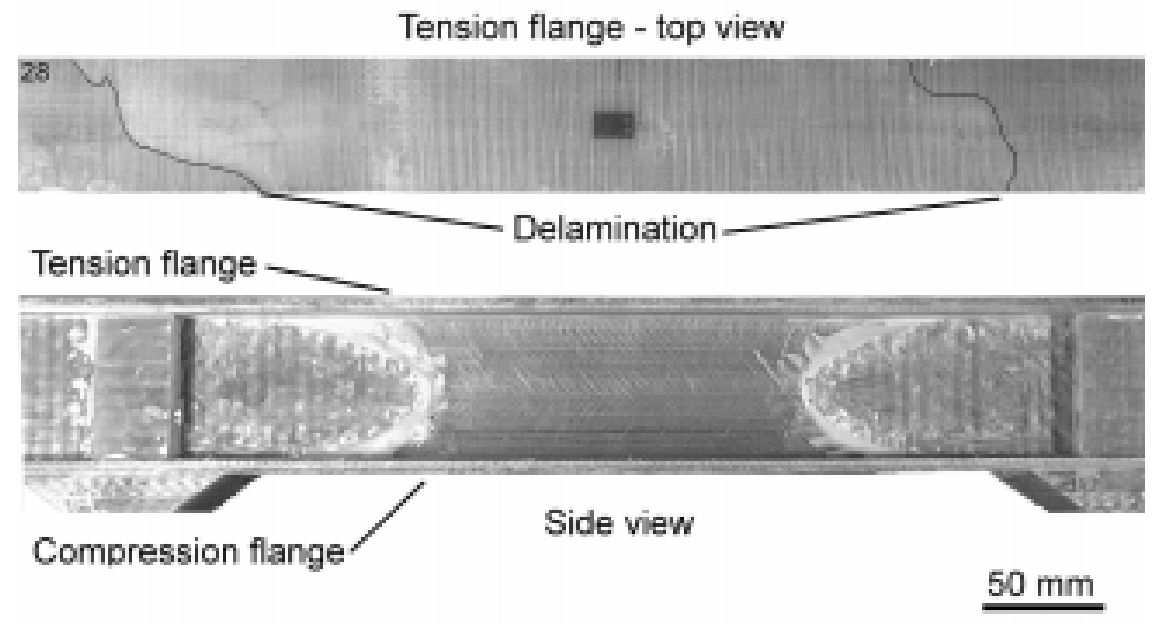

Figure 96. Beam 28. 


\section{BEAM 29}

Beam number 29 was fatigued at a rate of $4 \mathrm{~Hz}$ under sinusoidal load control with a maximum load of $48.9 \mathrm{kN}$ and a minimum load of $4.9 \mathrm{kN}$. The maximum load produced an initial maximum tension flange strain of $0.92 \%$ and a minimum compression flange strain of $-0.96 \%$. The initial beam stiffness was measured as $4,100 \mathrm{kN} / \mathrm{m}$. Kapton film was placed between the strain gages and the flanges in hopes of preventing the matrix cracks from traveling into the strain gages. The traveling was not stopped and the gages failed after 4,000 cycles. No significant improvement in strain gage lifetime, with the Kapton film, was observed. The beam was stopped after 815,684 cycles prior to beam failure. At this point the tension flange delamination extended between the $0^{\circ}$ ply (ply 5 , Table 24) and the $-45^{\circ}$ ply (ply 6, Table 4 ), $x=0$ to $115 \mathrm{~mm}$, and between the adhesive and the $0^{\circ}$ ply (ply 8 , Table 24), $x=115$ to $260 \mathrm{~mm}$. The compression flange showed three small transverse tensile cracks but otherwise no other damage. The beam is shown is Figure 97.

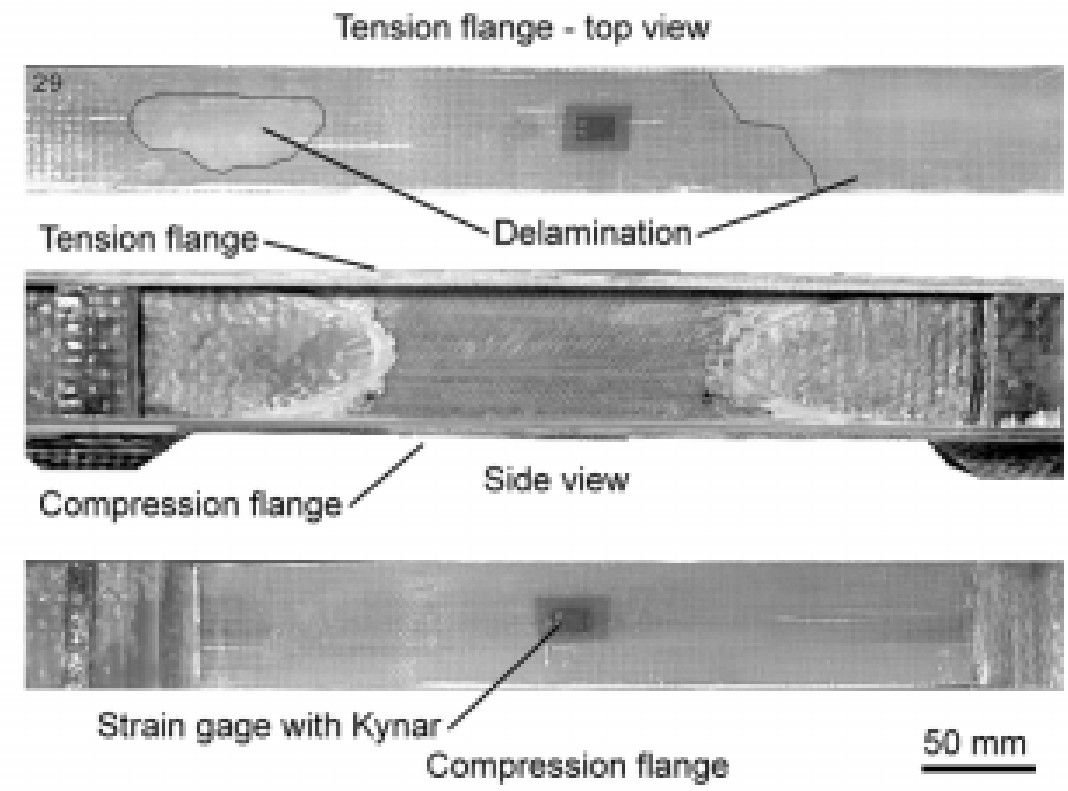

Figure 97. Beam 29. 


\section{Beams with DD5P Material Flanges and CH3 Web Material}

Beams 30, 31, 32 and 33 had a stiffer web, $\mathrm{CH} 3$ vs. $\mathrm{CH} 10$, to try to eliminate the tension flange from delaminating from the I - beam preform. The description of the I - Beam flange lay up and ply numbering scheme for these beams is outlined in Table 29 below.

Table 29. Ply Reference Notation for Beams 30, 31, 32 and 33.

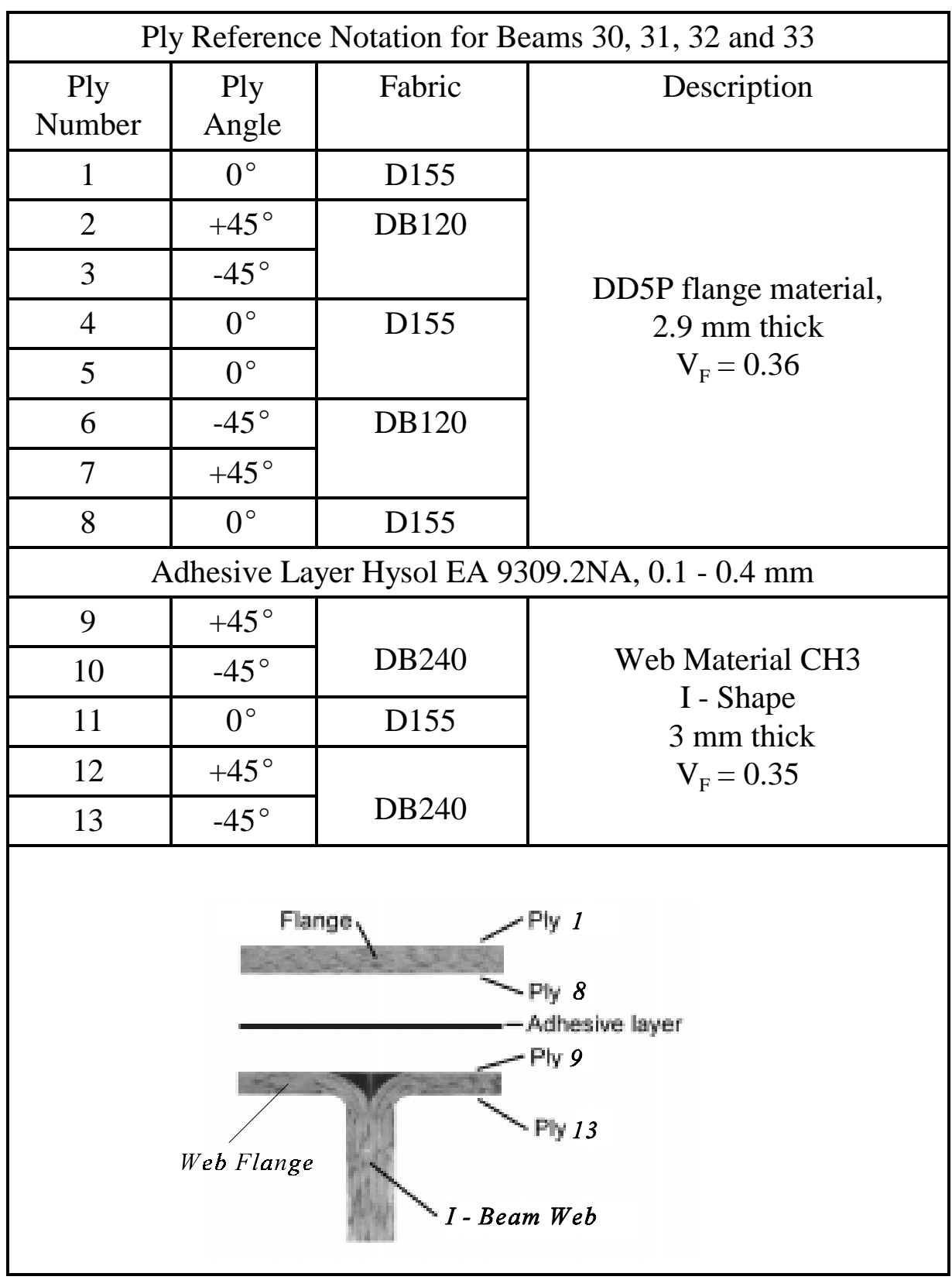




\section{BEAM 30}

Beam number 30 was fatigued at a rate of $2 \mathrm{~Hz}$ under sinusoidal load control with a maximum load of $62.3 \mathrm{kN}$ and a minimum load of $6.2 \mathrm{kN}$. The maximum load produced an initial maximum tension flange strain of $1.20 \%$ and a minimum compression flange strain of $-1.05 \%$. The initial beam stiffness was measured as $4,345 \mathrm{kN} / \mathrm{m}$. The beam had four acoustic emission sensors on the flanges: two on the tension flange centered at $\mathrm{x}=64$ and $533 \mathrm{~mm}$, and two on the compression flange centered at $x=178$ and $432 \mathrm{~mm}$. After 5,741 cycles, the test was stopped as the failure mode was identical to Beam number 26. The shear stiffeners had delaminated and the compression flange had a shear failure through its thickness at $\mathrm{x}=120 \mathrm{~mm}$, under a compression flange load pad. The shear stiffener had a crack at $x=120 \mathrm{~mm}$, which was the start of the stiffener taper, $30 \mathrm{~mm}$ up towards the tension flange. The compression flange had a few transverse tension cracks. The tension flange had started to delaminate over the shear stiffeners. No torsional stiffener or other tension flange damage or delaminations were visible. The failed beam is shown in Figures 98 and 99.

Tension flange - top view

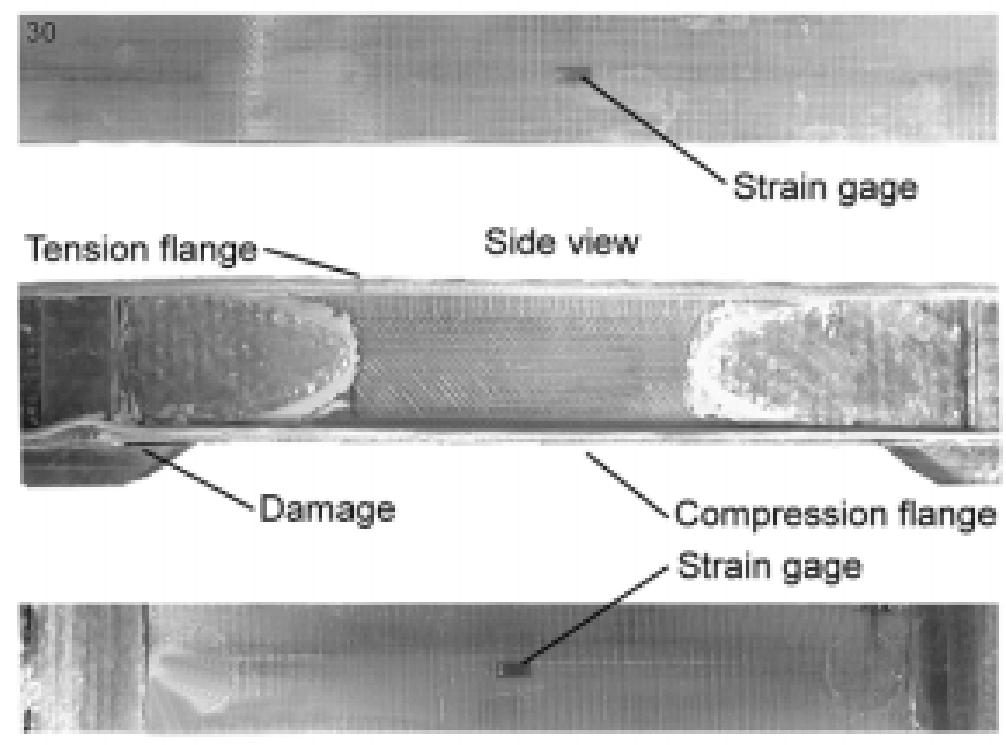

Compression flange

$50 \mathrm{~mm}$

Figure 98. Beam 30. 


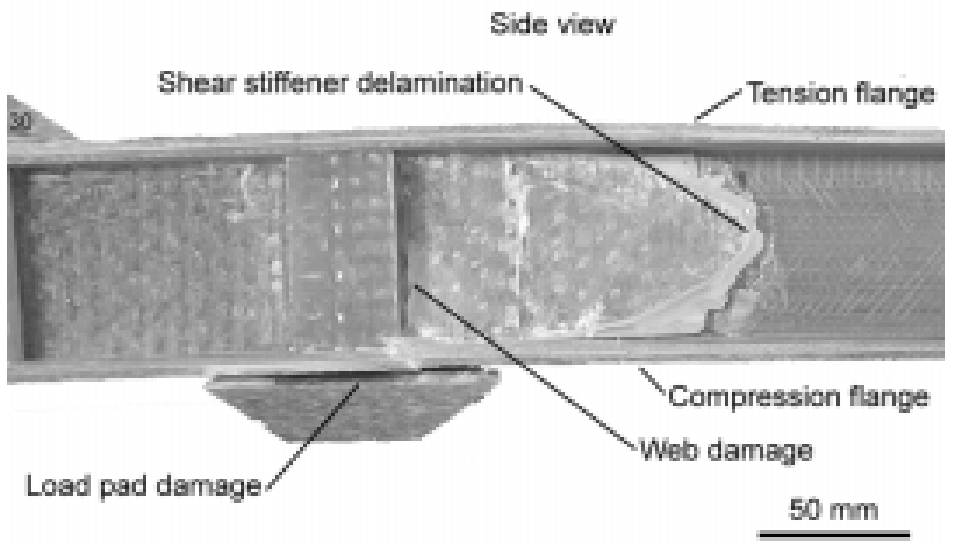

Figure 99. Beam 30.

\section{BEAM 31}

Beam number 31 was fatigued at a rate of $4 \mathrm{~Hz}$ under sinusoidal load control with a maximum load of $53.4 \mathrm{kN}$ and a minimum load of $5.3 \mathrm{kN}$. The maximum load produced an initial maximum tension flange strain of $1.92 \%$ and a minimum compression flange strain of $-0.89 \%$. The initial beam stiffness was measured as $4,764 \mathrm{kN} / \mathrm{m}$. The stiffness was also checked after a power outage at 796,633 cycles, $4,170 \mathrm{kN} / \mathrm{m}$ and after 2,030,240 cycles $3,248 \mathrm{kN} / \mathrm{m}$. The test was stopped after $2,030,240$ cycles. After these cycles 3 of the shear stiffeners had started to delaminate from the web and the tension flange had delaminated from the $C$ - channel between $x=25$ and $280 \mathrm{~mm}$. There was also web delamination damage at $\mathrm{x}=195 \mathrm{~mm}$ that extended down from the tension flange into the tapered shear stiffener area. The compression flange also had multiple transverse tension cracks under this shear stiffener area. The beam is shown in Figure 100.

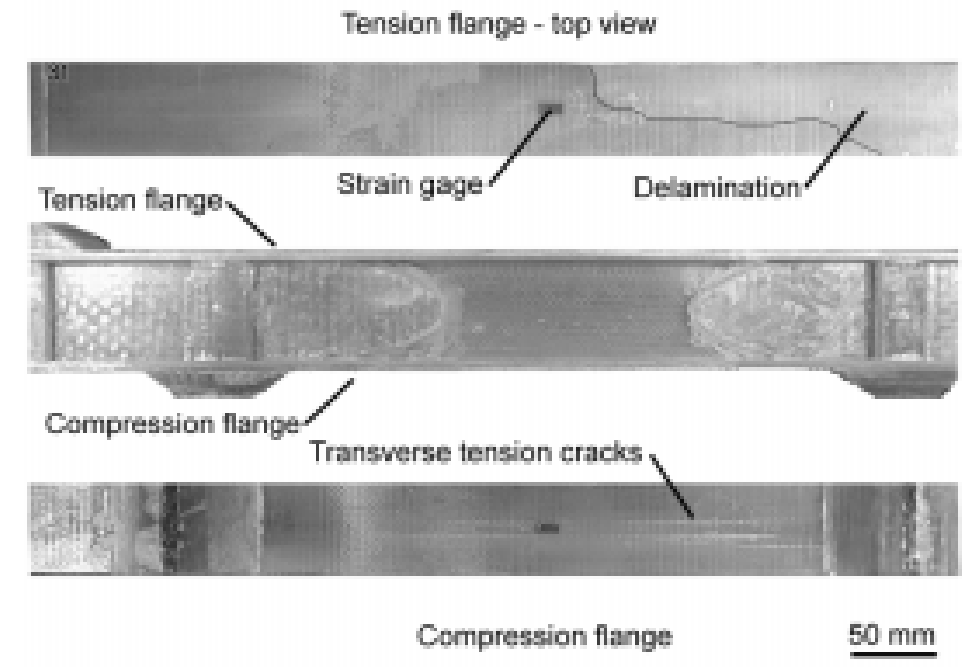

Figure 100. Beam 31. 


\section{BEAM 32}

Beam number 32 was fatigued at a rate of $5 \mathrm{~Hz}$ under sinusoidal load control with a maximum load of $53.4 \mathrm{kN}$ and a minimum load of $5.3 \mathrm{kN}$. The maximum load produced an initial maximum tension flange strain of $0.86 \%$ and a minimum compression flange strain of $-0.73 \%$. The initial beam stiffness was measured as 4,639 kN/m. The beam stiffness was checked throughout the test and is summarized in Table 30. The fatigue test was stopped after 783,153 cycles. Like Beams 26 and 30, this beam started to have the same failure mode. The compression flange has sheared through the thickness at $\mathrm{x}=127 \mathrm{~mm}$ under a compression flange load pad at the edge of the torsional stiffener. The compression flange did not have any visible transverse tension cracks. The only other damage on the beam was the spot delaminations on the tension flange over the shear stiffeners. The beam is shown in Figure 101.

Table 30 Beam 32 Stiffness vs. Cycles.

\begin{tabular}{|c|c|c|c|}
\hline Cycles & $\begin{array}{c}\text { Stiffness } \\
(\mathrm{K}), \mathrm{kN} / \mathrm{m}\end{array}$ & $\begin{array}{c}\text { Ratio } \\
(\mathrm{K} / 4,639)\end{array}$ & $\begin{array}{c}\mathrm{n} / \mathrm{N} \\
\mathrm{N}=783,153\end{array}$ \\
\hline 0 & 4,639 & 1 & --- \\
\hline 5,000 & 4,231 & 0.91 & 0.01 \\
\hline 10,000 & 4,149 & 0.89 & 0.01 \\
\hline 15,000 & 4,161 & 0.90 & 0.02 \\
\hline 20,000 & 4,180 & 0.90 & 0.03 \\
\hline 65,000 & 3,863 & 0.83 & 0.08 \\
\hline 75,000 & 3,844 & 0.83 & 0.10 \\
\hline 85,000 & 3,869 & 0.83 & 0.11 \\
\hline 250,000 & 3,823 & 0.82 & 0.32 \\
\hline
\end{tabular}

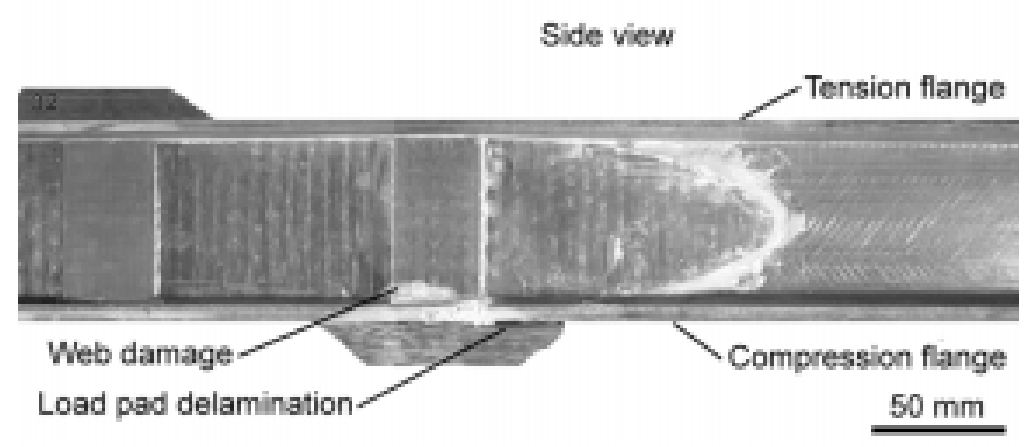

Figure 101. Beam 32. 


\section{BEAM 33}

Beam number 33 was fatigued at a rate of $4 \mathrm{~Hz}$ under sinusoidal load control with a maximum load of $53.4 \mathrm{kN}$ and a minimum load of $5.3 \mathrm{kN}$. The maximum load produced an initial maximum tension flange strain of $0.94 \%$ and a minimum compression flange strain of $-0.93 \%$. The initial beam stiffness was measured as 4,606 kN/m. The beam stiffness was checked throughout the test and is summarized in Table 31. The beam was stopped after 3,200,000 cycles. Although the beam had not failed, there was some tension flange delamination, three spots, which were growing and extended down into the $\mathrm{C}$ - channel at $\mathrm{x}=318 \mathrm{~mm}$. The compression flange had some minor transverse tension cracks. The beam is shown in Figure 102.

Table 31 Beam 33 Stiffness vs. Cycles.

\begin{tabular}{|c|c|c|c|}
\hline Cycles & $\begin{array}{c}\text { Stiffness } \\
(\mathrm{K}), \mathrm{kN} / \mathrm{m}\end{array}$ & $\begin{array}{c}\text { Ratio } \\
(\mathrm{K} / 4,606)\end{array}$ & $\begin{array}{c}\mathrm{n} / \mathrm{N} \\
\mathrm{N}=3,200,000\end{array}$ \\
\hline 0 & 4,606 & 1 & --- \\
\hline 200,000 & 4,184 & 0.91 & 0.06 \\
\hline 300,000 & 4,215 & 0.92 & 0.09 \\
\hline 500,000 & 4,150 & 0.90 & 0.16 \\
\hline $3,200,000$ & 3,873 & 0.84 & 1 \\
\hline
\end{tabular}
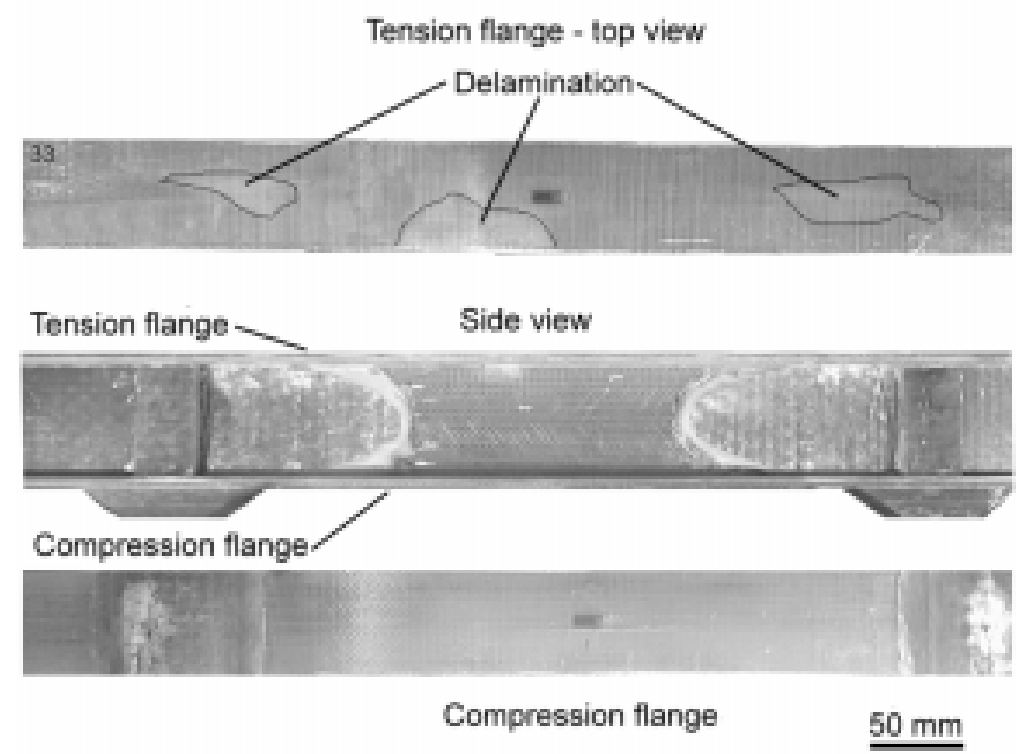

Figure 102. Beam 33. 


\section{Beams With DD5P Material Flanges With CH12 Material Webs}

Although the tension flanges were still delaminating from the web flange, Beams 34 and 35 had their fiber volume reduced to $0.34, \mathrm{CH} 12$ material, with the same $\left( \pm 45^{\circ} / 0^{\circ} \pm 45^{\circ}\right)_{2}$ layup as the previous beams. This fiber volume showed promising fatigue response in standard coupon tests.

\section{Beam 34}

Beam 34 involved a static test. The beam was loaded under actuator displacement control at a rate of $0.075 \mathrm{~mm} / \mathrm{s}$ until failure, which involved a total ramp time of 65 seconds and a total mid-span deflection of approximately $8 \mathrm{~mm}$. An initial beam stiffness of $4,990 \mathrm{kN} / \mathrm{m}$ was measured. The beam had two additional strain gages on the compression flange edges, both top and bottom of the flange. This was done to determine when the flange starts to buckle. The beam was loaded statically to 60 $\mathrm{kN}$ three times before the actual static test. The initial load - flange absolute maximum strain graph is shown in Figure 103 and shows the two standard strain gages on the center of the tension and compression flanges. Figure 104 shows the two compression flange edge gages, back-to-back, which indicates that the onset of buckling in this beam occurs at approximately $75 \mathrm{kN}$ or $1.4 \%$ strain. The third load-up involved the static test and indicated a maximum tension flange strain of $1.92 \%$ and a minimum compression flange strain of $-1.69 \%$ that occurred at a ultimate applied load of 83.22 $\mathrm{kN}$. The failure occurred on the compression flange at $\mathrm{x}=292 \pm 20 \mathrm{~mm}$. The compression flange had transverse tension cracks and multiple delaminations between $\mathrm{x}=150$ and $457 \mathrm{~mm}$. The delaminations extended through the web and into the adhesive layer on the tension flange, producing a delamination from $\mathrm{x}=178$ to $381 \mathrm{~mm}$. The failed beam is shown in Figures 105 and 106.

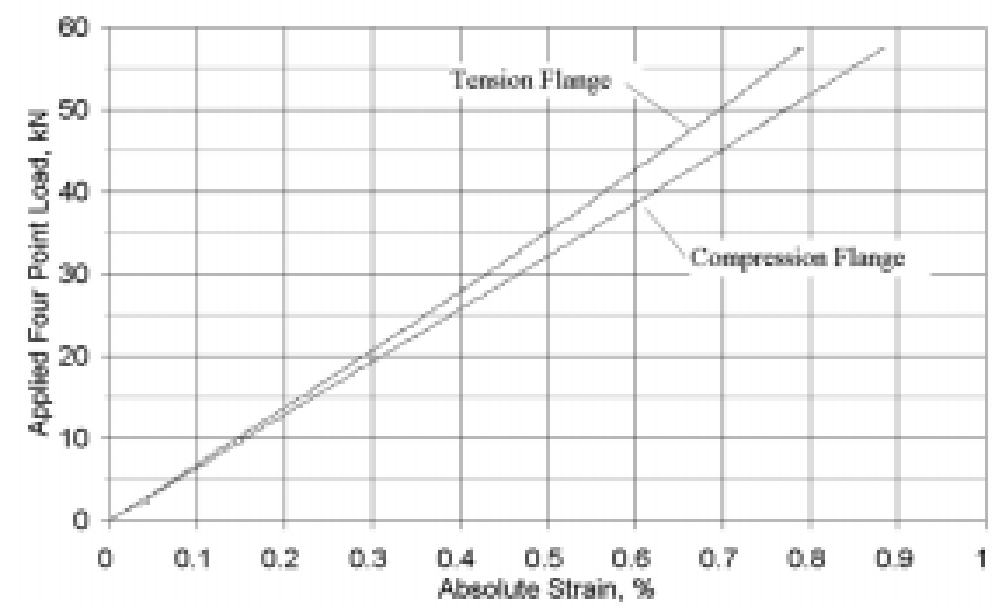

Figure 103. Absolute flange strain vs. load, initial four point loading, beam 34. 


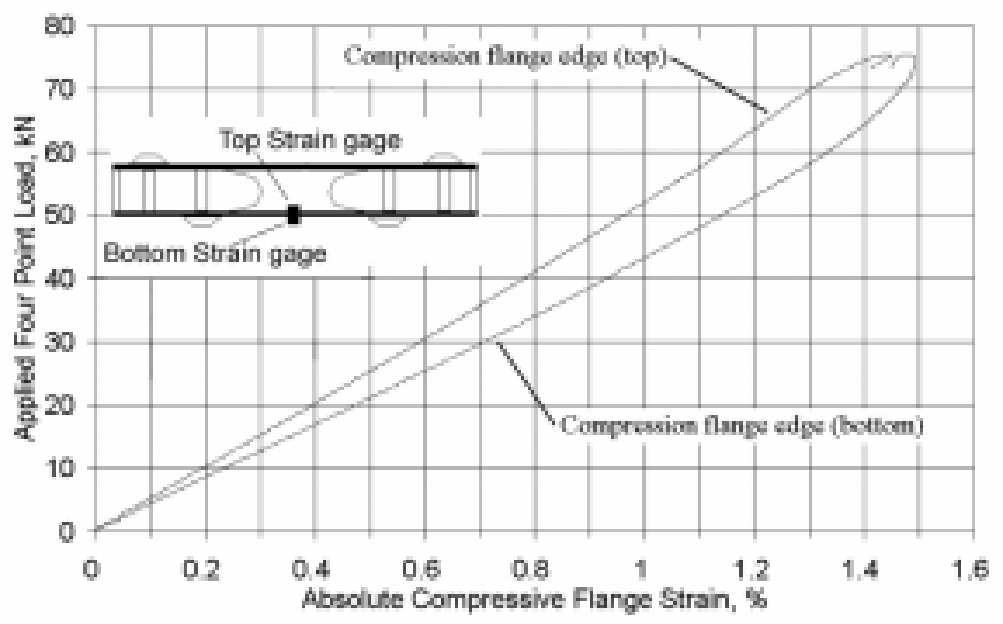

Figure 104. Load vs. compressive flange strain, beam 34 .
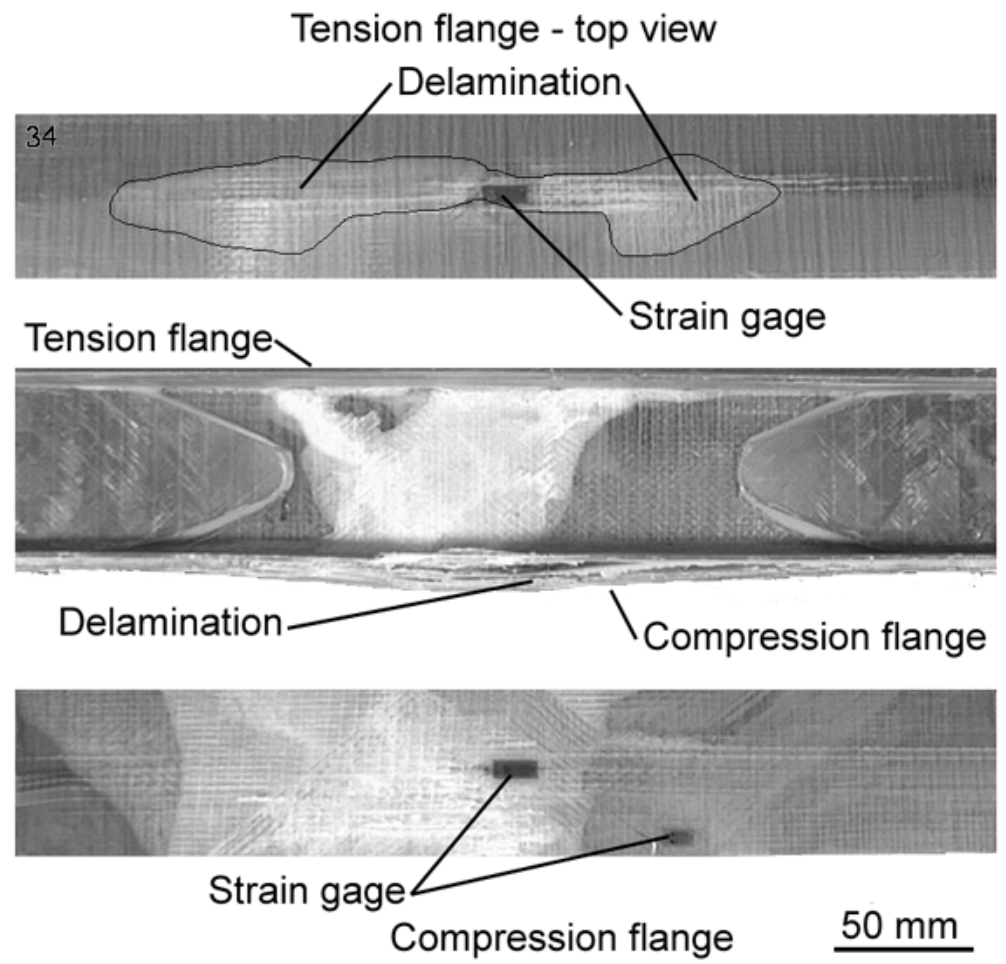

Figure 105. Beam 34. 


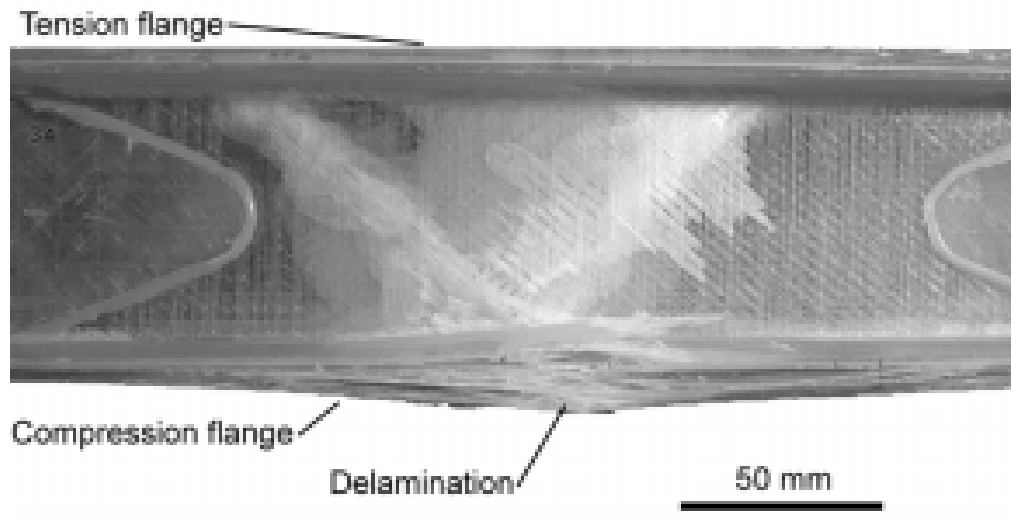

Figure 106. Beam 34.

\section{BEAM 35}

Beam number 35 was fatigued at a rate of $2 \mathrm{~Hz}$ under sinusoidal load control with a maximum load of $62.3 \mathrm{kN}$ and a minimum load of $6.3 \mathrm{kN}$. The maximum load produced an initial maximum tension flange strain of $1.04 \%$ and a minimum compression flange strain of $-1.02 \%$. The initial beam stiffness was measured as $4,347 \mathrm{kN} / \mathrm{m}$. The compression flange delaminated from $\mathrm{x}=-75$ to 458 $\mathrm{mm}$, after 9,771 cycles. The delamination of the flange caused the web to fail at $\mathrm{x}=190 \mathrm{~mm}$ with delamination in the web from $\mathrm{x}=178$ to $267 \mathrm{~mm}$. There were two spot delaminations on the tension flange, caused by the failure, at $x=190$ to $356 \mathrm{~mm}$. The failed beam is shown in Figures 107 and 108.
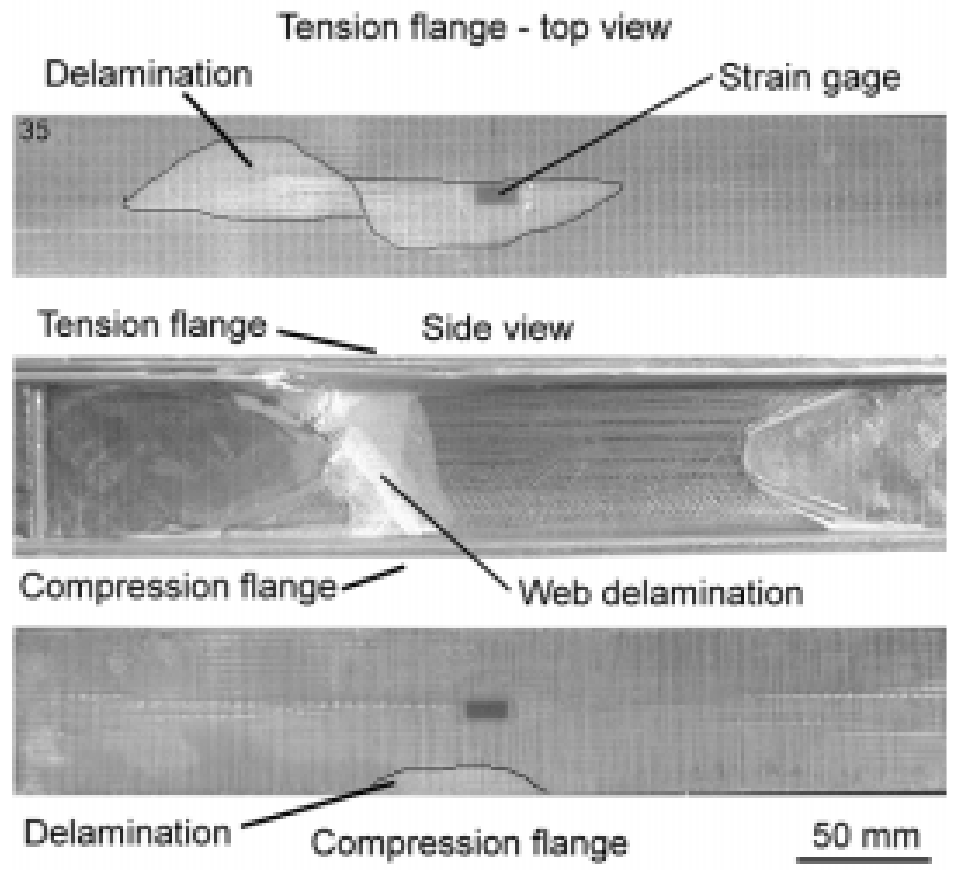

Figure 107. Beam 35. 

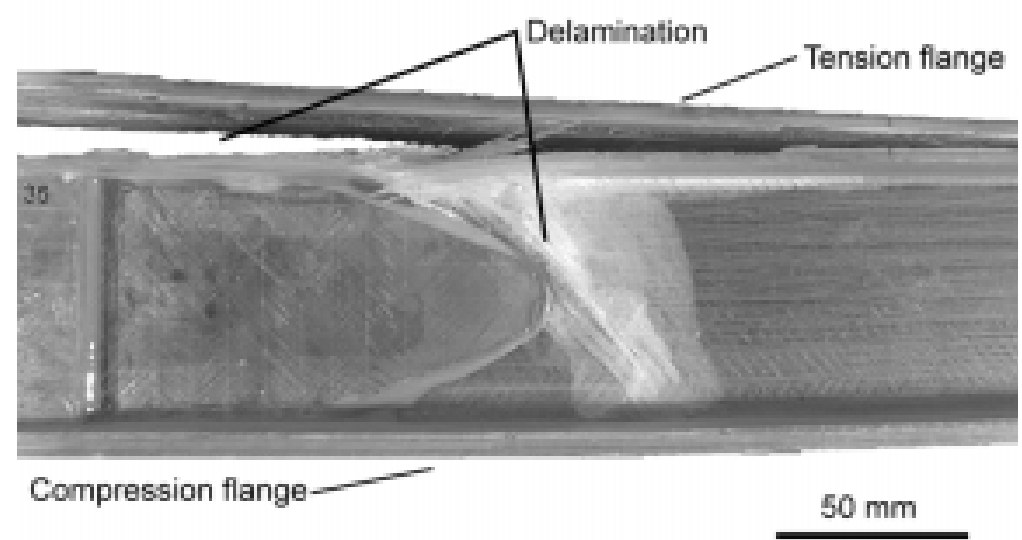

Figure 108. Beam 35. 


\section{DD5P Material Flanges with DD5P Web Material}

Beams 51 through 55 were manufactured with both the flange and web consisting of DD5P material. This was done to increase the stiffness and fatigue response of the web. Beam 53 was tested first, which resulted in a shear stiffener failure. It was therefore necessary to increase the stiffener reinforcement under the load pads to handle the increased loads. The ply lay-up and numbering scheme is shown in Table 32.

\section{BEAM 51}

Beam number 51 was fatigued at a rate of $6 \mathrm{~Hz}$ under sinusoidal load control with a maximum load of $53.4 \mathrm{kN}$ and a minimum load of $5.3 \mathrm{kN}$. The maximum load produced an initial maximum tension flange strain of $0.76 \%$ and a minimum compression flange strain of $-0.75 \%$. The initial beam stiffness was measured as $4,867 \mathrm{kN} / \mathrm{m}$. The beam was stopped after $3,000,000$ cycles with no significant change in stiffness and no major damage. Figure 109 shows the only noticeable damage on the beam, transverse tension cracks on the compression flange. Figure 110 shows the additional shear stiffener material that was added to the beam.

\section{BEAM 52}

Beam number 52 was fatigued at a rate of $3 \mathrm{~Hz}$ under sinusoidal load control with a maximum load of $62.3 \mathrm{kN}$ and a minimum load of $6.2 \mathrm{kN}$. The maximum load produced an initial maximum tension flange strain of $0.93 \%$ and a minimum compression flange strain of $-0.89 \%$. The initial beam stiffness was measured as $5,145 \mathrm{kN} / \mathrm{m}$. Initially the compression flange showed no evidence of buckling, but after 16,000 cycles, it was noticed that the compression flange had a small localized buckling node at $\mathrm{x}=395 \mathrm{~mm}$ that was present on only one flange edge. This node, or area of increased localized displacement, did not change until the failure of the beam after 62,843 cycles. The compression flange failed at $\mathrm{x}=395 \mathrm{~mm}$, the node, with multiple delaminations in the preform and flange. The compression flange delaminations extended from $x=200$ to $460 \mathrm{~mm}$ and were between the $0^{\circ}$ ply and adjacent $45^{\circ}$ plies throughout the flange and preform thickness. This delamination also traveled into the web. The failed beam is shown in Figure 111. 
Table 32. Ply Reference Notation for Beams 51 through 55.

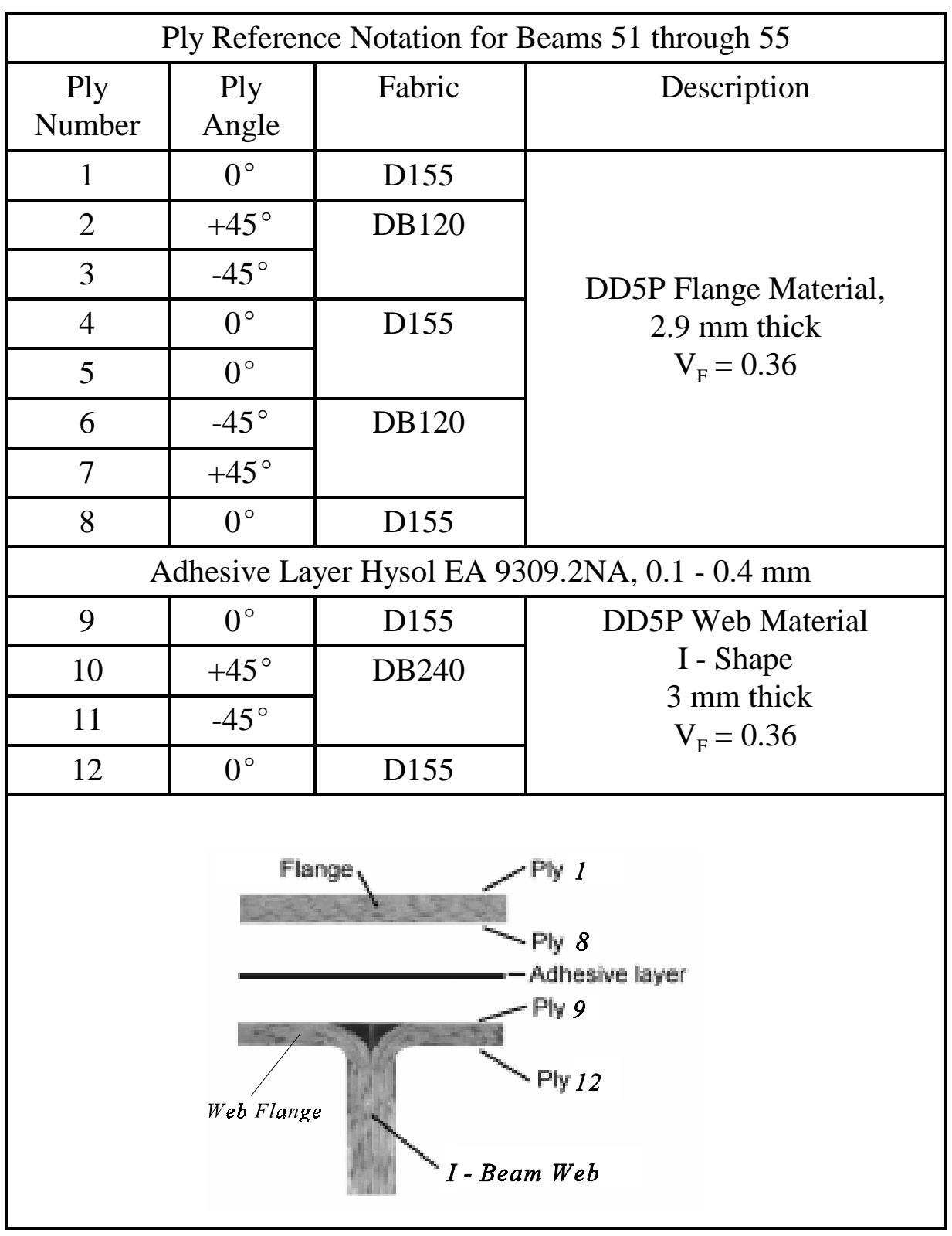




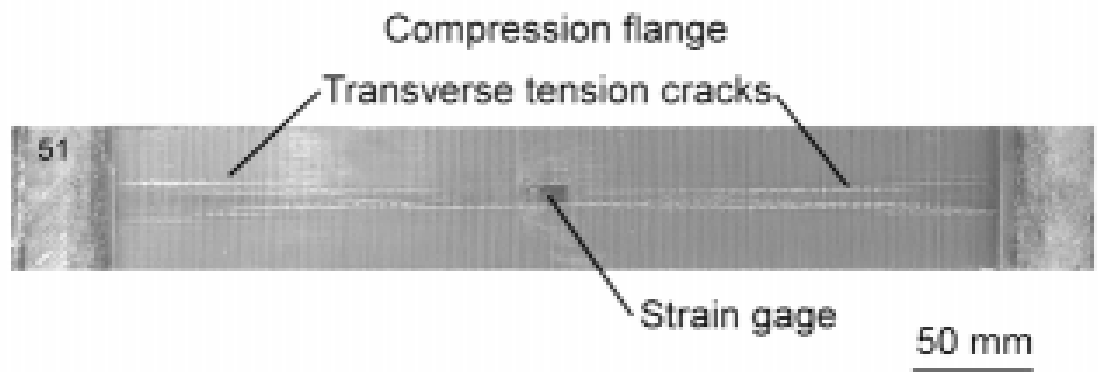

Figure 109. Beam 51.

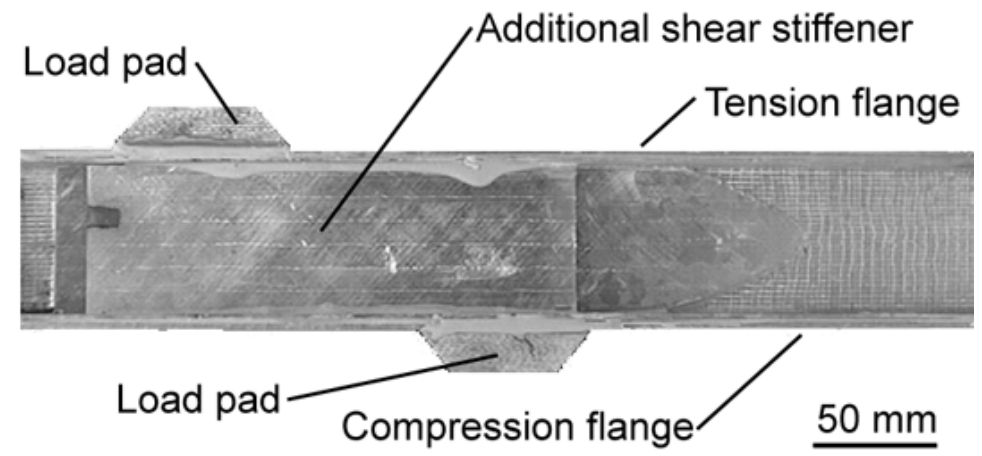

Figure 110. Additional shear stiffener material.

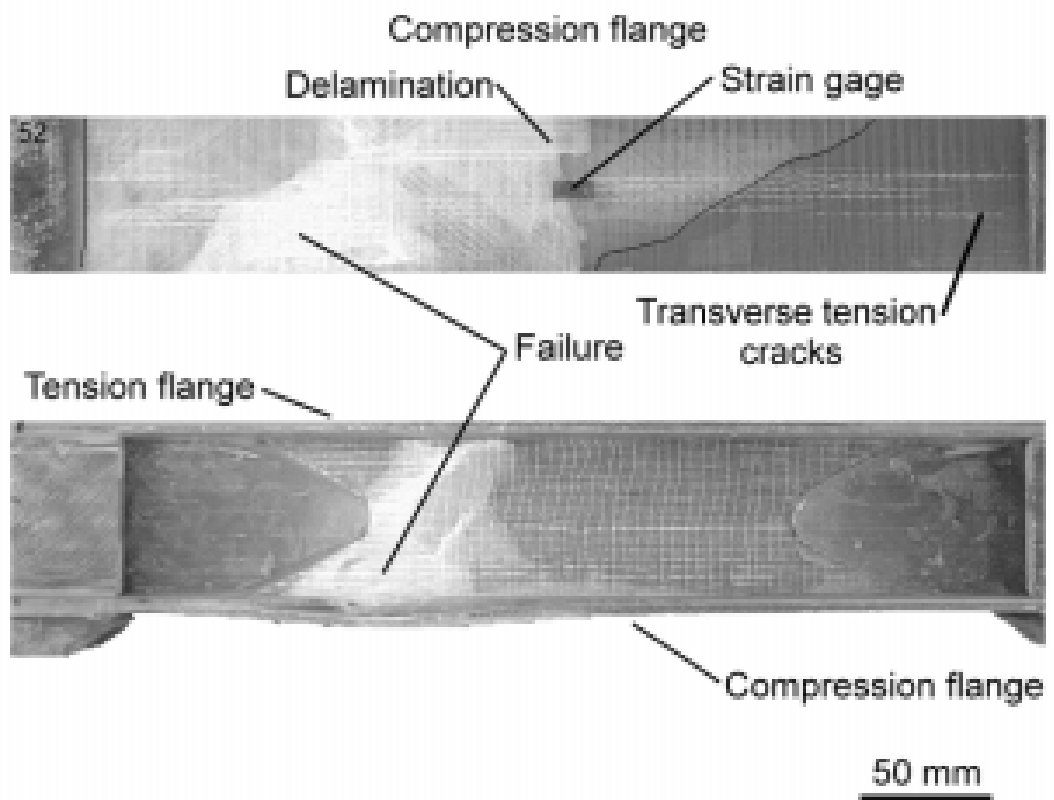

Figure 111. Beam 52. 


\section{BEAM 53}

Beam number 53 was fatigued at a rate of $3 \mathrm{~Hz}$ under sinusoidal load control with a maximum load of $62.3 \mathrm{kN}$ and a minimum load of $6.2 \mathrm{kN}$. The maximum load produced an initial maximum tension flange strain of $0.94 \%$ and a minimum compression flange

strain of $-0.89 \%$. The initial beam stiffness was measured as $4,901 \mathrm{kN} / \mathrm{m}$. The beam was stopped after 8,700 cycles due to a shear stiffener and web failure inside the shear loading area of the load pads. This damage is shown in Figure 112. Due to this failure, additional stiffener material was added to the other beams $(51,52$ and 54) tested at this or higher loads.

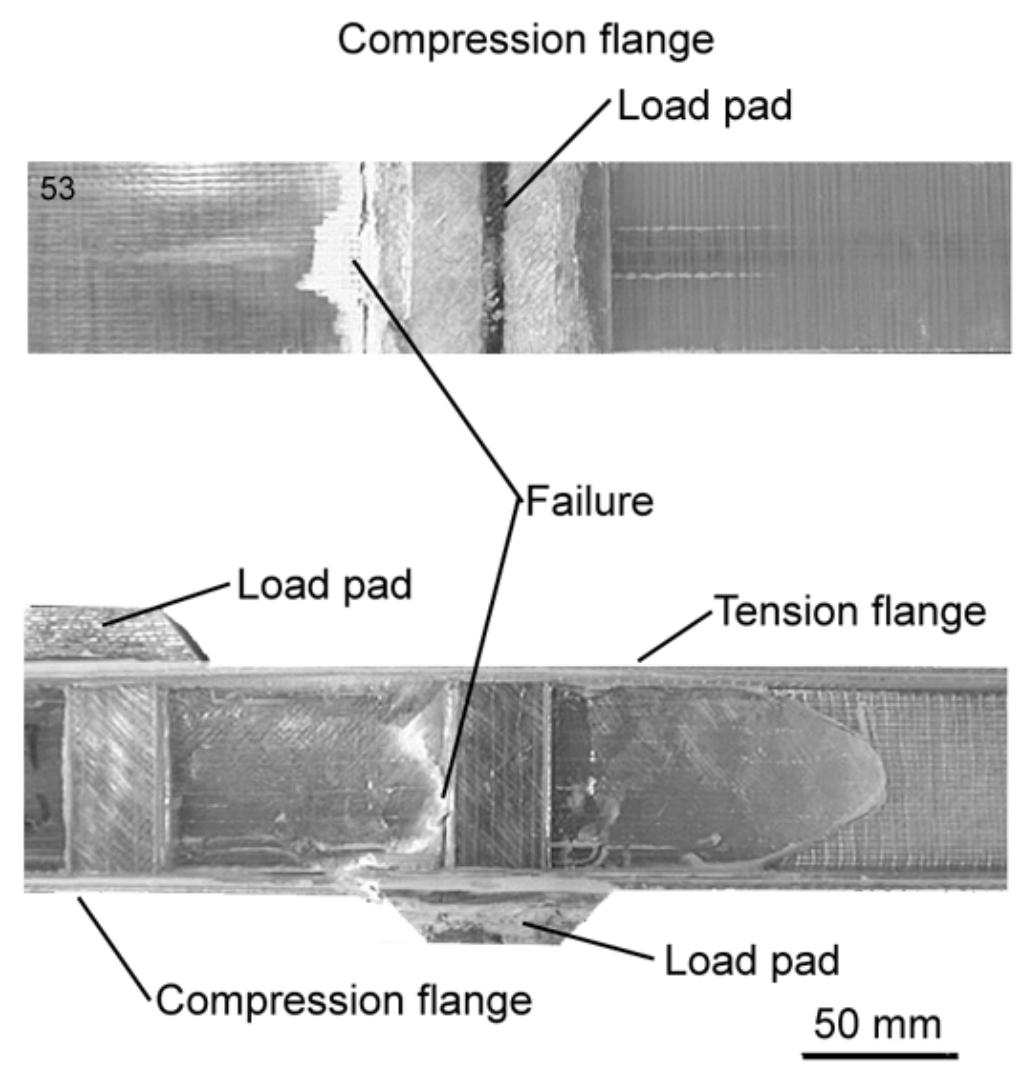

Figure 112. Beam 53. 


\section{BEAM 54}

Beam number 54 was fatigued at a rate of $4 \mathrm{~Hz}$ under sinusoidal load control with a maximum load of $62.3 \mathrm{kN}$ and a minimum load of $6.2 \mathrm{kN}$. The maximum load produced an initial maximum tension flange strain of $0.88 \%$ and a minimum compression flange strain of $-0.88 \%$. The initial beam stiffness was measured as $4,951 \mathrm{kN} / \mathrm{m}$. The compression flange showed no evidence of buckling throughout the test. The beam failed after 2,744,704 cycles with a web and shear stiffener failure shown in Figure 113.

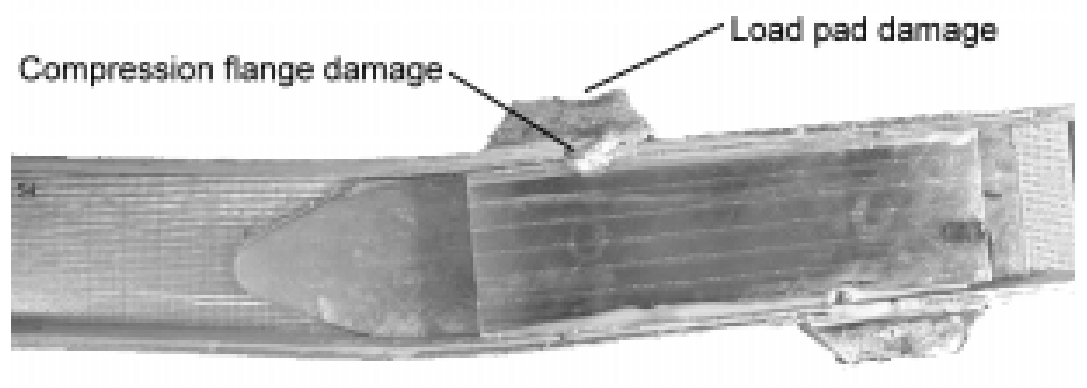

Tension flange

$50 \mathrm{~mm}$

Figure 113. Beam 54. 


\section{BEAMS WITH STRUCTURAL DETAILS}

\section{Beams With Holes In AA Material (Triax) Flanges}

To study the effects of severe flaws in flanges, $13 \mathrm{~mm}$ diameter holes were drilled on $102 \mathrm{~mm}$ centers along the length of each flange, through the flange thickness. This geometry, shown in Figure 114 , included two holes on the compression flange and four holes on the tension flange. The holes were drilled into the flanges prior to the adhesive bonding to the preform. This was done to ensure that no damage was initiated in the web. Therefore, the flange hole penetrated the flange thickness, but stopped at the adhesive layer above the web flange. The tension flange had four - $13 \mathrm{~mm}$ diameter holes located at $\mathrm{x}=152,254,365$ and $457 \mathrm{~mm}$ on the center line of the flange $(\mathrm{y}=0)$. The compression flange had two $-13 \mathrm{~mm}$ diameter holes at $\mathrm{x}=254$ and $356 \mathrm{~mm}$. The web was CH10 Material, as in the foregoing series.

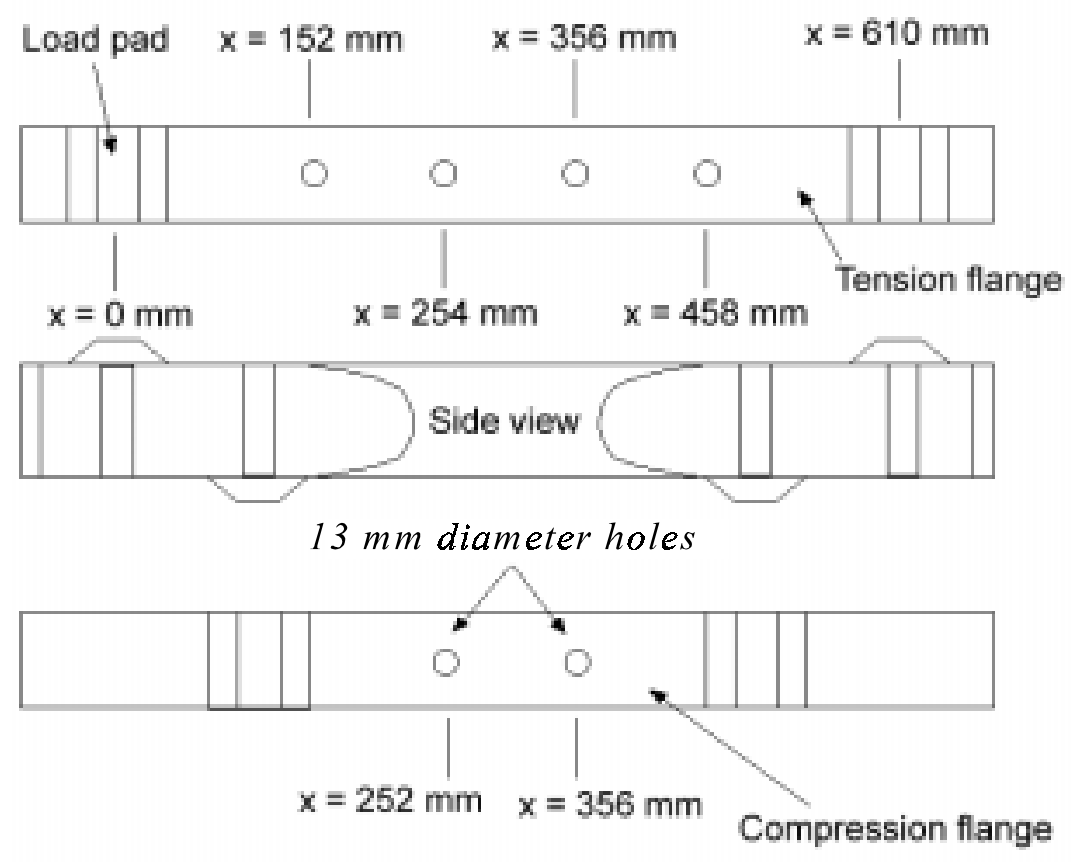

Figure 114. Beams 15, 16 and 17 flange geometry. 


\section{BEAM 15}

Beam number 15 was fatigued at a rate of $1 \mathrm{~Hz}$ under sinusoidal load control with a maximum load of $31.1 \mathrm{kN}$ and a minimum load of $3.1 \mathrm{kN}$. The maximum load produced an initial maximum tension flange strain of $0.83 \%$ and a minimum compression flange strain of $-0.78 \%$, both measured between hole locations. The initial beam stiffness was measured as 3,260 kN/m. The stiffness was checked after 2,163 cycles and was $3,064 \mathrm{kN} / \mathrm{m}$ or $94 \%$ of the original stiffness. The tension flange had two strain gages: one in the center of the flange and another at the edge. During the initial load up, at 18 $\mathrm{kN}$, the center gage indicated $0.419 \%$ strain, while the edge gage was $0.429 \%$, which is no significant difference. During the fatigue test, damage started to develop at all the holes and grew until it reached the edge of the flange. The beam failed after 2,772 cycles, in compression with the compression damage at $\mathrm{x}=254 \mathrm{~mm}$. Multiple delaminations between the $0^{\circ}$ and $+45^{\circ}$ plies from $\mathrm{x}=229$ to $\mathrm{x}=286 \mathrm{~mm}$ were also present. The compression flange failure and delamination caused an additional delamination to travel into the web at $x=244$ to $x=279 \mathrm{~mm}$. The failed beam is shown in Figure 115. No shear stiffener, torsional stiffener damage or delaminations were visible.

Tension flange - top view
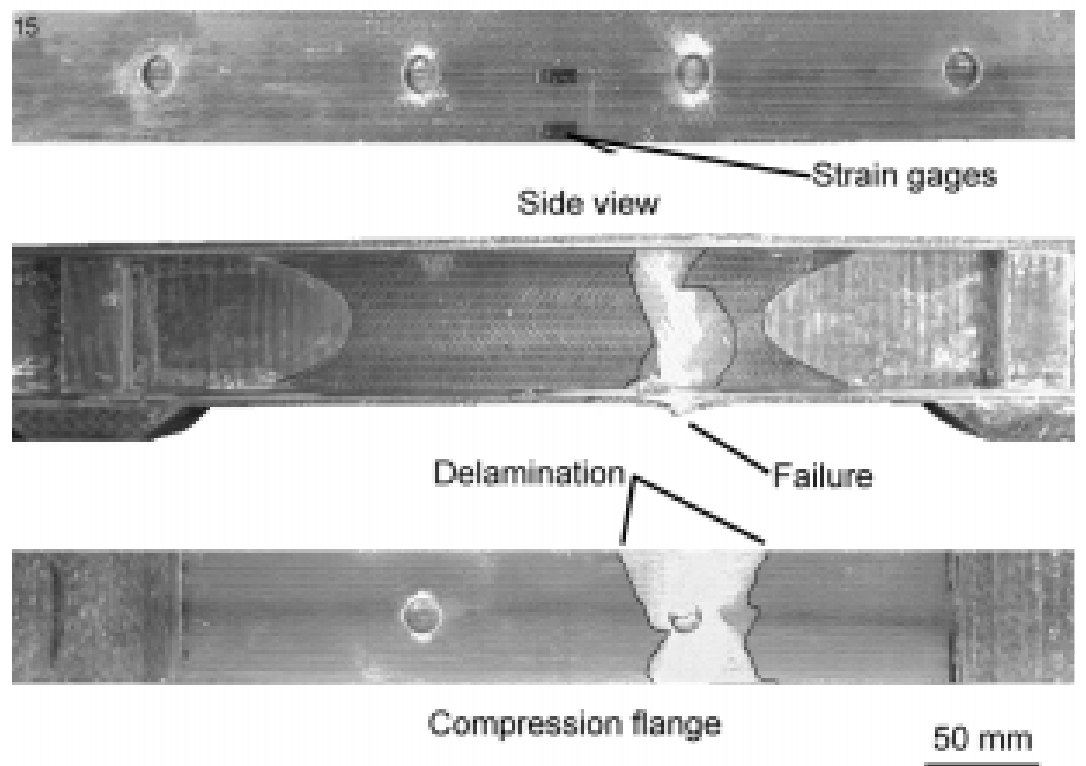

Figure 115. Beam 15. 


\section{BEAM 16}

Beam number 16 was fatigued at a rate of $5 \mathrm{~Hz}$ under sinusoidal load control with a maximum load of $24.5 \mathrm{kN}$ and a minimum load of $2.5 \mathrm{kN}$. The maximum load produced an initial maximum tension flange strain of $0.58 \%$ and a minimum compression flange strain of $-0.53 \%$. The initial beam stiffness was measured as 3,340 kN/m. During the fatigue test, damage started at the outside edges of the holes and continued to grow until failure after 40,448 cycles. The beam failed on the tension flange at $x=356 \pm 13 \mathrm{~mm}$ with the underlying delamination between $\mathrm{x}=325$ to $\mathrm{x}=394 \mathrm{~mm}$. This delamination also traveled $25 \mathrm{~mm}$ down into the web. Prior to failure, the web had a large number of 1.0 to $1.5 \mathrm{~mm}$ long tensile cracks, all located at stitching cross over points. Although these small cracks probably did not have any influence on the failure, it is still disconcerting that every stitch cross-over point on the tension side of the neutral axis had a crack. Some minor delamination damage was present on the tension flange around the holes. No shear stiffener, torsional stiffener damage or delaminations were visible. The failed beam is shown in Figures 116 and 117.

Tension flange - top view
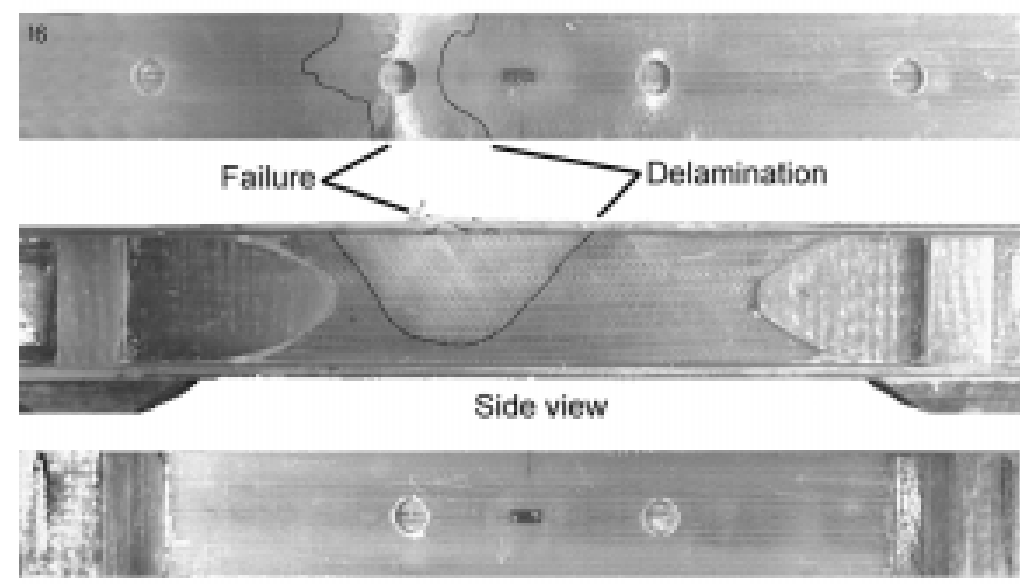

Compression flange $\quad \underline{50 \mathrm{~mm}}$

Figure 116. Beam 16.

Tension flange - top view

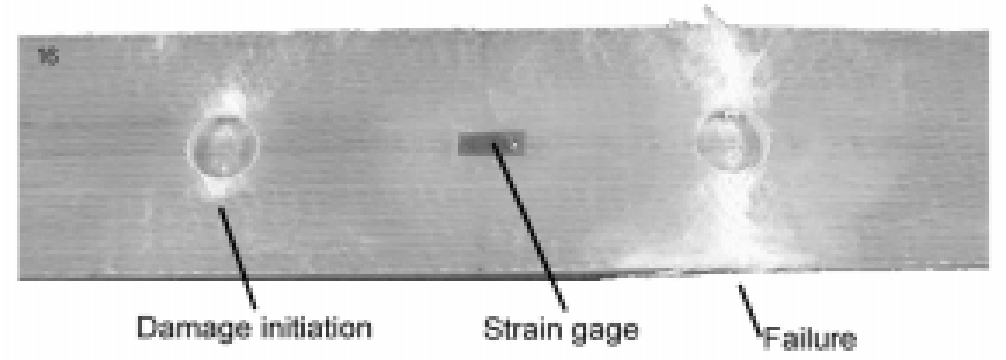

Figure 117. Beam 16. 


\section{BEAM 17}

Beam 17 was tested statically to failure. The beam was loaded under actuator displacement control at a rate of $0.05 \mathrm{~mm} / \mathrm{s}$ until failure, which had a total ramp time of 196 seconds. An initial beam stiffness of 3,350 kN/m was measured. The beam had a total of six strain gages, with three on the tension flange and three on the compression flange. At $18 \mathrm{kN}$, the tension flange indicated a center strain of $0.334 \%$ while the two edge gages indicated $0.423 \%$ and $0.416 \%$. The compression flange center gage indicated $-0.365 \%$ and the two edge gages indicated $-0.388 \%$ and $-0.374 \%$. The difference in strain from the center, where the flange is discontinuous, and the edge is more pronounced than the strains recorded from Beam 15. As the beam was loaded, the compression flange did not appear to twist as in the other beam static tests. The load-flange absolute maximum strain graph is shown in Figure 118, indicating a maximum tension flange center strain of $1.30 \%$ and a minimum compression flange center strain of $-1.08 \%$. These strains occurred at a ultimate applied load of $46.97 \mathrm{kN}$ at a maximum mid-span deflection of $15 \mathrm{~mm}$. The failed beam is shown in Figure 119. The compression flange failed at $\mathrm{x}=260 \pm 15 \mathrm{~mm}$ and created a flange delamination from $\mathrm{x}$ $=178$ to $\mathrm{x}=419 \mathrm{~mm}$. The delamination was between the $0^{\circ}$ ply (ply 10, Table 22) and $+45^{\circ}$ ply (ply 11, Table 22). This delamination traveled up towards the tension flange and produced a spot delamination at the tension flange hole. The second hole on the compression flange had a $12 \mathrm{~mm}$ delamination going towards the edge, but the damage at the other hole produced the flange failure first. 


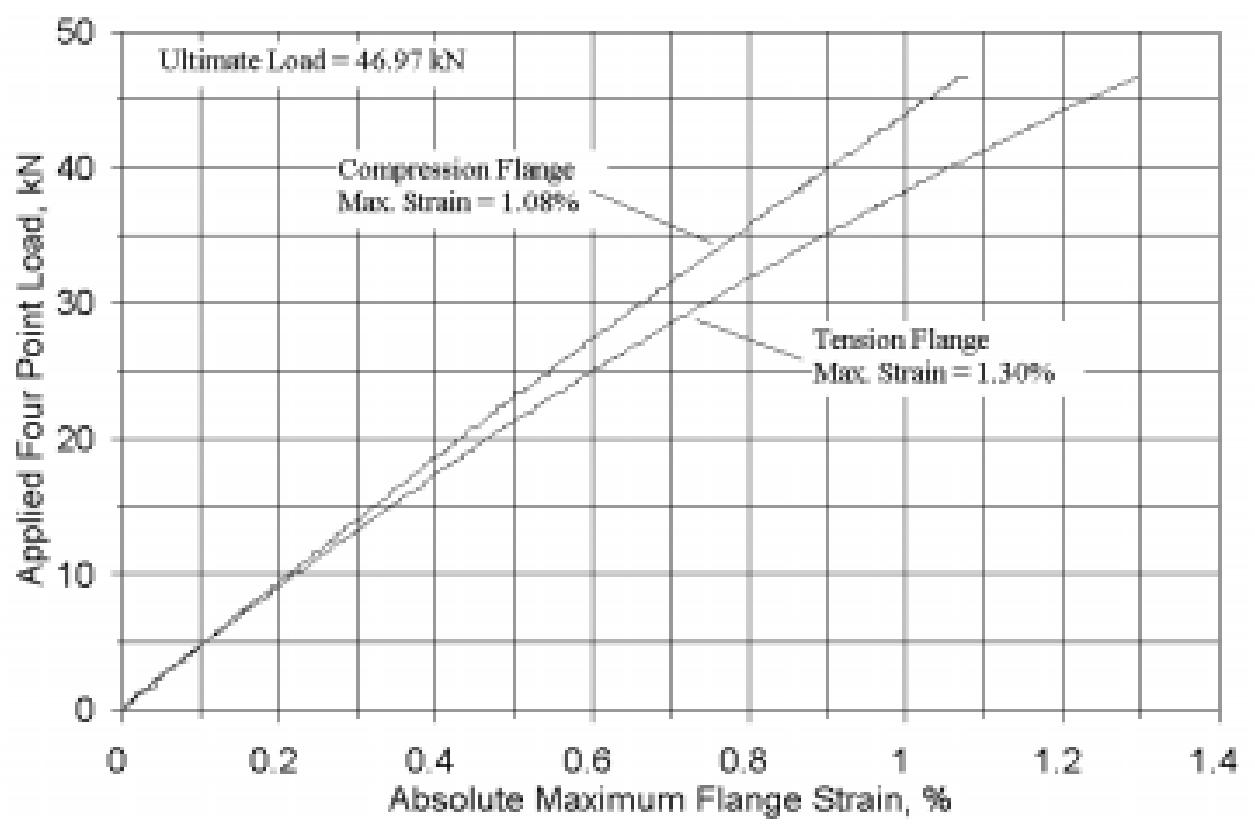

Figure 118. Load vs. maximum flange strain, beam 17, static test.

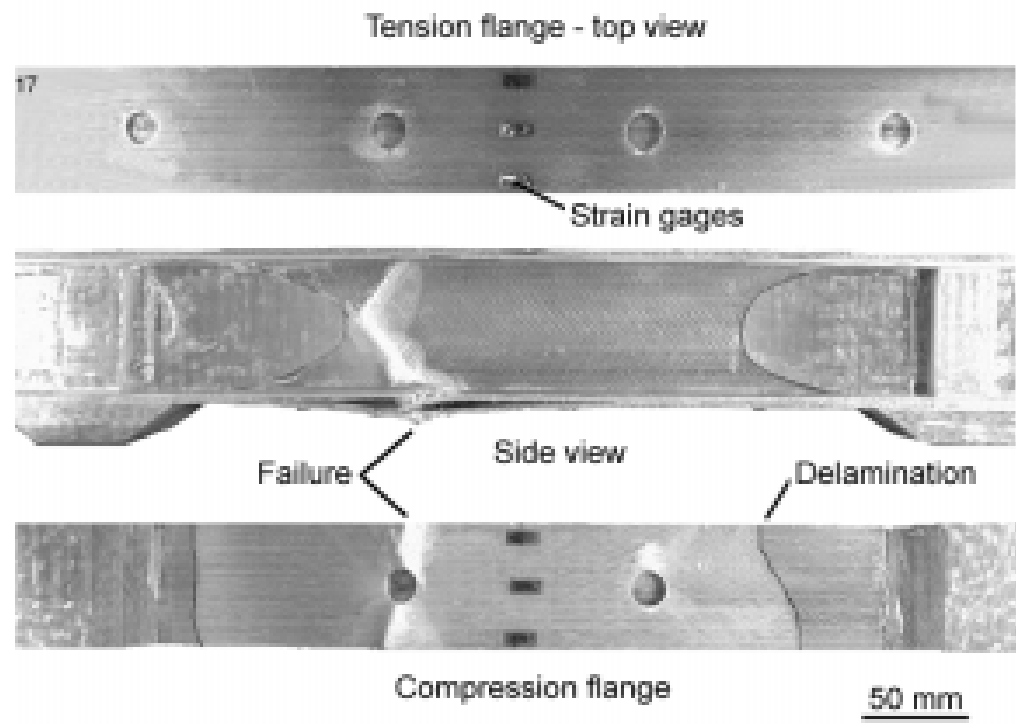

Figure 119. Beam 17. 


\section{Beam With Ply Drops in Flanges}

Material DD5P was modified to study the effects of dropping exterior and interior plies in the beam flanges. The ESA material flanges, with a single exterior ply drop, were tested in Beams 39, 44 and 48. ESB material, with a single interior ply drop, was tested in Beam 40. ESG material, with two exterior ply drops, was tested in Beams 41 and 42, and ESH material, with two interior ply drops, was tested in Beams 49 and 50. The material lay-ups are detailed in Table 33 and the following sections. During the fatigue tests, the length of delamination was determined by averaging the four flange edge delamination lengths as each flange had two separate ply drop regions.

Table 33. Lay up of Fiberglass Materials with Ply Drops.

\begin{tabular}{|c|c|c|}
\hline \multicolumn{3}{|c|}{ Lay up of Fiberglass Materials with Ply Drops } \\
\hline Material & Ply Configuration & Description \\
\hline ESA & {$\left[0 * /(0 / \pm 45 / 0)_{\mathrm{s}}\right]$} & Single Exterior Ply Drop \\
\hline ESB & {$\left[0 / 0^{*} / \pm 45 / 0 / 0 / \pm 45 / 0\right]$} & Single Interior Ply Drop \\
\hline ESG & {$\left[0 * / 0 * /(0 / \pm 45 / 0)_{3}\right]$} & Two exterior ply drops with thicker laminate \\
\hline ESH & {$\left[0 / 0 * / 0 * / \pm 45 / 0 /(0 / \pm 45 / 0)_{2}\right]$} & Two interior ply drops with thicker laminate \\
\hline \multicolumn{3}{|c|}{$*$ Ply being terminated } \\
\hline
\end{tabular}

\section{Beam 39 (Flange Material ESA)}

Beam number 39 was fatigued at a rate of $4 \mathrm{~Hz}$ with a maximum load of $35.6 \mathrm{kN}$ and a minimum load of $3.6 \mathrm{kN}$. The maximum load produced an initial maximum tension flange strain of $0.62 \%$ an a minimum compressive flange strain of $-0.64 \%$. The initial beam stiffness was measured as 4,804 $\mathrm{kN} / \mathrm{m}$. The flange material was the ESA laminate, which had a single, exterior ply drop (ply 1 , Table 34). The ply drops on the tension flange were at $x=277$ and $328 \mathrm{~mm}$. The ply drops on the compression flange were at $\mathrm{x}=292$ and $314 \mathrm{~mm}$. On the tension flange, the delamination started immediately between the surface $0^{\circ}$ ply and second internal $0^{\circ}$ ply (plies 1 and 2, Table 34). This delamination was uniform across the width of the tension flange. The delamination on the tension flange continued to grow at an average rate of $6.95 \times 10^{-5} \mathrm{~mm} / \mathrm{cycle}$ until the beam was taken out of the apparatus at 1,225,650 cycles. The tension flange itself did not delaminate from the web flange. The compression flange did not start to show delamination until approximately 11,000 cycles. The compression flange delamination also occurred between the two top $0^{\circ}$ plies (plies 1 and 2, Table 34) and grew approximately $30 \mathrm{~mm}$ in length and then arrested for the duration of the test. Table 35 lists the average delamination length versus cycles. The beam is shown in Figure 120. No shear stiffener, torsional stiffener or other flange damage or delaminations were visible. 
Table 34. Reference Notation for Beams 39, 44 and 48 with ESA Laminate.

\begin{tabular}{|c|c|c|c|}
\hline \multicolumn{4}{|c|}{ Reference Notation for Beams 39, 44 and 48 with ESA Laminate } \\
\hline $\begin{array}{c}\text { Ply } \\
\text { Number }\end{array}$ & $\begin{array}{c}\text { Ply } \\
\text { Angle }\end{array}$ & Fabric & Description \\
\hline 1 & $0^{\circ}$ & D155 & Dropped Ply \\
\hline 2 & $0^{\circ}$ & D155 & \multirow{8}{*}{ DD5P material } \\
\hline 3 & $+45^{\circ}$ & DB120 & \\
\hline 4 & $-45^{\circ}$ & & \\
\hline 5 & $0^{\circ}$ & D155 & \\
\hline 6 & $0^{\circ}$ & D155 & \\
\hline 7 & $+45^{\circ}$ & \multirow[t]{2}{*}{ DB120 } & \\
\hline 8 & $-45^{\circ}$ & & \\
\hline 9 & $0^{\circ}$ & D155 & \\
\hline \multicolumn{4}{|c|}{ Adhesive Layer Hysol EA 9309.2NA, $0.1-0.4$ mm } \\
\hline 10 & $+45^{\circ}$ & DB240 & \multirow{5}{*}{$\begin{array}{c}\text { Web Material CH12 } \\
\text { I - Beam Web Flange, } \\
3 \mathrm{~mm} \text { thick, } \\
\mathrm{V}_{\mathrm{F}}=0.35\end{array}$} \\
\hline 11 & $-45^{\circ}$ & & \\
\hline 12 & 0 & D155 & \\
\hline 13 & $-45^{\circ}$ & \multirow[t]{2}{*}{ DB240 } & \\
\hline 14 & $+45^{\circ}$ & & \\
\hline
\end{tabular}

Table 35. Average Tension Flange Delamination vs. Cycles for Beam 39.

\begin{tabular}{|c|c|}
\hline Cycles & $\begin{array}{c}\text { Average Tension Flange } \\
\text { Delamination, } \mathrm{mm}\end{array}$ \\
\hline 500 & 6 \\
\hline 5,000 & 10 \\
\hline 10,000 & 14 \\
\hline 41,000 & 20 \\
\hline 50,000 & 22 \\
\hline 93,000 & 28 \\
\hline 171,000 & 36 \\
\hline 390,000 & 51 \\
\hline 812,000 & 66 \\
\hline $1,200,000$ & 79 \\
\hline
\end{tabular}




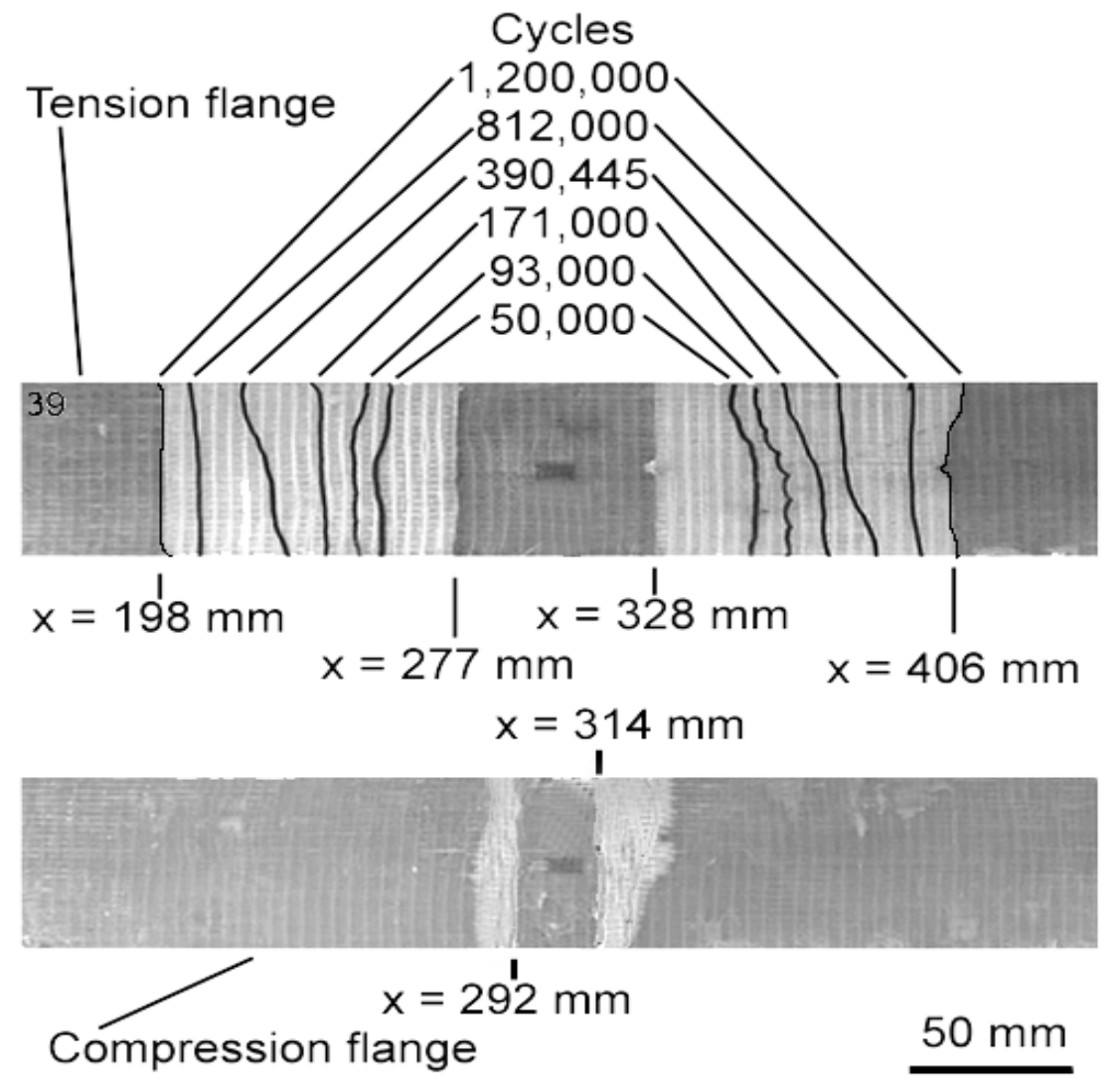

Figure 120. Beam 39.

\section{BEAM 44 (Flange Material ESA)}

Beam number 44 was fatigued at a rate of $4 \mathrm{~Hz}$ with a maximum load of $35.6 \mathrm{kN}$ and a minimum load of $3.6 \mathrm{kN}$. The maximum load produced an initial maximum tension flange strain of $0.57 \%$ an a minimum compressive flange strain of $-0.58 \%$. The initial beam stiffness was measured as 4,527 $\mathrm{kN} / \mathrm{m}$. This beam had the same ply drops as Beam 39, except the ply drops were positioned over the shear stiffeners. The tension flange ply drops were at $\mathrm{x}=152$ and $455 \mathrm{~mm}$. The compression flange ply drops were at $\mathrm{x}=222$ and $383 \mathrm{~mm}$. This ply drop position did not allow the ply drops to be subjected to a pure bending moment, which renders these less useful than those with ply drops in the gage section. The average delamination length versus cycles is listed in Table 36 . The tension flange had a calculated average delamination rate of $2.66 \times 10^{-5} \mathrm{~mm} /$ cycle. The delamination on the compression flange did not start growing until 185,000 cycles, and arrested at $5 \mathrm{~mm}$. No shear stiffener, torsional stiffener or other flange damage or delaminations were visible. The beam is shown in Figure 121. 
Table 36. Average Flange Delamination vs. Cycles for Beam 44.

\begin{tabular}{|c|c|c|}
\hline Cycles & $\begin{array}{c}\text { Average Tension } \\
\text { Flange } \\
\text { Delamination, } \mathrm{mm}\end{array}$ & $\begin{array}{c}\text { Average Compression } \\
\text { Flange Delamination, } \\
\mathrm{mm}\end{array}$ \\
\hline 200 & 3 & -- \\
\hline 2,000 & 4 & -- \\
\hline 6,300 & 5 & -- \\
\hline 40,000 & 8 & -- \\
\hline 79,000 & 11 & -- \\
\hline 184,000 & 13 & 5 \\
\hline 213,000 & 14 & 5 \\
\hline 289,000 & 16 & 5 \\
\hline 382,000 & 16 & 5 \\
\hline 600,000 & 16 & 5 \\
\hline
\end{tabular}

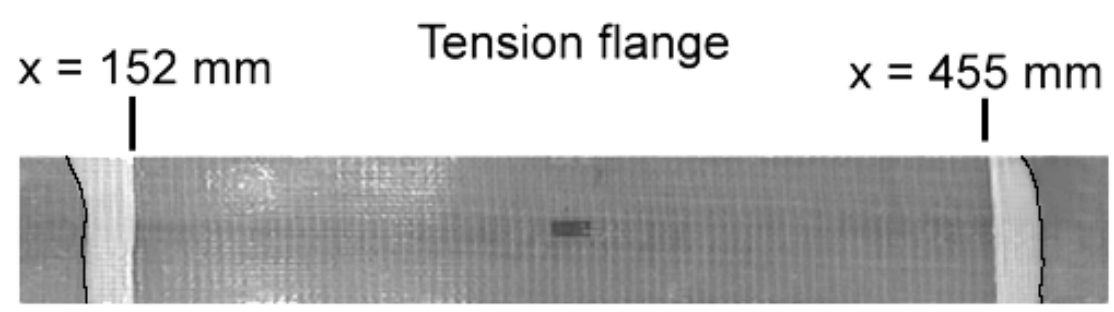

Compression flange

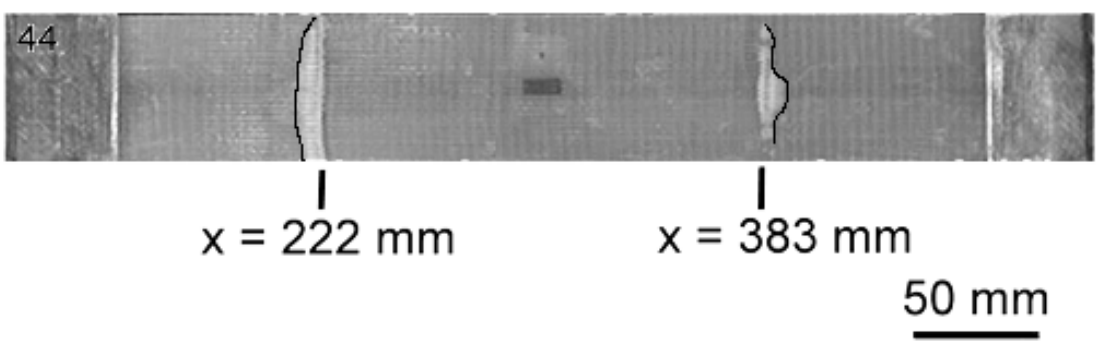

Figure 121. Beam 44. 


\section{BEAM 48 (Flange Material ESA)}

Beam number 48 was fatigued at a rate of $4 \mathrm{~Hz}$ with a maximum load of $35.6 \mathrm{kN}$ and a minimum load of $3.6 \mathrm{kN}$. The maximum load produced an initial maximum tension flange strain of $0.66 \%$ an a minimum compressive flange strain of $-0.67 \%$. The initial beam stiffness was measured as 4,650 $\mathrm{kN} / \mathrm{m}$. Unlike Beam 44, the ply drops were situated over the constant moment section of the beam with the tension ply drops at $\mathrm{x}=272$ and $327 \mathrm{~mm}$ and the compression flange ply drops at $\mathrm{x}=295$ and $320 \mathrm{~mm}$. The delamination on the tension flange was uniform across the width and had propagated at an average calculated rate of $6.3 \times 10^{-4} \mathrm{~mm} / \mathrm{cycle}$. The compression flange did not start to delaminate until approximately 2,500 cycles and grew at an average calculated rate of $5.5 \times 10^{-5}$ $\mathrm{mm} / \mathrm{cycle}$. The web and shear stiffeners showed no damage after 72,000 cycles. The delamination length versus cycles is shown in Table 37 and the beam is shown in Figure 122.

Table 37. Average Flange Delamination vs. Cycles for Beam 48.

\begin{tabular}{|c|c|c|}
\hline Cycles & $\begin{array}{c}\text { Average Tension Flange } \\
\text { Delamination, } \mathrm{mm}\end{array}$ & $\begin{array}{c}\text { Average Compression } \\
\text { Flange Delamination, } \mathrm{mm}\end{array}$ \\
\hline 2,500 & 11 & -- \\
\hline 4,000 & 13 & -- \\
\hline 6,000 & 16 & -- \\
\hline 7,500 & 16 & -- \\
\hline 10,000 & 19 & -- \\
\hline 16,000 & 22 & -- \\
\hline 37,500 & 34 & 4 \\
\hline 72,000 & 45 & 6 \\
\hline
\end{tabular}




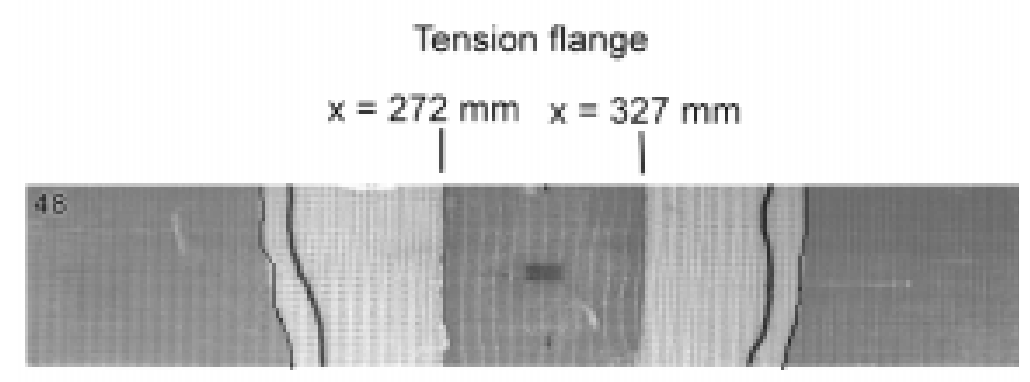

Compression flange

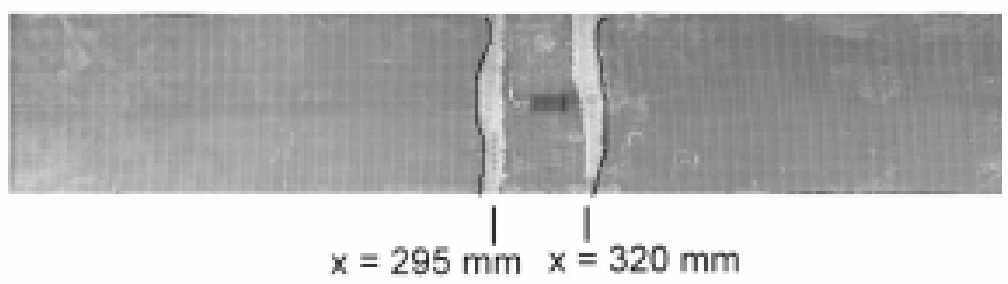

$50 \mathrm{~mm}$

Figure 122. Beam 48.

\section{BEAM 40 (Flange Material ESB)}

Beam number 40 was fatigued at a rate of $3 \mathrm{~Hz}$ with a maximum load of $35.6 \mathrm{kN}$ and a minimum load of $3.6 \mathrm{kN}$. The maximum load produced an initial maximum tension flange strain of $0.96 \%$ and a minimum compressive flange strain of $-0.85 \%$. The initial beam stiffness was measured as 4,787 $\mathrm{kN} / \mathrm{m}$. The flange material was the ESB laminate, which had a single, interior ply drop, that was located between plies 1 and 3, as shown in Table 38. The tension flange ply drops were located at $\mathrm{x}=145$ and $452 \mathrm{~mm}$, while the compression flange ply drops were located at $\mathrm{x}=226$ and $376 \mathrm{~mm}$. The compression flange delaminated after 264,137 cycles in the adhesive layer between $\mathrm{x}=150$ and $690 \mathrm{~mm}$ that caused the beam to fail. No ply drop delaminations were visible after this failure. No other shear stiffener, torsional stiffener or other flange damage or delaminations were visible. Figure 123 shows the failed beam. 
Table 38. Reference Notation for Beam 40 with ESB Laminate.

\begin{tabular}{|c|c|c|c|}
\hline \multicolumn{4}{|c|}{ Reference Notation for Beam 40 with ESB Laminate } \\
\hline $\begin{array}{c}\text { Ply } \\
\text { Number }\end{array}$ & $\begin{array}{c}\text { Ply } \\
\text { Angle }\end{array}$ & Fabric & Description \\
\hline 1 & $0^{\circ}$ & D155 & \\
\hline 2 & $0^{\circ}$ & D155 & Dropped ply \\
\hline 3 & $+45^{\circ}$ & DB120 & \multirow{7}{*}{ DD5P Material } \\
\hline 4 & $-45^{\circ}$ & & \\
\hline 5 & $0^{\circ}$ & D155 & \\
\hline 6 & $0^{\circ}$ & D155 & \\
\hline 7 & $+45^{\circ}$ & \multirow[t]{2}{*}{ DB120 } & \\
\hline 8 & $-45^{\circ}$ & & \\
\hline 9 & $0^{\circ}$ & D155 & \\
\hline \multicolumn{4}{|c|}{ Adhesive Layer Hysol EA 9309.2NA, $0.1-0.4$ mm } \\
\hline 13 & $+45^{\circ}$ & \multirow[t]{2}{*}{ DB240 } & \multirow{5}{*}{$\begin{array}{c}\text { Web Material CH12 } \\
\text { I - Beam Web } \\
\text { Flange } \\
3 \text { mm thick } \\
\mathrm{V}_{\mathrm{F}}=0.35\end{array}$} \\
\hline 14 & $-45^{\circ}$ & & \\
\hline 15 & 0 & D155 & \\
\hline 16 & $-45^{\circ}$ & \multirow[t]{2}{*}{ DB240 } & \\
\hline 17 & $+45^{\circ}$ & & \\
\hline
\end{tabular}

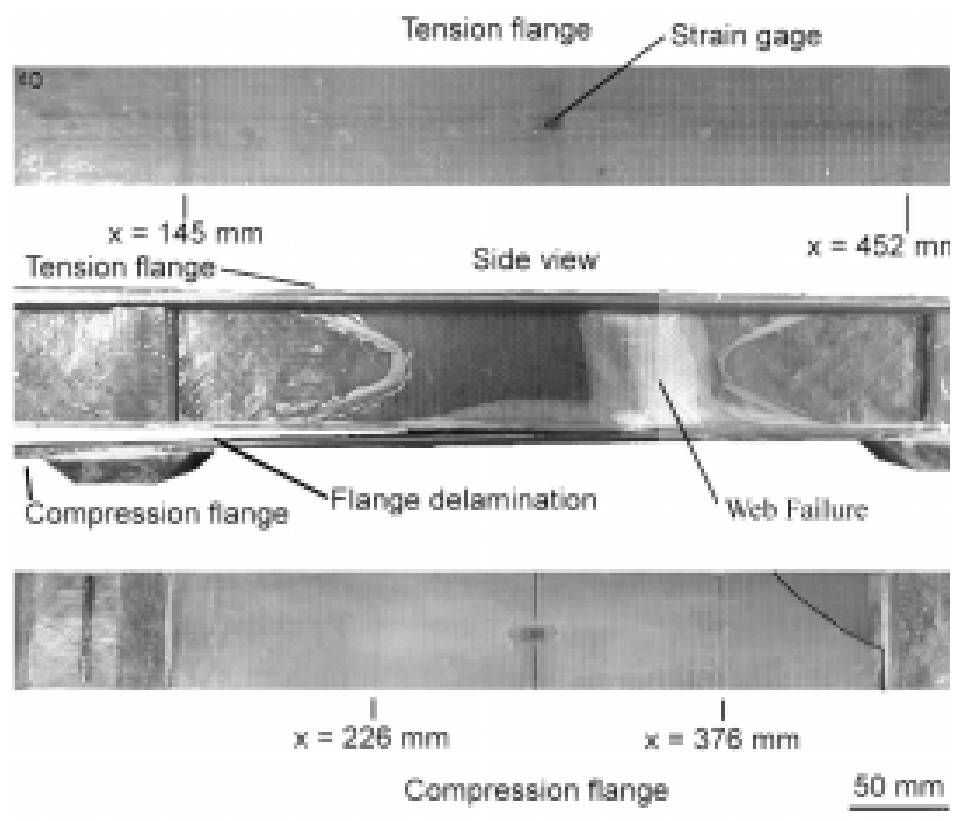

Figure 123. Beam 40. 


\section{BEAM 41 (Material ESG)}

Beam number 41 was fatigued at a rate of $3 \mathrm{~Hz}$ with a maximum load of $49 \mathrm{kN}$ and a minimum load of $4.9 \mathrm{kN}$. The maximum load produced an initial maximum tension flange strain of $0.74 \%$ and a minimum compressive flange strain of $-0.76 \%$. The initial beam stiffness was measured as 5,213 $\mathrm{kN} / \mathrm{m}$. The flange material was the ESG laminate, which had two, exterior $0^{\circ}$ ply drops (plies 1 and 2 , Table 39). The tension flange ply drops were located at $\mathrm{x}=282$ and $327 \mathrm{~mm}$ and the compression flange ply drops were at $\mathrm{x}=287$ and $331 \mathrm{~mm}$. On the tension side of the beam the delamination originally started between the $0^{\circ}$ ply (ply 2, Table 39) and the $+45^{\circ}$ (ply 3, Table 39), but continued between the $0^{\circ}$ ply (ply 5, Table 39) and the $-45^{\circ}$ ply (ply 4, Table 39 ). The average delamination length versus cycles is listed in Table 40. The calculated average delamination rate on the compression side was $1.75 \times 10^{-3} \mathrm{~mm} /$ cycle, while the rate on the tension flange was calculated as $4.97 \times 10^{-3} \mathrm{~mm} /$ cycle. The compression flange of the beam was almost identical to Beam 39 , which had a single exterior ply drop. The test was stopped after the delamination length extended into the shear stiffener area of the beam. No shear stiffener, torsional stiffener or other flange damage or delaminations were visible. Figure 124 shows the delaminated beam. 
Table 39. Reference Notation for Beams 41 and 42 with ESG Laminate.

\begin{tabular}{|c|c|c|c|}
\hline \multicolumn{4}{|c|}{ Reference Notation for Beams 41 and 42 with ESG Laminate } \\
\hline $\begin{array}{c}\text { Ply } \\
\text { Number }\end{array}$ & $\begin{array}{c}\text { Ply } \\
\text { Angle }\end{array}$ & Fabric & Description \\
\hline 1 & $0^{\circ}$ & D155 & \multirow[t]{2}{*}{ Dropped plies } \\
\hline 2 & $0^{\circ}$ & D155 & \\
\hline 3 & $+45^{\circ}$ & \multirow[t]{2}{*}{ DB120 } & \\
\hline 4 & $-45^{\circ}$ & & \\
\hline 5 & $0^{\circ}$ & D155 & \\
\hline 6 & $0^{\circ}$ & D155 & \\
\hline 7 & $+45^{\circ}$ & \multirow[t]{2}{*}{ DB120 } & \\
\hline 8 & $-45^{\circ}$ & & \\
\hline 9 & $0^{\circ}$ & D155 & \\
\hline 10 & $0^{\circ}$ & D155 & \\
\hline 11 & $+45^{\circ}$ & \multirow[t]{2}{*}{ DB120 } & \\
\hline 12 & $-45^{\circ}$ & & \\
\hline 13 & $0^{\circ}$ & D155 & \\
\hline \multicolumn{4}{|c|}{ Adhesive Layer Hysol EA 9309.2NA, $0.1-0.4$ mm } \\
\hline 14 & $+45^{\circ}$ & DB240 & \multirow{5}{*}{$\begin{array}{c}\text { Web Material CH12 } \\
\text { I - Beam Web Flange } \\
3 \mathrm{~mm} \text { thick, } \\
\mathrm{V}_{\mathrm{F}}=0.35\end{array}$} \\
\hline 15 & $-45^{\circ}$ & & \\
\hline 16 & 0 & D155 & \\
\hline 17 & $-45^{\circ}$ & \multirow[t]{2}{*}{ DB240 } & \\
\hline 18 & $+45^{\circ}$ & & \\
\hline
\end{tabular}


Table 40. Average Flange Delamination vs. Cycles for Beam 41.

\begin{tabular}{|c|c|c|}
\hline Cycles & $\begin{array}{c}\text { Average Tension Flange } \\
\text { Delamination, mm }\end{array}$ & $\begin{array}{c}\text { Average Compression } \\
\text { Flange Delamination, mm }\end{array}$ \\
\hline 20 & 11 & -- \\
\hline 200 & 13 & -- \\
\hline 600 & 21 & -- \\
\hline 1,000 & 25 & -- \\
\hline 1,500 & 29 & -- \\
\hline 2,100 & 33 & 3 \\
\hline 3,700 & 34 & 3 \\
\hline 13,997 & 70 & 21 \\
\hline
\end{tabular}

Tension flange

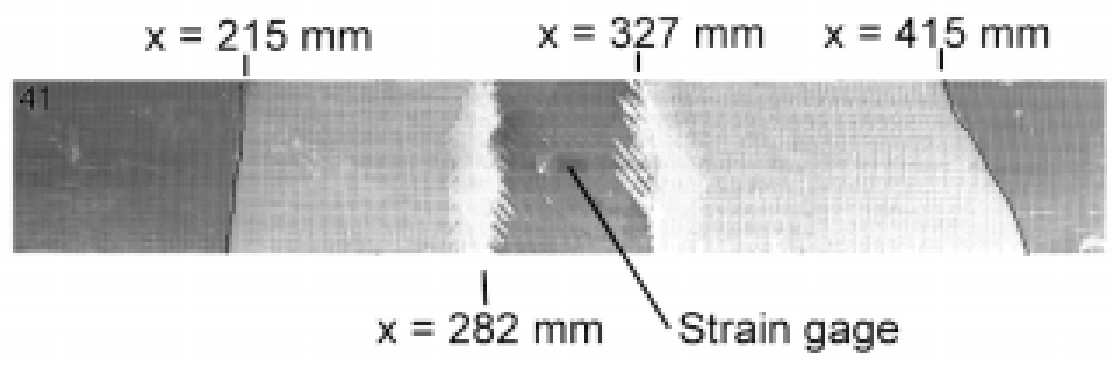

Compression flange

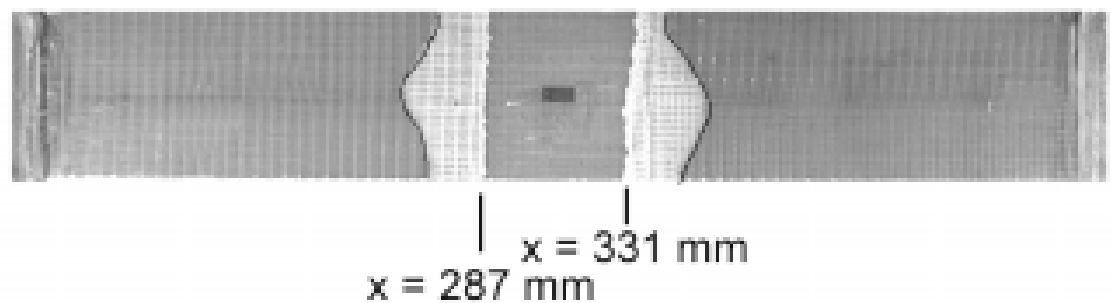

$50 \mathrm{~mm}$

Figure 124. Beam 41. 


\section{BEAM 42 (Flange Material ESG)}

Beam number 42 was fatigued at a rate of $4 \mathrm{~Hz}$ with a maximum load of $35.6 \mathrm{kN}$ and a minimum load of $3.6 \mathrm{kN}$. The maximum load produced an initial maximum tension flange strain of $0.55 \%$ an a minimum compressive flange strain of $-0.54 \%$. The initial beam stiffness was measured as 5,524 $\mathrm{kN} / \mathrm{m}$. The only difference between Beam 42, as compared with Beam 41, is the strain level at which the beams were run. The tension flange ply drops were located at $\mathrm{x}=280$ and $325 \mathrm{~mm}$ and the compression flange ply drops were at $\mathrm{x}=280$ and $328 \mathrm{~mm}$. The delamination appearing on the flanges were similar to Beam 41 . On the tension side of the beam the delamination originally started between the $0^{\circ}$ ply, (ply 2, Table 39) and the $+45^{\circ}$ (ply 3, Table 39), but continued between the $0^{\circ}$ ply (ply 5, Table 39) and the $-45^{\circ}$ ply (ply 4, Table 39). The average delamination length versus cycles is listed in Table 41. The average calculated delamination rate on the tension flange was $1.23 \times 10^{-4} \mathrm{~mm} /$ cycle. The compression flange did not start to delaminate until almost 100,000 cycles and the average calculated delamination rate was $3.84 \times 10^{-5} \mathrm{~mm} /$ cycle. The delaminated beam is shown in Figure 125 below.
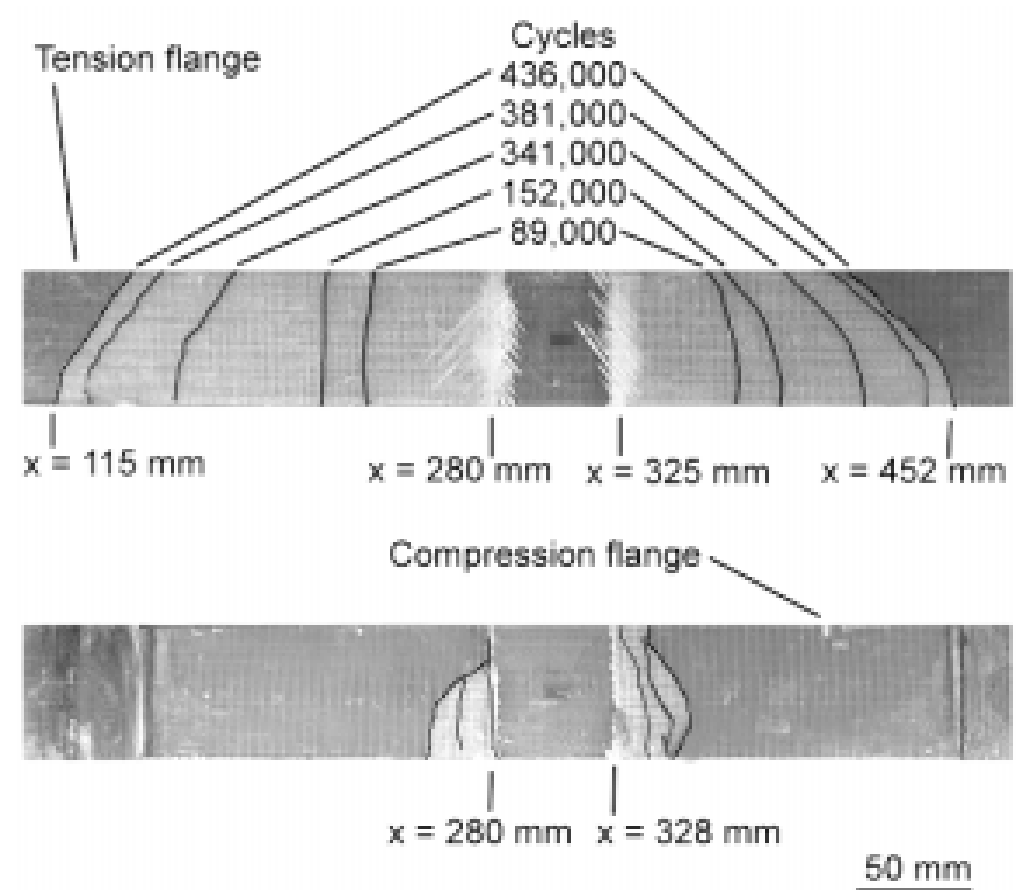

Figure 125. Beam 42. 
Table 41. Average Tension Flange Delamination vs. Cycles for Beam 42.

\begin{tabular}{|c|c|}
\hline Cycles & $\begin{array}{c}\text { Average Tension Flange } \\
\text { Delamination, mm }\end{array}$ \\
\hline 500 & 7 \\
\hline 1,000 & 12 \\
\hline 2,000 & 12 \\
\hline 3,500 & 14 \\
\hline 23,000 & 22 \\
\hline 35,000 & 29 \\
\hline 62,000 & 38 \\
\hline 85,000 & 43 \\
\hline 89,000 & 46 \\
\hline 152,000 & 61 \\
\hline 341,000 & 89 \\
\hline 381,000 & 109 \\
\hline 436,508 & 128 \\
\hline
\end{tabular}

\section{BEAM 49 (Flange Material ESH)}

Beam number 49 was fatigued at a rate of $3 \mathrm{~Hz}$ with a maximum load of $57.8 \mathrm{kN}$ and a minimum load of $5.8 \mathrm{kN}$. The maximum load produced an initial maximum tension flange strain of $0.76 \%$ an a minimum compressive flange strain of $-0.73 \%$. The initial beam stiffness was measured as 6,625 $\mathrm{kN} / \mathrm{m}$. The flange material was the ESH laminate, which had two internal $0^{\circ}$ ply drops (plies 2 and 3 , Table 42). The tension flange ply drops were located at $x=277$ and $326 \mathrm{~mm}$ and the compression flange ply drops were at $x=290$ and $335 \mathrm{~mm}$. The delamination on the tension side first propagated into the thin section of the flange, between the $0^{\circ}$ and $+45^{\circ}$ plies (plies $1-4$, Table 42), with a length of approximately $10 \mathrm{~mm}$. After this initial delamination, the crack started to propagate into the thick section, starting two cracks between the $0^{\circ}$ plies (plies 1 and 2, Table 42) and the $0^{\circ}$ ply and the $+45^{\circ}$ ply (plies 3 and 4 , Table 42). The delamination was uniform across the width of the flange and the average calculated delamination rate was $9.3 \times 10^{-5} \mathrm{~mm} / \mathrm{cycle}$. Delamination on the compression flange did not start until approximately 6,800 cycles. Once the delamination did start on the compression flange, it grew at an average calculated rate of $4.2 \times 10^{-2} \mathrm{~mm} /$ cycle until it reached the load pads at $\mathrm{x}=150$ and $455 \mathrm{~mm}$. Even with the delamination on the compression side extending to the load pads, the stiffness of the beam remained approximately unchanged at $6,281 \mathrm{kN} / \mathrm{m}$ after 25,500 cycles. The average delamination length versus cycles is shown in Table 43. The delaminated beam is shown in Figure 126. 
Table 42. Reference Notation for Beams 49 and 50 with ESH Laminate.

\begin{tabular}{|c|c|c|c|}
\hline \multicolumn{4}{|c|}{ Reference Notation for Beams 49 and 50 with ESH Laminate } \\
\hline $\begin{array}{c}\text { Ply } \\
\text { Number }\end{array}$ & $\begin{array}{c}\text { Ply } \\
\text { Angle }\end{array}$ & Fabric & Description \\
\hline 1 & $0^{\circ}$ & D155 & \\
\hline 2 & $0^{\circ}$ & D155 & \multirow[t]{2}{*}{ Dropped plies } \\
\hline 3 & $0^{\circ}$ & D155 & \\
\hline 4 & $+45^{\circ}$ & \multirow[t]{2}{*}{ DB120 } & \\
\hline 5 & $-45^{\circ}$ & & \\
\hline 5 & $0^{\circ}$ & D155 & \\
\hline 6 & $0^{\circ}$ & D155 & \\
\hline 7 & $+45^{\circ}$ & \multirow{2}{*}{ DB120 } & \\
\hline 8 & $-45^{\circ}$ & & \\
\hline 9 & $0^{\circ}$ & D155 & \\
\hline 10 & $0^{\circ}$ & D155 & \\
\hline 11 & $+45^{\circ}$ & \multirow[t]{2}{*}{ DB120 } & \\
\hline 12 & $-45^{\circ}$ & & \\
\hline 13 & $0^{\circ}$ & D155 & \\
\hline \multicolumn{4}{|c|}{ Adhesive Layer Hysol EA 9309.2NA, $0.1-0.4$ mm } \\
\hline 14 & $+45^{\circ}$ & DB240 & \multirow{5}{*}{$\begin{array}{c}\text { Web Material CH12 } \\
\text { I-Beam Web Flange } \\
3 \text { mm thick, } \\
V_{F}=0.35\end{array}$} \\
\hline 15 & $-45^{\circ}$ & & \\
\hline 16 & 0 & D155 & \\
\hline 17 & $-45^{\circ}$ & \multirow[t]{2}{*}{ DB240 } & \\
\hline 18 & $+45^{\circ}$ & & \\
\hline
\end{tabular}

Table 43. Average Flange Delamination vs. Cycles for Beam 49.

\begin{tabular}{|c|c|c|}
\hline Cycles & $\begin{array}{c}\text { Average Tension Flange } \\
\text { Delamination, mm }\end{array}$ & $\begin{array}{c}\text { Average Compression } \\
\text { Flange Delamination, } \mathrm{mm}\end{array}$ \\
\hline 10 & 4 & -- \\
\hline 1,000 & 4 & -- \\
\hline 2,000 & 4 & -- \\
\hline 6,800 & 8 & 12 \\
\hline 12,868 & 20 & 191 \\
\hline 25,500 & 20 & 191 \\
\hline
\end{tabular}




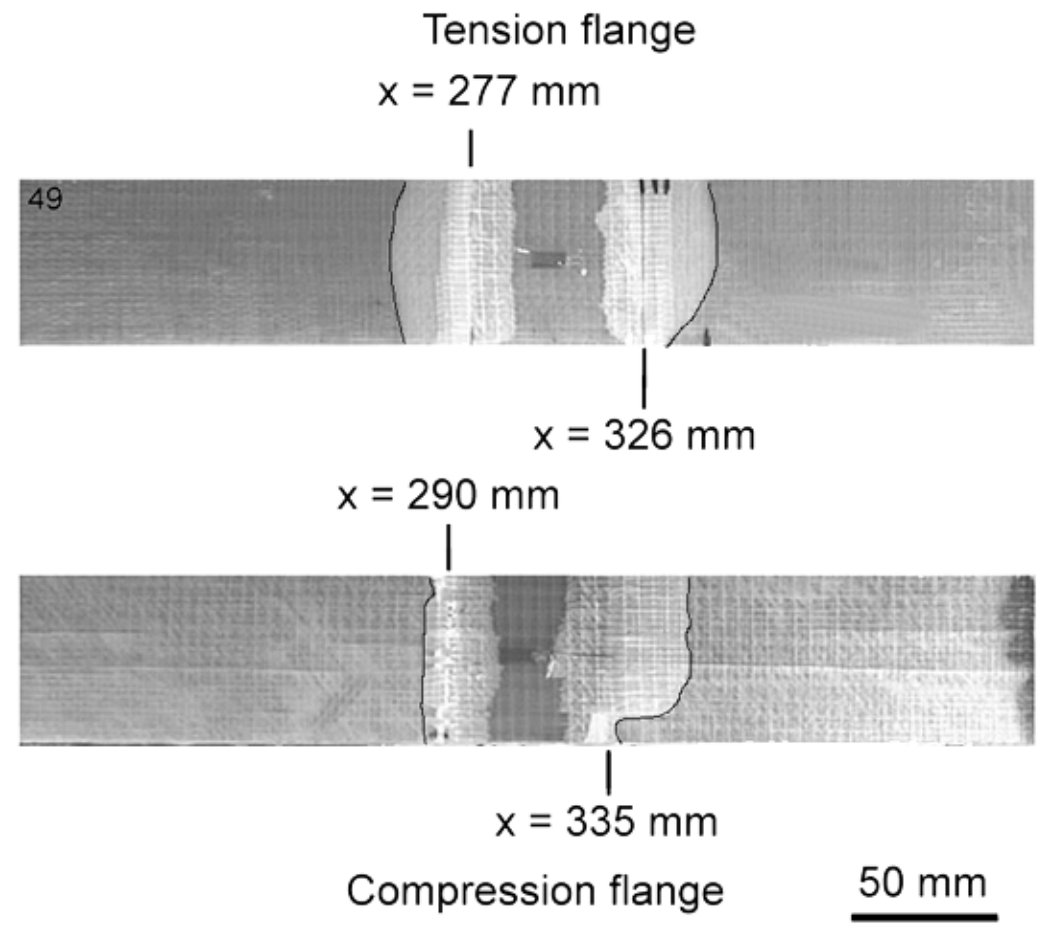

Figure 126. Beam 49.

\section{BEAM 50 (Flange Material ESH)}

Beam number 50 was fatigued at a rate of $3 \mathrm{~Hz}$ with a maximum load of $48.9 \mathrm{kN}$ and a minimum load of $4.9 \mathrm{kN}$. The maximum load produced an initial maximum tension flange strain of $0.63 \%$ and a minimum compressive flange strain of $-0.63 \%$. The initial beam stiffness was measured as 6,054 $\mathrm{kN} / \mathrm{m}$. The tension flange ply drops were located at $\mathrm{x}=265$ and $325 \mathrm{~mm}$ and the compression flange ply drops were at $x=270$ and $320 \mathrm{~mm}$. Delamination started into the thin section of the tension flange and then arrested, just as with previous beams. The average delamination length versus cycles is shown in Table 44. The delamination on the tensile flange started into the thick cross-section and propagated uniformly at an average calculated rate of $5.08 \times 10^{-4} \mathrm{~mm} /$ cycle. The compression side of the beam showed delamination being initiated at one corner of the ply drop and slowly working its way along the flange edge and then across the flange. Once the crack had propagated across the flange width, the delamination grew unstably to the load pads. The beam was then tested for residual strength after 204,100 cycles. The residual strength was $88.2 \mathrm{kN}$. The failed beam is shown in Figure 127 , indicating a compression flange failure. This failure load compares favorably with that for Beam $34,83.22 \mathrm{kN}$, with no ply drops, but thinner flange material. 
Table 44. Average Tension Flange Delamination for Beam 50.

\begin{tabular}{|c|c|}
\hline Cycles & $\begin{array}{c}\text { Average Tension Flange } \\
\text { Delamination, } \mathrm{mm}\end{array}$ \\
\hline 500 & 4 \\
\hline 2,500 & 19 \\
\hline 7,000 & 24 \\
\hline 12,000 & 30 \\
\hline 31,800 & 30 \\
\hline 82,000 & 30 \\
\hline 105,000 & 43 \\
\hline 131,000 & 52 \\
\hline 176,000 & 102 \\
\hline 204,100 & 102 \\
\hline
\end{tabular}
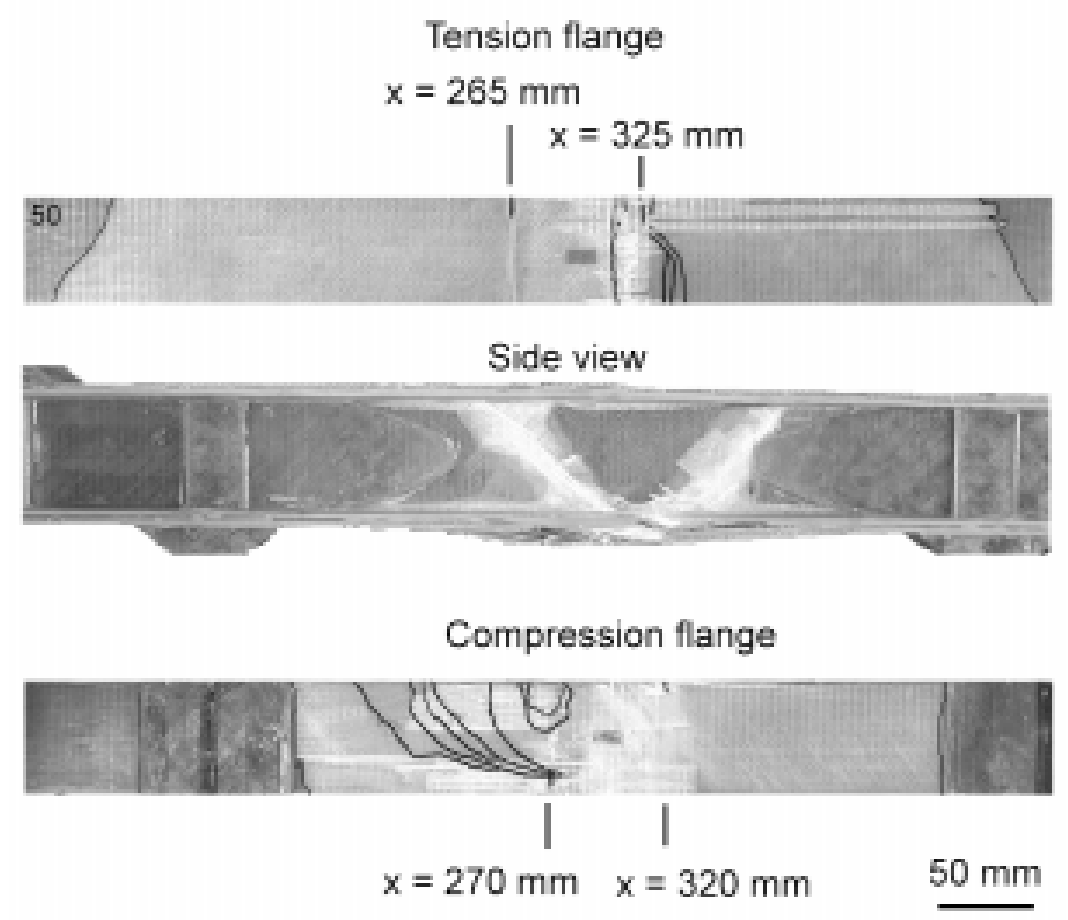

Figure 127. Beam 50. 


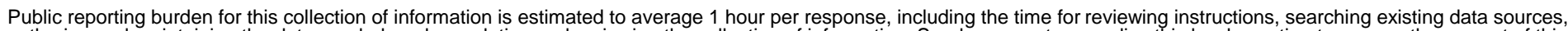

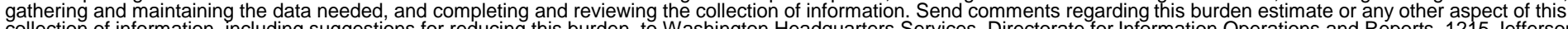

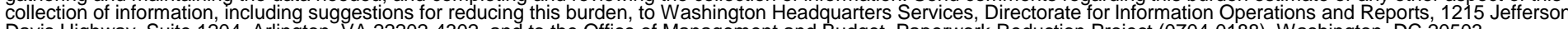
Davis Highway, Suite 1204, Arlington, VA 22202-4302, and to the Office of Management and Budget, Paperwork Reduction Project (0704-0188), Washington, DC 20503.

\begin{tabular}{|l|l|l} 
1. & $\begin{array}{l}\text { 2. REPORT DATE } \\
\text { November } 1998\end{array}$ & $\begin{array}{l}\text { 3. REPORT TYPE AND DATES COVERED } \\
\text { Subcontractor Report }\end{array}$ \\
\hline
\end{tabular}

4. TITLE AND SUBTITLE

5. FUNDING NUMBERS

Fatigue of Composite Material Beam Elements Representative of Wind Turbine Blade Substructure

C: XF-1-11009-5 and

XAF-5-14076-04

TA: WE902350

6. $\operatorname{AUTHOR}(\mathrm{S})$

John F. Mandell, Daniel D. Samborsky, David W. Combs, M. Ethan Scott, Douglas S. Cairns

7. PERFORMING ORGANIZATION NAME(S) AND ADDRESS(ES)

Department of Chemical Engineering

Montana State University

Bozeman, Montana 59717

8. PERFORMING ORGANIZATION REPORT NUMBER

10. SPONSORING/MONITORING AGENCY REPORT NUMBER

National Renewable Energy Laboratory

1617 Cole Blvd.

SR-500-24379

Golden, CO 80401-3393

11. SUPPLEMENTARY NOTES

12a. DISTRIBUTION/AVAILABILITY STATEMENT

National Technical Information Service

12b. DISTRIBUTION CODE

U.S. Department of Commerce

5285 Port Royal Road

Springfield, VA 22161

\section{ABSTRACT (Maximum 200 words)}

The database and analysis methods used to predict wind turbine blade structural performance for stiffness, static strength, dynamic response, and fatigue lifetime are validated through the design, fabrication, and testing of substructural elements. We chose a test specimen representative of wind turbine blade primary substructure to represent the spar area of a typical wind turbine blade. We then designed an Ibeam with flanges and web to represent blade structure, using materials typical of many U.S.-manufactured blades. Our study included the fabrication and fatigue testing of 52 beams and many coupons of beam material. Fatigue lifetimes were consistent with predictions based on the coupon database. The final beam specimen proved to be a very useful tool for validating strength and lifetime predictions for a variety of flange and web materials, and is serving as a test bed to ongoing studies of structural details and the interaction between manufacturing and structural performance. The beam test results provide a significant validation of the coupon database and the methodologies for predicting fatigue of composite material beam elements.

\begin{tabular}{|c|c|c|c|c|c|c|c|}
\hline \multirow[t]{2}{*}{14.} & \multirow{2}{*}{\multicolumn{5}{|c|}{ renewable energy; wind energy; wind turbines; wind turbine blade composite testing }} & 15. & NUMBER OF PAGES \\
\hline & & & & & & 16. & PRICE CODE \\
\hline 17. & $\begin{array}{l}\text { SECURITY } \\
\text { CLASSIFICATION } \\
\text { OF REPORT } \\
\text { Unclassified }\end{array}$ & & $\begin{array}{l}\text { SECURITY } \\
\text { CLASSIFICATION } \\
\text { OF THIS PAGE } \\
\text { Unclassified }\end{array}$ & & $\begin{array}{l}\text { SECURITY } \\
\text { CLASSIFICATION } \\
\text { OF ABSTRACT } \\
\text { Unclassified }\end{array}$ & 20. & $\begin{array}{l}\text { LIMITATION OF ABSTRACT } \\
\text { UL }\end{array}$ \\
\hline
\end{tabular}

NSN 7540-01-280-5500

Standard Form 298 (Rev. 2-89) Prescribed by ANSI Std. Z39-18 